\title{
Flow Field Measurement and Qualification of the West Virginia University Environmental Wind Tunnel
}

\author{
Katherine Mary Reid \\ West Virginia University, krreid@mix.wvu.edu
}

Follow this and additional works at: https://researchrepository.wvu.edu/etd

Part of the Aerodynamics and Fluid Mechanics Commons, and the Other Aerospace Engineering Commons

\section{Recommended Citation}

Reid, Katherine Mary, "Flow Field Measurement and Qualification of the West Virginia University Environmental Wind Tunnel" (2021). Graduate Theses, Dissertations, and Problem Reports. 8026. https://researchrepository.wvu.edu/etd/8026

This Thesis is protected by copyright and/or related rights. It has been brought to you by the The Research Repository @ WVU with permission from the rights-holder(s). You are free to use this Thesis in any way that is permitted by the copyright and related rights legislation that applies to your use. For other uses you must obtain permission from the rights-holder(s) directly, unless additional rights are indicated by a Creative Commons license in the record and/ or on the work itself. This Thesis has been accepted for inclusion in WVU Graduate Theses, Dissertations, and Problem Reports collection by an authorized administrator of The Research Repository @ WVU. For more information, please contact researchrepository@mail.wvu.edu. 


\title{
Flow Field Measurement and Qualification of the West Virginia University Environmental Wind Tunnel
}

\author{
Katherine M. Reid
}

Thesis submitted

to the Benjamin M. Statler College of Engineering and Mineral Resources

at West Virginia University

in partial fulfillment of the requirements for the degree of

Master of Science in

Aerospace Engineering

Patrick H. Browning, Ph.D., Chair

Christopher Griffin, Ph.D.

Cosmin Dumitrescu, Ph.D.

Department of Mechanical and Aerospace Engineering

Morgantown, West Virginia

2021

Keywords: Environmental Wind Tunnel, Velocity Profiles

Copyright 2021 Katherine M. Reid 


\title{
Abstract \\ Flow Field Measurement and Qualification of the West Virginia University Environmental Wind Tunnel
}

\author{
Katherine M. Reid
}

In 2013 West Virginia University acquired an Environmental Wind Tunnel from Cornell University. Due to the state of the tunnel, elements of the tunnel were redesigned and rebuilt at the West Virginia University Hangar in Morgantown, West Virginia. The motivation of this research was to evaluate and qualify the flow field within the test section of this redesigned and reconstructed wind tunnel. The tunnel has many uses for the university, including outside research opportunities as well as educational purposes for students in the Aerospace Engineering Department. The methods employed for this effort included developing a grid of pitot tubes to cover the test section cross sectional area. An electric pressure-scanning module that contained 64 pressure scanning ports was utilized, thus allowing the grid to contain 64 pitot tubes arranged into an $8 \times 8$ formation.

Using this grid and pressure-scanning module system, the flow field of the test section was mapped across the velocity range of the tunnel. The available power in the test section was also calculated along with the tunnel efficiency. Results revealed variation in motor speed across the test section had little impact on the shape of the velocity profile in the test section. A linear relationship between test section average speed and motor speed was found to be almost one knot, or roughly $1.16 \mathrm{MPH}$ per Hz. This relationship allows for a quick estimation of necessary motor speed given a desired average speed in the test section. The wind power in the test section was found to be approximately half that of the total power output of the motors. The relationship between motor speed and power required was cubic. From this, a model was created so that desired test section speed could be input and required motor speed in $\mathrm{Hz}$ was output. 


\section{Acknowledgements}

I would like to acknowledge:

My parents for all their love and support throughout my life and this very long college career.

My advisor and committee chair Dr. Browning for taking me under his wing, protecting me from politics, and helping me every step of the way to complete this research.

My committee members Dr. Christopher Griffin and Dr. Cosmin Dumitrescu for their input and guidance.

The Department of Mechanical and Aerospace Engineering for giving me the resources to allow this research to become a reality, as well as Kande Brandt for always being an incredible help.

Dr. Peter Gall for encouraging me to start this journey and always believing I would go far and do great things.

Dr. Todd Hamrick for always being a listening and encouraging ear and fostering in me a deeper appreciation for engineering.

My mentor and friend, Frederick Beamer, for believing in me and always offering words of wisdom throughout my college career.

My friend, Alexandra Brannon, CPA, for always being there for me and being each other's shoulder to cry on to get through college and life.

Finally, last but not least, my fiancé Jerry Hardway for all of his love and support, and all of his brain and brawn.

Thank you to everyone that has loved and supported me through this journey. 


\section{Table of Contents}

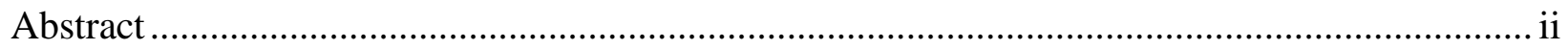

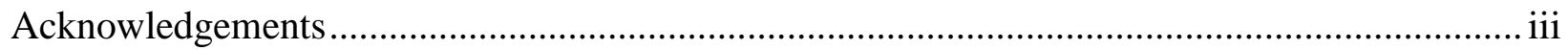

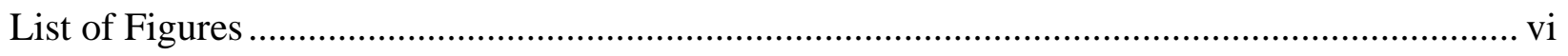

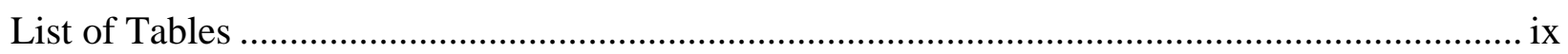

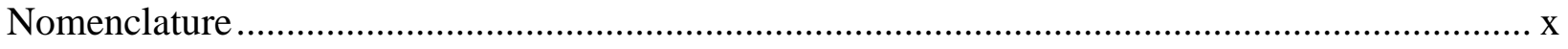

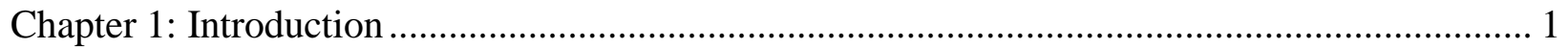

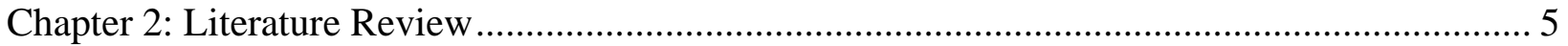

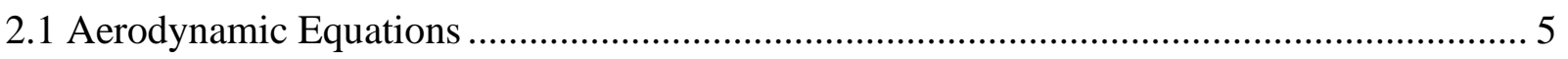

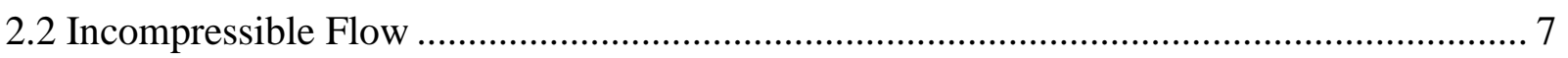

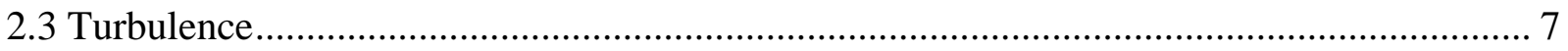

2.4 Latin Square Experimental Design ........................................................................ 9

2.5 Flowfield Measurements in the NASA Lewis Research Center Low-Speed Wind Tunnel 9

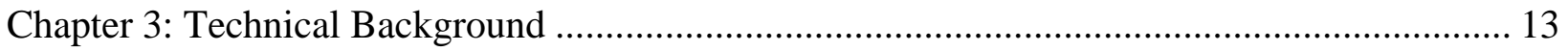

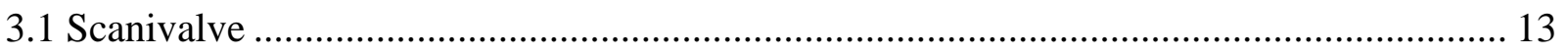

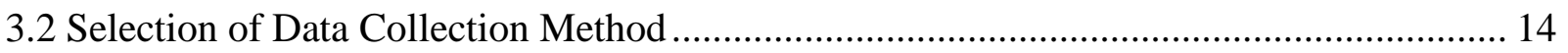

3.3 Methodology for Pitot Tube Size Selection ....................................................................... 14

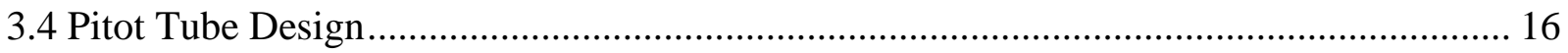

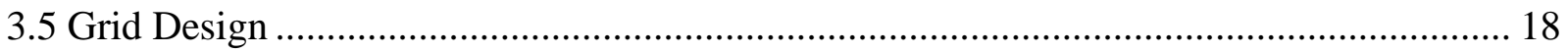

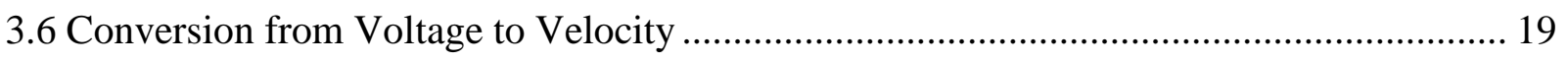

Chapter 4: Experimental Design And Setup ............................................................................ 21

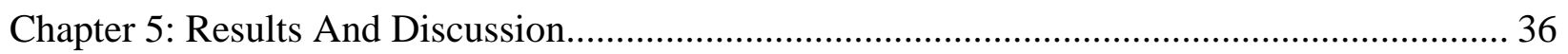

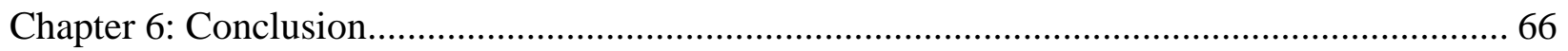

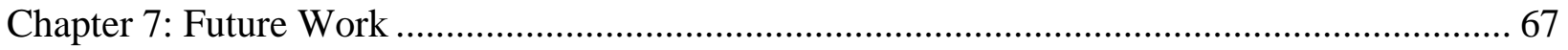

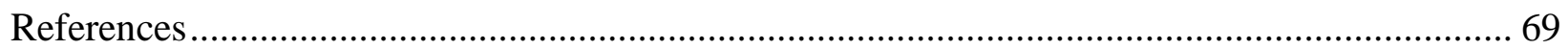

Appendix A: Mean Voltages and Standard Deviations for Pitot Tube Selection.......................... 71

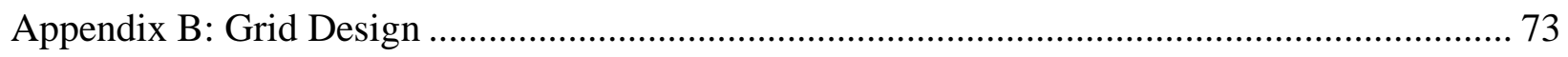

Appendix C: Calibration Code and Curves …………….......................................................... 75

Appendix D: DAQ Initialization and Configuration Code .......................................................... 91

Appendix E: Parts for Control Board and Scanivalve Control …………………….................... 92

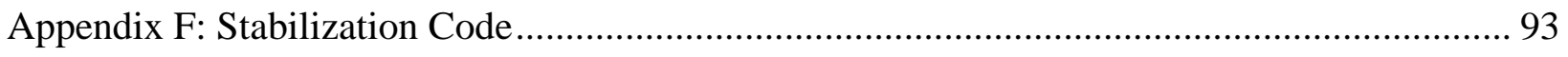

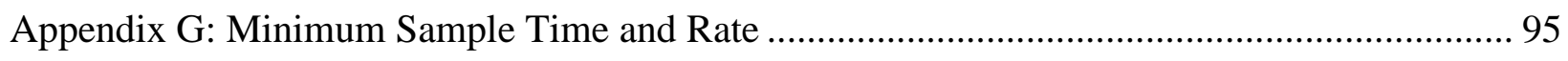




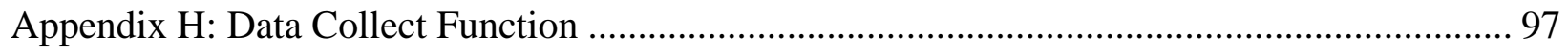

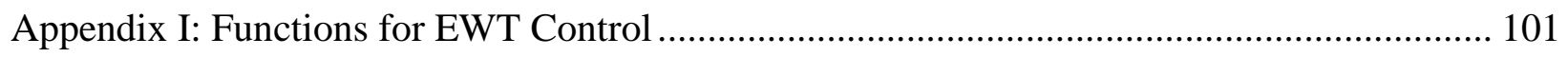

Appendix J: Randomized Speed Matrix Code .................................................................. 109

Appendix K: Speed versus Frequency Plots Code ........................................................... 110

Appendix L: Averaged and Maximum Averaged Pressure Values ...................................... 116

Appendix M: Averaged and Maximum Averaged Velocity Values ....................................... 119

Appendix N: Boundary Layer Code ............................................................................. 122

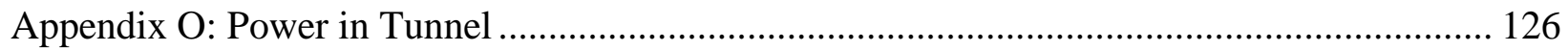

Appendix P: Horsepower Values per Motor Frequency ................................................... 129

Appendix Q: EWT Speed Estimation Function ............................................................. 130

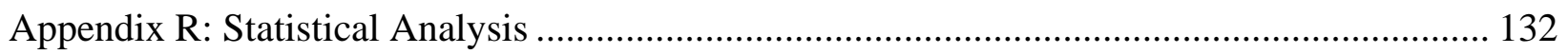




\section{$\underline{\text { List of Figures }}$}

Figure 2.5.1: Cross section of NASA Lewis Low-Speed Wind Tunnel with numbered locations of some flow measurements [8].

Figure 2.5.2: Cross section of length of NASA Lewis Low-Speed Wind Tunnel test section looking down from top [8] 10

Figure 2.5.3: Flow survey rake mounted in the test section of the NASA Lewis Low-Speed Wind Tunnel [8] 11

Figure 2.5.4: Boundary layer survey rake in the NASA Lewis Low-Speed Wind Tunnel [8]..... 11 Figure 2.5.5: Cross sectional view of length of tunnel with survey rake locations in the NASA Lewis Low-Speed Wind Tunnel [8]. 12

Figure 3.3.1: (a) CAD design, (b) realized test stand within the test section at the WVU EWT. 15 Figure 3.3.2: Sketch of telescoped tubes on test stand in the WVU EWT. 15

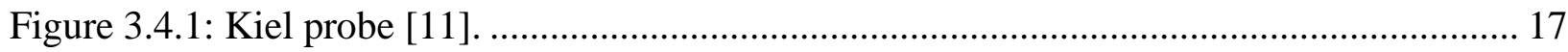

Figure 3.4.2: Pitot tube nose shape impact on inclination of flow [1] ................................. 17 Figure 3.4.3: Performance of square and hemispherical nose shapes of pitot tubes across Reynolds

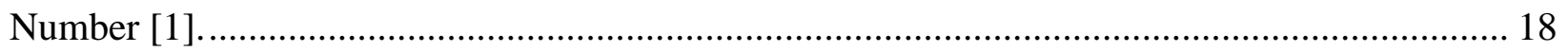

Figure 3.5.1: CAD design of grid and realized grid in the WVU EWT. 19

Figure 4.1: Mockup of the fans with each experiment set showing which fans to hold constant. 21

Figure 4.2: Eagle PCB design for conversion circuit board. ................................................ 24

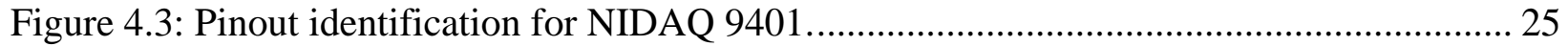

Figure 4.4: Pinout identification for NIDAQ 9205............................................................ 25

Figure 4.5: D-sub Pinout identification at Scanivalve housing box. ...................................... 26

Figure 4.6: DAQ Connections made at the NIDAQ 9205 and NIDAQ 9401 modules in the NI

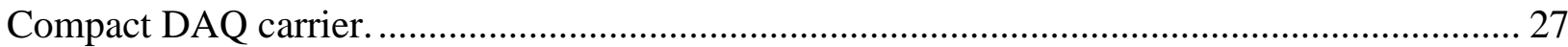

Figure 4.7: Power supply connections to create a positive and negative 15V for the Scanivalve.28 


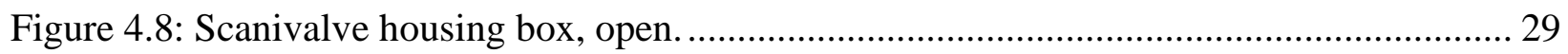

Figure 4.9: Scanivalve constant pressure switch modes.................................................... 30

Figure 4.10: Scanivalve Voltage Output Drift over an eight-hour period, no pressure applied... 31

Figure 4.11: Minimum Sample Time for $0 \mathrm{~Hz}$ Drive Frequency. ........................................... 32

Figure 4.12: Minimum Sample Time for 18Hz Drive Frequency. ........................................ 32

Figure 4.13: Minimum Sample Time for 30Hz Drive Frequency........................................ 33

Figure 4.14: Minimum Sample Time for 45Hz Drive Frequency. .......................................... 33

Figure 4.15: Minimum Sample Time for $60 \mathrm{~Hz}$ Drive Frequency. .......................................... 34

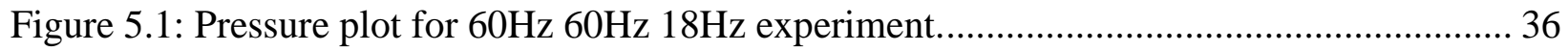

Figure 5.2: Pressure plot for $18 \mathrm{~Hz} 60 \mathrm{~Hz} 60 \mathrm{~Hz}$ experiment.............................................. 37

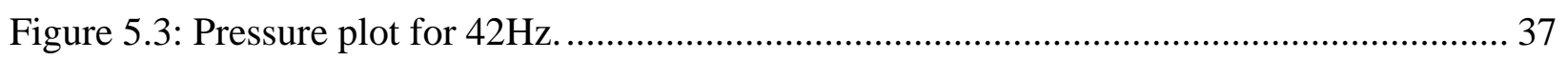

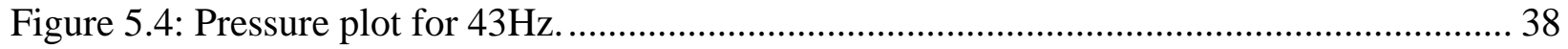

Figure 5.5: Pressure difference between varied fan speed and constant fan speed................... 39

Figure 5.6: Averaged pressure values against fan frequencies for each day of testing.............. 41

Figure 5.7: Single averaged pressure values against fan frequencies and polynomial fits.......... 42

Figure 5.8: Air speed in MPH against fan frequencies and linear approximation...................... 43

Figure 5.9: Pressure surface plots for $18 \mathrm{~Hz}$ through $21 \mathrm{~Hz}$ drive frequencies......................... 44

Figure 5.10: Pressure surface plots for $22 \mathrm{~Hz}$ through $25 \mathrm{~Hz}$ drive frequencies. ........................ 44

Figure 5.11: Pressure surface plots for $26 \mathrm{~Hz}$ through $29 \mathrm{~Hz}$ drive frequencies....................... 45

Figure 5.12: Pressure surface plots for $30 \mathrm{~Hz}$ through $33 \mathrm{~Hz}$ drive frequencies........................ 45

Figure 5.13: Pressure surface plots for $34 \mathrm{~Hz}$ through $37 \mathrm{~Hz}$ drive frequencies....................... 46

Figure 5.14: Pressure surface plots for $38 \mathrm{~Hz}$ through $41 \mathrm{~Hz}$ drive frequencies........................ 46

Figure 5.15: Pressure surface plots for $42 \mathrm{~Hz}$ through $45 \mathrm{~Hz}$ drive frequencies....................... 47

Figure 5.16: Pressure surface plots for $46 \mathrm{~Hz}$ through $49 \mathrm{~Hz}$ drive frequencies....................... 47

Figure 5.17: Pressure surface plots for $50 \mathrm{~Hz}$ through 53Hz drive frequencies....................... 48

Figure 5.18: Pressure surface plots for $54 \mathrm{~Hz}$ through $57 \mathrm{~Hz}$ drive frequencies......................... 48

Figure 5.19: Pressure surface plots for $58 \mathrm{~Hz}$ through $60 \mathrm{~Hz}$ drive frequencies....................... 49

Figure 5.20: Velocity profile surface plots for $18 \mathrm{~Hz}$ through $21 \mathrm{~Hz}$ drive frequencies............... 50

Figure 5.21: Velocity profile surface plots for $22 \mathrm{~Hz}$ through $25 \mathrm{~Hz}$ drive frequencies.............. 50

Figure 5.22: Velocity profile surface plots for $26 \mathrm{~Hz}$ through $29 \mathrm{~Hz}$ drive frequencies. .............. 51 
Figure 5.23: Velocity profile surface plots for $30 \mathrm{~Hz}$ through $33 \mathrm{~Hz}$ drive frequencies.............. 51

Figure 5.24: Velocity profile surface plots for $34 \mathrm{~Hz}$ through $37 \mathrm{~Hz}$ drive frequencies.............. 52

Figure 5.25: Velocity profile surface plots for $38 \mathrm{~Hz}$ through $41 \mathrm{~Hz}$ drive frequencies............... 52

Figure 5.26: Velocity profile surface plots for $42 \mathrm{~Hz}$ through $45 \mathrm{~Hz}$ drive frequencies............... 53

Figure 5.27: Velocity profile surface plots for $46 \mathrm{~Hz}$ through $49 \mathrm{~Hz}$ drive frequencies.............. 53

Figure 5.28: Velocity profile surface plots for $50 \mathrm{~Hz}$ through $53 \mathrm{~Hz}$ drive frequencies.............. 54

Figure 5.29: Velocity profile surface plots for $54 \mathrm{~Hz}$ through $57 \mathrm{~Hz}$ drive frequencies............... 54

Figure 5.30: Velocity profile surface plots for $58 \mathrm{~Hz}$ through $60 \mathrm{~Hz}$ drive frequencies.............. 55

Figure 5.31: Laminar and turbulent boundary layers in a pipe [12] ...................................... 56

Figure 5.32: Overlay of a side view of a surface plot onto laminar and turbulent boundary layers

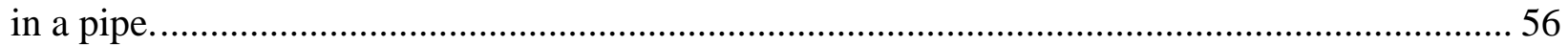

Figure 5.33: Wake rake placed on its side in the center of the test section. ............................. 57

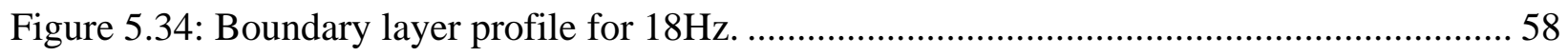

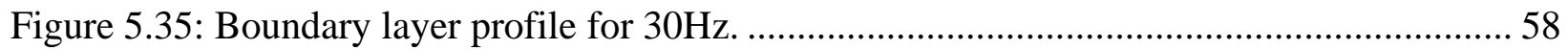

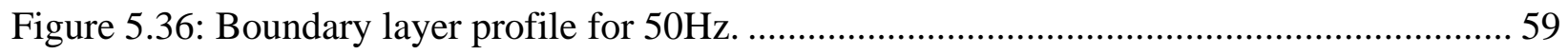

Figure 5.37: Horsepower as a function of frequency for each of the six drives...................... 61

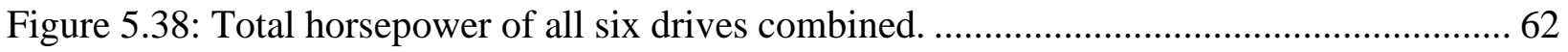

Figure 5.39: Test section area divisions for power calculations.......................................... 63

Figure 5.40: Wind horsepower in the test section as a function of frequency.......................... 64

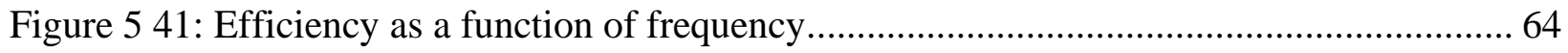




\section{$\underline{\text { List of Tables }}$}

Table 3.1: Pneumatic logic for Scanivalve modes..................................................................... 13

Table 4.1: Reduced Latin Square Design for Experiments....................................................... 22

Table 5.1: Percent differences between varied fan speeds and constant fan speeds for each pitot

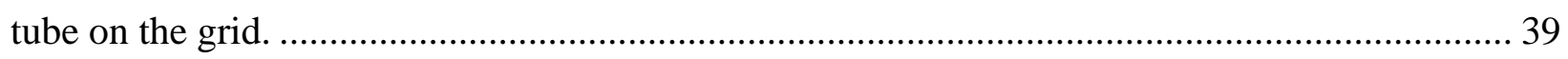

Table 5.2: Daily nuisance variables collected over four days of testing, three times per test. ..... 40

Table 5.3: Theoretical pressure loss for each section of the tunnel, determined from previous

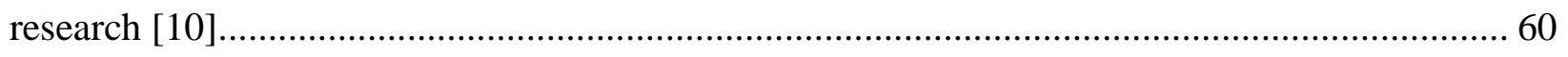




\section{Nomenclature}

PTV

WVU

EWT

VFD

IGV

D

$\beta$

V

$\boldsymbol{r}$

$t$

$\nabla$

$\rho$

$\boldsymbol{F}_{B}$

$\boldsymbol{F}_{S}$

$g$

$p$

$\mu$

$\dot{\boldsymbol{S}}$

T

$C_{v}$

$k$

$R$

$T_{R}$

$u, v, w$

P

Px

HWA

OD

CAD
Particle Tracking Velocimetry

West Virginia University

Environmental Wind Tunnel

Variable Frequency Drives

Inlet Guide Vanes

Total Derivative

Example Variable for Total Derivative

Vector Fluid Velocity

Three-Component Position Vector

Time

Gradient

Fluid Density

Body Force per Unit Mass

Surface Force per Unit Volume

Gravitational Acceleration

Pressure

Coefficient of Viscosity

Rate of Strain Tensor

Temperature

Specific Heat at Constant Volume

Thermal Conductivity

Universal Gas Constant

Temperature in Rankine

Velocity Components in $\mathrm{x}, \mathrm{y}$, and $\mathrm{z}$ respectively

Pressure

Pressure at Port x on Scanivalve

Hot Wire Anemometer

Outer Diameter

Computer Aided Design 


\begin{tabular}{|c|c|}
\hline$C_{p a}$ & $\begin{array}{l}\text { Equation for the difference between the pressure at angle of attack and } \\
\text { pressure at zero angle of attack, over dynamic pressure }\end{array}$ \\
\hline$C_{p(s t a g)}$ & $\begin{array}{l}\text { Equation for the difference between stagnation pressure and pressure, over } \\
\text { dynamic pressure }\end{array}$ \\
\hline $\mathrm{Re}$ & Reynolds Number \\
\hline$m$ & Slope \\
\hline$b$ & $\mathrm{y}$-intercept \\
\hline$V$ & Velocity \\
\hline$\Delta P$ & Change in Pressure \\
\hline DAQ & Data Acquisition \\
\hline $\mathrm{IC}$ & Integrated Circuit \\
\hline $\mathrm{MPH}$ & Miles per Hour \\
\hline$K_{i}$ & Pressure Loss Coefficient for Each Tunnel Section \\
\hline$q_{i}$ & Dynamic Pressure for Each Tunnel Section \\
\hline$\Delta P_{i}$ & Pressure Loss for Each Tunnel Section \\
\hline$A_{T S}$ & Area of Test Section \\
\hline$V_{T S}$ & Velocity in the Test Section \\
\hline$\Delta P_{\text {Tot }}$ & Total Pressure Loss \\
\hline$V_{\|}$ & Line to Line Voltage \\
\hline$I$ & Current \\
\hline $\cos (\Phi)$ & Power Factor \\
\hline GUI & Graphical User Interface \\
\hline TS & Test Section \\
\hline
\end{tabular}




\section{Chapter 1: Introduction}

Wind tunnels have long been an important part of the aerospace industry, from measuring the drag forces on early airfoils, designing streamlined vehicles, aiding in the development of large-scale windmills for renewable energy, and even replicating weather phenomenon such as tornados and sand dune formation. While wind tunnels weren't the first instrument used for aerodynamic replications, they are one of the most common today. Technological advancements have allowed wind tunnels to evolve to mimic almost any wind flow imaginable. They can range from as small as being able to set on a table to as large as having a full-scale airplane in the test section.

There are two general types of wind tunnel designs: closed circuit and open circuit. There are also two basic test section configurations: open test section and closed test section. Closed circuit wind tunnels recirculate the same air continuously in a loop, while open circuit wind tunnels have a straight path of flow with fans typically pulling the flow through the tunnel from the rear and exhaust into the open room. The basic path of air in an open circuit wind tunnel starts through a contraction - often with the use of flow straightening screens - to the tunnel test section, where it then enters a diffuser section, the fans, and then exhausts into the room. The path is similar for closed circuit tunnels, except instead of the air exhausting at the end of its path, it simply turns through the use of turning vanes and recirculates through the tunnel. The most common test section for both types of wind tunnel is a closed test section. A closed test section means that the test section is closed off from the rest of the room where the tunnel is housed. The model being tested is fitted into the test section and is not accessible after the test section is closed. An open test section means that the test section is not closed off when a model is fitted within it, but is typically still enclosed in a room to prevent air being drawn into the test section not coming from the inlet. This is typically done to help reduce or eliminate tunnel wall effects, such as boundary conditions of no-slip at the wall and allows for a more uniform velocity profile in the test section [1].

There are advantages and disadvantages to both types of wind tunnels. Open circuit wind tunnels are typically much less costly to construct and are more conducive to flow visualization experiments using smoke as the air is not recirculated. However, they also typically require more 
energy to run, since there is not air recirculation that already has momentum. They also tend to be very noisy and may need extensive noise treatment. Closed circuit wind tunnels typically have a high quality of flow control with the use of turning vanes in the corners as well as screens to help straighten the flow. Opposite to that of open circuit wind tunnels, they require less energy to operate, and often produce less noise. However, closed circuit tunnels are often much more expensive due to the precision necessary for the turning vanes and return ducts, and a cooling method, such as an air exchanger, may be necessary due to friction if the tunnel has high utilization [1].

There are many different methods for flow measurement that can be used within wind tunnels to gain an understanding and visualization of the velocity profiles within the test section. It is critical to understand the air flow in a wind tunnel so that the aerodynamic forces around a body being tested can be understood. Often, being able to visualize the flow on or around a body gives a much greater insight into solutions for aerodynamic problems than just computational calculations can provide [2]. One commonly used method of flow visualization is Particle Tracking Velocimetry (PTV). This non-contact visual method consists of atomizing an oil and introducing it into the flow; this is called seeding. A laser is then shone into the flow and images are captured within milliseconds of each other, in which the atomized oil particles show up as bright dots moving through the flow. The velocity in the tunnel can then be estimated by determining the distance a particle traveled over the time between two images. This method is typically used in very small tunnels, and the glass that the laser shines through needs to be exceptionally clean and free from inconsistencies that may cause the laser to refract [2]. Hot wire and hot film anemometers are also common tools used for flow measurements. These are small probes introduced into the flow that have either an extremely thin wire or film that is heated by an electric current. As air flows over the probe, the rate of heat loss due to convection is measured, and thus the velocity can be determined. However, these are typically only used to measure variables of turbulent flows, such as mean flow, turbulent fluctuations, and turbulence intensity. They are also incredibly expensive and susceptible to foreign object debris damage in tunnels with high turbulence and little upstream flow treatment [2]. Other optical methods, such as Schlieren mirrors, can also be used to gain qualitative and quantitative insight about the flow based on recording density changes and the influence on light beams passing through the flow. Schlieren mirrors are often used in supersonic flows to view shock waves [2]. 
One of the most common methods of flow measurement are pitot tubes. Pitot tubes were developed by Henri Pitot in 1732 to determine if fluid velocities in a river were greater near the river's bed or near the surface of the flow. His design consisted of two glass tubes mounted to a wooden frame with a vertical ruler. The first tube, the Pitot tube, had a ninety-degree bend at the bottom and pointed upstream into the flow. The second tube pointed straight down perpendicular to the flow. Henri Pitot then measured the difference in height of the fluid levels in the tubes when lowered into the river. Henry Darcy, with the assistance of Henri Bazin, later made improvements to Pitot's design in 1856, many of which are still implemented in Pitot tubes today. Using Torricelli's equation, Darcy was able to formulate an equation for velocity measurement from the pitot tube. Darcy also developed three variations for the instrument's tip, and Ludwig Prandtl later also developed the hemispherical tip, most commonly used on aircraft today. Because of Darcy's contributions to improving the pitot tube, many people now refer to them as Pitot-Darcy tubes [3]. Since many flow situations approach a one-dimensional representation, pitot tubes and pitot-static tubes are suitable measuring devices for many different flow scenarios [4]. Pitot tubes are simple to design and build, relatively low cost, and not as complex as other methods.

The open circuit tunnel acquired by West Virginia University (WVU) is called an Environmental Wind Tunnel (EWT) and is a low-speed wind tunnel. EWTs are typically built to be much more durable than other tunnels, both open and closed circuit, as they are used to study environmental phenomenon. EWTs have been used to study hurricane and tornado force winds, sand dune formation, snow drifts, as well as applications involving air moving over water surfaces. The fans used in EWTs are designed to withstand foreign particles, or aerosols, that may come free during tests, such as sand, gravel, sticks and leaves from plants and trees, water droplets, and more. It is dangerous to test such things that may cause foreign debris in closed circuit tunnels as the debris can then travel through the tunnel and damage the fans, turning vanes, and screens. The test section of the EWT at WVU is an open test section enclosed in a separate room to avoid outside air being drawn into the test section. The tunnel was acquired in 2013, but the attainable velocity profiles have not been documented yet. Low-speed wind tunnels typically operate at speeds up to 0.3 to 0.4 Mach. It is essential to document the velocity profiles for the EWT not only for ongoing and future research using the tunnel, but also for educational purposes for students in the Aerospace Engineering program as well. The nominal test section size of the tunnel is approximately four feet by four feet, and the flow is driven by six fans stacked three on top of three. The fans are 
driven by variable frequency drives (VFD) and are also equipped with inlet guide vanes (IGV) for a greater range of flow adjustment and control [5]. The objective of this study is to experimentally test the EWT test section in various drive system operational conditions to correlate the EWT inputs with test section outputs, i.e. test section velocity profiles. An early empirical mapping for the drive system settings to user-defined test section velocity profiles will be developed, and this model can be validated and/or verified by separate accepted analytical and numerical techniques. 


\section{Chapter 2: Literature Review}

\subsection{Aerodynamic Equations}

The WVU EWT is a low-speed wind tunnel, therefore there are three fundamental equations used to describe the flow. These equations are the Conservation of Mass or the Continuity Equation, Newton's Second Law, and the First Law of Thermodynamics or the Energy Equation. These three equations together express the relationships among certain values such as density, velocity, pressure, viscosity, and more, as they vary in space and time. The "Lagrangian" and "Eulerian" approaches to relating time derivatives focus on the motions of particles. The Lagrangian approach focuses on each individual particle at a time and essentially follows and describes their motions as a function of time. The Eulerian approach focuses on one particular point in space and describes the particles passing through the space as a function of time. The "total derivative" or "material derivative" is the derivative from the Lagrangian perspective, shown in Equation 2.1.1. The capital $D$ is the total derivative symbol, the value of $\beta$ has been used as an example, $\boldsymbol{V}$ is the vector fluid velocity, and $\boldsymbol{r}$ is a three-component position vector and $t$ is time.

$$
\frac{D \beta(\boldsymbol{r}, t)}{D t}=\frac{\partial}{\partial t} \beta(\boldsymbol{r}, t)+(\boldsymbol{V} \cdot \nabla) \beta(\boldsymbol{r}, t)
$$

The Continuity Equation, shown in Equation 2.1.2, can be written as a partial differential equation. The value of $\rho$ is the fluid density, and similarly to the total derivative, $\boldsymbol{V}$ is the vector fluid velocity, and $t$ is time.

$$
\frac{\partial \rho}{\partial t}+\nabla \cdot(\rho \boldsymbol{V})=0
$$

Newton's Second Law is the relation between force and motion and can be written generally as shown in Equation 2.1.3.

$$
\rho\left(\frac{D V}{D t}\right)=\rho \boldsymbol{F}_{B}+\boldsymbol{F}_{S}
$$

The value of $\boldsymbol{F}_{B}$ represents the body force per unit mass, $\boldsymbol{F}_{S}$ represents the surface force per unit volume, and the total derivative is present from Equation 2.1.1, this time with respect to an inertial reference frame and $\boldsymbol{V}$ is the element velocity. Expanding the left-hand side of the equation, this 
expanded form, shown in Equation 2.1.4, is useful for deriving the Bernoulli Equation when appropriate conditions apply.

$$
\rho\left(\frac{D V}{D t}\right)=\rho\left(\frac{\partial \boldsymbol{V}}{\partial t}+\nabla \frac{V^{2}}{2}-\boldsymbol{V} \times(\nabla \times \boldsymbol{V})\right)
$$

Expanding the right-hand side of Equation 2.1.3, the body force value can be neglected for aerodynamic cases, but not in hydrodynamic cases. However, in both cases the body force is simply gravitational acceleration. The surface force for a Newtonian fluid is based in the relationship between stress and strain. This relationship is given by Stoke's law of friction, which states that the "stress is proportional to the time rate of strain." Using this relationship, the surface force equation can be written as shown in Equation 2.1.5. These equations are known as the Navier-Stokes equations. The value $g$ is gravitational acceleration, $p$ is pressure, $\mu$ is coefficient of viscosity, and $\dot{\boldsymbol{S}}$ is the rate of strain tensor.

$$
\rho\left(\frac{\partial \boldsymbol{V}}{\partial t}+(\boldsymbol{V} \cdot \nabla) \boldsymbol{V}\right)=\rho g-\nabla\left(p+\frac{2}{3} \mu \nabla \cdot \boldsymbol{V}\right)+2 \nabla \cdot(\mu \dot{\boldsymbol{S}})
$$

Finally, the First Law of Thermodynamics gives a representation of the principle of conservation of energy. Equation 2.1.6 shown is appropriate for a fluid flow where there may be heat transfer by conduction, transformation between mechanical energy and thermal energy by both reversible and irreversible processes, and energy contribution or absorption by body force of gravitational origin but no radiative transfer. The value of $T$ is for temperature, $C_{v}$ is the specific heat at constant volume, and $k$ is the thermal conductivity.

$$
\begin{aligned}
\rho \frac{\partial}{\partial t}\left(C_{v} T+\frac{V^{2}}{2}\right) & +\rho \boldsymbol{V} \cdot \boldsymbol{\nabla}\left(C_{v} T+\frac{V^{2}}{2}\right) \\
& =\rho \boldsymbol{g} \cdot \boldsymbol{V}-\nabla \cdot p \boldsymbol{V}+\nabla \cdot\left[2 \mu \nabla\left(\frac{V^{2}}{2}\right)+\mu(\nabla \times \boldsymbol{V}) \times \boldsymbol{V}-\frac{2}{3} \mu(\nabla \cdot \boldsymbol{V}) \boldsymbol{V}\right]+\nabla \cdot k \nabla
\end{aligned}
$$

While the previous three relations described in equations 2.1.2, 2.1.5, and 2.1.6 provide relationships between density, velocity, pressure, temperature, and viscosity, two additional relations are necessary to obtain a solvable set of equations. Assuming that air in a low-speed wind tunnel is a perfect gas, this means that the specific heat values are constant, as well as the 
thermal conductivity value is constant. The perfect gas equation therefore leads to the next relation necessary, and its equation is shown in Equation 2.1.7, where the value of $R$ is the universal gas constant.

$$
p=\rho R T
$$

The final relation necessary for a solvable set is a specification of variation of viscosity with temperature. This relation is given by Sutherland's law for air, shown in Equation 2.1.8. The value of $T_{R}$ is the temperature in Rankine, $\mu_{0}$ is the reference viscosity, and $T_{0}$ is the reference temperature.

$$
\frac{\mu}{\mu_{0}}=\left(\frac{T_{R}}{T_{0}}\right)^{3 / 2} \frac{T_{0}+198.6}{T_{R}+198.6}
$$

Each scenario using these equations can be solved with an appropriate set of initial and boundary conditions [1].

\subsection{Incompressible Flow}

Continuing with the fact that the WVU EWT is a low-speed wind tunnel, the flow can be considered incompressible, or the density is constant. With this assumption and the simplification of the continuity equation, the Navier-Stokes equation from section 2.1, Equation 2.1.5 becomes Equation 2.2.1.

$$
\frac{\partial}{\partial \hat{t}} \widehat{\boldsymbol{V}}+\widehat{\nabla}\left(\frac{1}{2} \widehat{V}^{2}\right)+(\widehat{\nabla} \times \widehat{\boldsymbol{V}}) \times \widehat{\boldsymbol{V}}=-\frac{1}{2} \widehat{\nabla} c_{p}+\frac{1}{R_{e}}(2 \widehat{\nabla} \cdot \dot{\hat{\boldsymbol{S}}})
$$

Often in situations when the density is constant, the temperature variation is also then negligible if the flow is adiabatic. This allows the new continuity equation form and Eq. 2.2.1 to be sufficient for three components of velocity and the pressure coefficient [1].

\subsection{Turbulence}

The flow within the WVU EWT can largely be considered turbulent. Therefore it is important to reintroduce the Conservation of Mass, Momentum, and Energy Equations from Section 2.1 in their turbulent forms. As it is nearly impossible to determine a turbulent flow 
solution at any given point in time and space, Reynolds developed the method of using timeaveraged equations for turbulence. He proposed that it could be possible to remove some of the complications with turbulent flows if the average behavior over a long period of time was considered instead. Using these average values for velocities, pressure, and temperature created a much simpler flow field without fluctuations. The transformations to time-averaged flows begins with the following equations, listed together as Equation 2.3.1. The variables $u, v$, and $w$ represent the velocity components in $x, y$, and $z$ respectively, and the variables $P$ and $T$ represent pressure and temperature. The barred variables are the average values gathered from time averaging over a long period, and the apostrophized variables are the fluctuation components.

$$
\begin{aligned}
& u=\bar{u}+u^{\prime} \\
& v=\bar{v}+v^{\prime} \\
& w=\bar{w}+w^{\prime} \\
& P=\bar{P}+P^{\prime} \\
& T=\bar{T}+T^{\prime}
\end{aligned}
$$

Using these relationships to transform the Conservation of Mass equation yields the following Equation 2.3.2. This equation is analytically identical to its original.

$$
\frac{\partial \bar{u}}{\partial x}+\frac{\partial \bar{v}}{\partial y}+\frac{\partial \bar{w}}{d z}=0
$$

Applying the same relationships from Equation 2.3.1 to the Momentum equation yields the following equation, Equation 2.3.3, for the x-direction of momentum, and the equations for the $\mathrm{y}$ and z-directions follow suit but are not listed here.

$$
\bar{u} \frac{\partial \bar{u}}{\partial x}+\bar{v} \frac{\partial \bar{u}}{\partial y}+\bar{w} \frac{\partial \bar{u}}{\partial z}=-\frac{1}{\rho} \frac{\partial \bar{P}}{\partial x}+v \nabla^{2} \bar{u}-\frac{\partial}{\partial x} \overline{\left(u^{\prime 2}\right)}-\frac{\partial}{\partial y} \overline{\left(u^{\prime} v^{\prime}\right)}-\frac{\partial}{\partial z} \overline{\left(u^{\prime} w^{\prime}\right)}
$$

Finally, the same relationships from Equation 2.3.1 can also be applied to the Energy equation to yield the following equation, Equation 2.3.4 [6].

$$
\bar{u} \frac{\partial \bar{T}}{\partial x}+\bar{v} \frac{\partial \bar{T}}{\partial y}+\bar{w} \frac{\partial \bar{T}}{\partial z}=\alpha \nabla^{2} \bar{T}-\frac{\partial}{\partial x} \overline{\left(u^{\prime} T^{\prime}\right)}-\frac{\partial}{\partial y} \overline{\left(v^{\prime} T^{\prime}\right)}-\frac{\partial}{\partial z} \overline{\left(w^{\prime} T^{\prime}\right)}
$$




\subsection{Latin Square Experimental Design}

The design of the experiment was formulated using a Latin Square method. Latin square designs are used to eliminate sources of variability in two directions, or two nuisance factors. From Design and Analysis of Experiments by Montgomery, "In general, a Latin square for $p$ factors, or a $p \times p$ Latin square, is a square containing $p$ rows and $p$ columns. Each of the resulting $p^{2}$ cells contain one of the $p$ letters that corresponds to the treatments, and each letter occurs once and only once in each row and column. The statistical model for a Latin square is

$$
y_{i j k}=\mu+\alpha_{i}+\tau_{j}+\beta_{k}+\epsilon_{i j k}\left\{\begin{array}{l}
i=1,2, \ldots, p \\
j=1,2, \ldots, p \\
k=1,2, \ldots, p
\end{array}\right\}
$$

where $y_{i j k}$ is the observation in the $i$ th row and $k$ th column for the $j$ th treatment, $\mu$ is the overall mean, $\alpha_{i}$ is the $i$ th row effect, $\tau_{j}$ is the $j$ th treatment effect, $\beta_{k}$ is the $k$ th column effect, and $\epsilon_{i j k}$ is the random error [7]."

\subsection{Flowfield Measurements in the NASA Lewis Research Center Low-Speed Wind} Tunnel

Low-speed wind tunnels are very common and used in many different applications. It is very important that the flow be analyzed and known for these tunnels in order to use them to their fullest potential. In the 1980s, NASA Lewis Research Center in Cleveland, Ohio, now known as NASA Glenn Research Center, conducted an experimental investigation on their 9 by 15 foot lowspeed wind tunnel to analyze and document the flow conditions of the test section. This tunnel is a closed-circuit wind tunnel. They implemented different series of pitot-static flow survey rakes at different positions within the test section in order to accomplish the investigation. One rake spanned the test section horizontally to capture cross-sectional total and static pressure at the entrance of the test section, where models are placed, and near the exit of the test section. At each of these locations, the cross-sectional surveys were collected by repositioning the survey rake vertically. They also conducted boundary layer surveys at each of these locations in the test section. Their results discovered that the total pressure profiles and static pressure were uniform outside the boundary layers, and that near the walls the profiles were impacted by the flow around the test section wall slots and the large contraction ratio in the test section inlet. These variations 
occurred at higher tunnel speeds and lessened in severity at lower speeds. With these results, they determined that pressure measurements in the tunnel must be corrected to determine accurate freestream conditions where the models are mounted in the test section for all flow conditions. Figure 2.5.1 shows general dimensions of the test section entrance and exit, as well as numbered locations of where some of the flow survey was conducted.

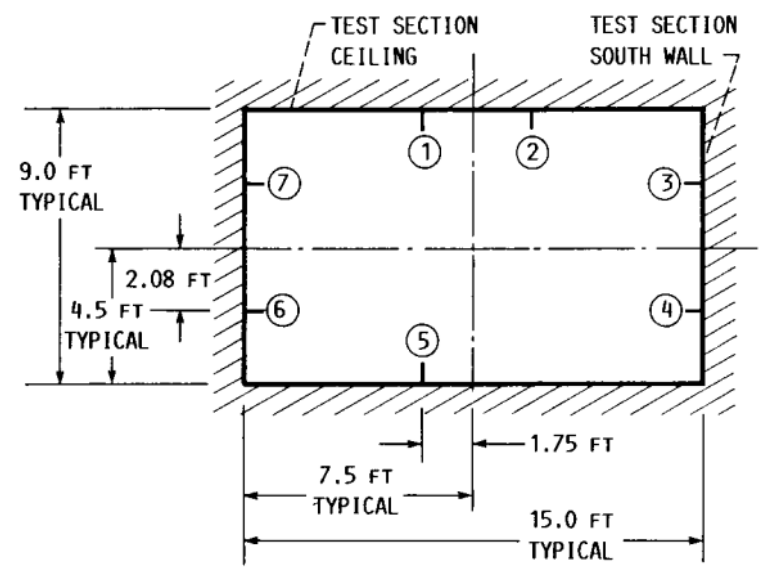

(a) FORWARD BOUNDARY LAYER, TEST SECTION STATION 28 (NEAR TEST SECTION ENTRANCE), DOWNSTREAM VIEW.

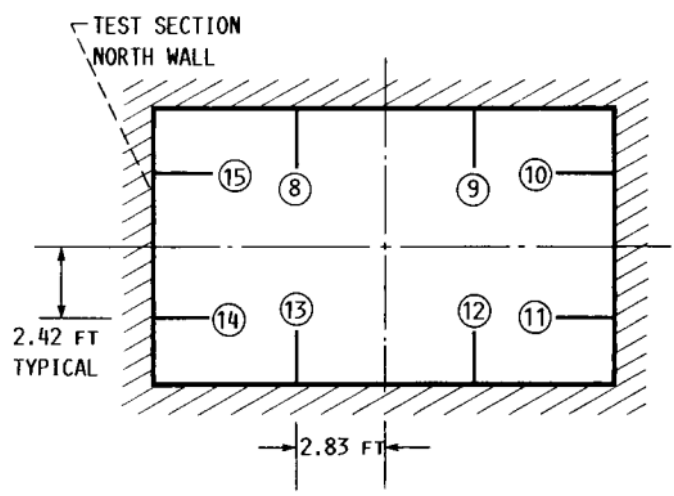

(b) AFT BOUNDARY LAYER, TEST SECTION STATION 336 (NEAR TEST SECTION EXIT), DOWNSTREAM VIEW.

Figure 2.5.1: Cross section of NASA Lewis Low-Speed Wind Tunnel with numbered locations of some flow measurements [8].

Figure 2.5.2 shows a view of the length of the test section looking down from above and shows survey rake locations.

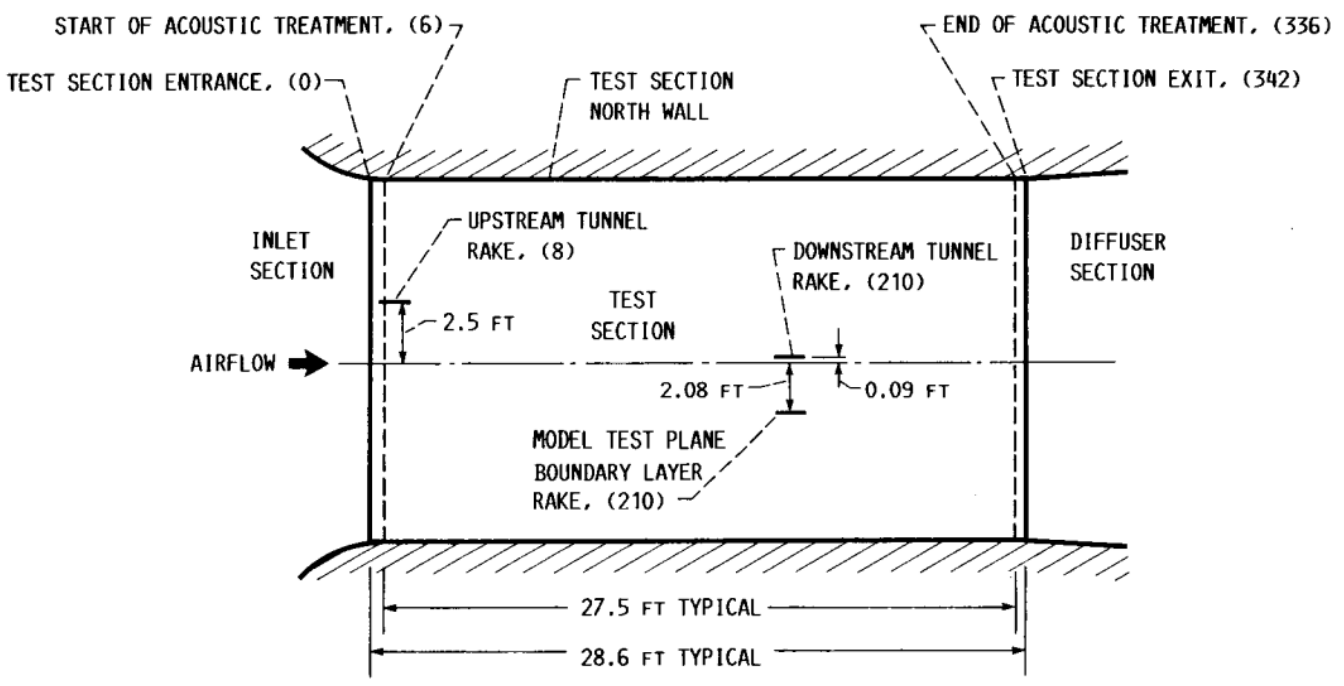

Figure 2.5.2: Cross section of length of NASA Lewis Low-Speed Wind Tunnel test section looking down from top [8]. 
Figure 2.5.3 shows a picture of the flow survey rake mounted in the test section.

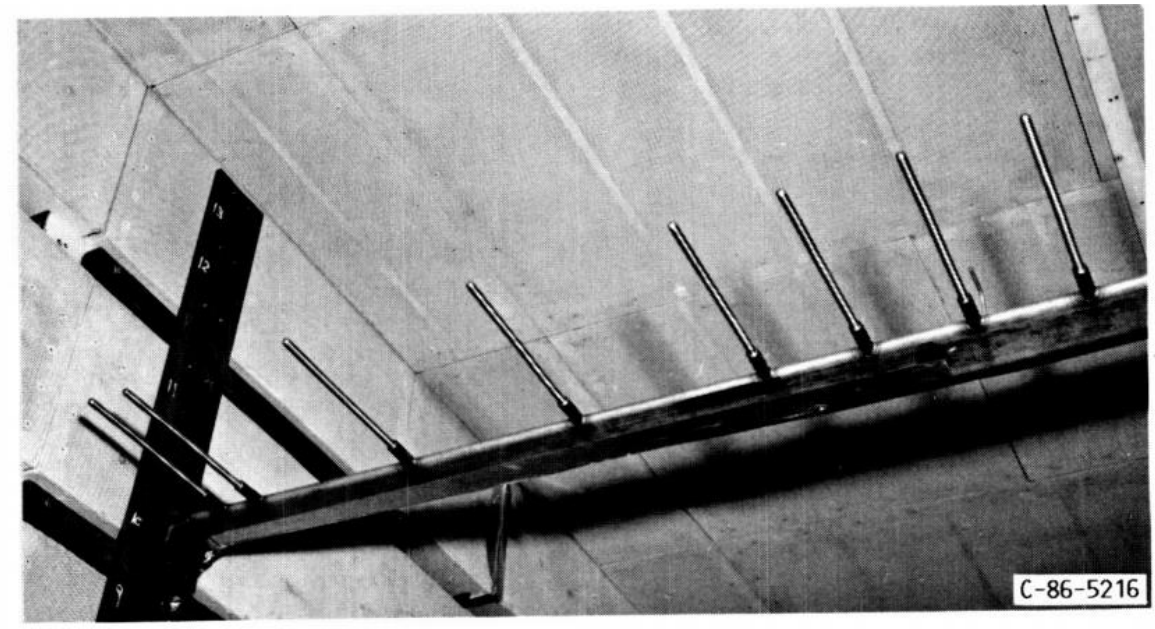

Figure 2.5.3: Flow survey rake mounted in the test section of the NASA Lewis Low-Speed Wind Tunnel [8].

Figure 2.5.4 shows a picture of the boundary layer survey rake mounted in the test section at the location where models would be mounted.

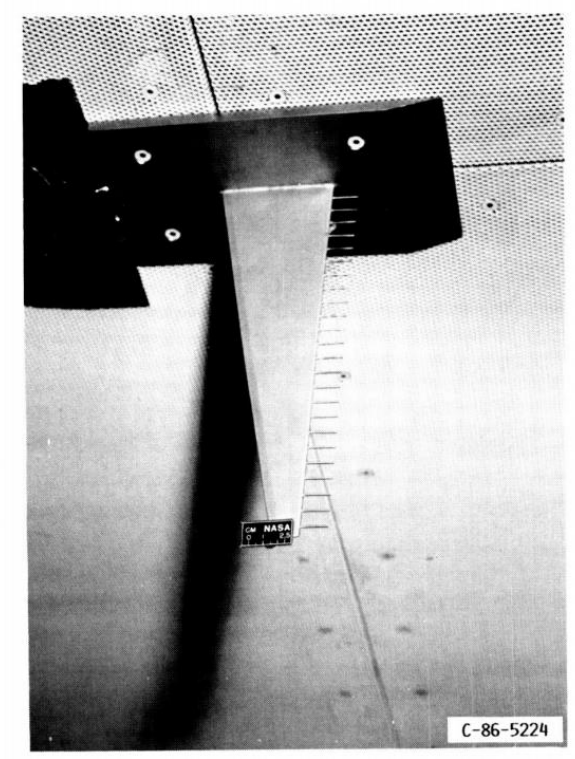

(a) MODEL TEST PLANE BOUNDARY LAYER SURVEY RAKE, ON TEST SECTION CEILING.

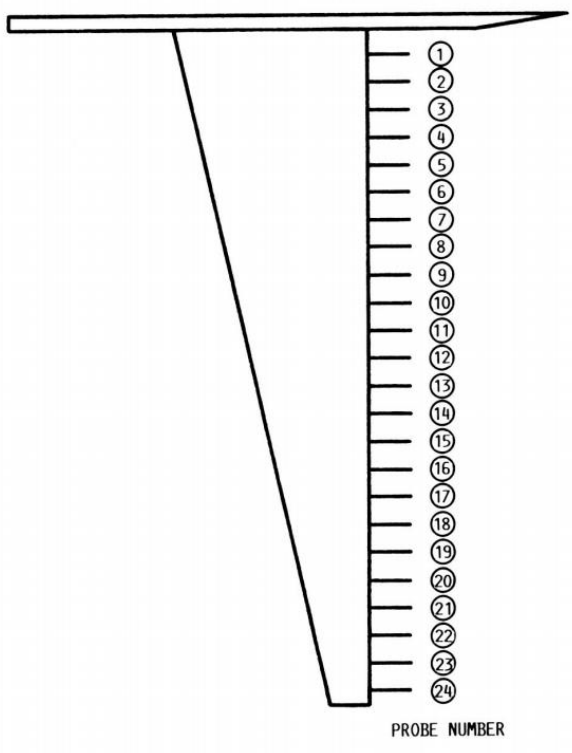

(b) SCHEMATIC OF TOTAL PRESSURE PROBE LOCATIONS ON RAKE.

Figure 2.5.4: Boundary layer survey rake in the NASA Lewis Low-Speed Wind Tunnel [8].

Figure 2.5.5 shows the locations of the survey rakes for both the boundary layers and crosssections [8]. 


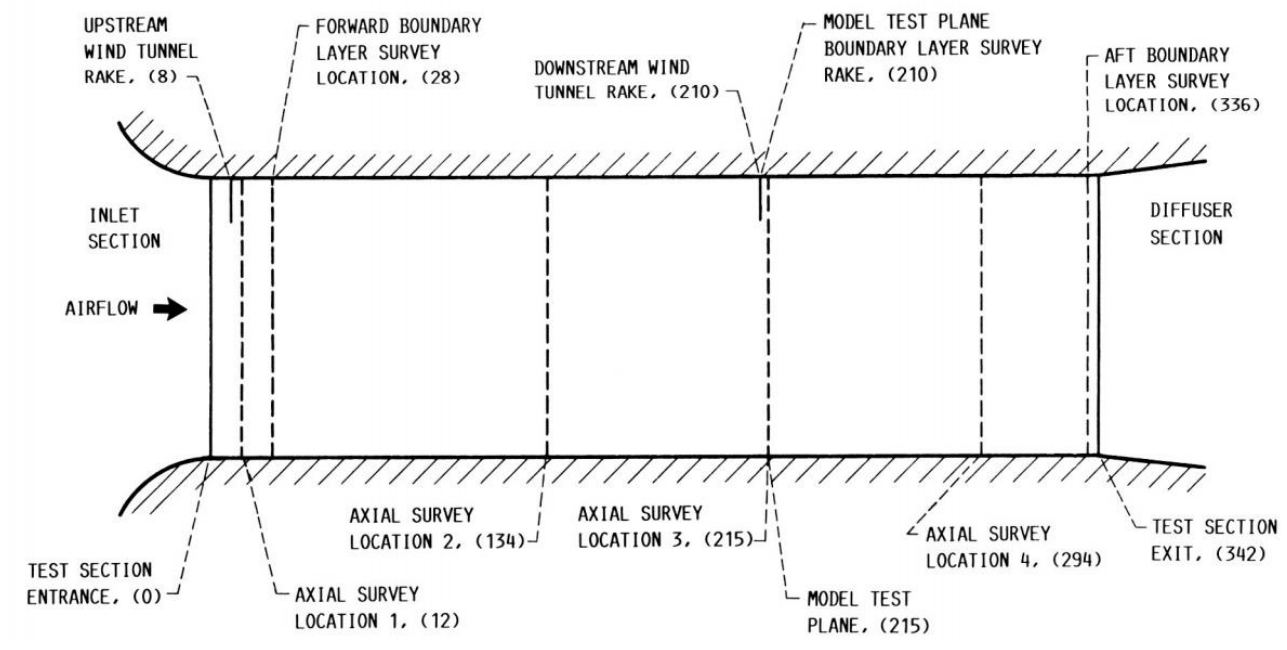

Figure 2.5.5: Cross sectional view of length of tunnel with survey rake locations in the NASA Lewis Low-Speed Wind Tunnel [8]. 


\section{Chapter 3: Technical Background}

\subsection{Scanivalve}

The device used for data collection was the Scanivalve ZOC 33/64Px Electronic Pressure Scanning Module, henceforth referenced to simply as the Scanivalve. The Scanivalve required $\pm 15 \mathrm{VDC}$ power at $120 \mathrm{~mA}$, and outputs signals on a $\pm 2.5 \mathrm{~V}$ scale. This model has 64 piezoelectric pressure sensing ports, arranged in eight sets of eight ports. Each set has a separate calibration port with four modes of operation: Operate, Calibrate, Purge, and Isolate. Applying an external control pressure determines which mode was selected, and the Scanivalve defaults to Purge mode when no pressure is applied. Operate mode connects each pressure, Px, input to its associated pressure sensor. Calibration mode connects all the pressure sensors to the calibration input and disconnects the Px ports. Purge mode connects the Px inputs to the pressure sensors and the Calibration input, and a safe purge pressure can be applied to purge the input lines. Isolate mode isolates the pressure sensors from the Px and calibration lines. Table 3.1 shows the state tables of the pneumatic logic for each mode. Applying a constant pressure of $65 \mathrm{psi}$ to the calibration control port puts the Scanivalve in Operate mode, while applying a constant pressure of 65 psi to the Px control port puts the Scanivalve in Calibrate mode.

Table 3.1: Pneumatic logic for Scanivalve modes.

\begin{tabular}{|c|c|c|}
\hline Mode & Px CTL & CAL CTL \\
\hline Operate & $\mathrm{x}$ & $65 \mathrm{psi}$ \\
\hline Calibrate & $65 \mathrm{psi}$ & $\mathrm{x}$ \\
\hline Purge & $\mathrm{x}$ & $\mathrm{x}$ \\
\hline Isolate & $65 \mathrm{psi}$ & $65 \mathrm{psi}$ \\
\hline
\end{tabular}

A pressure applied to any Px input port of the Scanivalve during Operate mode will apply a force on the respective piezoelectric sensor which will output a voltage linearly proportional to that force. Since the area of the sensor is constant, the voltage is also linearly related to the pressure. The Scanivalve reads these pressures one at a time through all 64 ports via a 6-bit digital input word which selects the port to output voltage from. The Scanivalve requires a minimum 20 microsecond signal settling time to achieve an accurate reading, or a maximum effective sample rate of $40 \mathrm{kHz}$. The accuracy of the Scanivalve readings is $\pm 0.08 \%-0.12 \%$ of full span, i.e., if a measurement span is 0-100 in $\mathrm{H}_{2} \mathrm{O}$, accuracy would be \pm 0.08 in $\mathrm{H}_{2} \mathrm{O}$ [9]. 


\subsection{Selection of Data Collection Method}

Previous research conducted with the WVU EWT recommended methods for qualification of the tunnel velocity. One of these recommendations included using hot wire anemometers (HWA) that determine air speed by heating an incredibly small metal wire using current and measures the cooling rate of the wire as air passes over it. This allows for a relationship between voltage and velocity to be determined and create a calibration curve. Another advantage of HWA is that they can also measure turbulence intensity, which could be a very beneficial variable to measure. However, HWA are very expensive and fragile, and the previous recommended method of employing them in the tunnel consisted of having only one HWA attached to a mechanism that would move the HWA around to different points of the test section cross section. This could make measuring less repeatable as it would be difficult to ensure that the HWA was in the exact same location for each repeated measurement. It also removes some of the ability for measurements to be instantaneous across the test section and could therefore introduce error as the flow may be unsteady and turbulent.

Another recommendation for velocity qualification was the use of pitot tubes. While this was not the desired option given during the previous research, pitot tubes are much easier and cheaper to construct, and a set of commercially available pitot-static probes were already outfitted inside the tunnel and connected to a manometer. Pitot tubes measure the pressure of the flow when facing directly into the flow and use Bernoulli's equation to solve for velocity. The choice was ultimately made to use pitot tubes for the test section qualification method, and a grid design of multiple pitot tubes was employed in order to cover the whole cross section and record the flow almost instantaneously at multiple points. This would allow for a more accurate velocity field picture and allow for error to be reduced and averaged out by having all of the pitot tubes at static positions [10].

\subsection{Methodology for Pitot Tube Size Selection}

Three different sizes of tubes were considered for the pitot tube design of the main grid. The tube material selected was ultra-formable 260 brass for its ability to be easily cut and soldered. The outer diameters (OD) of the three sizes chosen were 1/8", 3/32", and 1/16". These tubes were able to be telescoped, i.e. each tube would fit snug into the next size up. In order to determine the best size choice for all 64 tubes for the grid, a small apparatus was built to hold one of each size 
tube, as shown in Figure 3.3.1 (a) computer aided design (CAD) and (b) realized test stand within the test section, with the longest section of tube facing upstream.
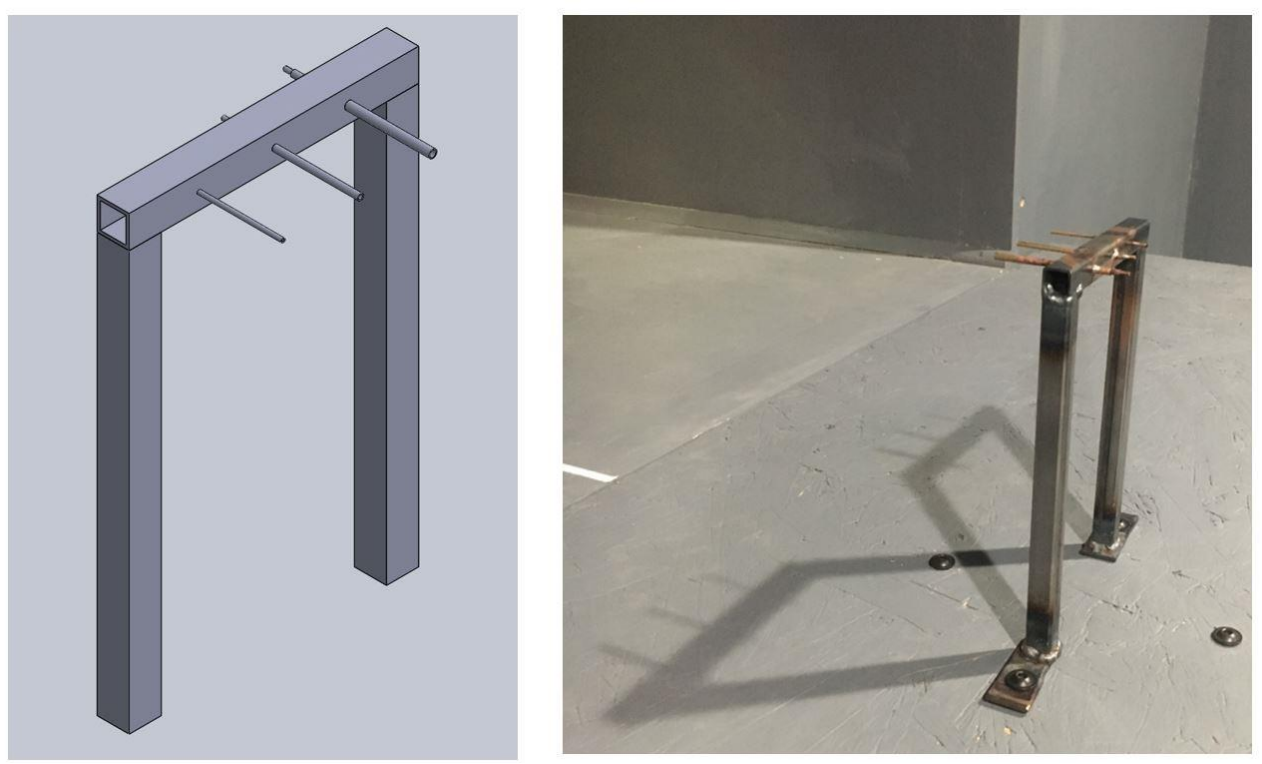

Figure 3.3.1: (a) CAD design, (b) realized test stand within the test section at the WVU EWT.

The largest tube with the 1/18" OD was telescoped down to the 1/16" OD tube using a smaller piece of the $3 / 32$ " and $1 / 16$ " tube to allow the polyurethane tubing to connect to the Scanivalve. The same process was completed for the 3/32" OD tubing down to the 1/16" tubing. The telescoping of the tubes was accomplished by soldering to ensure no air would escape at the connection points. Figure 3.3.2 shows a sketch of how these tubes were telescoped. Each tube was roughly 2 " in length, and was soldered in place into the steel apparatus.

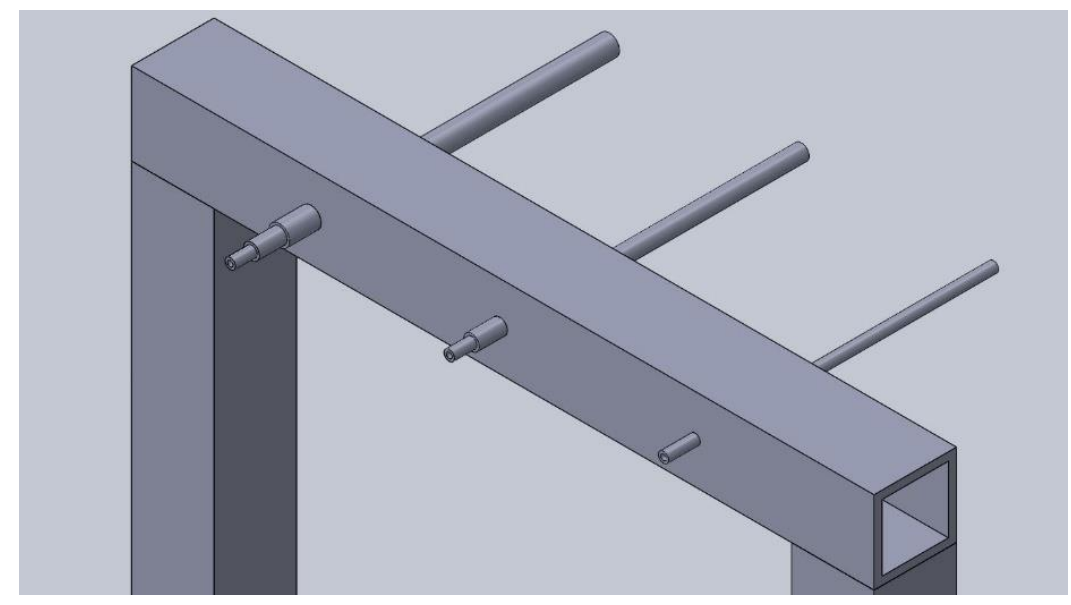

Figure 3.3.2: Sketch of telescoped tubes on test stand in the WVU EWT. 
With the apparatus placed inside the WVU EWT, the three tubes could be connected to the Scanivalve in order to collect data while the tunnel was running in order to determine which tube produced the best collection data. The tunnel was already outfitted with two commercially available pitot-static tubes, one of which was connected to a manometer. This was used as the control data to which the three tubes would be compared. For the first test, data for the three tubes was collected for 10 seconds at a time with the tunnel off, a speed of $18 \mathrm{~Hz}$ for all fans, $30 \mathrm{~Hz}$, $45 \mathrm{~Hz}$, and $60 \mathrm{~Hz}$. However, after scrutinizing the data at a later date, it was determined that the Scanivalve was temperature sensitive and also required time to stabilize and had not fully adapted to the environment inside the tunnel before data was collected, and so this data was discarded. Thus, a second test was run at a later date after allowing the Scanivalve to acclimate to the temperature inside the tunnel. For this test, data for the three tubes was collected again for 10 seconds at a time first with the tunnel off, then four times at $30 \mathrm{~Hz}$, four times at $60 \mathrm{~Hz}$, and then again once with the tunnel off. The mean voltage values and standard deviations collected from

the Scanivalve are presented in Appendix A in a table for each tube size as well as figures to present the voltage values collected during each run for each tube size. From these, it was clear that the 1/16" OD tube collected the cleanest data when compared to the commercially available pitot tube placed in the tunnel, and thus this was the tubing size chosen for the 64 pitot tubes in the grid.

\subsection{Pitot Tube Design}

The design of a pitot tube is quite simple if it does not include a static measurement system. The most important part of the pitot tube design is the leading edge, or nose, of the tubes. One of the most common nose shapes for pitot tubes is simply a flat, or square, nose. However, pointed cone-like shapes and rounded hemispherical nose shapes are also very common. Each shape lends itself to different applications. Hemispherical and square nose shapes tend to have the lowest tolerance to inclination in flow at about $8^{\circ}$ inclination, while pointed nose shapes have a greater tolerance at about $15^{\circ}$ inclination. Kiel probes have a much different shape and are most commonly applied in a grid form to observe the wake of Formula racecar tires. Kiel probes have one of the highest tolerances to inclination though at $30^{\circ}$ or more inclination. However, they are very costly and cannot be easily made for simple applications. The inlet to the pitot tube in a Kiel 
probe, shown in Figure 3.4.1, is protected by an outer shield, which helps to direct the flow to the tube, making them less sensitive to changes in angle of attack [11].

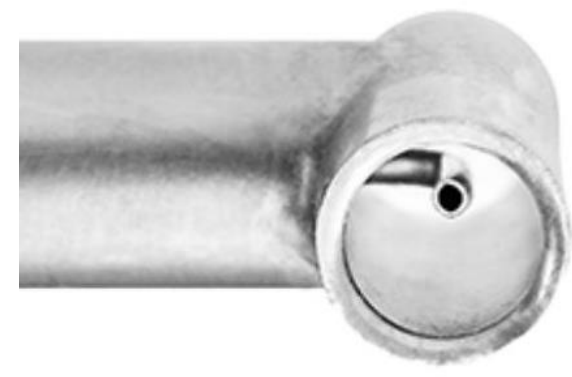

Figure 3.4.1: Kiel probe [11].

Figure 3.4.2 shows a graph of different nose shapes for pitot tubes and how effective they are at varying degrees of inclination. The variable $C_{p a}$ is an equation for the difference between the pressure at angle of attack and pressure at zero angle of attack, over dynamic pressure.

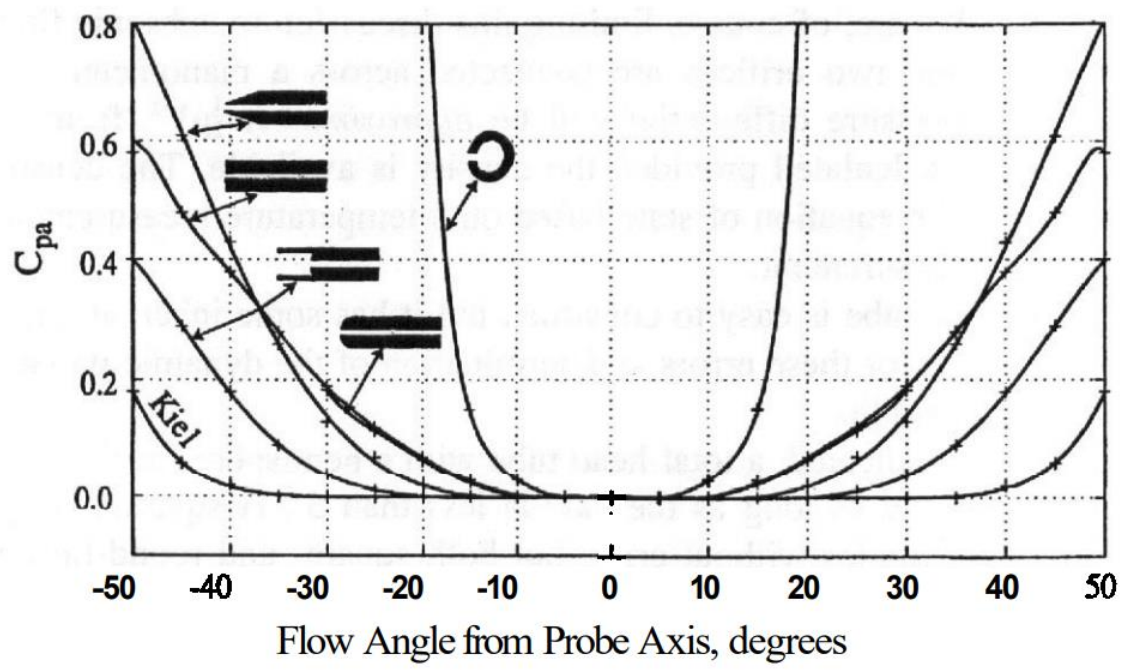

Figure 3.4.2: Pitot tube nose shape impact on inclination of flow [1].

The shape of the nose also impacts the performance of pitot tubes at different Reynolds numbers $(\mathrm{Re})$. Figure 3.4.3 shows how the performance of square and hemispherical noses deviates at low Re and begins to level out as Re increases, where $C_{p(s t a g)}$ is the difference in stagnation pressure and pressure over dynamic pressure [1]. 


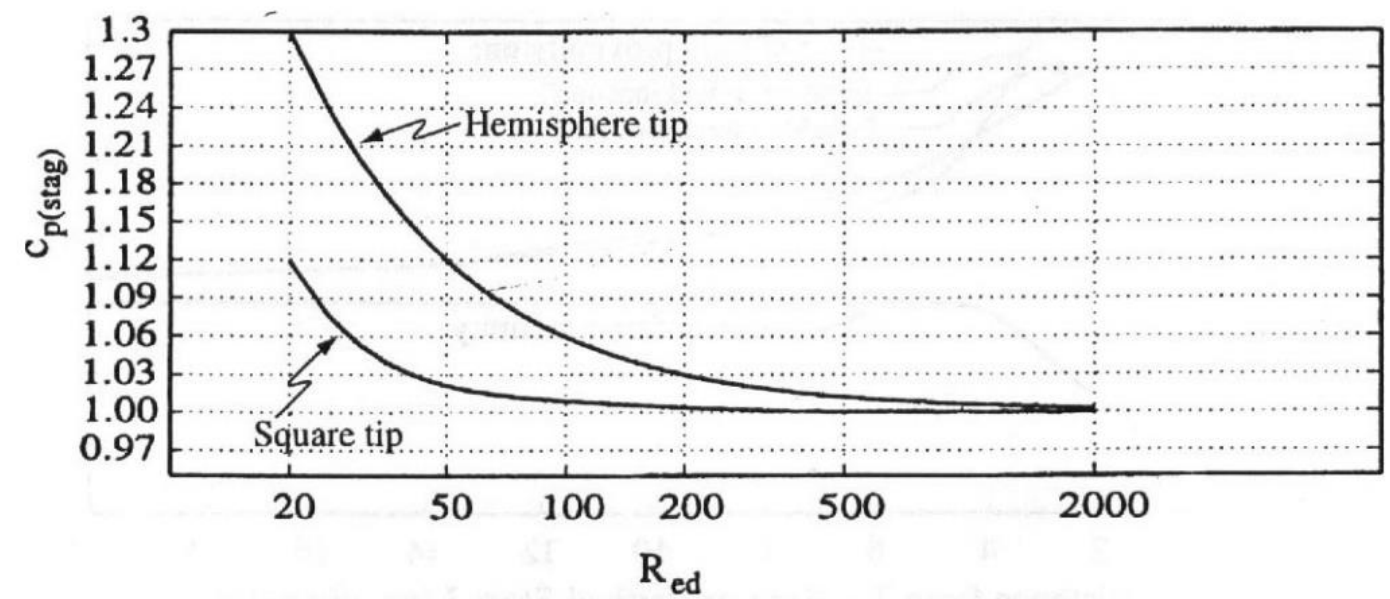

Figure 3.4.3: Performance of square and hemispherical nose shapes of pitot tubes across Reynolds Number [1].

The pitot tubes for the grid for this experiment were cut by hand and not machined, and therefore have square noses. This allowed for quick and easy development of the grid, but did however require more care that the tubes not have too much inclination to avoid skewing data.

\section{$\underline{3.5 \text { Grid Design }}$}

As mentioned above, a grid was designed in order to hold multiple pitot tubes across the test section cross section. From Section 3.1, the Scanivalve to be used for data collection contains 64 pressure reading ports, which would allow for 64 pitot tubes to be connected. The exit of the fetch into the test section of the WVU EWT was measured to be 45 " tall by 48 " wide. Since the test section cross section is roughly square, the grid would be designed to hold the pitot tubes in eight rows of eight. To get a broader picture of the velocity profiles in the test section cross section, 6" was added to both lengths so that some of the pitot tubes would be outside of the theoretical test section to gain insight into where the velocity profile ends. The grid was constructed using 0.5 " by $0.5 ", 0.049 "$ wall thickness, low-carbon steel rectangular tubing. Each row was a solid length of the tubing 54" long, and struts between each row were approximately 6.6875 " tall in order to make the grid approximately 51" tall. The final dimensions of the grid after construction were approximately 51 " tall by 54" wide. The holes for the pitot tubes were drilled into the 54" lengths of steel tubing at intervals of approximately 7.55 " in order create consistent spacing between all 64 tubes. The 2" long 1/16" OD ultra-formable 260 brass tubes, mentioned in Section 
3.3, were soldered into these holes with approximately a quarter inch of the tube protruding from the rear of the grid for the polyurethane tubing to connect them to the Scanivalve. Finally, the grid was painted to match other models and the paint within the tunnel. Figure 3.5.1 shows a side by side of the CAD of the grid design and the final product placed within the tunnel. See Appendix $\mathrm{B}$ for drawings and dimensions of the grid. The pitot tubes were numbered starting at the top lefthand corner looking at the back of the grid in the second image, and ended at the bottom righthand corner, the furthest corner in the image on the table.
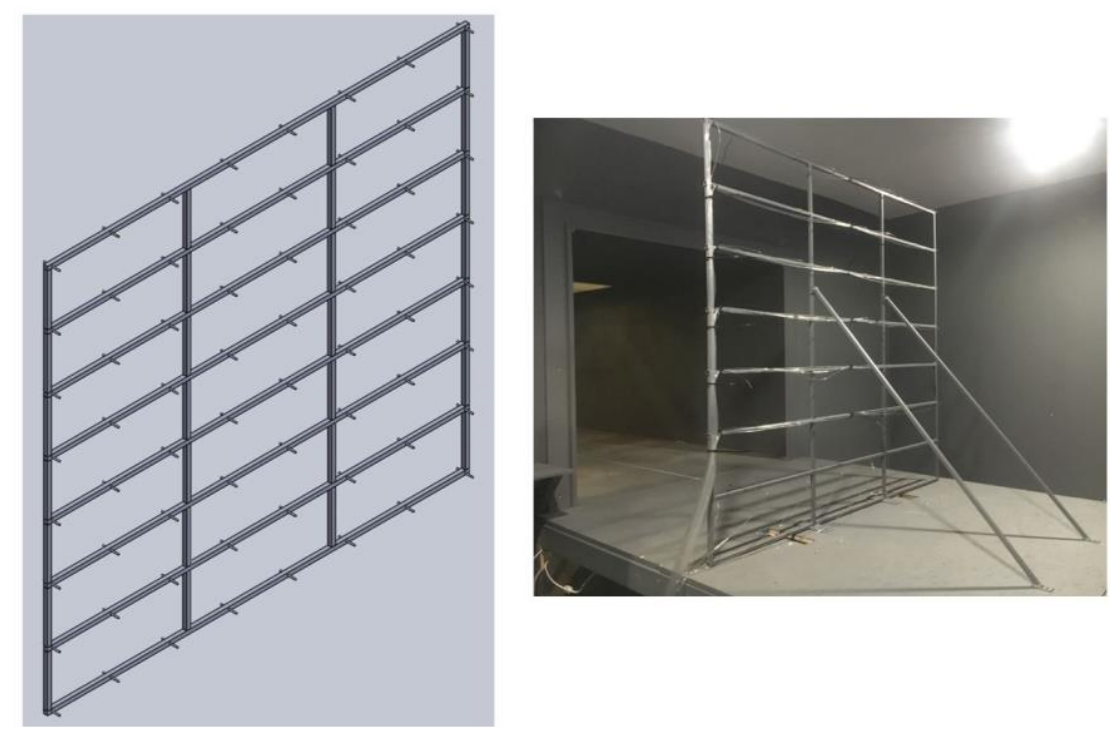

Figure 3.5.1: CAD design of grid and realized grid in the WVU EWT.

\subsection{Conversion from Voltage to Velocity}

When collecting data from the WVU EWT, the Scanivalve was used to measure the difference in pressure between the static pressure and dynamic pressure measured by the pitot tubes. The Scanivalve outputs this difference in pressure as a voltage. To scale the voltage to the proper difference in pressure, a calibration curve was created. To do this, data was collected at three different conditions in the tunnel, with all fans off, followed by fans running at $18 \mathrm{~Hz}$ and $30 \mathrm{~Hz}$. The actual change in pressure was recorded from the permanently mounted commercially available pitot tube in the tunnel connected to a manometer. Values were recorded at a rate of $10000 \mathrm{~Hz}$ for 0.5 seconds at drive frequency $0 \mathrm{~Hz}, 1$ second at drive frequency $18 \mathrm{~Hz}$, and 2 seconds at drive frequency $30 \mathrm{~Hz}$. These points were chosen so that calibration was not too long. With 
only these points, calibration took approximately 5-10 minutes and did not run the risk of being skewed by voltage drift in the Scanivalve. During the calibration all 64 ports of the Scanivalve, via the calibration port, were connected to a single pitot tube on the grid that is closest in line to the existing commercially available pitot tube in the tunnel via the calibration port of the Scanivalve. The use of a commercially available pressure transducer calibration tool would be better suited for this calibration, but was unavailable during the time of testing. This data was plotted as pressure from the commercially available pitot tube manometer values in inches $\mathrm{H}_{2} \mathrm{O}$ versus voltage collected from the Scanivalve, see Appendix C for calibration code and curves. A linear regression was fit to this data to calculate the slope and y-intercept for a linear equation in the form $y=m \mathrm{x}+b$, where $m$ is the slope, $b$ is the $\mathrm{y}$-intercept, $\mathrm{x}$ is the voltage, and $y$ is the corresponding pressure. From this equation, which was unique for each port, the voltage values for all 64 ports could be converted to pressure. Using these pressures and neglecting the gravitational term as fluid height is negligible in this case, the Bernoulli equation could be used to find velocity. Equation 3.6.1 below shows the Bernoulli equation rearranged to solve for velocity.

$$
V=\sqrt{\frac{2 \Delta P}{\rho}}
$$

In this equation, $V$ is velocity, $\Delta P$ is the change in pressure measured by the Scanivalve, and $\rho$ is the fluid density. The commercially available pitot-static probe connected to the manometer that was already outfitted in the tunnel was also used to verify that results seen from the grid were correct. 


\section{Chapter 4: Experimental Design And Setup}

This chapter details the experimental setup of the flow field testing in the WVU EWT using a pitot tube grid apparatus as well as the setup and qualification of the Scanivalve to collect data using the grid. The EWT has six fans, three upper horizontal and three lower horizontal. To simplify the experimental design, it was decided to restrict the tests to having all six fans running at all times (i.e. no singular fan would ever be off during runs where data collection is occurring). Another design parameter was to have two different types of runs. Type one would consist of all fans in a row always running at the same speed, and type two would consist of all fans in a column always running at the same speed. To begin designing the Latin square, five experiments were developed:

- Experiment 1: Hold bottom row of fans at constant speed, vary top row speed

- Experiment 2: Hold top row of fans at constant speed, vary bottom row speed

- Experiment 3: Hold left and center columns at constant speed, vary right column speed

- Experiment 4: Hold right and center columns at constant speed, vary left column speed

- Experiment 5: Hold outside two columns at constant speed, vary middle column speed

Figure 4.1 shows a mockup of the fans. For each set, (a) through (e), a box has been placed around the fans that would be held constant for each respective experiment.

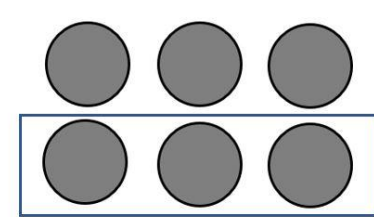

(a) Exp 1: Hold bottom row constant

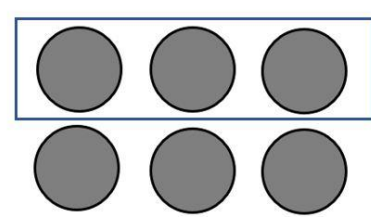

(b) Exp 2: Hold top row constant

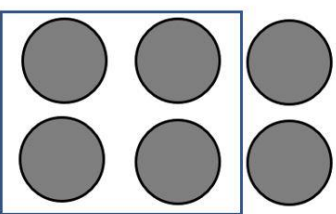

(c) Exp 3: Hold left two columns constant

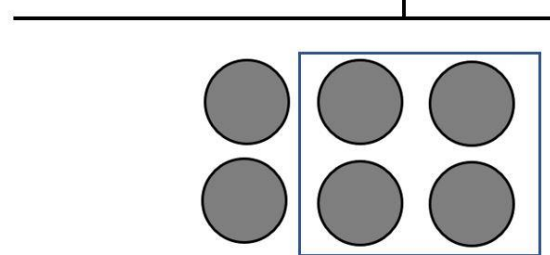

(d) Exp 4: Hold right two columns constant

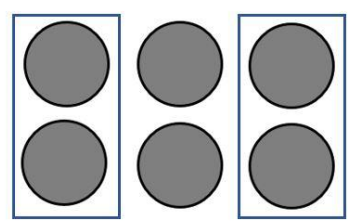

(e) Exp 5: Hold outer two columns constant

Figure 4.1: Mockup of the fans with each experiment set showing which fans to hold constant. 
In order to randomize these experiments and averaging out random error, these experiments were placed into the Reduced Latin Square design, as shown in Table 4.1. On the left of the table is the number of days for conducting the experiments, in this case five days. The first row and first column are in numerical order for experiments, which is the classic design for a Reduced Latin Square. The experiments would then each occur in a random order over the five days of testing, aiding in reducing and balancing the impacts of environmental factors outside of control, such as temperature fluctuations, pressure differences, humidity, etc. To read this Latin square, for the first row, which is Day 1, the five experiments would occur in numerical order, 1 through 5. For Day 2, the experiments would occur in order of 2, 1, 4, 5, and 3.

Table 4.1: Reduced Latin Square Design for Experiments.

\begin{tabular}{c|ccccc} 
Day & \multicolumn{5}{|c}{ Experiment } \\
\hline 1 & 1 & 2 & 3 & 4 & 5 \\
2 & 2 & 1 & 4 & 5 & 3 \\
3 & 3 & 4 & 5 & 1 & 2 \\
4 & 4 & 5 & 2 & 3 & 1 \\
5 & 5 & 3 & 1 & 2 & 4
\end{tabular}

Other design factors for these experiments include the fan speeds. The fans can vary in speed from $18 \mathrm{~Hz}$ to $60 \mathrm{~Hz}$, in steps of one tenth of a Hz. The fans would be run between these two values in steps of $6 \mathrm{~Hz}$, and would also be randomized in order to reduce and average any error.

To collect data to develop velocity profiles within the wind tunnel test section, a grid of pitot tubes was developed to take wind speed measurements at strategic intervals across the test section cross section. To further simplify the experiment, this grid would be placed at one location in the test section, an area most commonly used for experiments conducted in this tunnel, as opposed to conducting the experiments at several cross sections of the wind tunnel test section. Since the tunnels test section cross section is approximately four foot by four foot, the grid was designed to span this area plus a quarter foot each direction in order to get a full picture of the velocity profiles. The grid consists of 64 pitot tubes, placed in an eight-by-eight square. The pitot tubes have a 1/16" OD and are two inches in length each. The grid that the pitot tubes were mounted to was made from square-steel-tubing with a half-inch by half-inch profile. Holes to fit the pitot tubes were drilled in the grid, and a quarter inch of the pitot tubes stuck out the rear of the 
frame so that polyurethane tubing could be connected. The rest of the pitot tubes faced out the front of the grid upstream into the flow. The spacing between each pitot tube is approximately 7.3 inches, both vertically and horizontally. See Sections 3.3 and 3.5 as well as Appendix B for more detail on the pitot tubes and grid design.

The OD of the pitot tubes in the grid was 1/16", and each tube was fitted with clear polyurethane tubing on the rear of the pitot tube. This tubing extended down to a pneumatic connector male side from Scanivalve Corp. The pneumatic connector in question was the 73ZOC male connection. This pneumatic connector has 73 ports for tubing to be connected to and allowed for the 64 pitot tubes to be connected. The 73ZOC male pneumatic connector then connected with the 73ZOC female bulkhead connector. This pneumatic connection was an intermediate step in the tubing to allow for a couple things to occur. One, this allowed for the tubing to change size from that connected to the pitot tubes, to the smaller size connected to the Scanivalve system. Two, this intermediate step also allowed for interchangeability in the future. The female bulkhead connector was connected to the housing box for the Scanivalve and will always stay in this position. The male connection can be removed so that another connection for a different model could be easily made.

From the female bulkhead pneumatic connector, the tubing size decreased to 0.040 " diameter to connect with the Scanivalve. To control the Scanivalve multiplexer and select which channel to read, the Scanivalve required a CMOS level sinking output capable of withstanding 15 volts. To reference all 64 channels, the Scanivalve required 6 individual digital outputs. The digital outputs follow a binary-minus-one sequence position, or $\mathrm{n}-1$, where $\mathrm{n}$ is the desired channel. For example, port 63 of the Scanivalve would be referenced by binary value 62 . Due to the fact that most data acquisition (DAQ) systems operate on a 5V TTL level output, Scanivalve offered a schematic of a circuit to convert from 5V TTL sourcing output to a $15 \mathrm{~V}$ CMOS sinking output required for the Scanivalve. This circuit used an integrated circuit (IC) chip, Texas Instruments SN7404N Buffer Non-Inverting 6 Element 1 Bit per Element Open Collector Output 14-PDIP, to do this conversion. The chip required a constant $5 \mathrm{~V}$ DC power source to operate. To provide this power source, a linear voltage regulator chip, Texas Instruments UA78L05ACLPM Linear Voltage Regulator IC Positive Fixed 1 Output 100mA TO-92-3, was used to regulate the 15V input from the Scanivalve power supply down to $5 \mathrm{~V}$ for power of the circuit. A low current LED was placed in parallel with the input and output of the conversion circuit to aid in troubleshooting and 
verification of output. A lit LED indicates a value of 1 for the particular input or output. Eagle PCB design software was used to design a schematic and circuit board layout to mount all the components for the conversion board, as shown in Figure 4.2. National Instruments NIDAQ 9401 was selected to be used for the $5 \mathrm{~V}$ output source to control the Scanivalve.

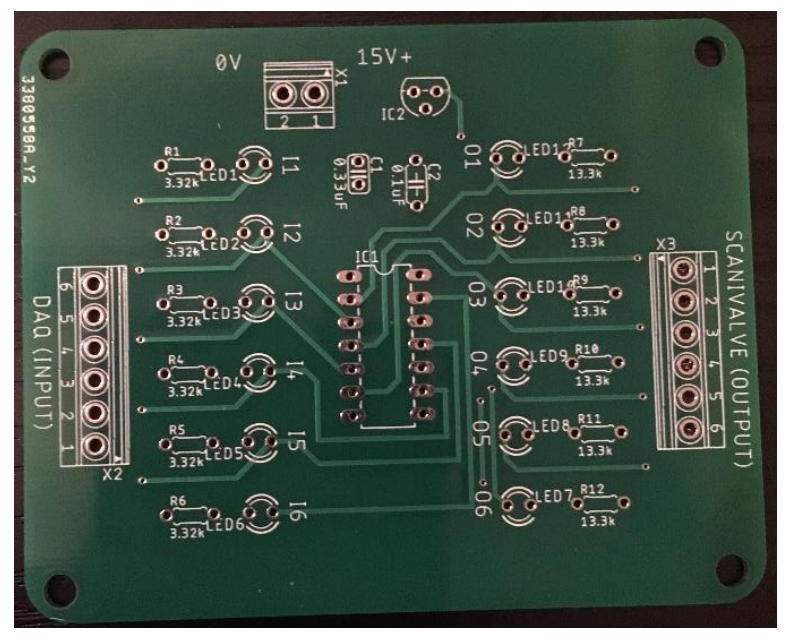

Figure 4.2: Eagle PCB design for conversion circuit board.

The Scanivalve outputs pressure as a linear voltage signal from $-2.5 \mathrm{~V}$ to $2.5 \mathrm{~V}$ over the full range of Scanivalve readings. This signal was directly wired to a differential analog input module, NIDAQ 9205. To quickly connect and disconnect the Scanivalve from the DAQ, a 25-pin D-sub connector was mounted to the Scanivalve housing box. A 25-pin D-sub connecter is standard for the 9401 digital output module, and the 9205 analog input module uses push-in quick-connect for individual wires. As shown in Figure 4.3 of the NIDAQ 9401 Pinout identification, connections A0-A5 indicate connections for the 6-bit digital words for channel selection, and COM indicates the common. Figure 4.4 shows the Pinout identification for the NIDAQ 9205, including the SIG+ and SIG- connections and the $1 \mathrm{M} \Omega$ resister. The D-sub pinout at the Scanivalve box is shown in Figure 4.5. The connection for temperature measurement from the Scanivalve was also made for future use but was not utilized for this case. 


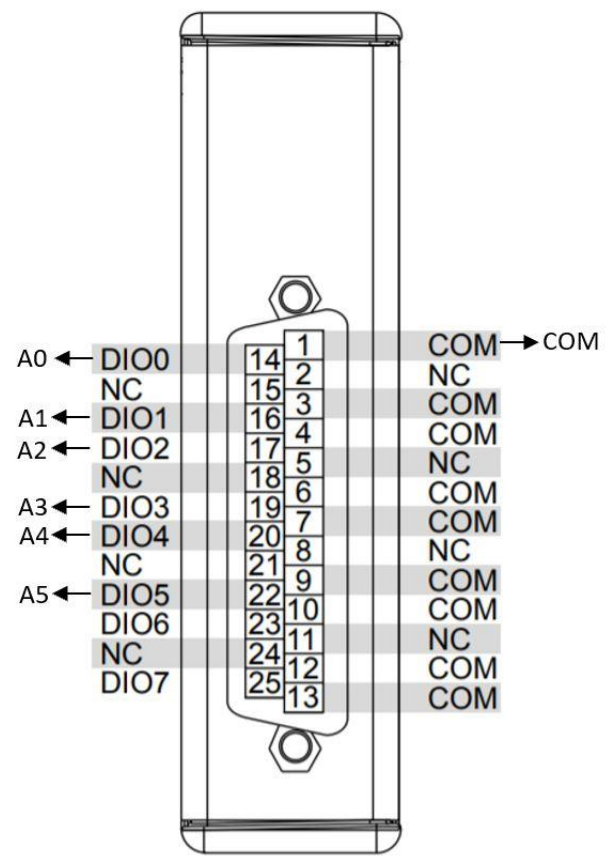

Figure 4.3: Pinout identification for NIDAQ 9401.

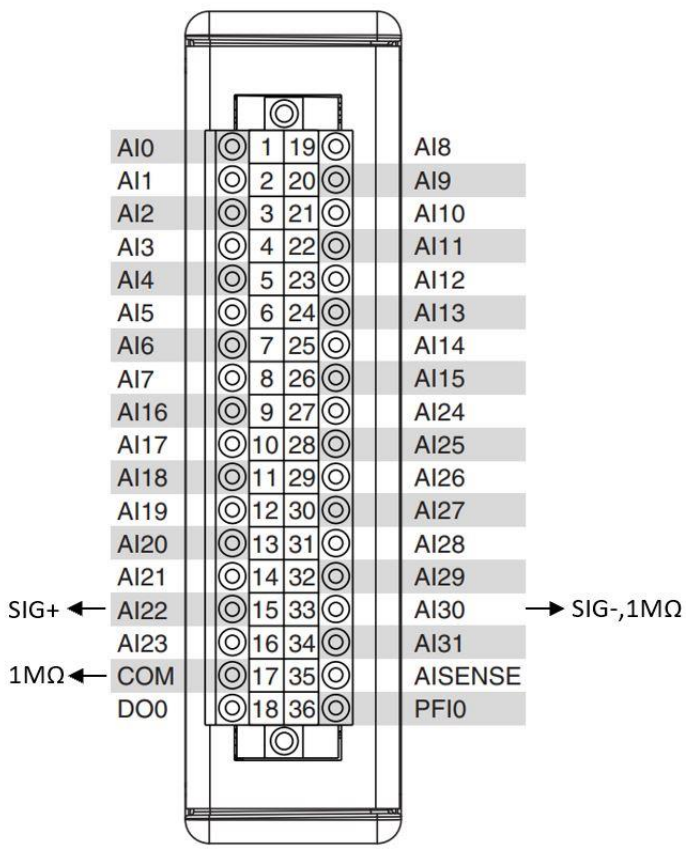

Figure 4.4: Pinout identification for NIDAQ 9205. 


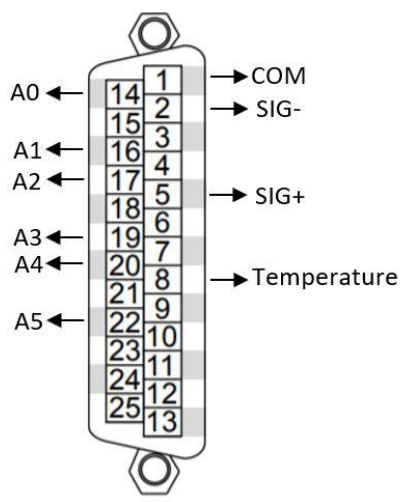

Figure 4.5: D-sub Pinout identification at Scanivalve housing box.

All of the digital outputs for the multiplexer control connected through the D-sub connector on the 9401 module. The SIG+ and SIG- cables were pulled from the cable near the D-sub connector for the DAQ. In initial testing, instability of the Scanivalve output and unexplained voltage clipping of the DAQ were experienced. In order to combat this, a $1 \mathrm{M} \Omega$ resistor was placed between the SIG- wire and the DAQ COM port at the 9205 interface to suppress floating voltages. These wires had to be manually inserted into the 9205 module push-in quick-connectors, with blue being SIG+ and black being SIG-, as shown in Figure 4.6. All connections were made through the D-sub connector at the Scanivalve housing box. The module in the middle is the 9205 module and the blue SIG+ and black SIG- wires can be seen connected along with a $1 \mathrm{M} \Omega$ resistor between the SIG- and COM ports. The module on the right is the 9401 module with the D-sub connector with the SIG+ and SIG- wires exiting the connector to reach the 9205 module. 


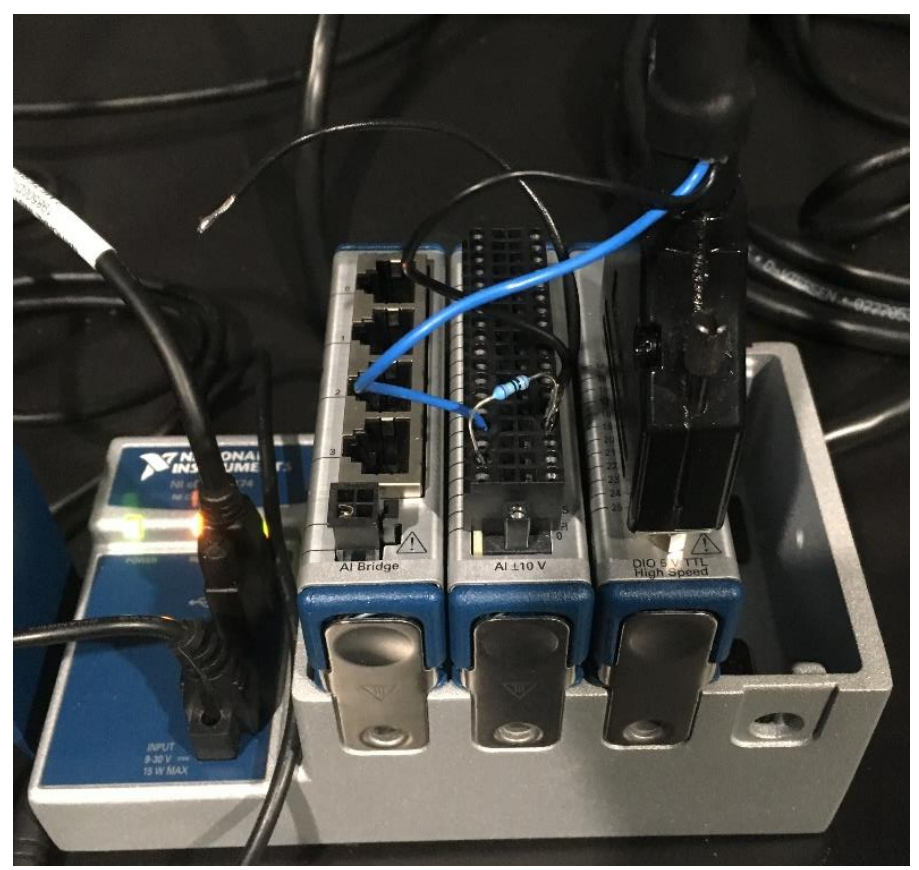

Figure 4.6: DAQ Connections made at the NIDAQ 9205 and NIDAQ 9401 modules in the NI Compact DAQ carrier.

The NIDAQ 9205 module was setup to read from a $\pm 1 \mathrm{~V}$ output. This was the lowest setting for the module and allowed for the most accuracy in measurements. A setting of $\pm 10 \mathrm{~V}$ held $\pm 1 \mathrm{mV}$ accuracy, while $\pm 1 \mathrm{~V}$ held an accuracy of $\pm 0.1 \mathrm{mV}$ accuracy per the 9205 manual. This correlates to \pm 0.0033 inches $\mathrm{H}_{2} \mathrm{O}$ from the DAQ during testing. However, this caused three ports to become unusable because their zero voltages were above $1 \mathrm{~V}$. These ports were placed along the outside of the grid so their reading would have a less significant impact on the flow measurement inside the test section. When the output plots were created the data for ports adjacent to the unusable ports were averaged to get an approximate value for those ports. The DAQ initialization and configuration code can be seen in Appendix D. Reference the National Instruments manuals for these two modules for more.

The Scanivalve was powered by $110 \mathrm{~V}$ AC via a cord and plug exiting the box. The $110 \mathrm{~V}$ power source powered two $15 \mathrm{~V}$ power supplies, models XP Power DRC30US15 AC/DC Converter $15 \mathrm{~V} 30 \mathrm{~W}$. The Scanivalve required a $+15 \mathrm{~V}$ power source at $120 \mathrm{~mA}$ and a separate $-15 \mathrm{~V}$ power source at $30 \mathrm{~mA}$. The conversion board also used the $+15 \mathrm{~V}$ power source. To achieve the positive and negative voltages from these power supplies, the positive terminal of the right supply was connected to the negative terminal of the left supply, shown in Figure 4.7. 


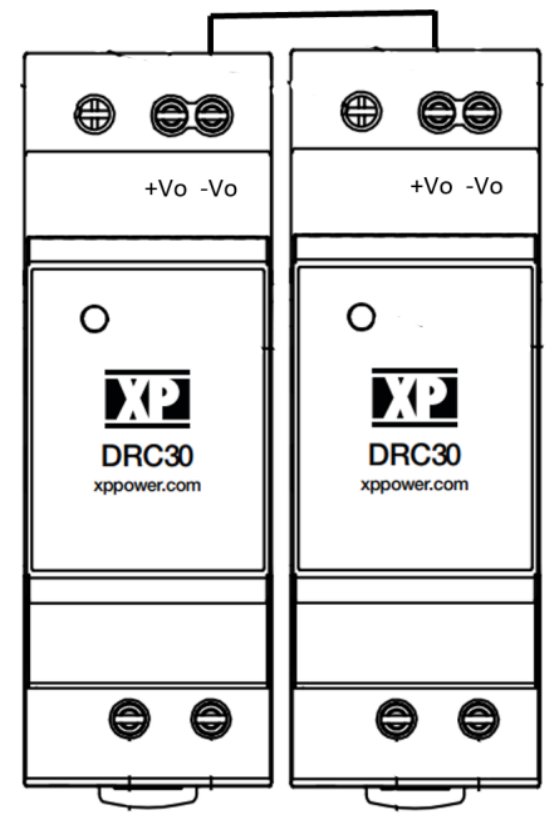

Figure 4.7: Power supply connections to create a positive and negative 15V for the Scanivalve.

See Appendix E for a table that lists all of the necessary parts for the PCB board as well as other components needed for the control of the Scanivalve should any part fail and/or need to be replaced.

As mentioned in Section 3.1, the Scanivalve requires a constant pressure of $65 \mathrm{psi}$ to calibrate and operate. To achieve this, a standard 150psi air compressor was used. Attached to the outside of the Scanivalve housing box was a line connection for the air compressor and a pressure regulator. After the pressure regulator, the air would pass through two air filters, one of a coarse grain and one of a finer grain, in order to assure that clean air without debris would pass to the Scanivalve. From there, the air would enter the housing box through the air line and was split by a tee-connection. One line would bring air to a switch for the calibration mode port, and the other line would bring air to a switch for the operate mode port. These switches, which were accessed from the outside of the housing box, allowed the pressure to be turned on or off to the ports. When the switch towards the rear of the housing box was in the on position and the switch closest to the front of the housing box was in the off position, the Scanivalve would be in Calibrate mode. When the switches were set to the opposite setting, the Scanivalve would be in Operate mode. With both switches in the off position, no pressure would be applied to the Scanivalve and thus would be in Purge mode. Finally, when both switches were set to the on position, the 
Scanivalve would be in Isolate mode. Figure 4.8 shows the Scanivalve housing box with air flow direction and accompanying parts labeled.

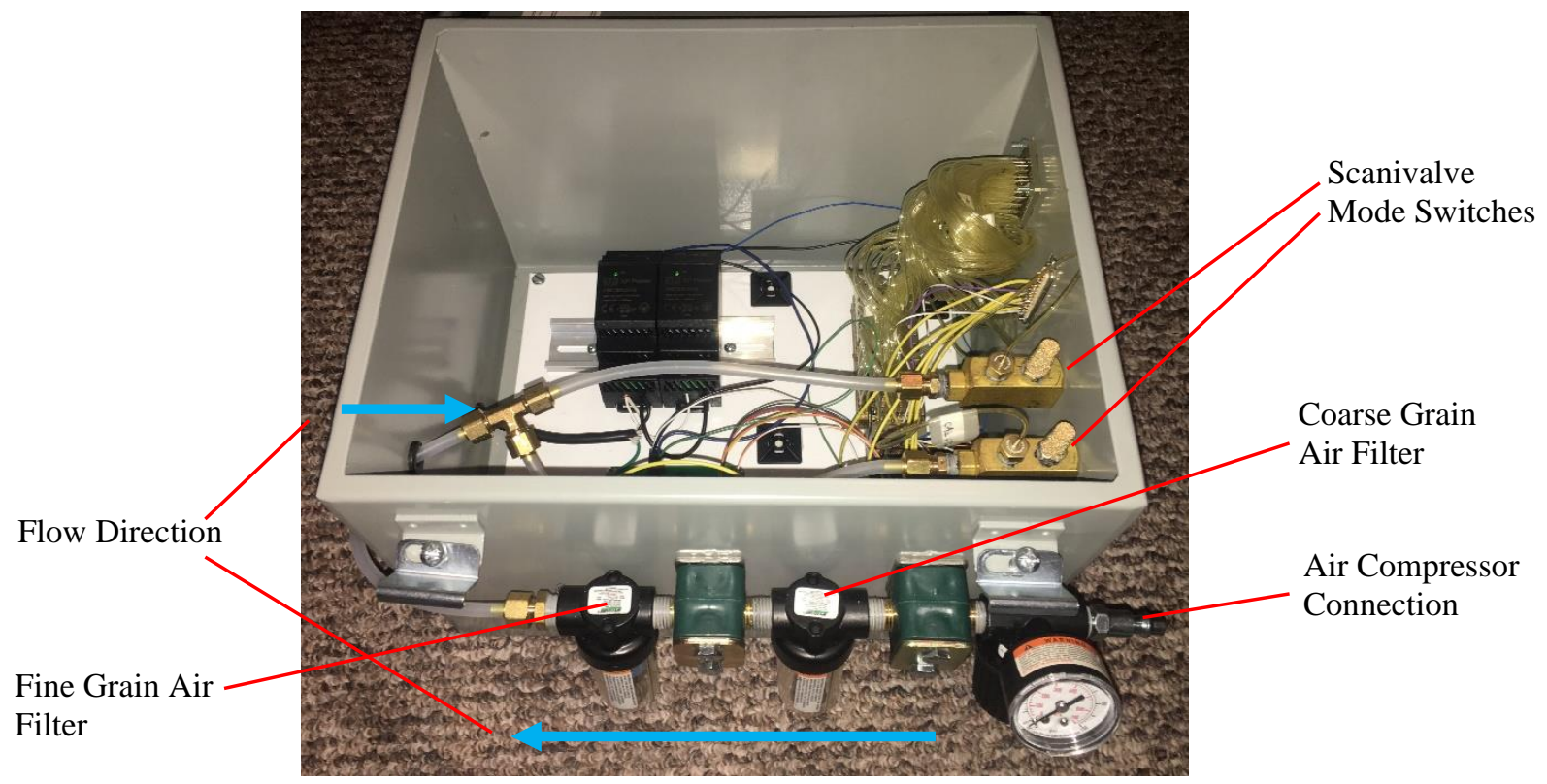

Figure 4.8: Scanivalve housing box, open.

Figure 4.9 shows all of the modes for the two switches. Table 3.1 in Section 3.1 explains which mode is activated when the constant 65 psi is applied to the Scanivalve. In Figure 4.9 the left switch is the one closest to the front of the Scanivalve housing box, and the right switch is the one closest to the rear of the Scanivalve housing box. In the first mode, the left switch is on and the right switch is off indicating Operate mode. In the second mode, the right switch is on and the left switch is off, indicating Calibrate mode. The final two modes are Purge mode with the switches both off, and Isolate mode with the switches both on. 


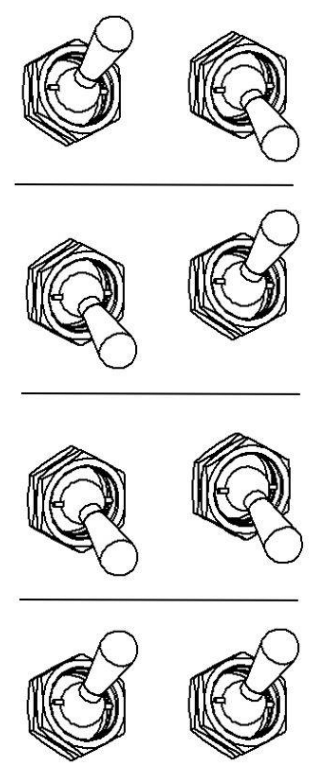

Figure 4.9: Scanivalve constant pressure switch modes.

To qualify the Scanivalve to the precision necessary for this experiment, a series of tests were performed, the first of which was a long-term output stability test. For this, the Scanivalve and DAQ modules were setup in a controlled area with constant temperature of approximately $70^{\circ} \mathrm{F}$. With no pressure applied to the Scanivalve, in other words the reference port and pressure inlet ports open to ambient conditions to cancel out variation in atmospheric pressure, the output voltage was measured over an eight-hour period. This test showed how much the output voltage would drift over time and how long it would take the Scanivalve output to stabilize from a cold start. A graph of the data output from this test for port 1 is shown in Figure 4.10. The first graph shows the voltages collected at a rate of $10 \mathrm{kHz}$, and the second shows these voltages averaged. Other ports showed similar results. From this data, it was deduced that the Scanivalve output voltage would stabilize after approximately one hour of run time. After the initial hour, the output oscillated up and down by approximately $5 \mathrm{mV}$, or $0.2 \%$ full scale voltage. See Appendix F for the code for this test. 

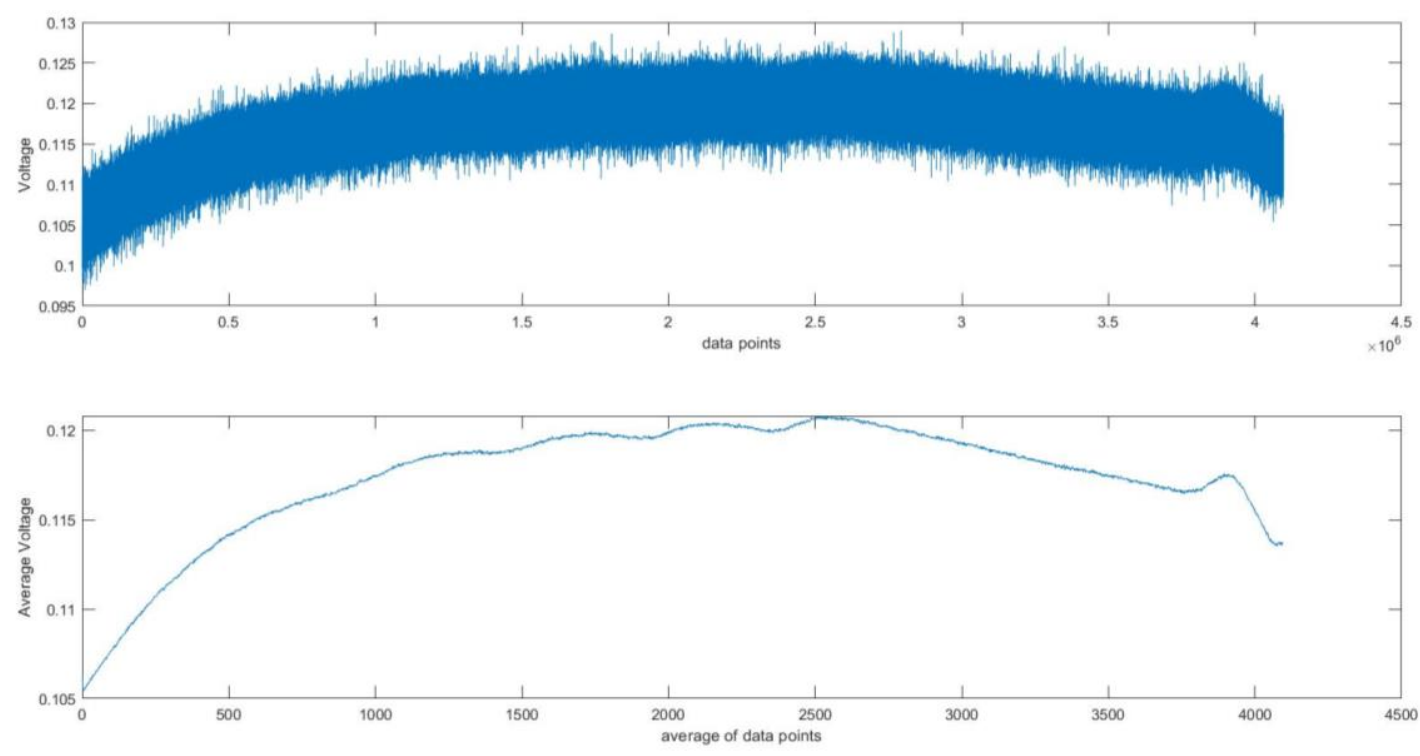

Figure 4.10: Scanivalve Voltage Output Drift over an eight-hour period, no pressure applied.

The second test was to determine the minimum sample time and rate so that the output voltage is minimally impacted by noise. To filter noise, the output voltage over the sample time was averaged. Based on testing, a longer sample time increased the repeatability and accuracy of the data collected but also significantly increased the amount of time required to collect that data. Increasing the sample rate increased the amount of data taken in the same amount of time, thus also gave more repeatability and accuracy. The sample rate is hardware limited with a maximum sample rate of $40 \mathrm{kHz}$ for the Scanivalve, and a maximum sample rate of $250 \mathrm{kHz}$ for the 9205 module. To stay away from equipment limits a maximum sample rate of $10 \mathrm{kHz}$ was set for this experiment. To select sample times for different testing scenarios, a code was written that would run the tunnel at a fixed speed and take data at increasingly longer sample times until either 25 samples were taken in a row with less than $0.5 \mathrm{mV}$ variation or the sample time was greater than 10 seconds. This test was conducted for drive frequencies $0 \mathrm{~Hz}, 18 \mathrm{~Hz}, 30 \mathrm{~Hz}, 45 \mathrm{~Hz}$, and $60 \mathrm{~Hz}$ with the sample rate being varied between 100, 1000, and 10000 for the $0 \mathrm{~Hz}$ drive frequency sample. A sample rate of 10000 decreased the amount of time required to achieve consistent results over a rate of 1000 and 100. Based on the results of Figures 4.11 through 4.15, the minimum sample time was selected as follows: $0-30 \mathrm{~Hz}$ drive frequencies at 0.5 seconds, $30-45 \mathrm{~Hz}$ at 1 second, and $45-60 \mathrm{~Hz}$ at 2 seconds, each taken at a sample rate of 10000. At higher speeds the flow in the tunnel becomes more unsteady and requires a larger sample time in order to achieve consistent 
results. At speeds above $45 \mathrm{~Hz}$ drive frequency consistent results with variation less than $0.5 \mathrm{mV}$ were not achievable at a sample time less than 10 seconds. See Appendix G for code for this test.

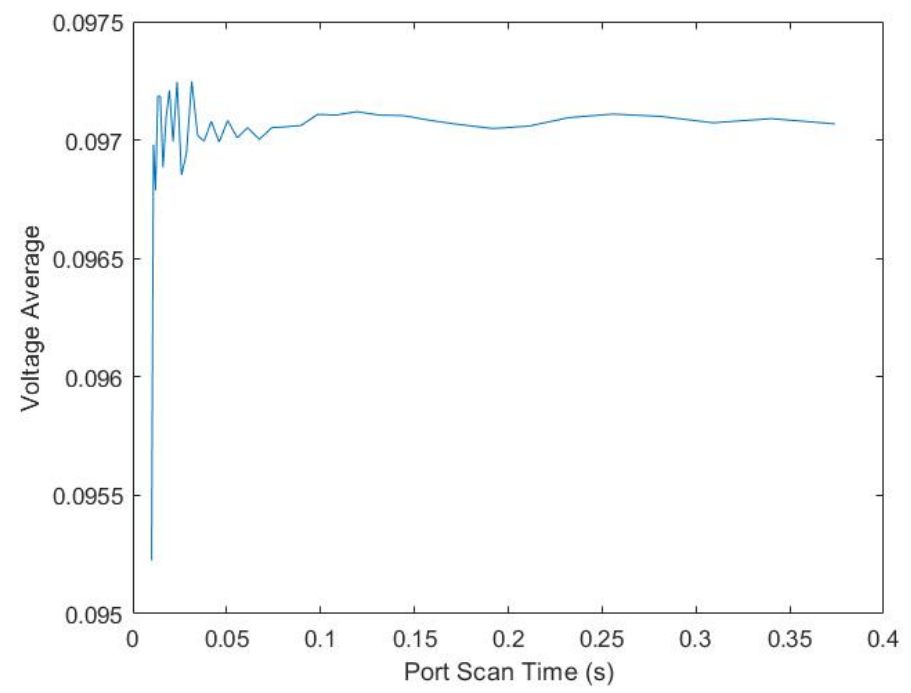

Figure 4.11: Minimum Sample Time for $\mathrm{OHz}$ Drive Frequency.

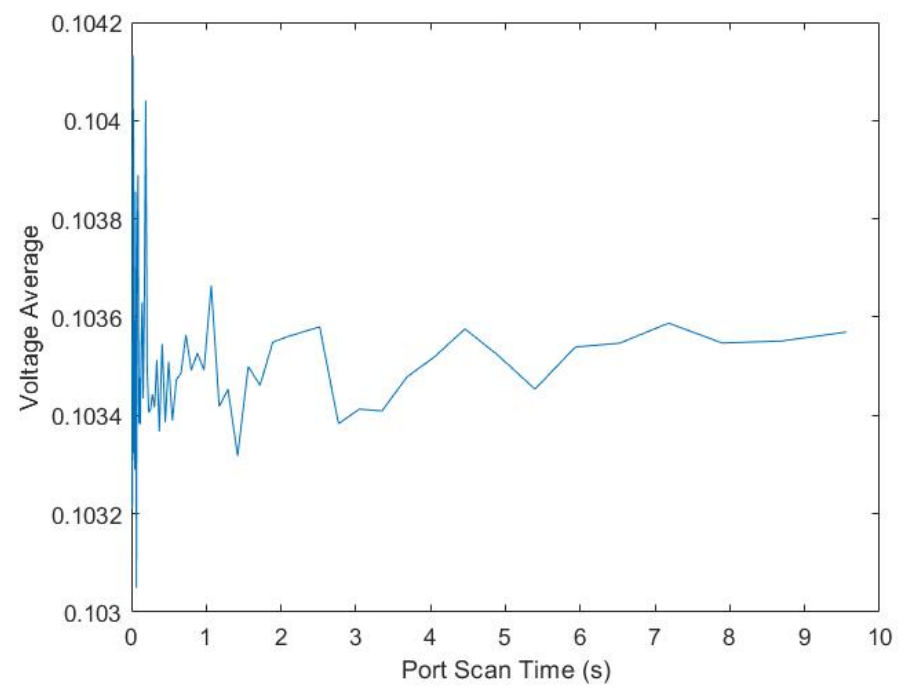

Figure 4.12: Minimum Sample Time for $18 \mathrm{~Hz}$ Drive Frequency. 


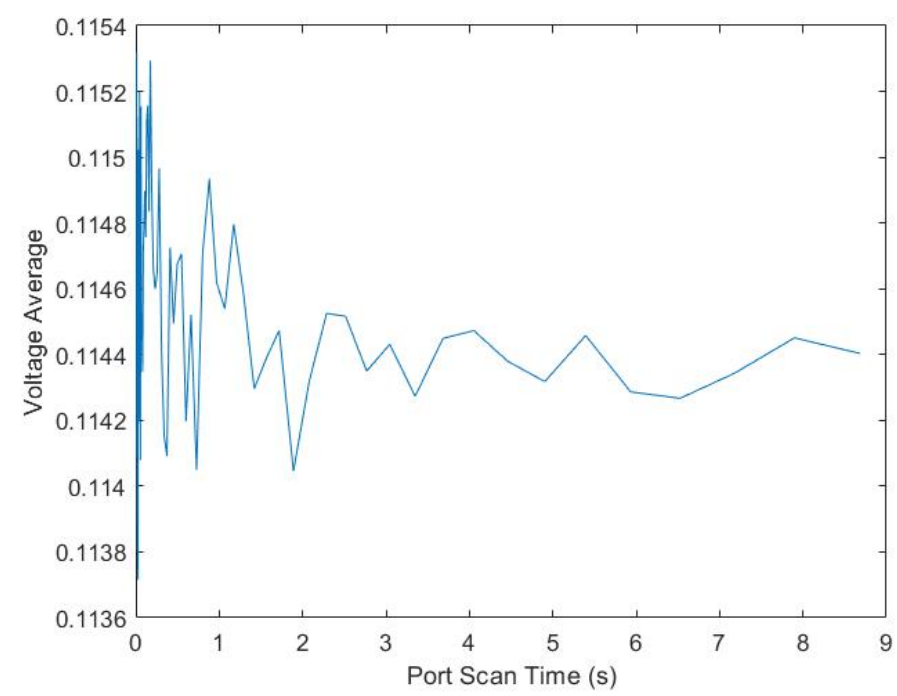

Figure 4.13: Minimum Sample Time for $30 \mathrm{~Hz}$ Drive Frequency.

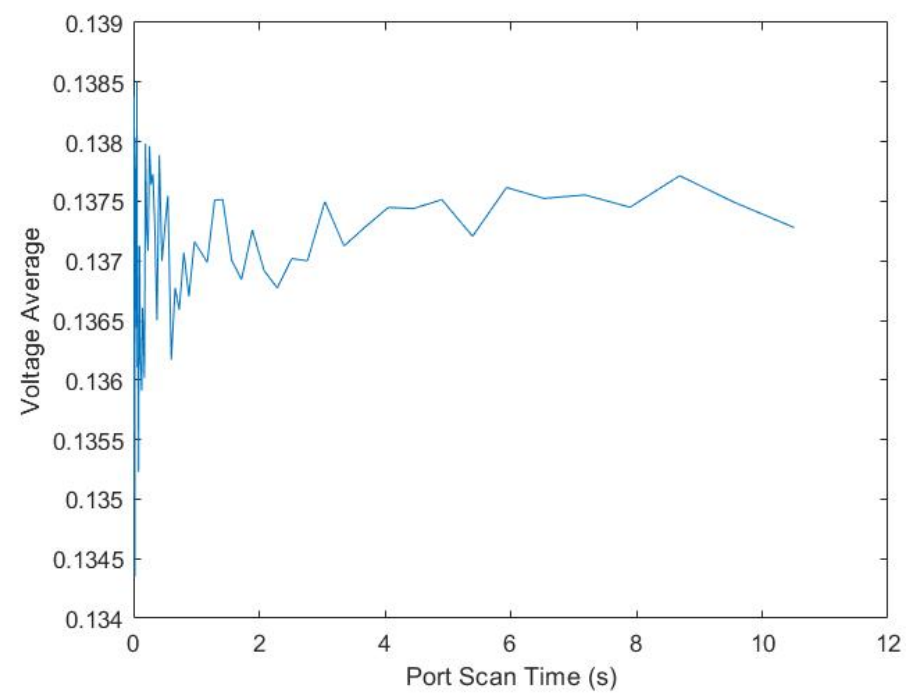

Figure 4.14: Minimum Sample Time for 45Hz Drive Frequency. 


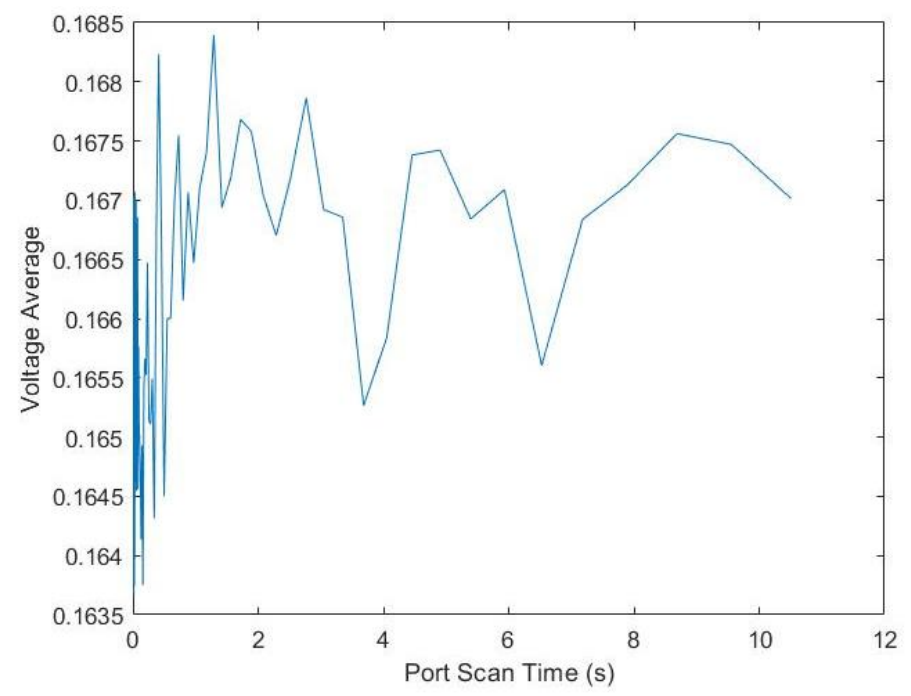

Figure 4.15: Minimum Sample Time for 60Hz Drive Frequency.

To determine the absolute accuracy of the system, the accuracy of the Scanivalve and the DAQs must be evaluated. Per the Scanivalve manual, the accuracy of the device over the full scale is $0.1 \%$ of full scale, which correlates to approximately \pm 0.07 inches $\mathrm{H}_{2} \mathrm{O}$. Compared with the above calculated accuracy of \pm 0.003 inches $\mathrm{H}_{2} \mathrm{O}$ from the DAQ, the total stated accuracy of the system is approximately \pm 0.07 inches $\mathrm{H}_{2} \mathrm{O}$ based on the higher uncertainty from the Scanivalve. During testing, short term repeatability proved to be better than the stated accuracy, with repeatability less than 0.02 inches $\mathrm{H}_{2} \mathrm{O}$. The long-term oscillations resulted in approximately \pm 0.07 inches $\mathrm{H}_{2} \mathrm{O}$ error if unaccounted for. To combat this, during testing a zero-pressure reading was taken approximately every 15 minutes and the calibration curve recalculated to compensate for the drift. This allowed for pressure readings to be repeatable to less than \pm 0.02 inches $\mathrm{H}_{2} \mathrm{O}$ over periods of data collection that were hours long. Without this correction, readings could drift as much as 0.14 inches $\mathrm{H}_{2} \mathrm{O}$ over a period of a few hours. This was done within a function called Data_Collect and can be seen in Appendix H. This function reads each port one at a time in a random order that is different for each pressure. Within a single read, the ports are repeatedly read in the same order for the duration of the read. Based on the previously selected sample rates and times, for drive frequencies between $18-30 \mathrm{~Hz}$, all 64 ports were read in a random order 5000 times, for frequencies between $30-45 \mathrm{~Hz}$ they were read 10000 times, and for frequencies $45 \mathrm{~Hz}$ and up they were read 20000 times. 
When the Scanivalve was received for this project it had been in storage for approximately 5 years, with little use prior. Initial inspection revealed that the calibration port for bank 5 (ports 33-40) was broken off and had been filled with what appeared to be hot glue. After initial testing and various calibration attempts, it was determined that those ports do not respond correctly to changes in pressure. It was assumed that the glue substance in the calibration port had damaged the valving for the bank and rendered them useless. Due to this, only 56 ports were available to collect data. To make the best use of the ports available, the top row of pitot tubes on the grid was unhooked from the Scanivalve and not used for this project. Due to the placement of the grid in the tunnel test section, bank 5 would have been connected to a row in the grid directly below center line, which is a highly likely location for a model. The first and second rows of pitot tubes on the grid were outside of the theoretical test section, so removing the first row of tubes still left one row outside of the test section on all sides of the grid. With this arrangement, bank 1 of the Scanivalve was then connected to the second row of pitot tubes from the top of the grid, bank 2 was connected to the third row, bank 3 was connected to the fourth row, bank 4 was connected to the fifth row, bank 5 was unconnected, bank 6 was connected to the sixth row, bank 7 was connected to the seventh row, and bank 8 was connected to the eighth row. This arrangement still allowed for a full picture of the test section where the flow was most important.

To control the wind tunnel, four functions were written. The purpose of these functions were to initialize connection with the drives, turn on the drives to a set frequency, change the speed of the drives, and finally to turn them off, titled respectively EWT_Initialize, EWT_On, EWT_Speed_Change, and EWT_Off. The initialize function is used inside the other three functions and generally not used independently. They allow large matrices of test scenarios to be created that the computer could automatically step through. These functions were based off code written for the previously created control graphical user interface (GUI). These functions and the GUI allowed the tunnel to be controlled from inside the tunnel test section room, where previously the drives could only be controlled from the control panels on each face of the drives. This required users of the tunnel to exit the test section room each time a change in speed was desired, as well as to turn the drives on and off. See Appendix I for these functions. 


\section{Chapter 5: Results And Discussion}

During initial testing of the experiments described at the beginning of Chapter 4, it was discovered that varying fan speeds across the tunnel had an insignificant change on velocity profiles in the test section. The greatest difference in speeds was running some fans at $60 \mathrm{~Hz}$ and others at $18 \mathrm{~Hz}$, the two furthest ends of the frequency range, which would have had the greatest impact on the shape of the velocity profiles. Varying the fan speeds in scenarios as described in Chapter 4 resulted in an averaging of the velocity profiles, or in other words the same velocity profile could be recreated by running all of the fans at a same lower speed. For example, running an example test of Experiments 3 and 4 with the steady fans held at $60 \mathrm{~Hz}$ and the varying fans at $18 \mathrm{~Hz}$ resulted in two almost completely identical velocity profiles even though the experiments were a mirror of each other. Figure 5.1 and 5.2 shows the pressure color plots for these two experiments. The differences in them are too small to be accurately measurable by the tools used for this experiment and can therefore be assumed to be so similar that the differences are minimal.

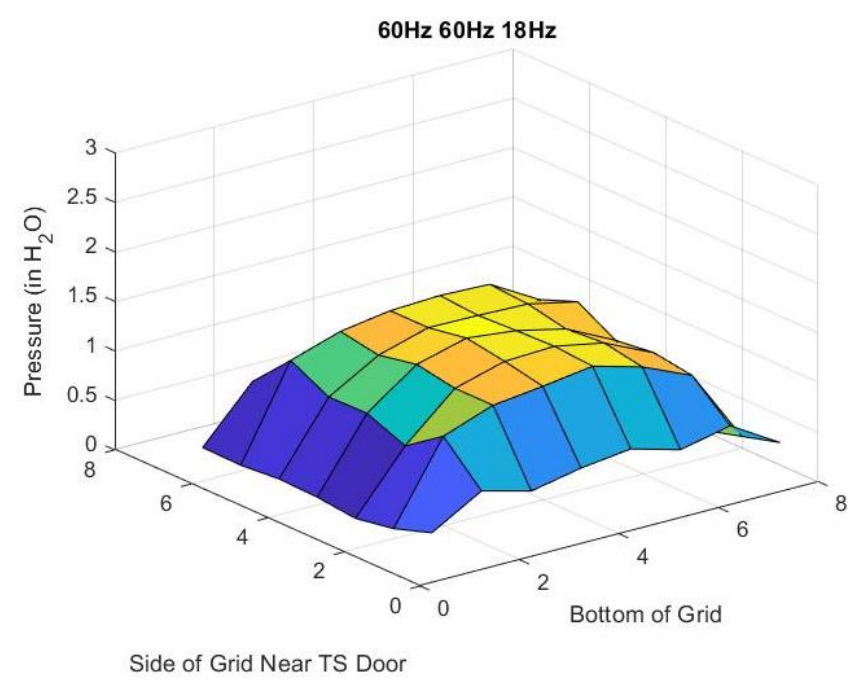

Figure 5.1: Pressure plot for $60 \mathrm{~Hz} 60 \mathrm{~Hz} 18 \mathrm{~Hz}$ experiment. 


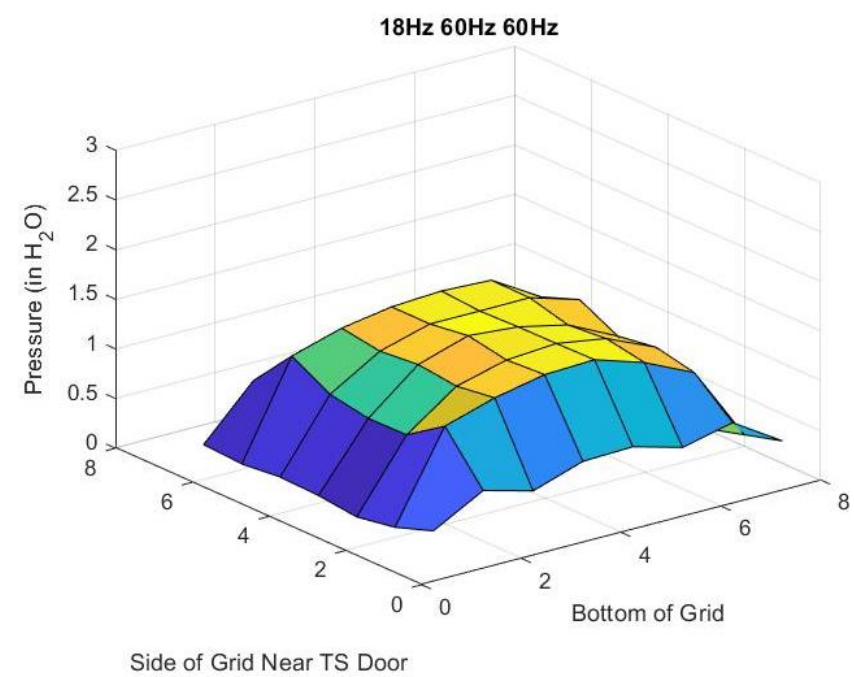

Figure 5.2: Pressure plot for $18 \mathrm{~Hz}, 60 \mathrm{~Hz}, 60 \mathrm{~Hz}$ experiment.

For this combination of fan frequencies, the averaged pressure readings were found to be most similar to that of having all of the fans running at between 42 and $43 \mathrm{~Hz}$. Figures 5.3 and 5.4 show the pressure color plot for these two frequency settings. Based on this analysis and similar conducted with other frequency variations, it was assumed that the tunnel test section wind speed is symmetric enough in nature that varying fan speeds had minimal impact on the velocity profiles seen in the test section, and simply running all six fans at the same speed could produce the same velocity profiles.

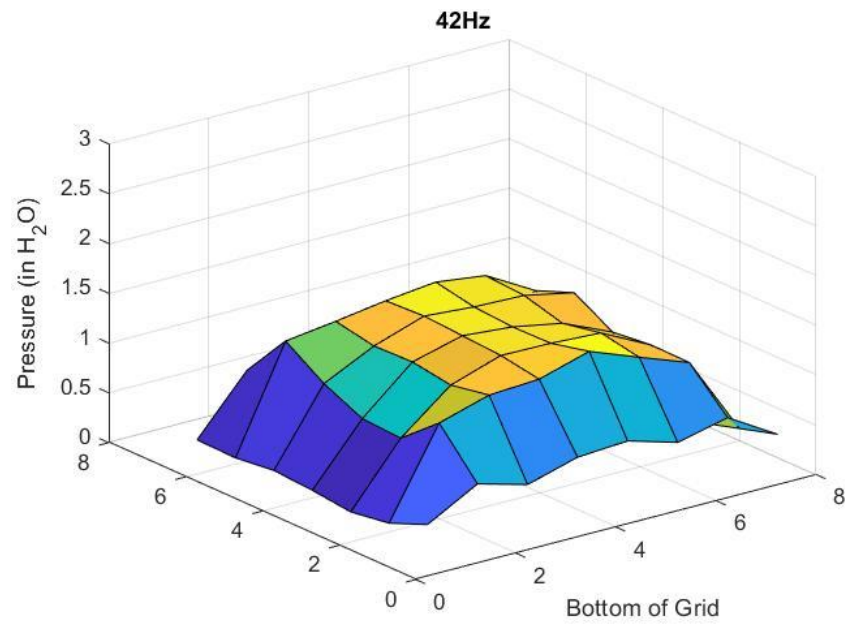

Side of Grid Near TS Door

Figure 5.3: Pressure plot for $42 \mathrm{~Hz}$. 


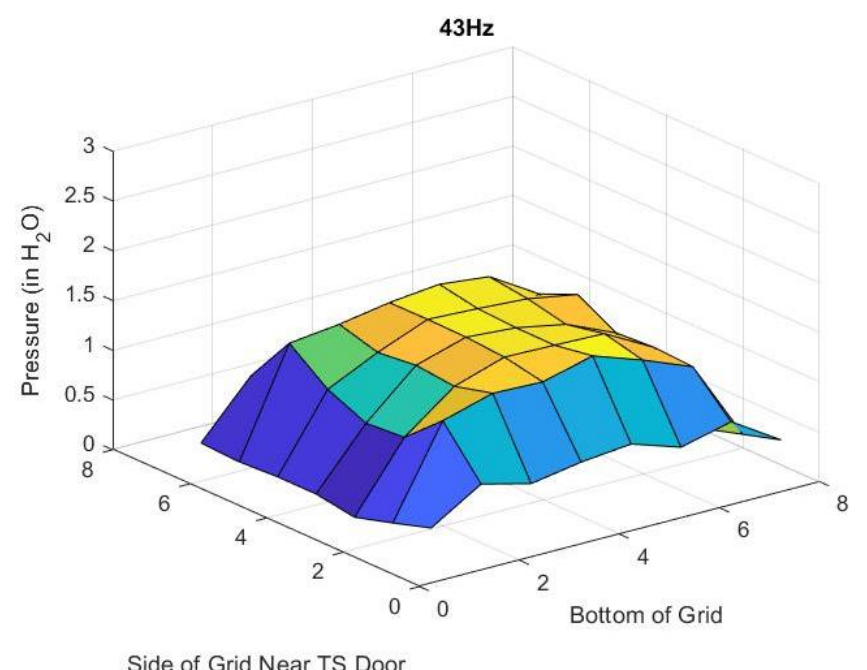

Figure 5.4: Pressure plot for $43 \mathrm{~Hz}$.

Referencing Figure 3.5.1 of the grid placed in the tunnel facing the exit of the fetch, the $x$ axis for these plots is the bottom of the grid setting on the table, the $y$-axis is the left edge that appears closest in the figure that is nearest the door entering the test section (TS), and the $z$-axis is the pressure in inches $\mathrm{H}_{2} \mathrm{O}$. Each node of the blocks making up these surface plots represents a pitot tube on the grid, and the node at $x$ and $y$ location 0 represents the pitot tube on the bottom corner of the grid at the table near the test section door. The calculated pressure differences between the values for Figure 5.1 and the average of Figures 5.3 and 5.4 are presented in Figure 5.5, and the percent differences presented in Table 5.1 for each pitot tube on the grid. The differences are very small, and based on the accuracy of the measurement instruments, can be considered immeasurable. The percent differences displayed in Table 5.1 include negatives to show which direction the differences occurred. The darkened outer boxes represent values that are outside of the nominal test section area. The average of the inner boxes is approximately $1.65 \%$. This relationship was seen with a wide variety of variations tested. 
Table 5.1: Percent differences between varied fan speeds and constant fan speeds for each pitot tube on the grid.

\begin{tabular}{|c|c|c|c|c|c|c|c|c|}
\hline & \multicolumn{8}{|c|}{ Grid Columns } \\
\hline \multirow{7}{*}{ 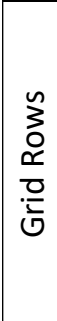 } & 3.76 & 3.01 & 3.00 & 4.25 & 2.48 & 0.35 & 3.61 & 10.16 \\
\hline & 18.73 & 2.42 & 1.47 & -0.86 & 0.64 & -0.31 & -0.26 & 41.36 \\
\hline & 18.15 & 3.66 & 0.69 & 1.54 & -0.84 & -1.10 & 0.00 & 72.56 \\
\hline & 24.83 & -1.41 & -1.74 & -1.60 & -1.22 & 0.57 & -0.26 & 22.77 \\
\hline & 5.75 & 3.94 & -0.18 & 3.25 & -1.08 & 1.93 & 2.80 & 25.92 \\
\hline & 21.39 & 2.71 & 1.45 & 3.37 & 2.51 & 1.96 & 3.87 & 58.65 \\
\hline & 21.48 & -0.10 & 5.75 & 3.87 & 6.21 & 2.84 & 5.60 & 32.13 \\
\hline
\end{tabular}

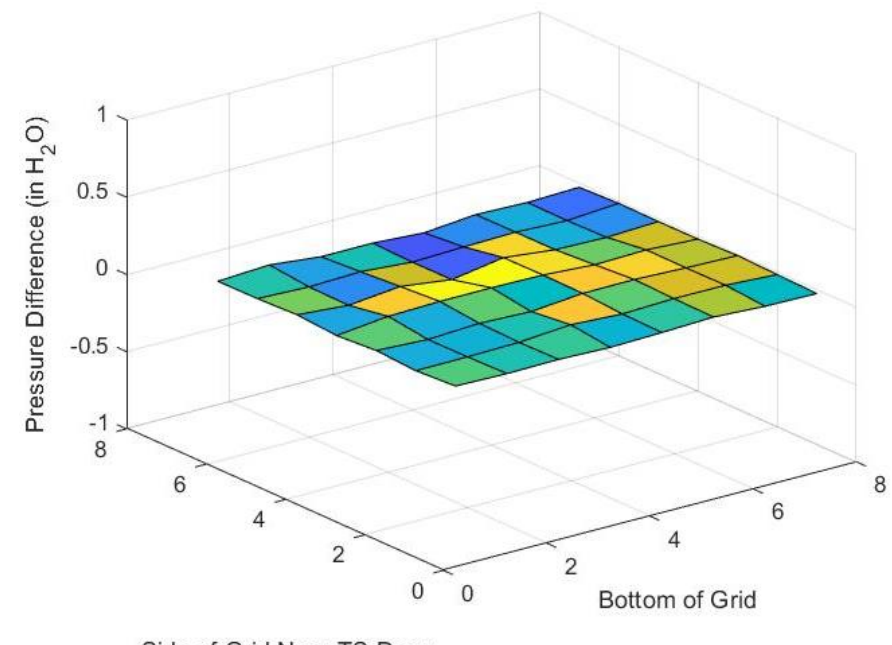

Side of Grid Near TS Door

Figure 5.5: Pressure difference between varied fan speed and constant fan speed.

With this realization, it was determined that the initial experimental design of five varying experiments would produce little value for the time required and the new process for data collection would consist of running all of the fans at the same speed in intervals of $1 \mathrm{~Hz}$ in the range of $18 \mathrm{~Hz}$ to $60 \mathrm{~Hz}$ over four days. This would allow a sufficient repository of information to be collected and for nuisance variables to be averaged out. Matlab code was written to create a different randomized matrix of frequencies in intervals of $1 \mathrm{~Hz}$ from $18 \mathrm{~Hz}$ to $60 \mathrm{~Hz}$ for each day of testing along with how long to collect data for each range of frequencies, described in Chapter 4. See Appendix $\mathbf{J}$ for this code. Three nuisance variables were also recorded each day at the beginning of testing, in the middle, and at the end of testing so that they could be averaged for each day and finally averaged over the entire data collection to help reduce random error. These nuisance variables were temperature, pressure, and humidity and are shown in Table 5.2. 
Table 5.2: Daily nuisance variables collected over four days of testing, three times per test.

\begin{tabular}{|c|c|c|c|c|}
\hline \multicolumn{4}{|c|}{ Day 1} & \multirow[b]{2}{*}{ Avg } \\
\hline & Start of Tests & Mid Tests & End of Tests & \\
\hline Temperature (F) & 68 & 70 & 71 & 69.67 \\
\hline Pressure (inHg) & 28.53 & 28.54 & 28.54 & 28.54 \\
\hline Humidity (\%) & 48 & 47 & 46.5 & 47.17 \\
\hline \multicolumn{5}{|c|}{ Day 2} \\
\hline & Start of Tests & Mid Tests & End of Tests & Avg \\
\hline Temperature (F) & 65 & 67 & 69 & 67.00 \\
\hline Pressure (inHg) & 28.72 & 28.67 & 28.63 & 28.67 \\
\hline Humidity (\%) & 47 & 47 & 46 & 46.67 \\
\hline \multicolumn{5}{|c|}{ Day 3} \\
\hline & Start of Tests & Mid Tests & End of Tests & Avg \\
\hline Temperature (F) & 64 & 67 & 73 & 68.00 \\
\hline Pressure (inHg) & 29.03 & 29.03 & 29.02 & 29.03 \\
\hline Humidity (\%) & 46 & 46 & 45 & 45.67 \\
\hline \multicolumn{5}{|c|}{ Day 4} \\
\hline & Start of Tests & Mid Tests & End of Tests & Avg \\
\hline Temperature (F) & 74 & 72 & 70 & 72.00 \\
\hline Pressure (inHg) & 28.86 & 28.9 & 28.9 & 28.89 \\
\hline Humidity (\%) & 50 & 55 & 57 & 54.00 \\
\hline
\end{tabular}

With the grid placed in the test section roughly three feet from the exit of the fetch, where most models would be placed in this test section, data was recorded using the Scanivalve and DAQ system described in Chapter 4 for four consecutive days. To begin each day, the Scanivalve and DAQ systems were turned on and allowed to set to acclimate and stabilize for at least one hour. During this time, the stabilization code mentioned in Chapter 4 was run so that it could be seen when the system had stabilized. After this initial stabilization period, the calibration code was run. This procedure is also described in Section 3.6. After calibration, the code to create a randomized matrix of frequencies and collection time was ran. Every 15 minutes this code would have the drives turn the tunnel off so that a zero-speed value could be taken and compared to the calibration values in order to offset the recorded values to account for the voltage drift discussed in Chapter 4. Once all tests were complete, data was stored in Matlab files in the form of voltage collected from the Scanivalve and DAQ systems, and those values also converted to pressures. The pressure and velocity matrices were combined and stored in 3D matrices at the conclusion of testing. The first dimension of these was speed, $18 \mathrm{~Hz}$ through $60 \mathrm{~Hz}$, the second dimension was pitot tube port, 
and the third dimension was the day. From these matrices, the data could be combined and averaged across the four days.

Each day the voltage and pressure values were averaged. Figure 5.6 shows the averaged pressure values for all four days against fan frequency, using only the middle $3 \times 4$ block of 12 ports to represent the free-flow pressure and velocity in the test section. These ports were 19-22, 27-30, and 43-46. It can be seen that day four saw slightly lower pressures compared to the first three days. Reviewing the daily nuisance values for day four this day had a higher average temperature and humidity than the previous three days, and the third highest pressure.

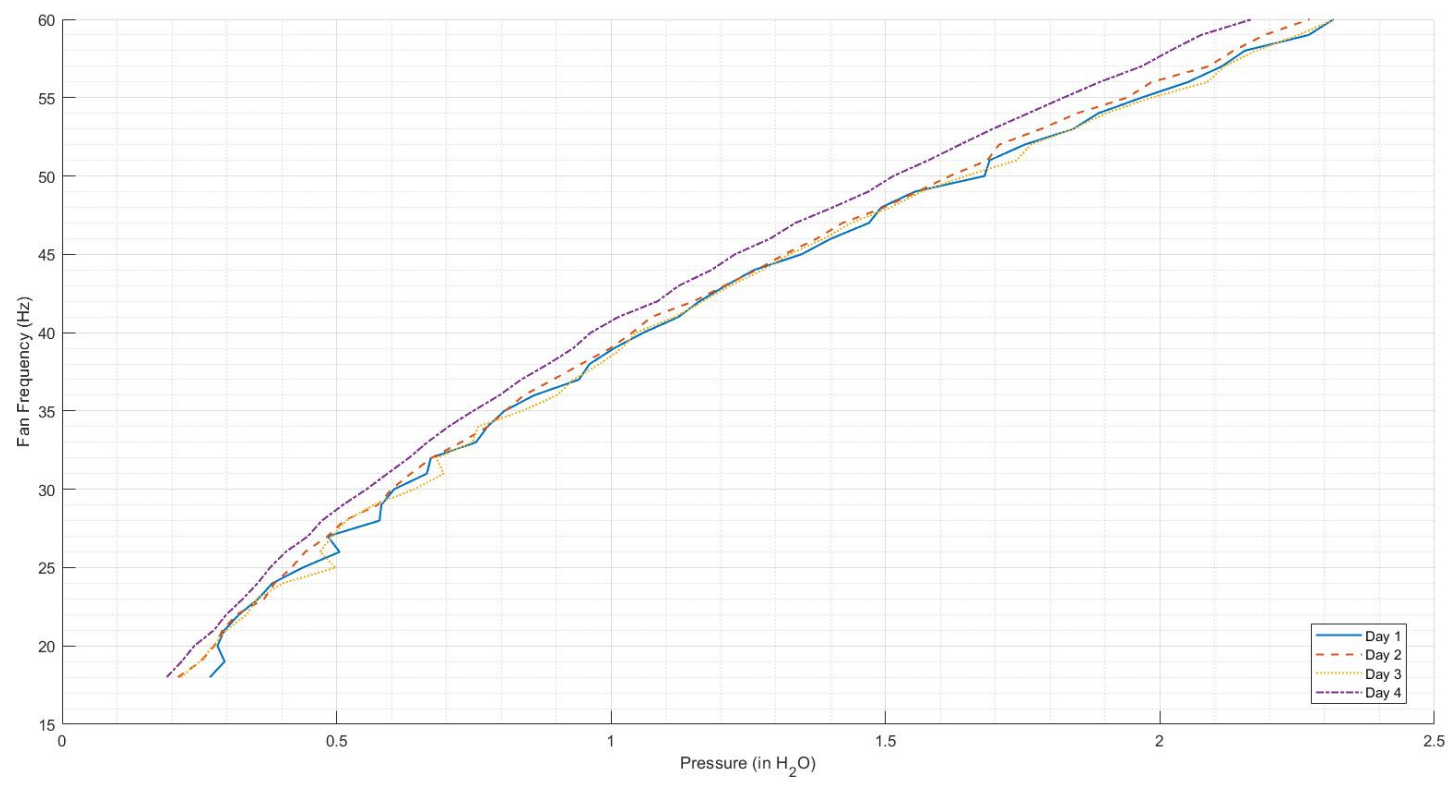

Figure 5.6: Averaged pressure values against fan frequencies for each day of testing.

After averaging each day's voltage and pressure values, all four days were also averaged together to achieve one averaged overview. Figure 5.7 shows the averaged pressure against fan frequency. This graph also shows estimation lines for a linear approximation and a quadratic approximation. The quadratic approximation R-Squared value, or the statistical measure for how closely the data fit to the regression, for this data was approximately 0.999, showing incredibly strong correlation to the quadratic fit. Polynomial values greater than the quadratic fit did not lead to any stronger correlation. 


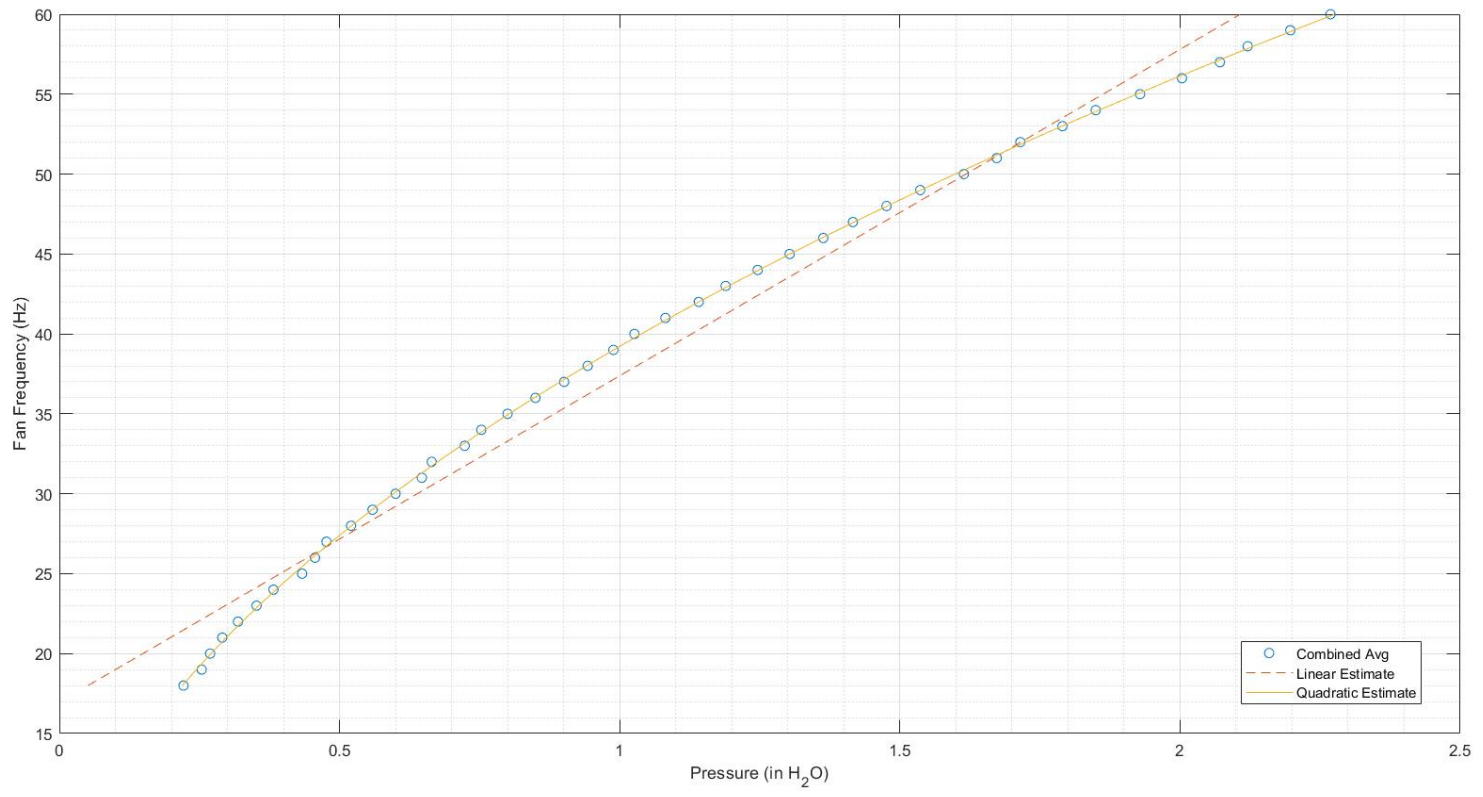

Figure 5.7: Single averaged pressure values against fan frequencies and polynomial fits.

The pressure values for each day were converted to velocity using the average daily nuisance values to calculate densities. These velocity values for each of the four days were then averaged to achieve one overall averaged velocity. Figure 5.8 shows a plot of the averaged air speed values against fan frequency, as well as an estimation line for a linear approximation. Since the pressure values had a quadratic profile, and to achieve the velocity values from pressure the square root was taken, the linear approximation makes sense. The R-Squared value for the linear approximation was approximately 0.999 as well, again showing a strong correlation. It is also interesting to note that at a fan speed of $60 \mathrm{~Hz}$ the air speed is approximately 70 miles per hour (MPH). Using this relation, dividing air speed by corresponding fan frequency gives a value of approximately 1.16 , or slightly above the conversion from knots to miles per hour of 1.15 . This is a simple relationship to remember when a certain average air speed is desired in the test section. For example, if a speed of 40MPH is desired, dividing 40 by 1.16 gives a fan frequency of approximately $34.5 \mathrm{~Hz}$. This is a close approximation method that will allow for a quick rough estimation of desired fan speed. 


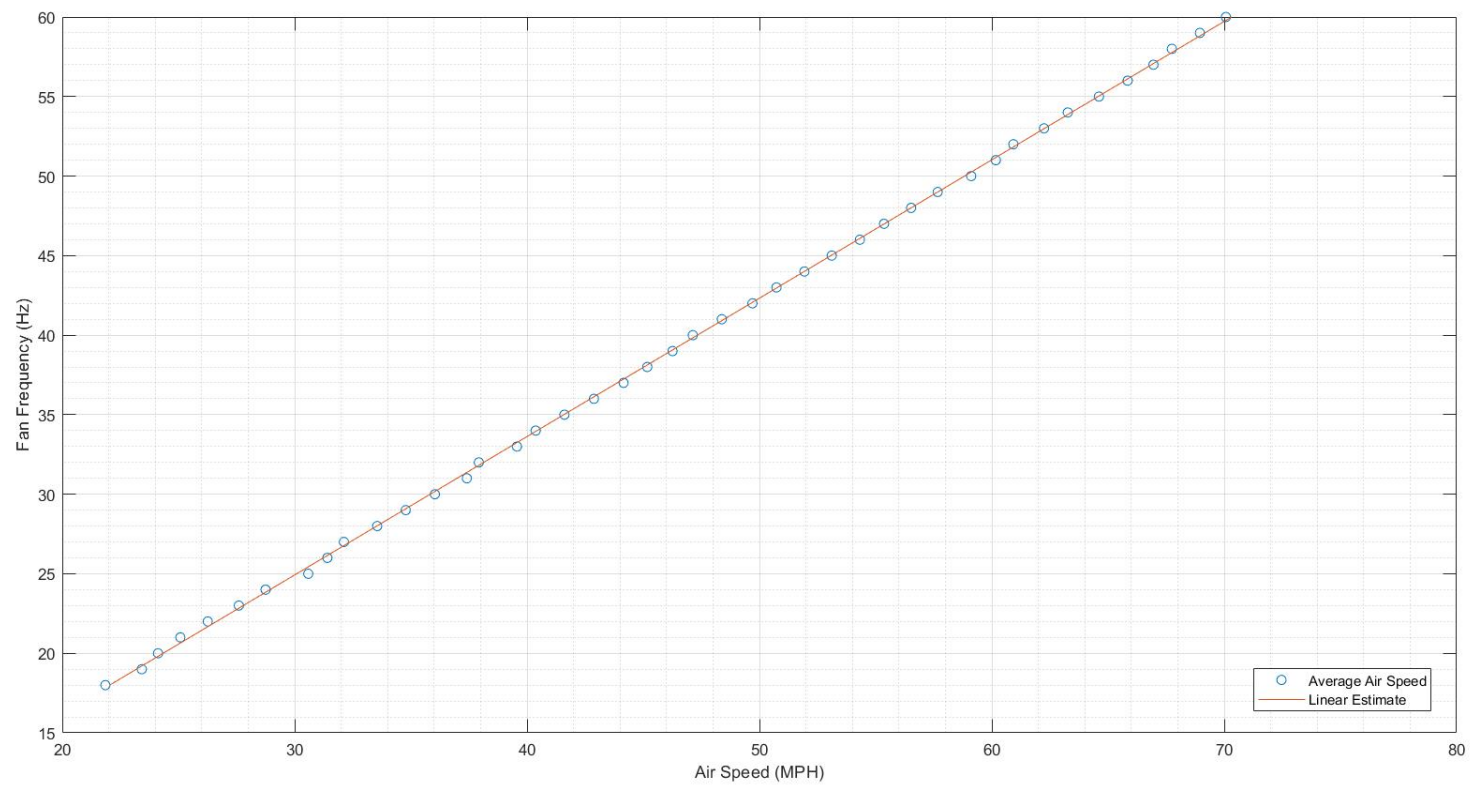

Figure 5.8: Air speed in MPH against fan frequencies and linear approximation.

Using the averaged pressure values, color plots were created for all 43 drive frequencies, $18 \mathrm{~Hz}$ through $60 \mathrm{~Hz}$. These can be seen in the following figures. Each plot is titled with the frequency at which all six fans were running, the $x$-axis is the where the bottom of the grid sat perpendicular to the flow and each node represents a pitot tube, the $y$-axis is the vertical side of the grid closest to the door entering the test section room also perpendicular to the flow, and the $z-$ axis is the pressure values seen by each pitot tube and is parallel to the flow. See Appendix K for this code. Looking at these plots, it can be seen how the profiles grow as speed increases. For $18 \mathrm{~Hz}$ drive frequency, the highest pressure value was approximately 0.24 inches $\mathrm{H}_{2} \mathrm{O}$, for $30 \mathrm{~Hz}$ it was approximately 0.65 inches $\mathrm{H}_{2} \mathrm{O}$, for $45 \mathrm{~Hz}$ it was approximately 1.43 inches $\mathrm{H}_{2} \mathrm{O}$, and for $60 \mathrm{~Hz}$ it was approximately 2.46 inches $\mathrm{H}_{2} \mathrm{O}$. For a full list of average and maximum average pressure values for each frequency see Appendix L. 


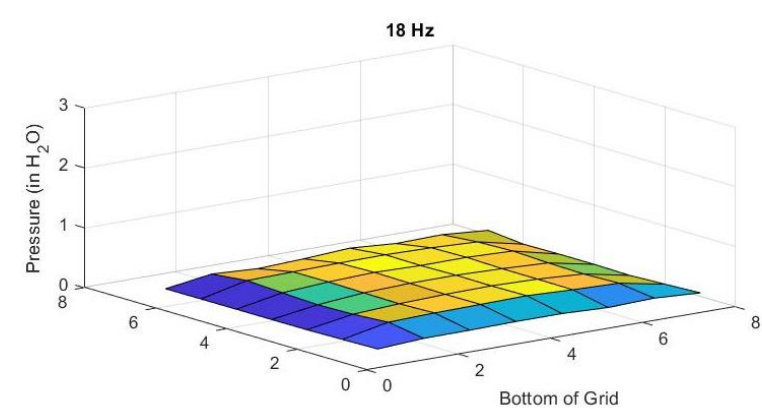

Side of Grid Near TS Door

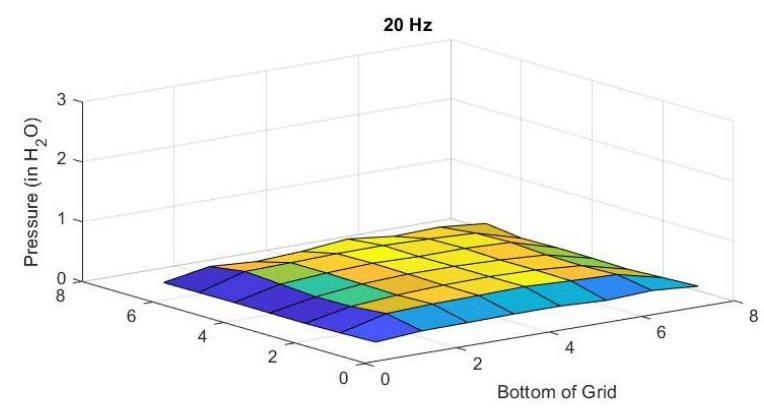

Side of Grid Near TS Door

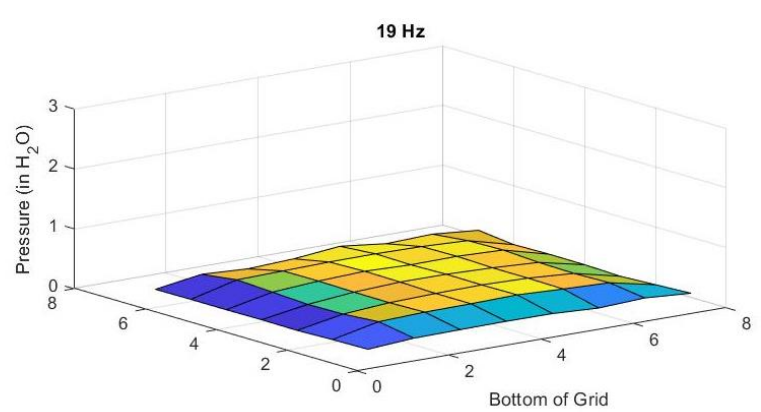

Side of Grid Near TS Door

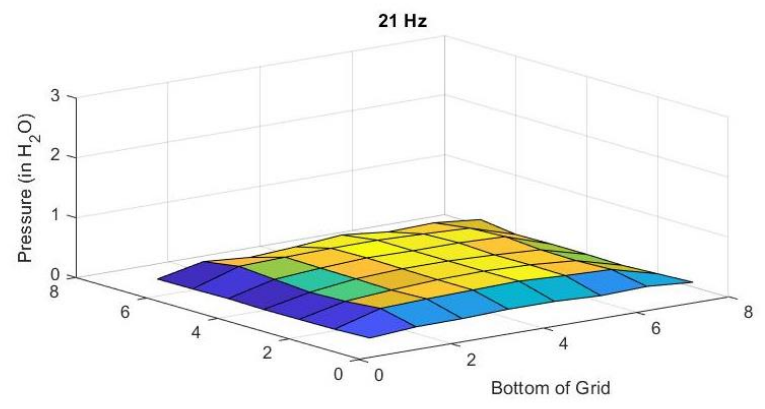

Side of Grid Near TS Door

Figure 5.9: Pressure surface plots for $18 \mathrm{~Hz}$ through $21 \mathrm{~Hz}$ drive frequencies.

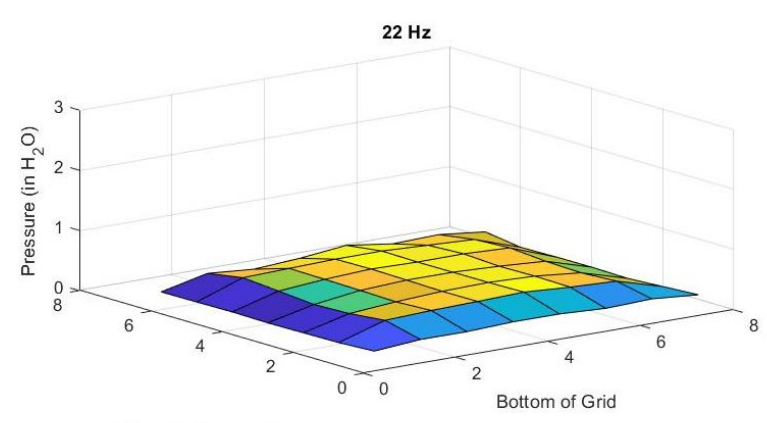

Side of Grid Near TS Door

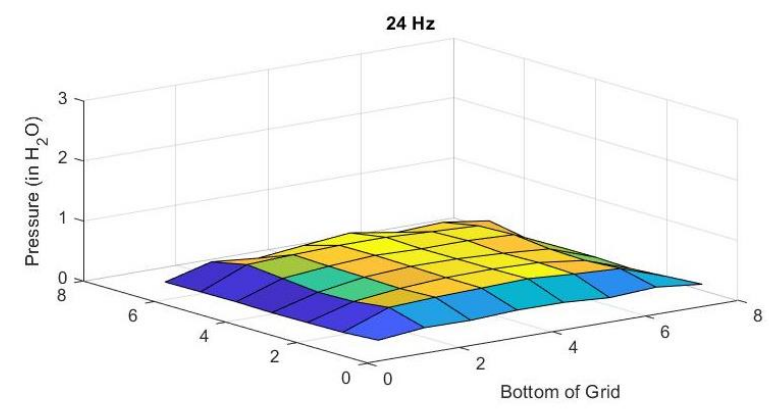

Side of Grid Near TS Door

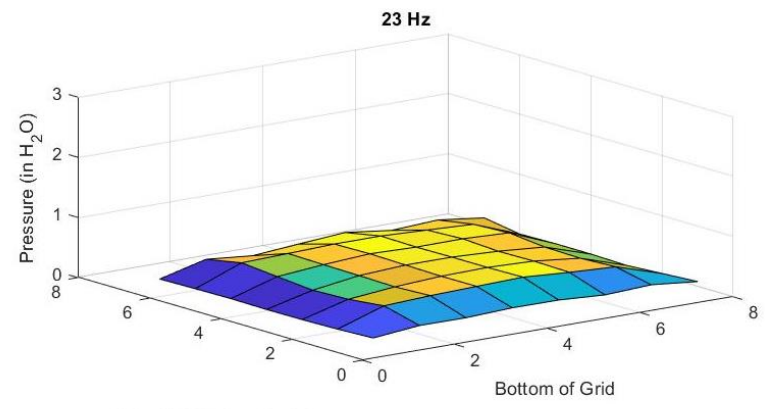

Side of Grid Near TS Door

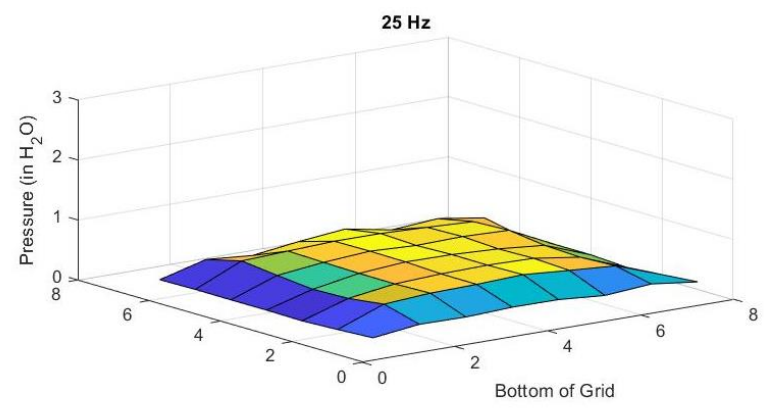

Side of Grid Near TS Door

Figure 5.10: Pressure surface plots for $22 \mathrm{~Hz}$ through $25 \mathrm{~Hz}$ drive frequencies. 


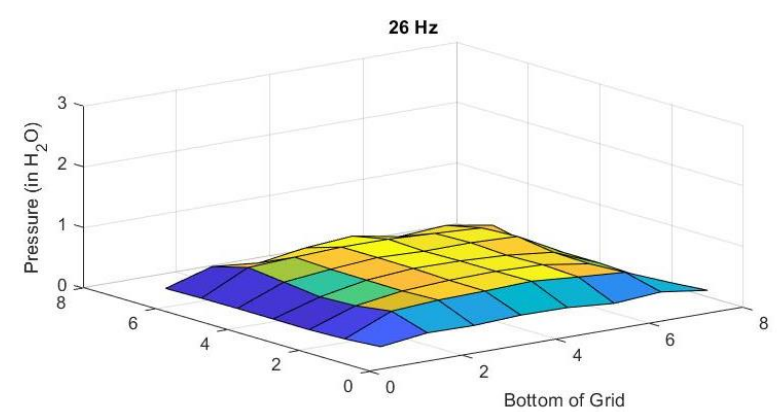

Side of Grid Near TS Door

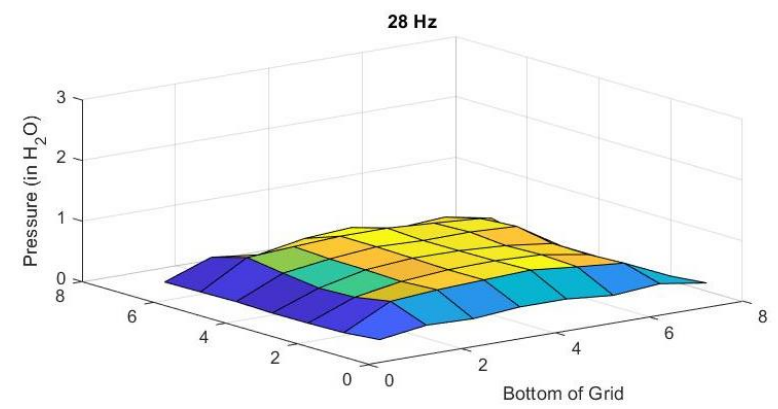

Side of Grid Near TS Door

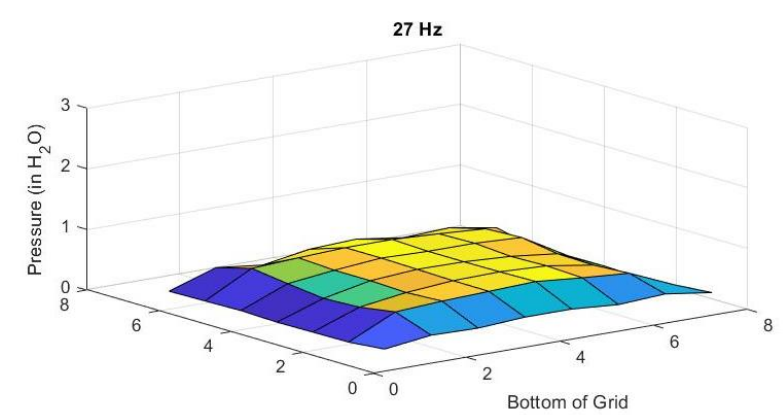

Side of Grid Near TS Door

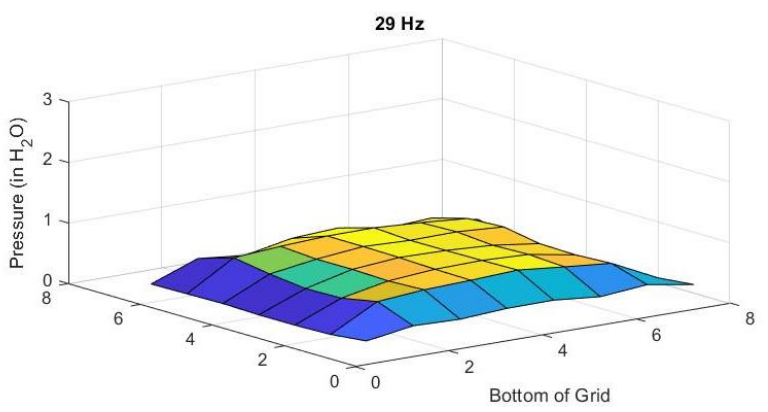

Side of Grid Near TS Door

Figure 5.11: Pressure surface plots for $26 \mathrm{~Hz}$ through $29 \mathrm{~Hz}$ drive frequencies.

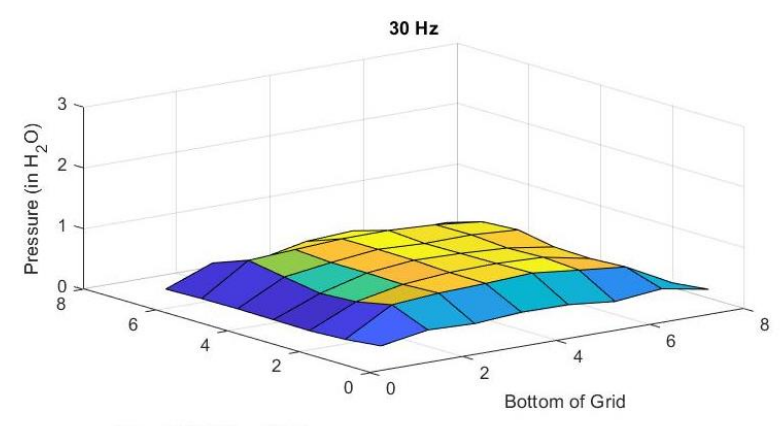

Side of Grid Near TS Door

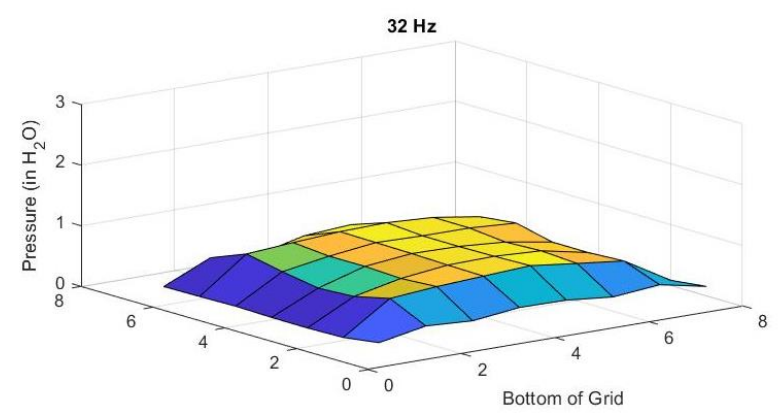

Side of Grid Near TS Door

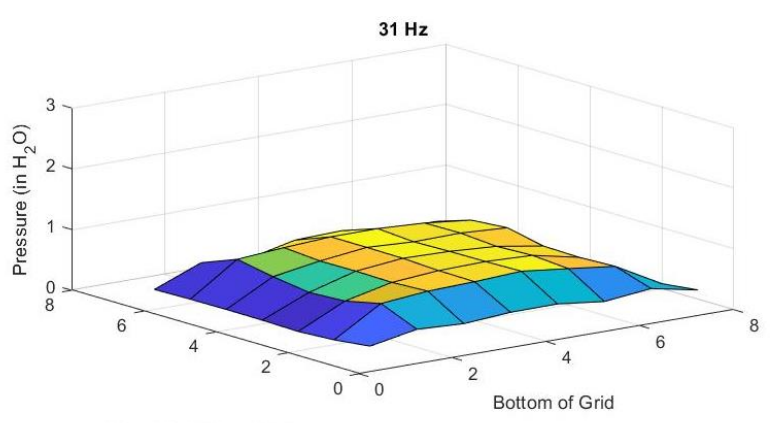

Side of Grid Near TS Door

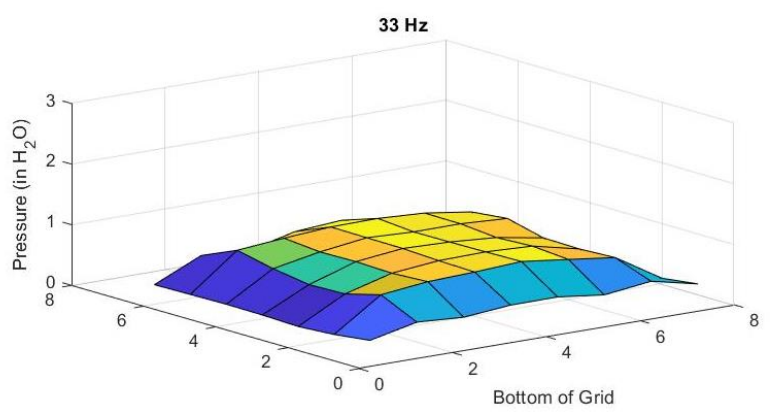

Side of Grid Near TS Door

Figure 5.12: Pressure surface plots for $30 \mathrm{~Hz}$ through $33 \mathrm{~Hz}$ drive frequencies. 


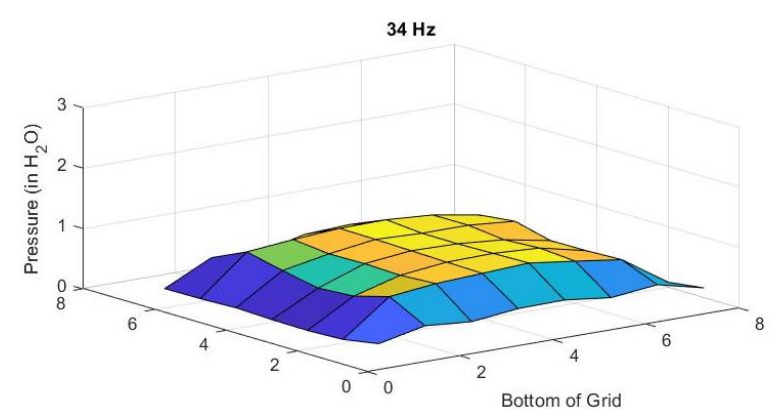

Side of Grid Near TS Door

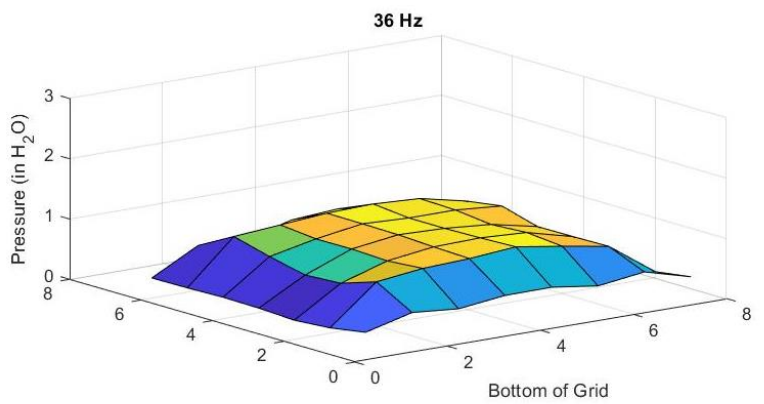

Side of Grid Near TS Door

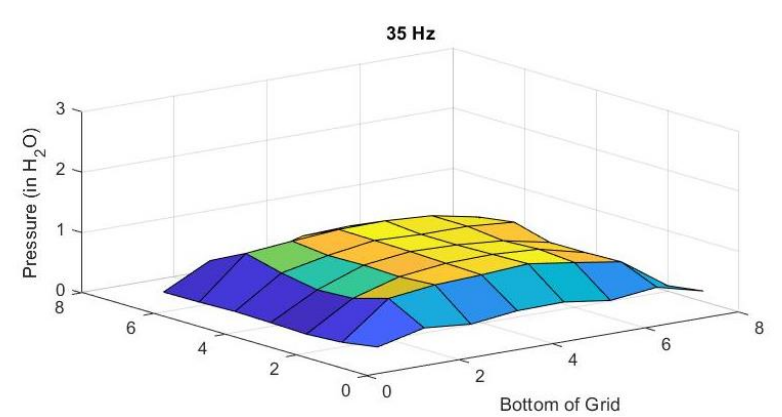

Side of Grid Near TS Door

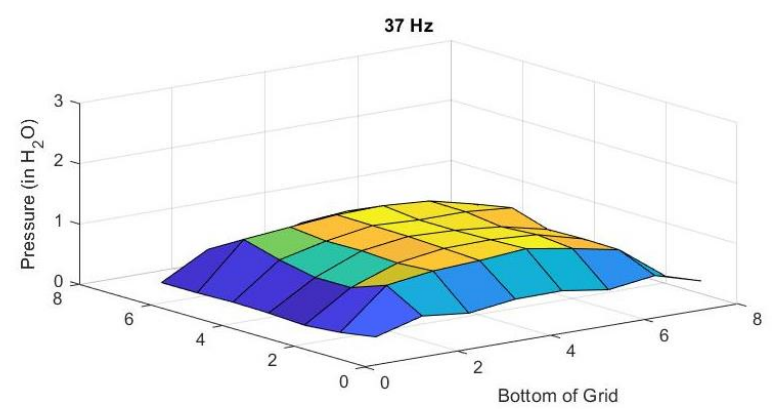

Side of Grid Near TS Door

Figure 5.13: Pressure surface plots for $34 \mathrm{~Hz}$ through $37 \mathrm{~Hz}$ drive frequencies.

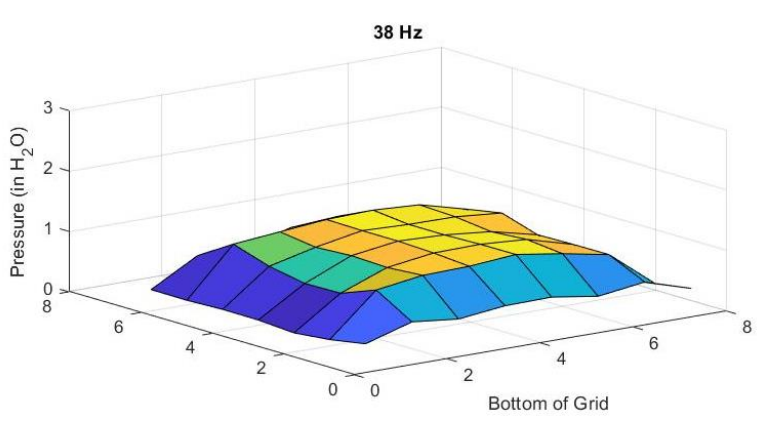

Side of Grid Near TS Door

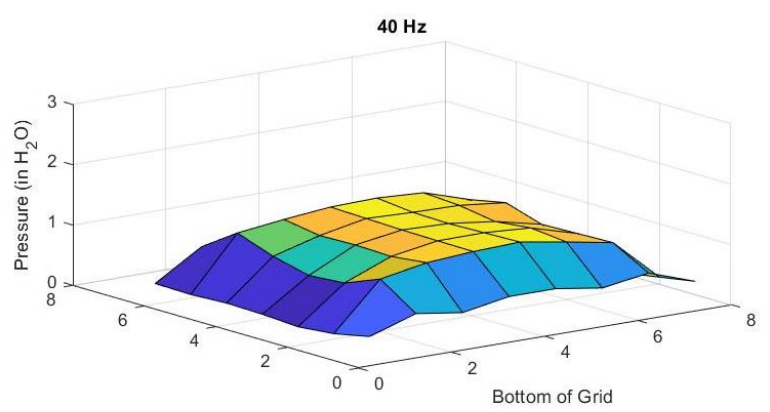

Side of Grid Near TS Door

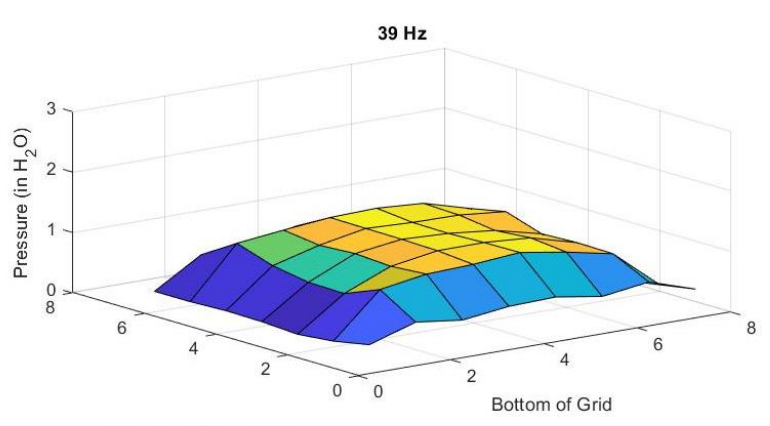

Side of Grid Near TS Door

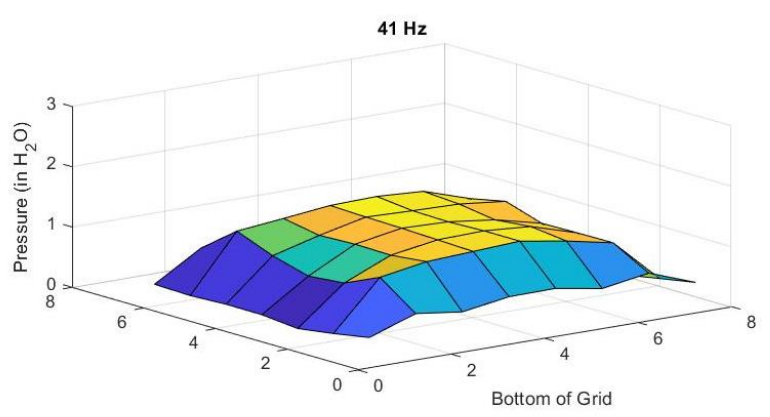

Side of Grid Near TS Door

Figure 5.14: Pressure surface plots for $38 \mathrm{~Hz}$ through $41 \mathrm{~Hz}$ drive frequencies. 


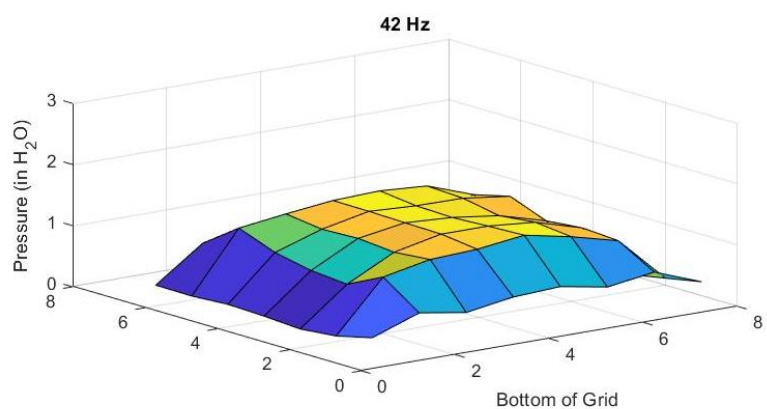

Side of Grid Near TS Door

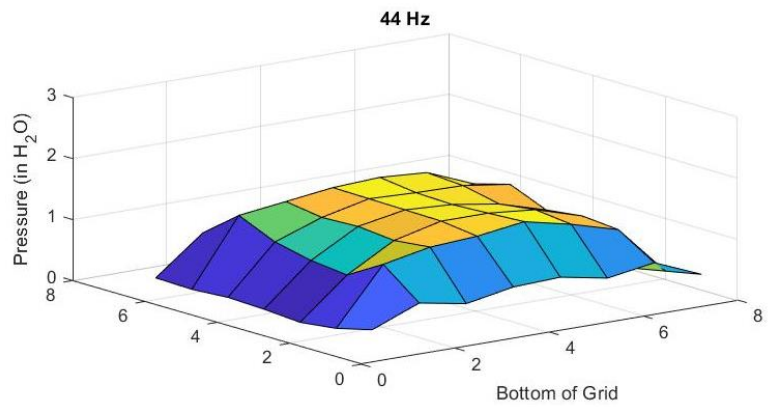

Side of Grid Near TS Door

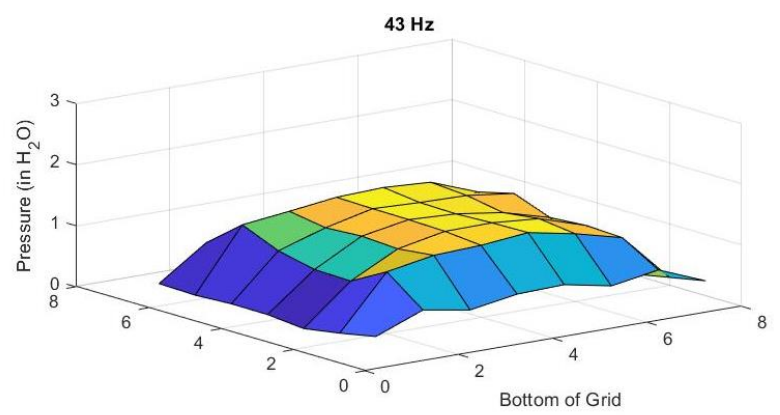

Side of Grid Near TS Door

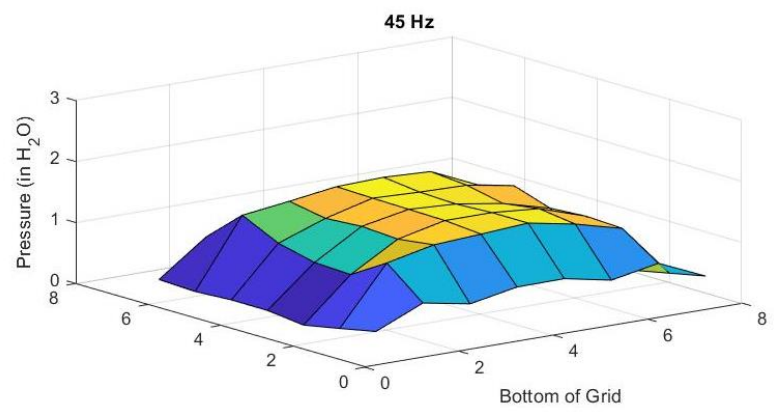

Side of Grid Near TS Door

Figure 5.15: Pressure surface plots for $42 \mathrm{~Hz}$ through $45 \mathrm{~Hz}$ drive frequencies.

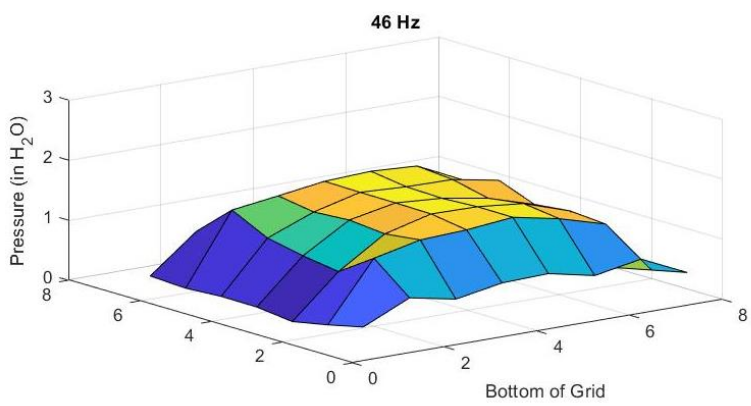

Side of Grid Near TS Door

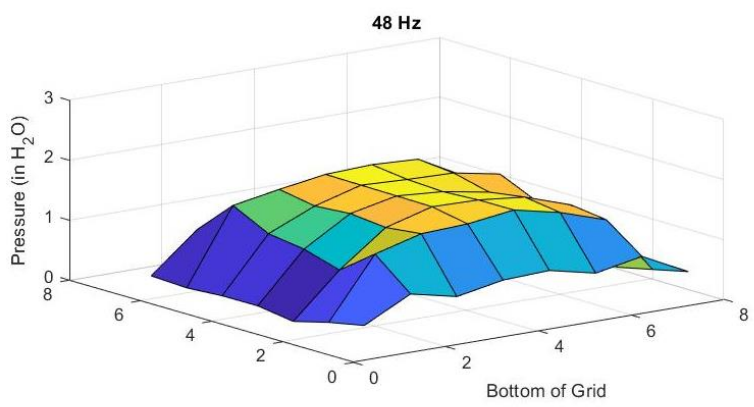

Side of Grid Near TS Door

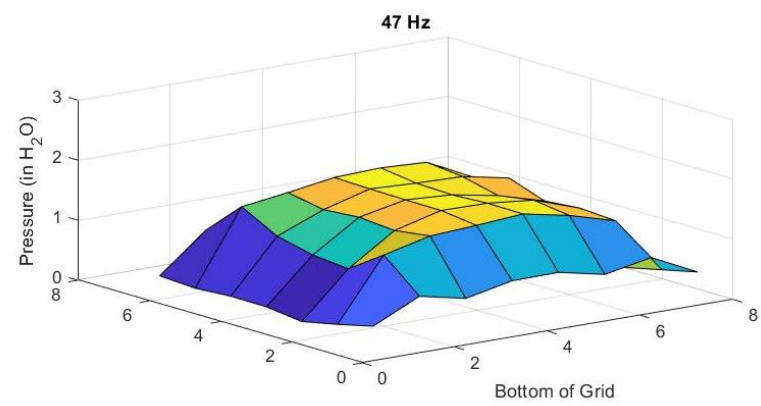

Side of Grid Near TS Door

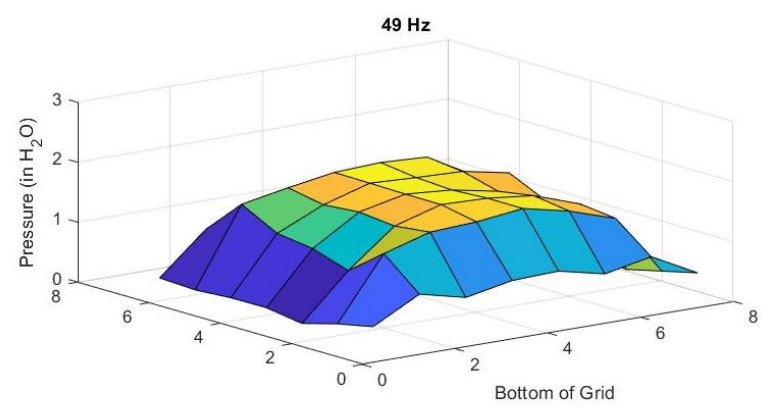

Side of Grid Near TS Door

Figure 5.16: Pressure surface plots for $46 \mathrm{~Hz}$ through $49 \mathrm{~Hz}$ drive frequencies. 


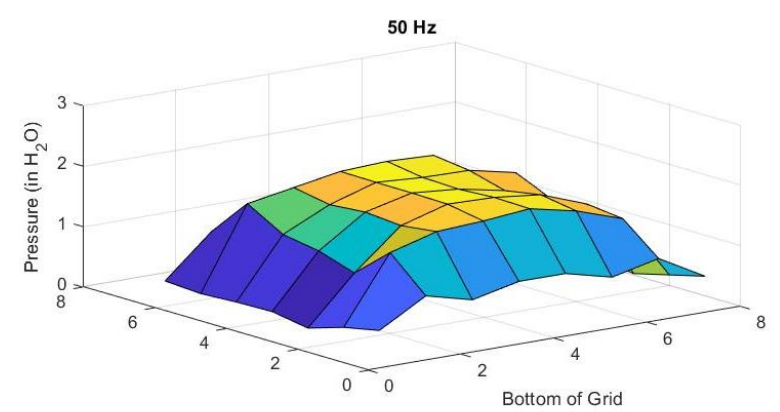

Side of Grid Near TS Door

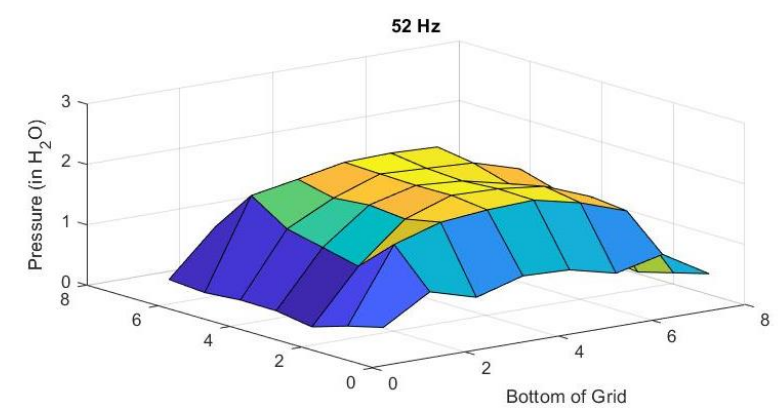

Side of Grid Near TS Door

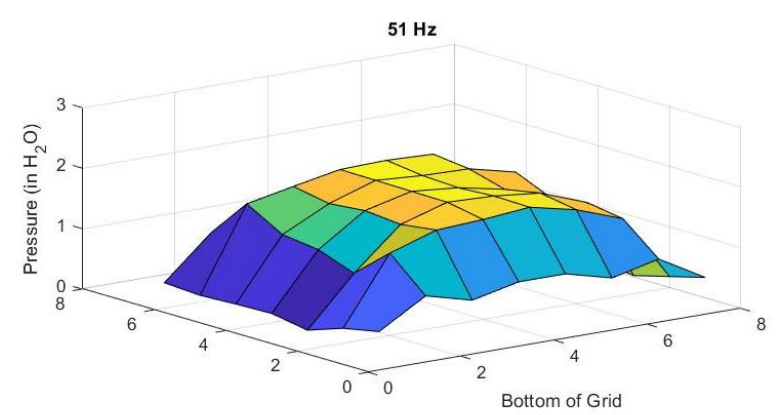

Side of Grid Near TS Door

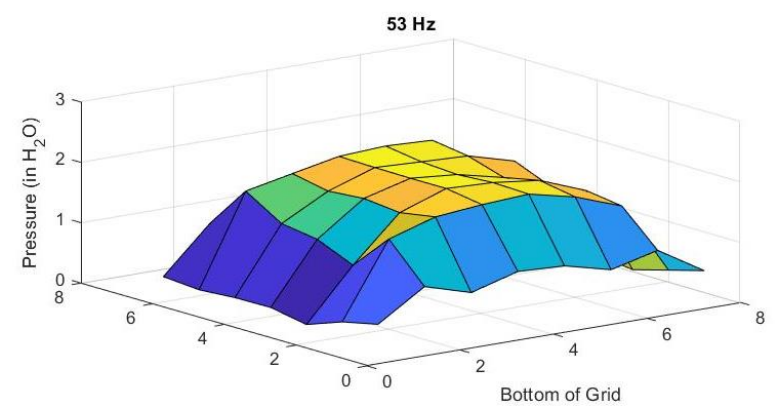

Side of Grid Near TS Door

Figure 5.17: Pressure surface plots for $50 \mathrm{~Hz}$ through $53 \mathrm{~Hz}$ drive frequencies.

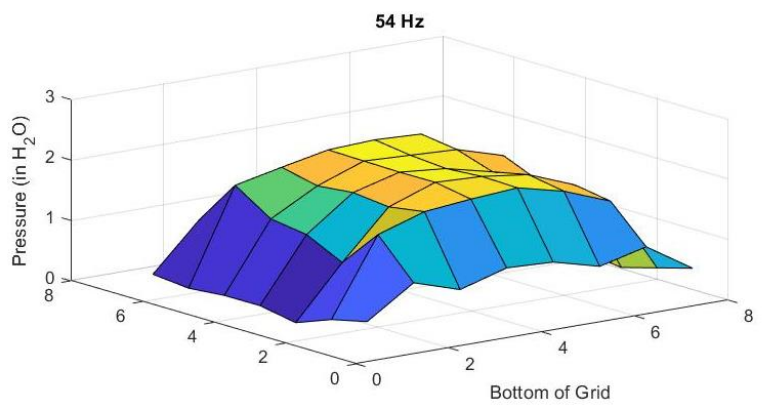

Side of Grid Near TS Door

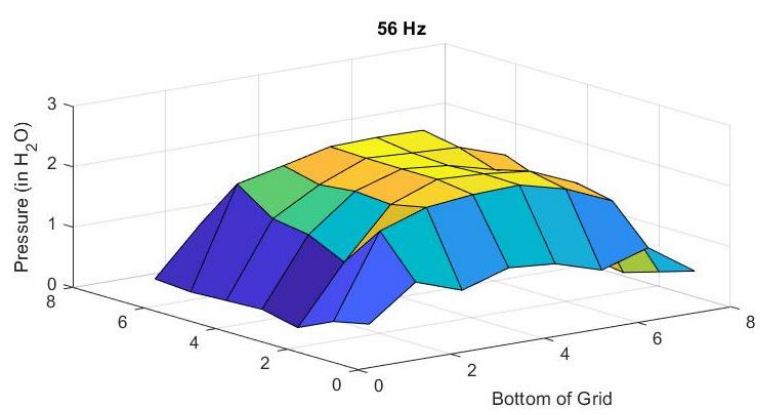

Side of Grid Near TS Door

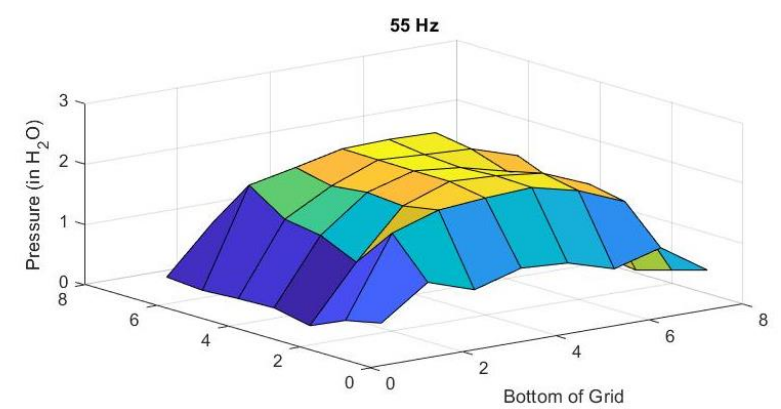

Side of Grid Near TS Door

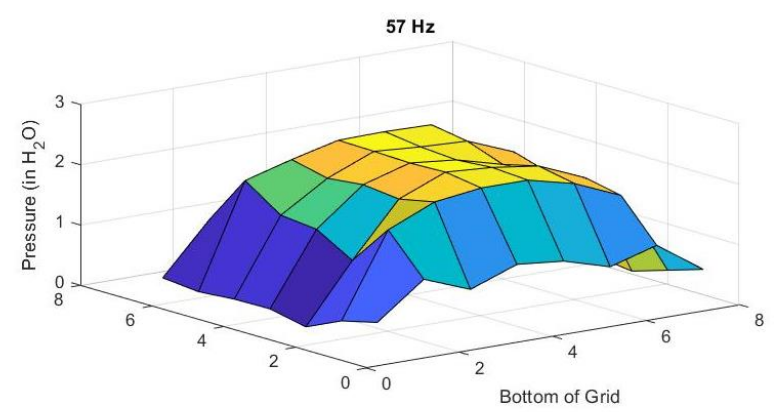

Side of Grid Near TS Door

Figure 5.18: Pressure surface plots for $54 \mathrm{~Hz}$ through $57 \mathrm{~Hz}$ drive frequencies. 


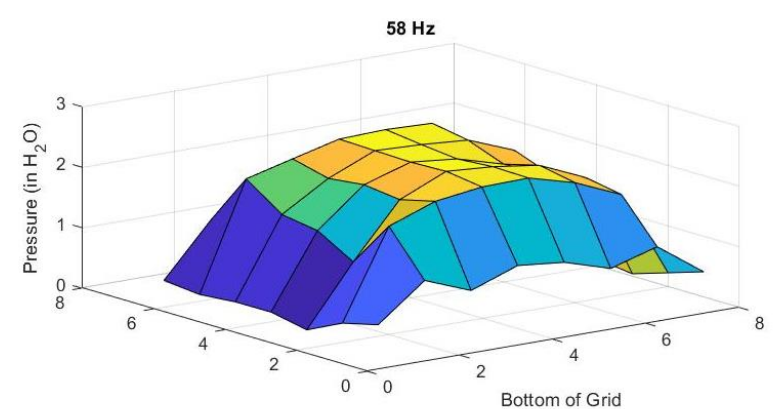

Side of Grid Near TS Door

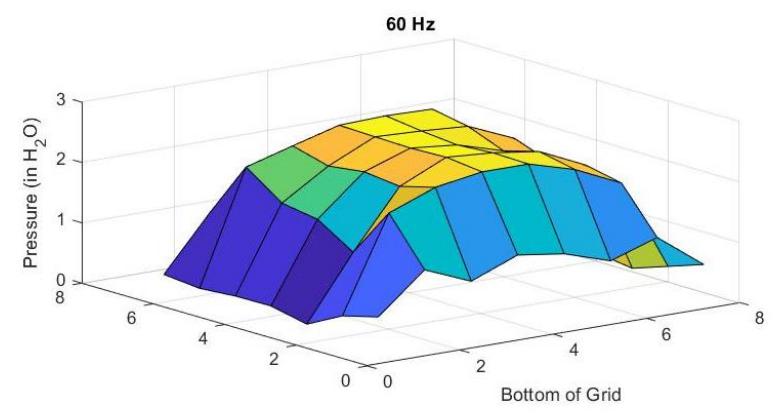

Side of Grid Near TS Door

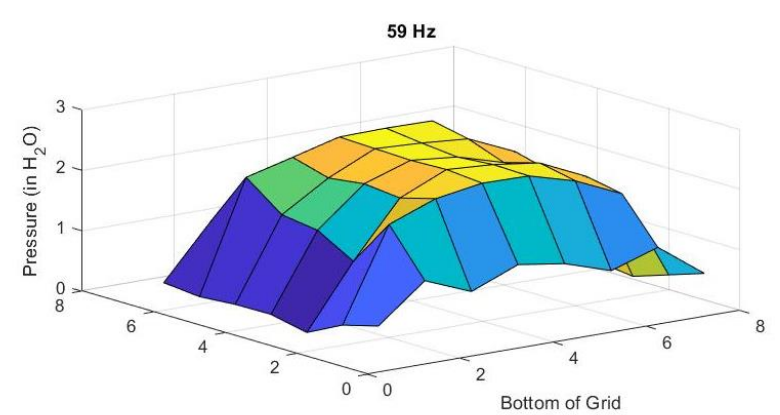

Side of Grid Near TS Door

Figure 5.19: Pressure surface plots for $58 \mathrm{~Hz}$ through $60 \mathrm{~Hz}$ drive frequencies.

The averaged velocities were also plotted as surface plots as seen in the following figures for all drive frequencies from $18 \mathrm{~Hz}$ to $60 \mathrm{~Hz}$. While these figures are seen from an angle, it can somewhat distort the way the figures are perceived. The maximum velocity for drive frequency $18 \mathrm{~Hz}$ was approximately $23 \mathrm{MPH}$, for $30 \mathrm{~Hz}$ it was approximately $38 \mathrm{MPH}$, for $45 \mathrm{~Hz}$ it was approximately $56 \mathrm{MPH}$, and for $60 \mathrm{~Hz}$ it was approximately $73 \mathrm{MPH}$. These maximum values do not follow the approximation described earlier of velocity divided by fan frequency of 1.16 as these are the maximum seen velocities and that relationship uses the average seen for that frequency. Attempting to develop a similar relationship for maximum velocities yields values between 1.26 and 1.21 as speed increases. For a table of these averaged and maximum averaged velocity values see Appendix M. 


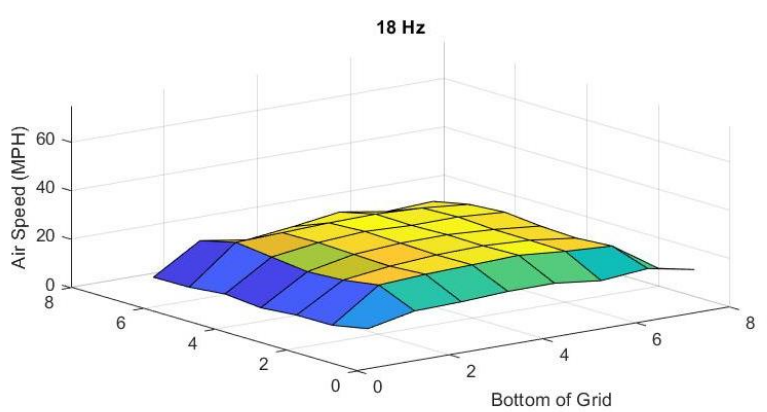

Side of Grid Near TS Door

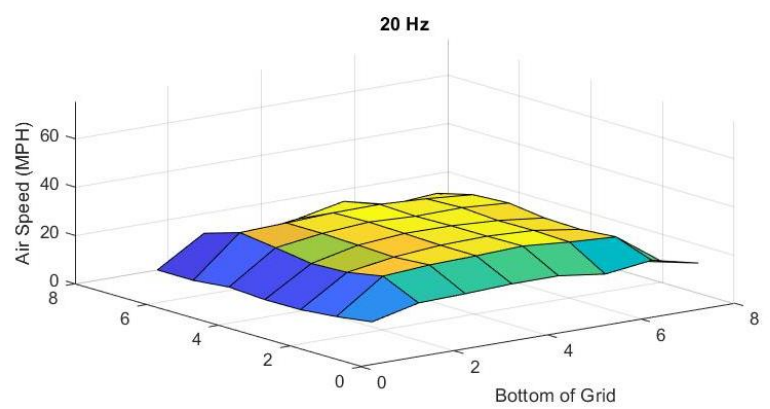

Side of Grid Near TS Door

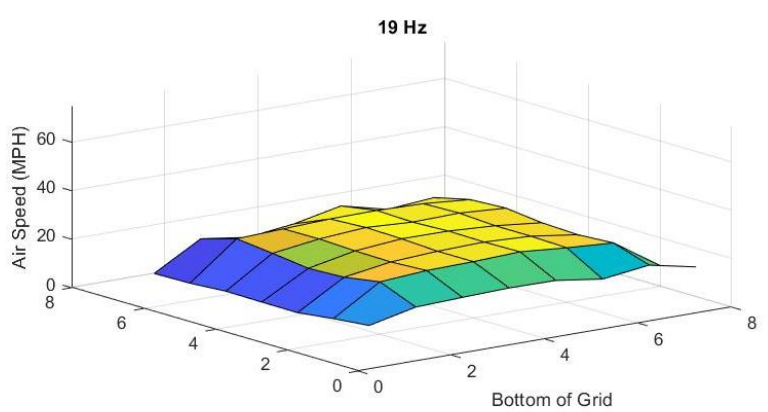

Side of Grid Near TS Door

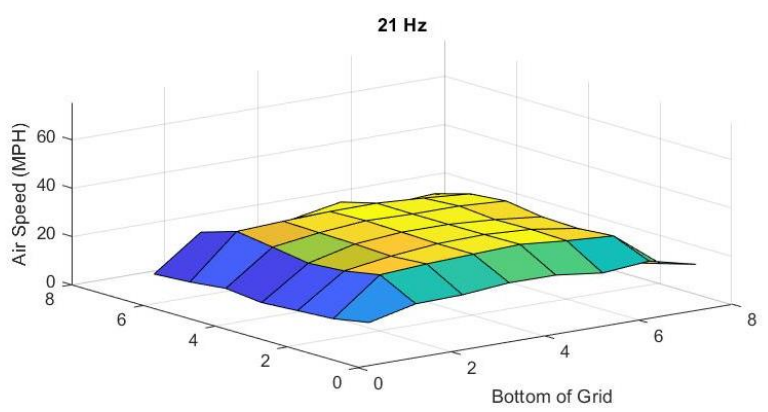

Side of Grid Near TS Door

Figure 5.20: Velocity profile surface plots for $18 \mathrm{~Hz}$ through $21 \mathrm{~Hz}$ drive frequencies.

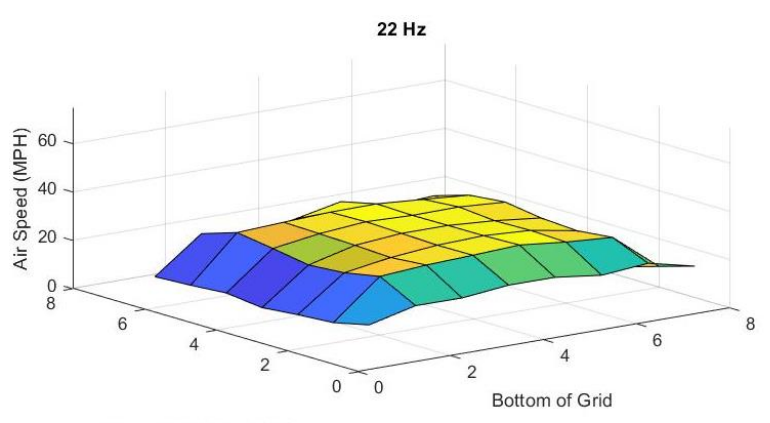

Side of Grid Near TS Door

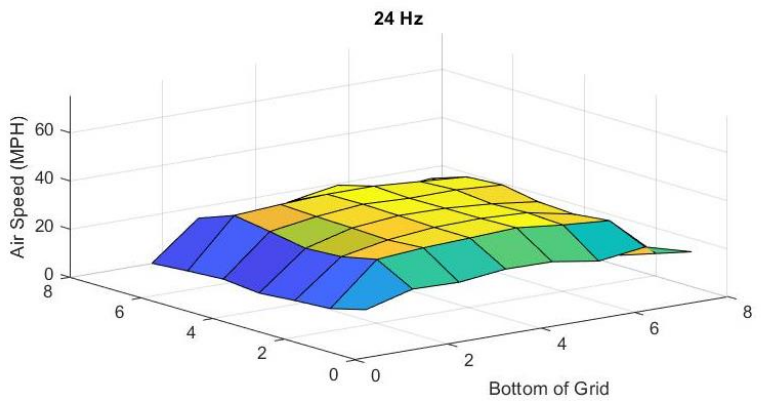

Side of Grid Near TS Door

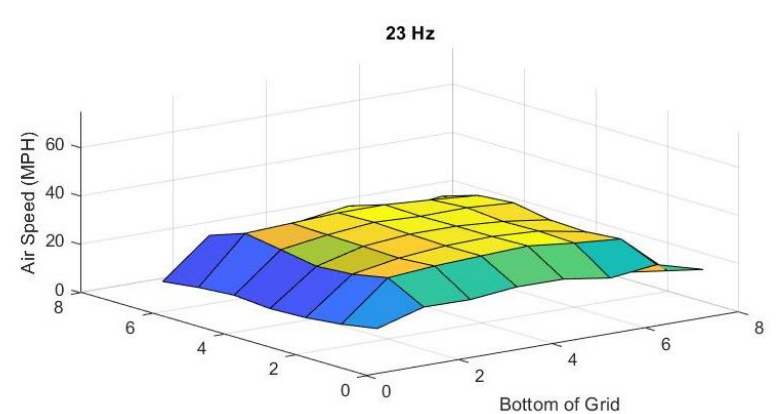

Side of Grid Near TS Door

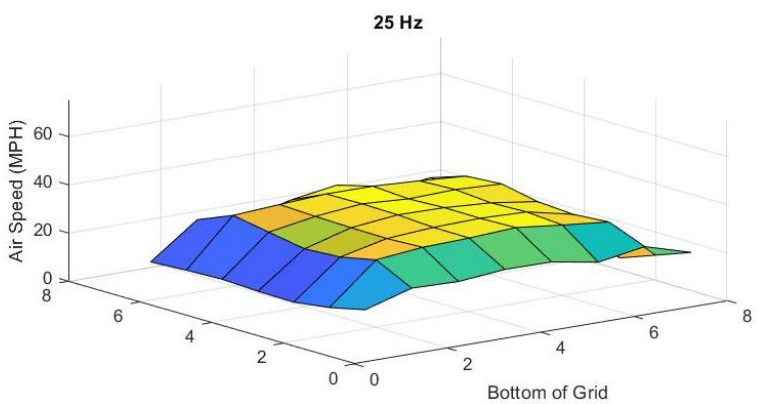

Side of Grid Near TS Door

Figure 5.21: Velocity profile surface plots for $22 \mathrm{~Hz}$ through $25 \mathrm{~Hz}$ drive frequencies. 


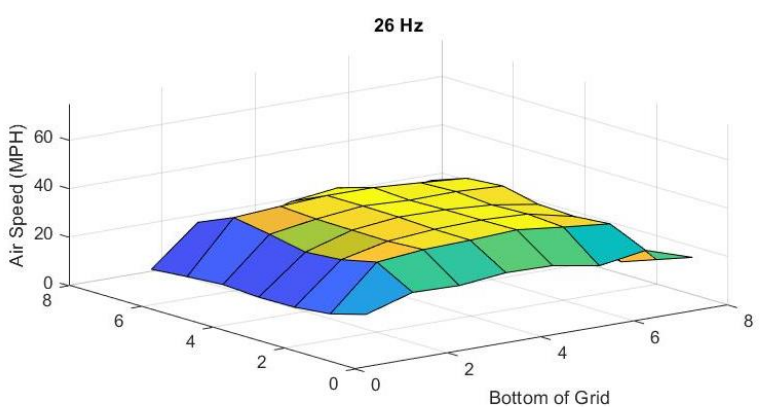

Side of Grid Near TS Door

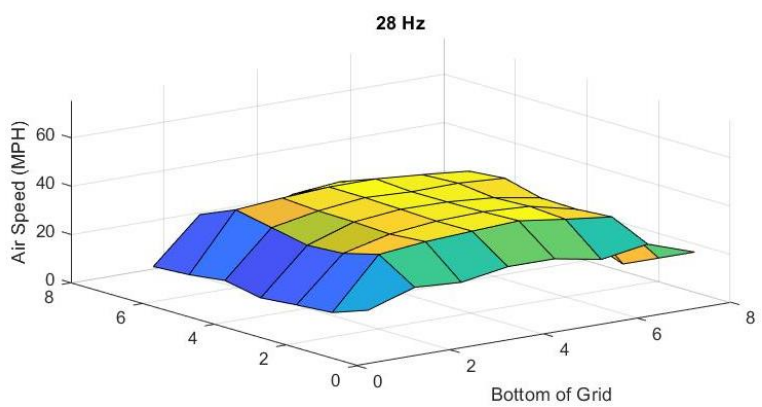

Side of Grid Near TS Door

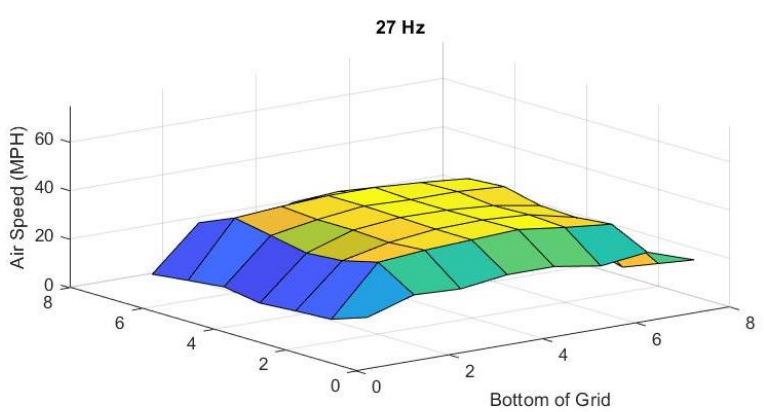

Side of Grid Near TS Door

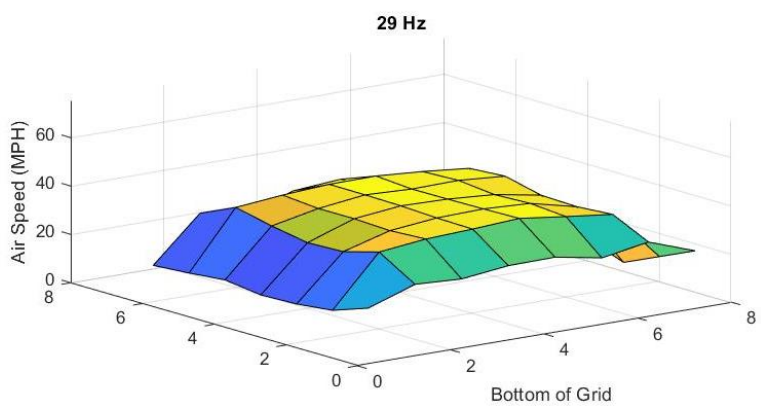

Side of Grid Near TS Door

Figure 5.22: Velocity profile surface plots for $26 \mathrm{~Hz}$ through $29 \mathrm{~Hz}$ drive frequencies.

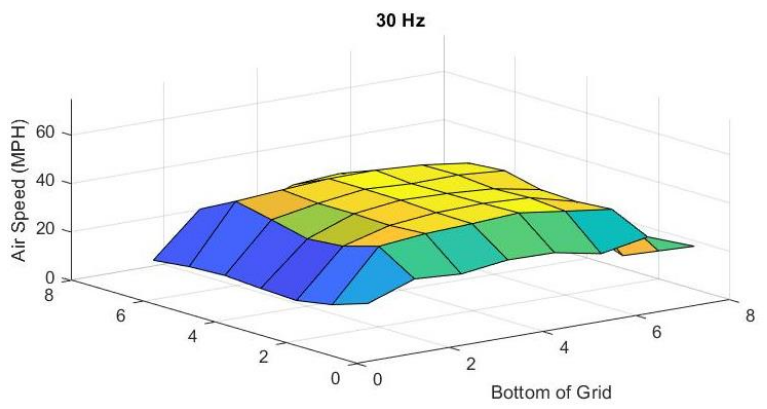

Side of Grid Near TS Door

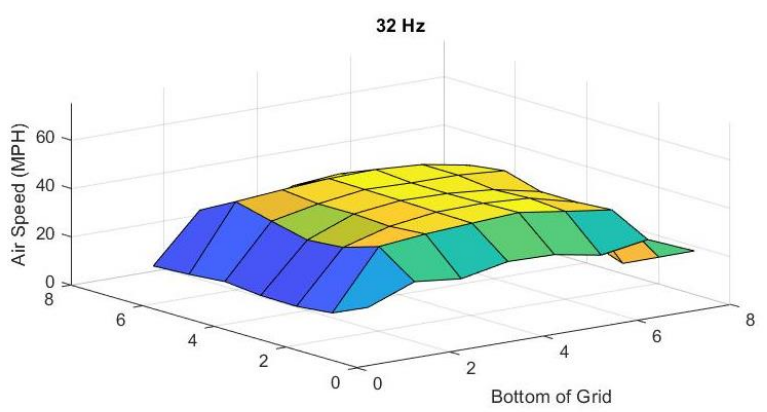

Side of Grid Near TS Door

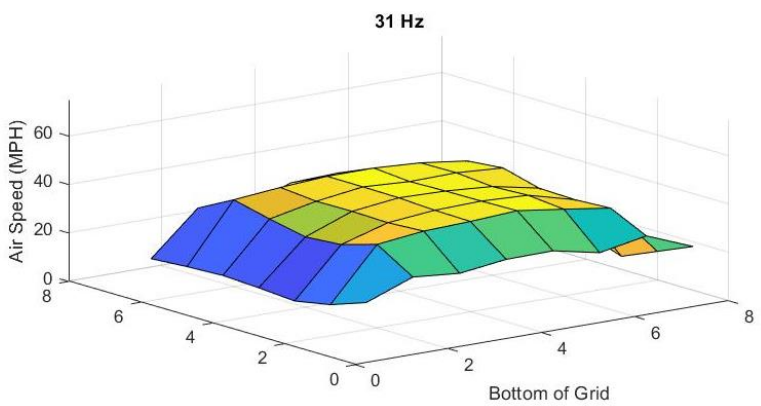

Side of Grid Near TS Door

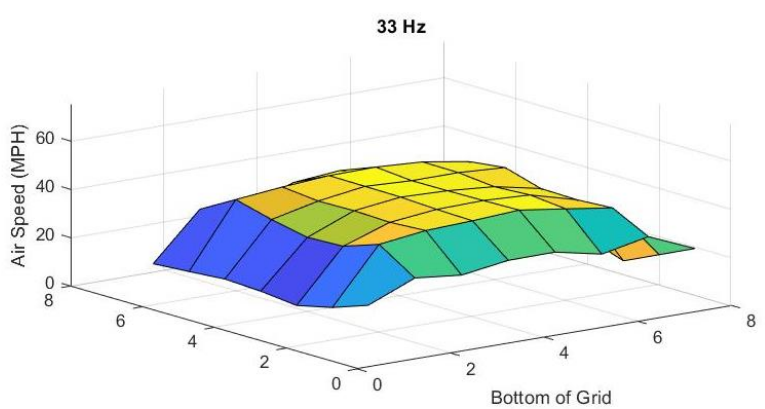

Side of Grid Near TS Door

Figure 5.23: Velocity profile surface plots for $30 \mathrm{~Hz}$ through $33 \mathrm{~Hz}$ drive frequencies. 


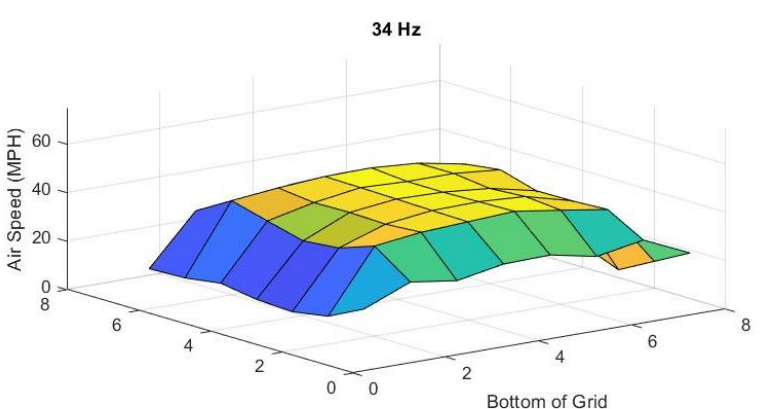

Side of Grid Near TS Door

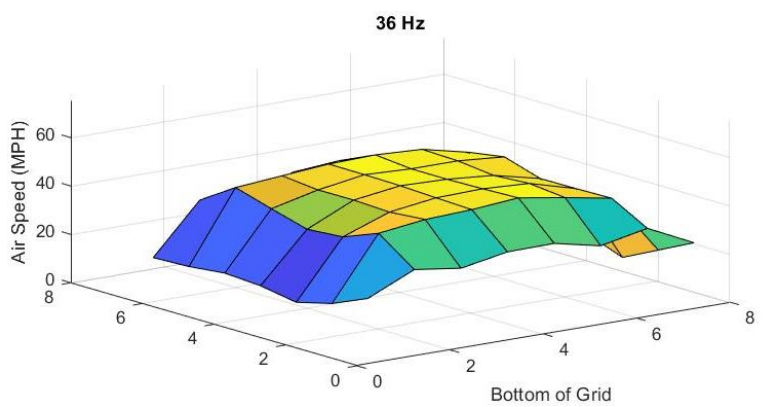

Side of Grid Near TS Door

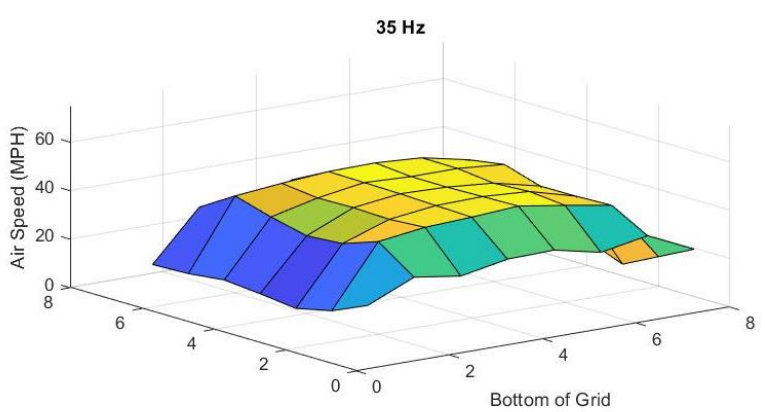

Side of Grid Near TS Door

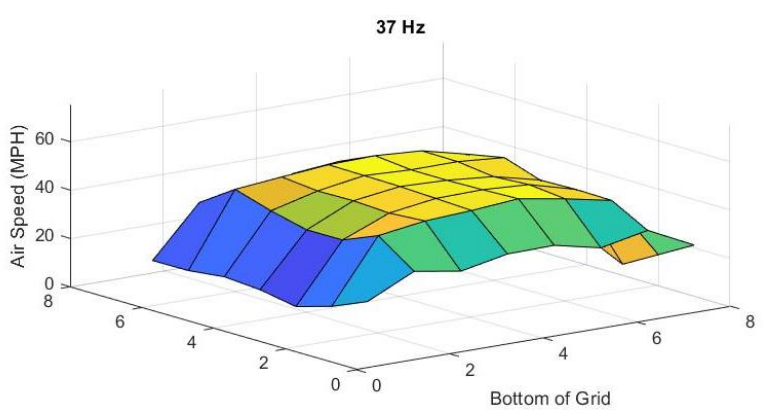

Side of Grid Near TS Door

Figure 5.24: Velocity profile surface plots for $34 \mathrm{~Hz}$ through $37 \mathrm{~Hz}$ drive frequencies.

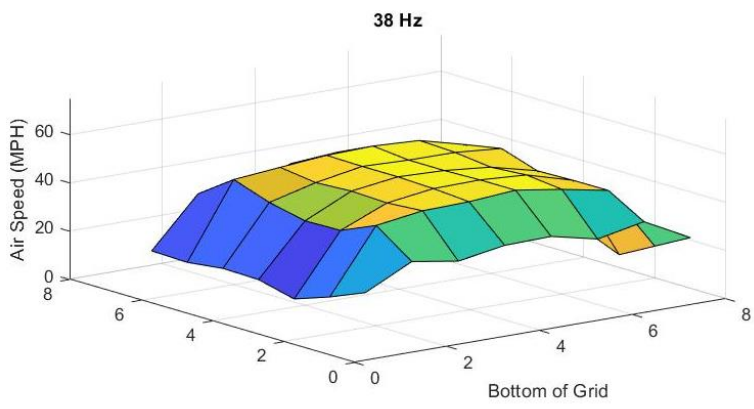

Side of Grid Near TS Door

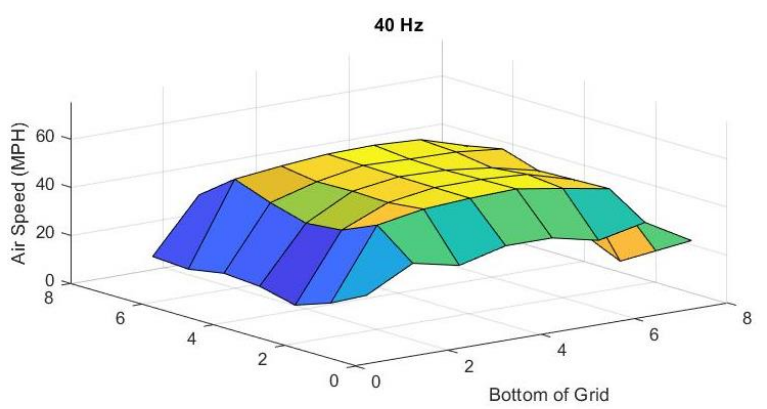

Side of Grid Near TS Door

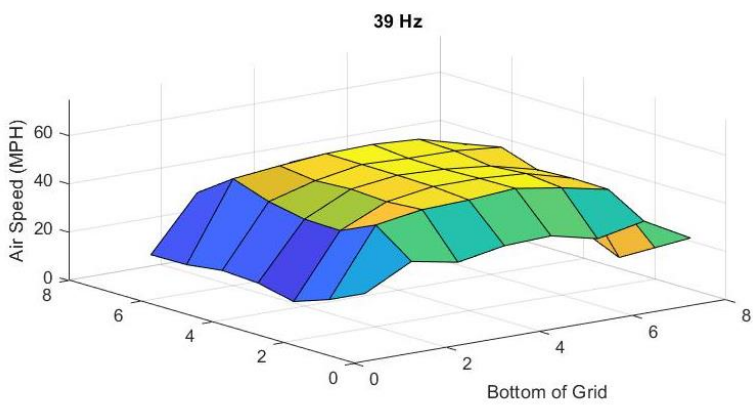

Side of Grid Near TS Door

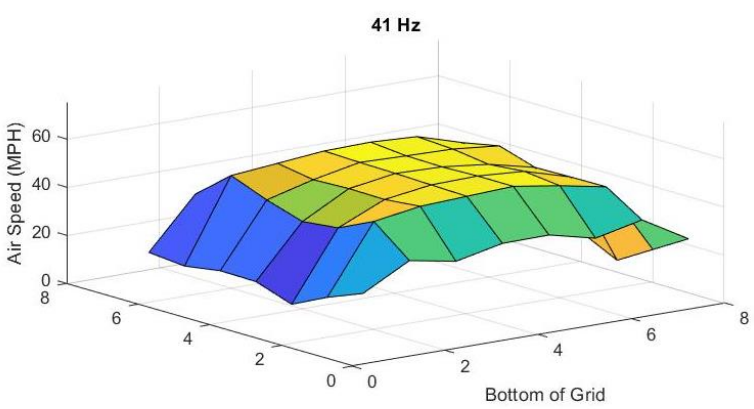

Side of Grid Near TS Door

Figure 5.25: Velocity profile surface plots for $38 \mathrm{~Hz}$ through $41 \mathrm{~Hz}$ drive frequencies. 


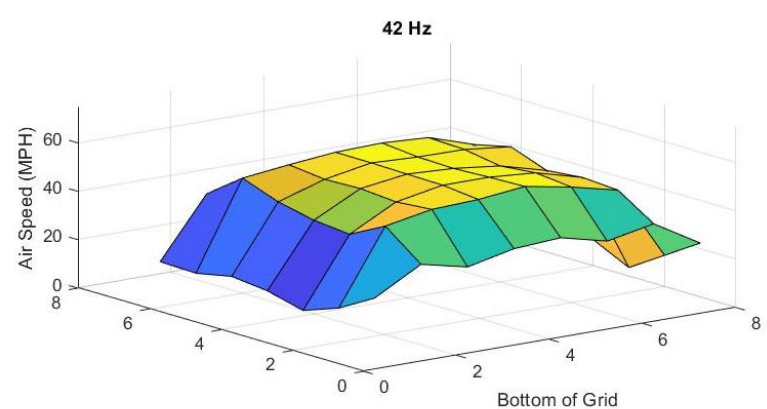

Side of Grid Near TS Door

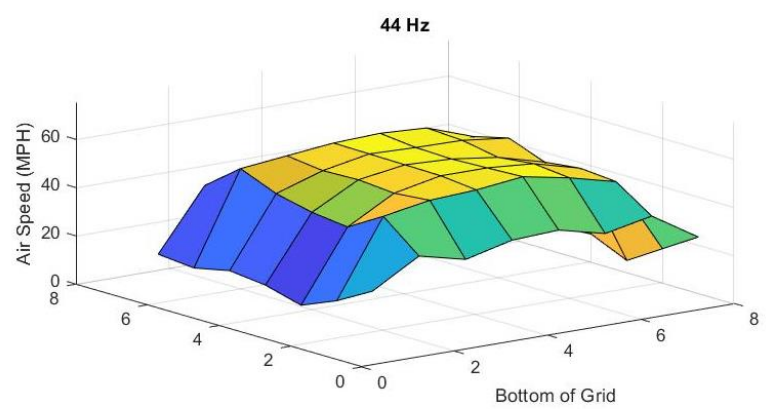

Side of Grid Near TS Door

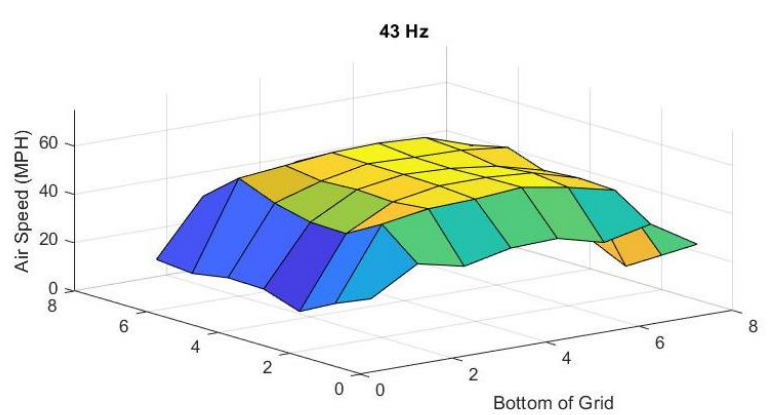

Side of Grid Near TS Door

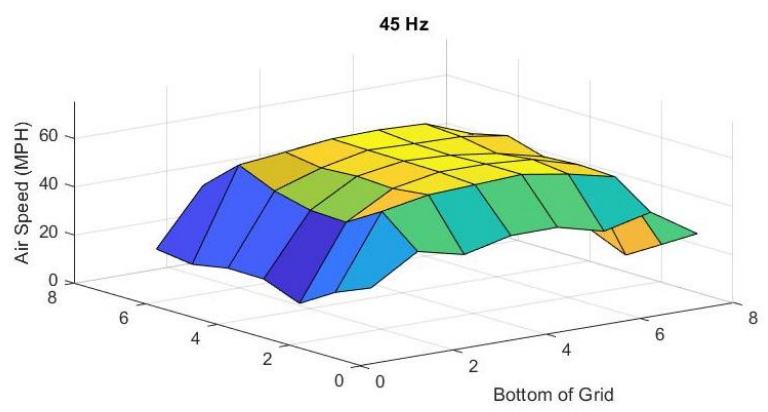

Side of Grid Near TS Door

Figure 5.26: Velocity profile surface plots for $42 \mathrm{~Hz}$ through $45 \mathrm{~Hz}$ drive frequencies.

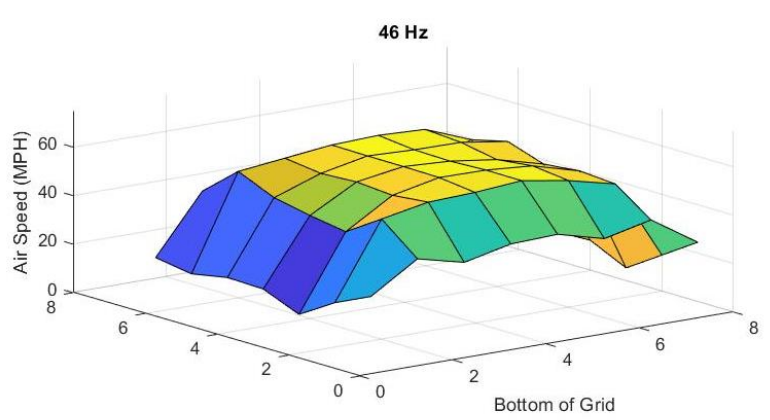

Side of Grid Near TS Door

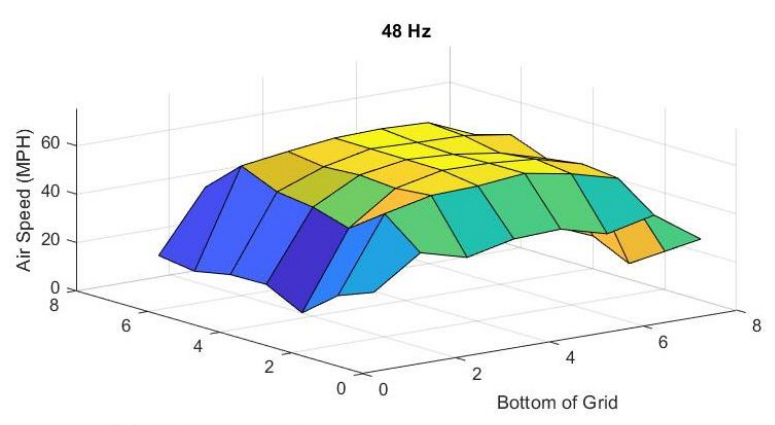

Side of Grid Near TS Door

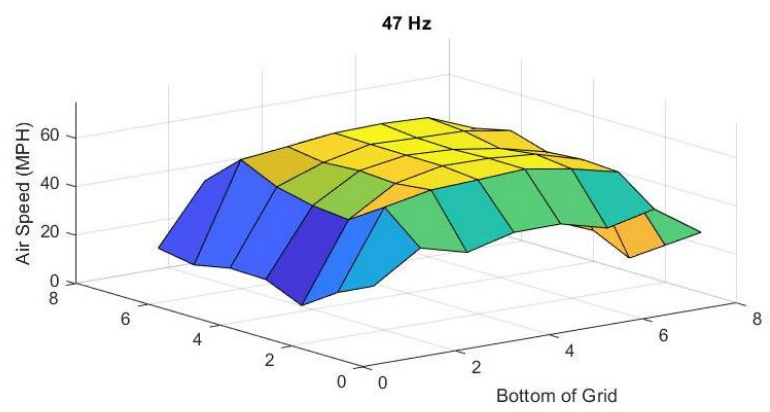

Side of Grid Near TS Door

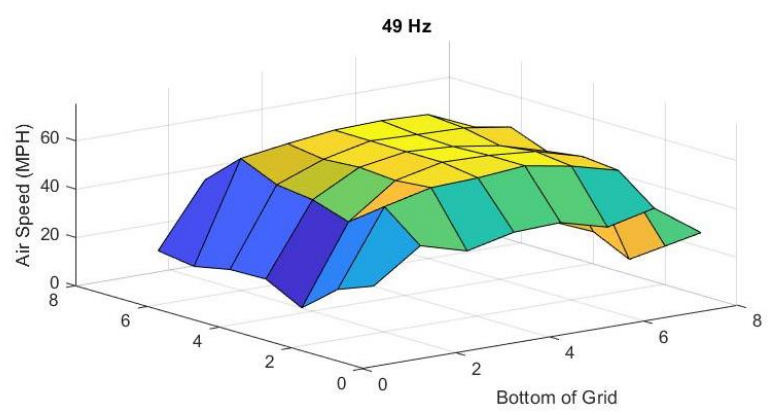

Side of Grid Near TS Door

Figure 5.27: Velocity profile surface plots for $46 \mathrm{~Hz}$ through $49 \mathrm{~Hz}$ drive frequencies. 


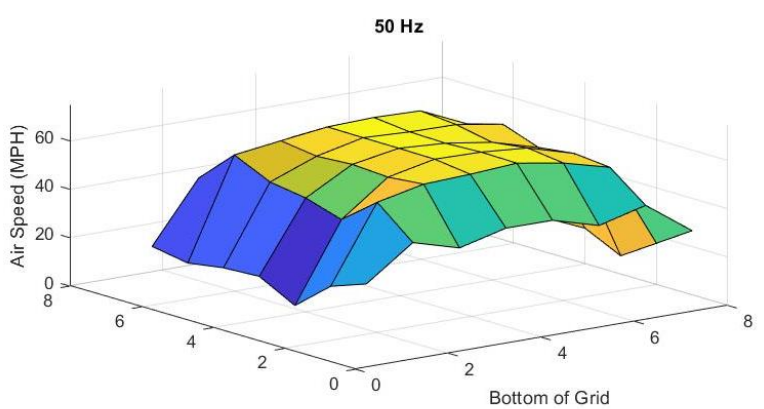

Side of Grid Near TS Door

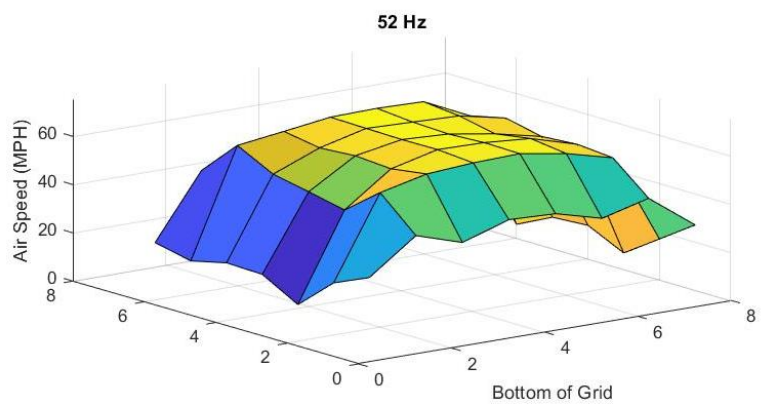

Side of Grid Near TS Door

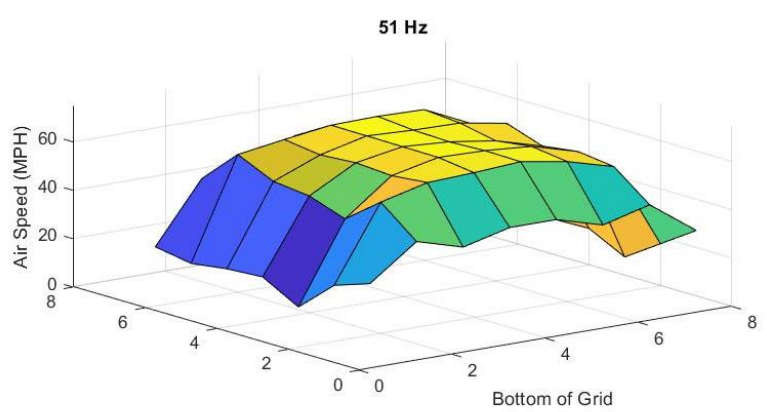

Side of Grid Near TS Door

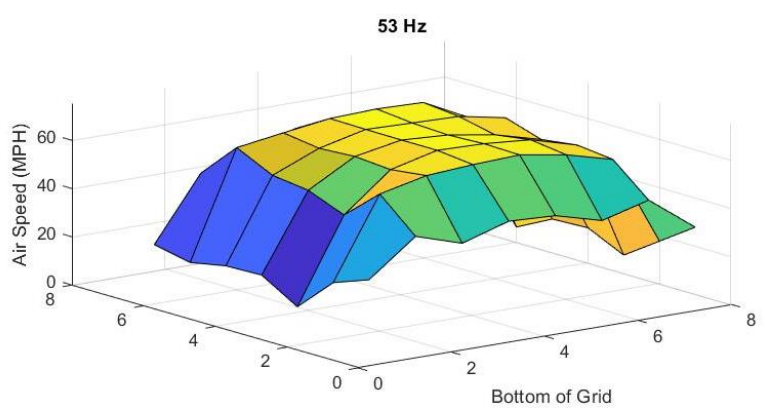

Side of Grid Near TS Door

Figure 5.28: Velocity profile surface plots for $50 \mathrm{~Hz}$ through $53 \mathrm{~Hz}$ drive frequencies.

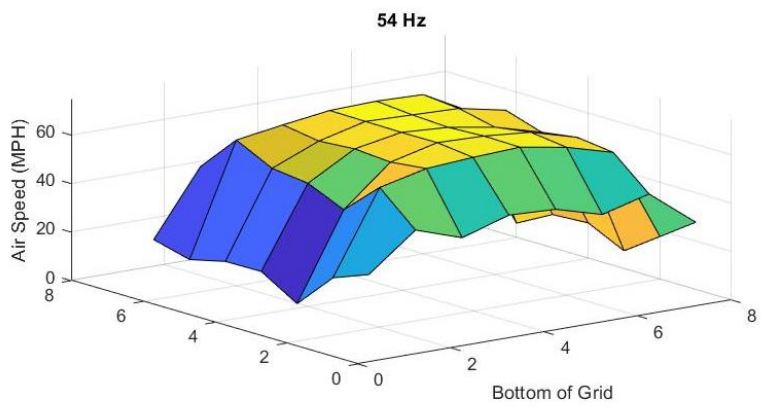

Side of Grid Near TS Door

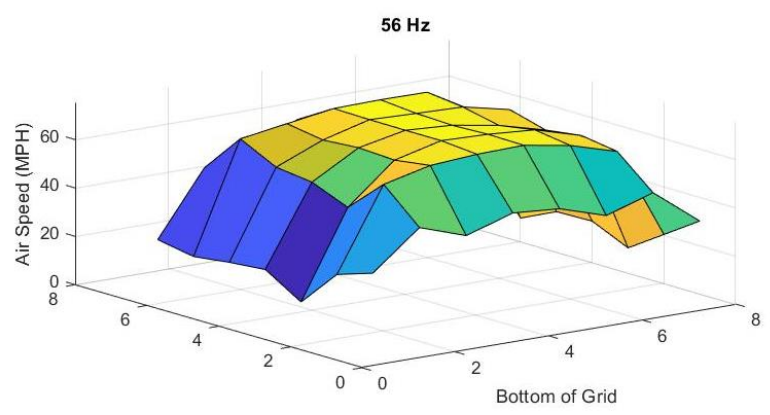

Side of Grid Near TS Door

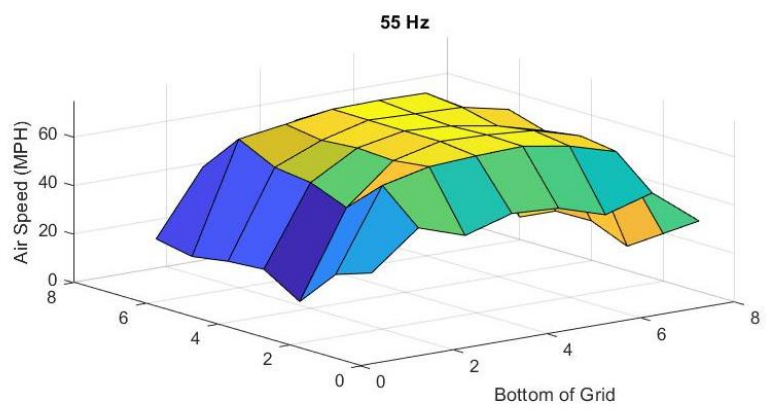

Side of Grid Near TS Door

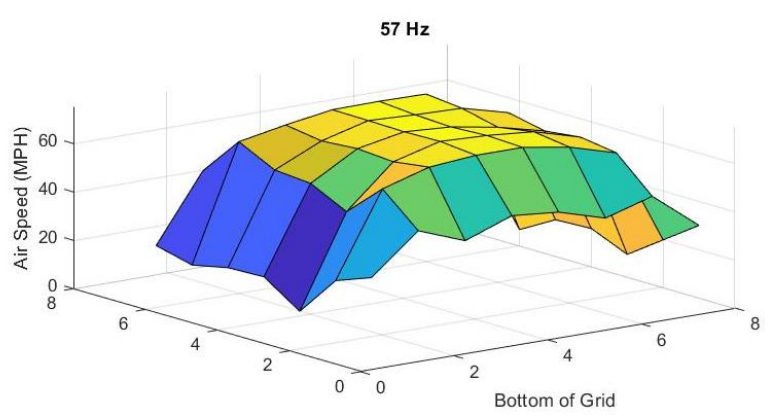

Side of Grid Near TS Door

Figure 5.29: Velocity profile surface plots for $54 \mathrm{~Hz}$ through $57 \mathrm{~Hz}$ drive frequencies. 


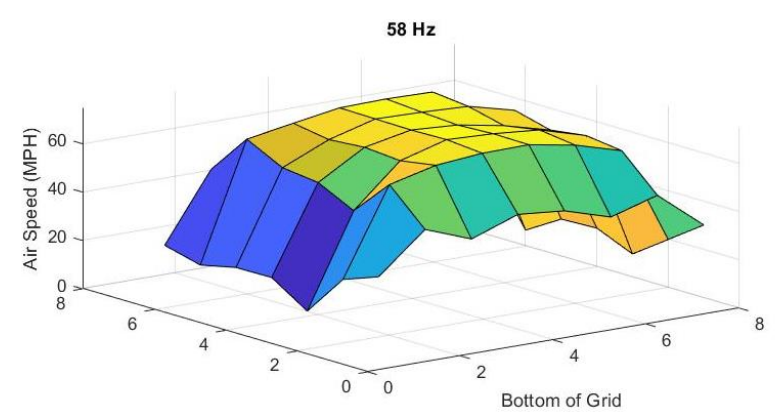

Side of Grid Near TS Door

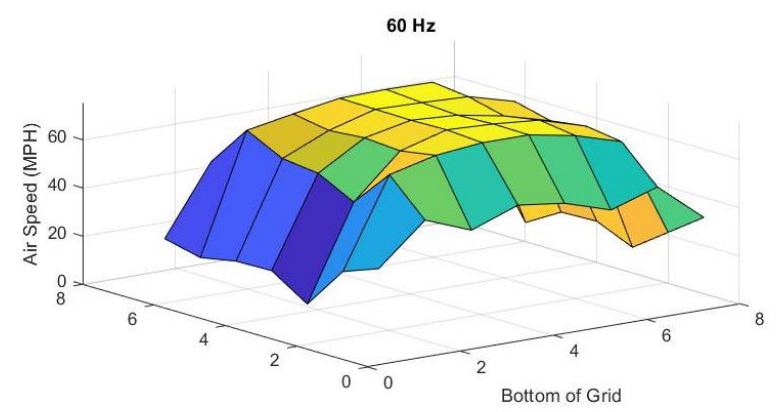

Side of Grid Near TS Door

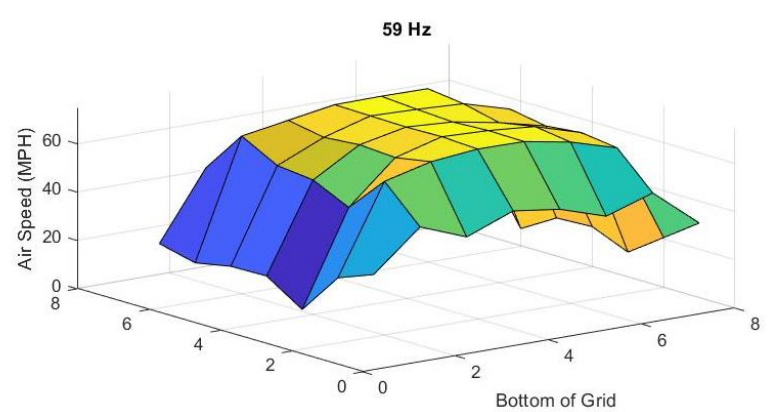

Side of Grid Near TS Door

Figure 5.30: Velocity profile surface plots for $58 \mathrm{~Hz}$ through $60 \mathrm{~Hz}$ drive frequencies.

Viewing these velocity profiles, it is important to understand what type of flow they are. A unit Reynolds number can be determined for the tunnel, which can then later be used when a model is placed in the tunnel. This unit Re will not be unitless as usual, and will instead have units of per feet, and once a model is placed in the tunnel, the characteristic distance measurement for the model can be used to achieve the unitless Re. The unit Re can be found using Equation 5.1, where $\rho$ is the density, $V$ is the velocity, and $\mu$ is the viscosity of air.

$$
R e_{u}=\frac{\rho V}{\mu}
$$

Observing the velocity surface plots from the previous figures, it can be seen that these are likely turbulent. Figure 5.31 shows a 2D theoretical sketch of laminar and turbulent velocity profiles in a pipe [12]. Calculating a Re for the tunnel using the hydraulic diameter at $60 \mathrm{~Hz}$ yields a value of approximately 1.8E6. Transition to turbulence in pipe flow is around a Re of 2500. 


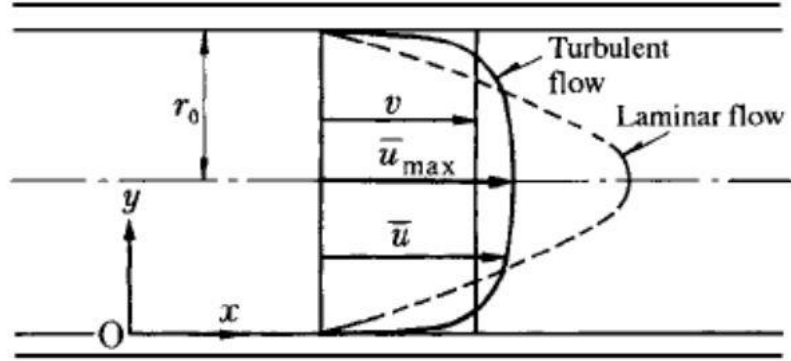

Figure 5.31: Laminar and turbulent boundary layers in a pipe [12].

Overlaying a side profile of one of the surface plots from this tunnel onto this theoretical depiction, as shown in Figure 5.32, it can be seen that these profiles follow closely that of the turbulent outline. With more pitot tubes, especially near the outside of the grid, a greater resolution could have been achieved to gather a more detailed picture of the boundary layers.

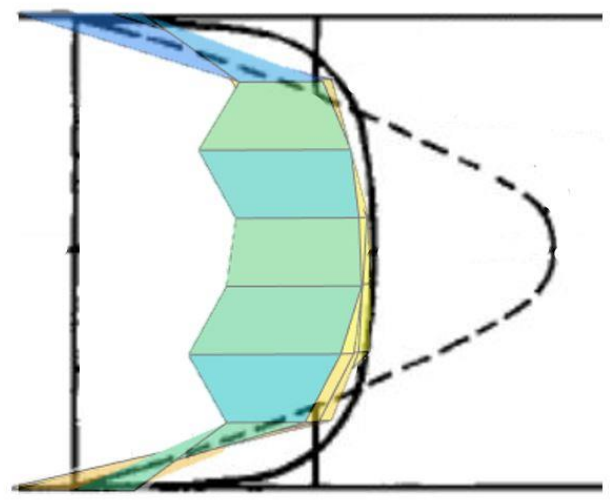

Figure 5.32: Overlay of a side view of a surface plot onto laminar and turbulent boundary layers in a pipe.

Using a wake rake from the Aerospace Engineering Department at WVU, an evaluation of boundary layer was also conducted. The wake rake is used often for the Experimental Aerospace course to determine the wake behind spheres and cylinders. It consists of 41 pitot tubes in a line $1 / 8$ " apart for a total length of 5". These pitot tubes are connected to a fin-like structure that added an extra 3.375 " to either side of the pitot tubes. This wake rake can be seen in Figure 5.33 placed on its side in the center of the tunnel test section just ahead of the grid. In this position, the finlike structure touched the top of the test section table, therefore setting the first pitot tube on the rake at 3.375 " above the surface of the table. 


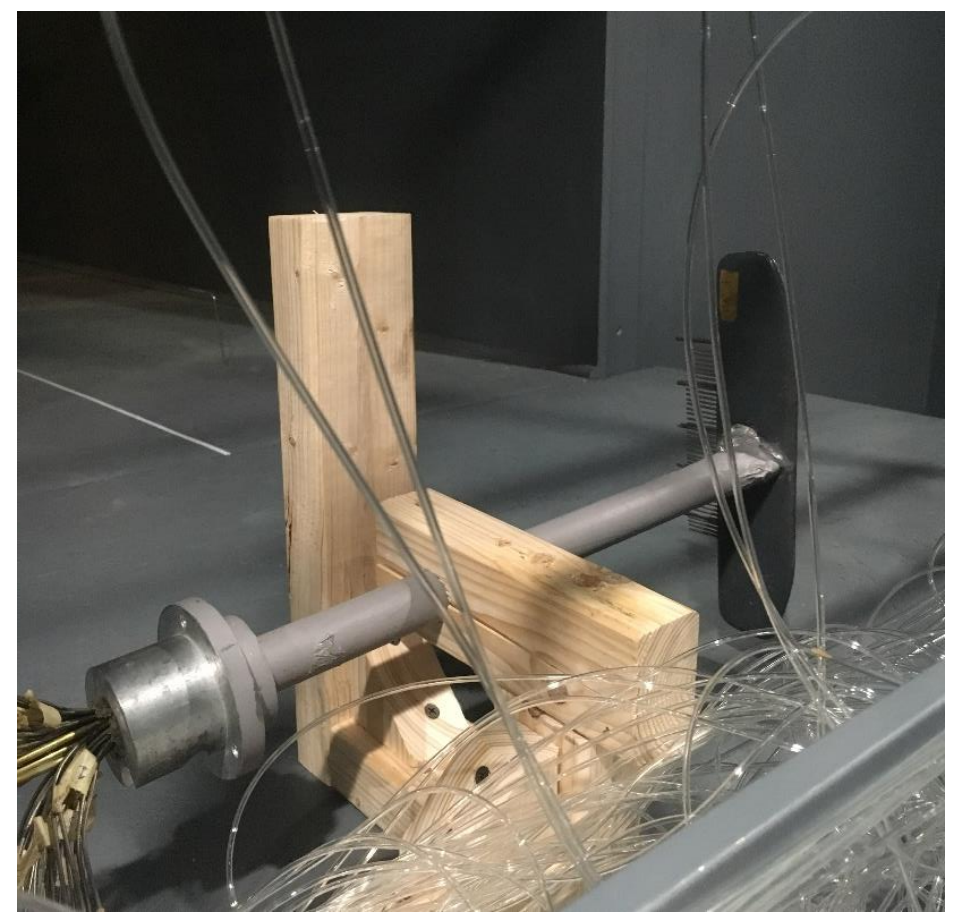

Figure 5.33: Wake rake placed on its side in the center of the test section.

Data was collected at different speeds to evaluate the boundary layer in this position. Figure 5.34 below shows the boundary layer plot in MPH for a frequency of $18 \mathrm{~Hz}$. The centerline is the smoothed data, and the vertical line is the determined height of the boundary layer for $99 \%$ of the max velocity. This profile is on its side in this image, and would also require 3.375 " be added to account for the wake rake position. Therefore the boundary layer height for this speed would be around 7'. See Appendix N for code for collecting and analyzing the boundary layers. 


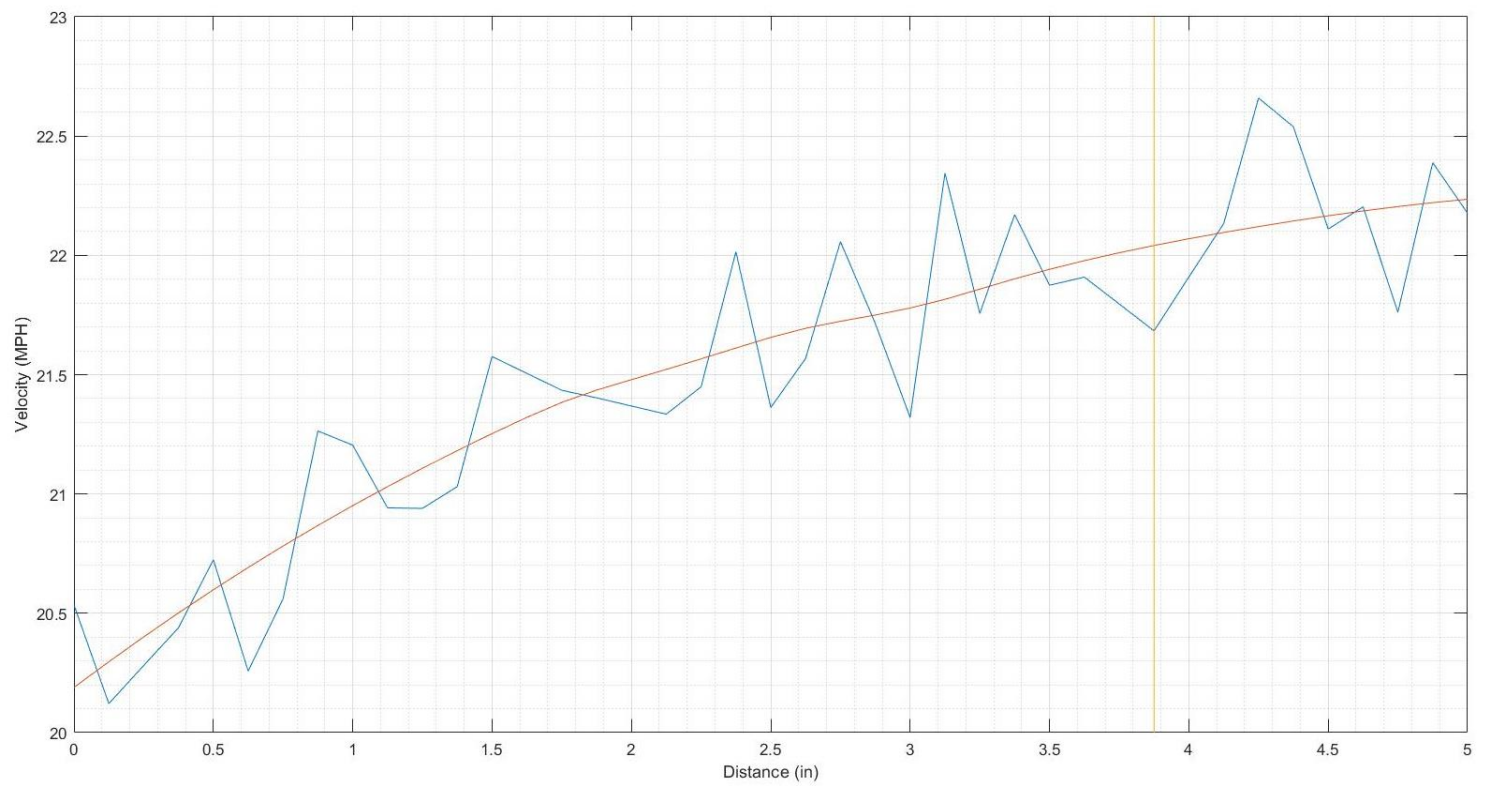

Figure 5.34: Boundary layer profile for $18 \mathrm{~Hz}$.

Figure 5.35 and 5.36 show the boundary layer profiles for $30 \mathrm{~Hz}$ and $50 \mathrm{~Hz}$ respectively and can be read similarly to Figure 5.34. The boundary layer heights for these speeds can be read as about 5.25" and 7.25" respectively. Boundary layers are difficult to evaluate in unsteady, turbulent flow, and are more theoretical in nature, hence the large variation of the boundary layer heights in these figures.

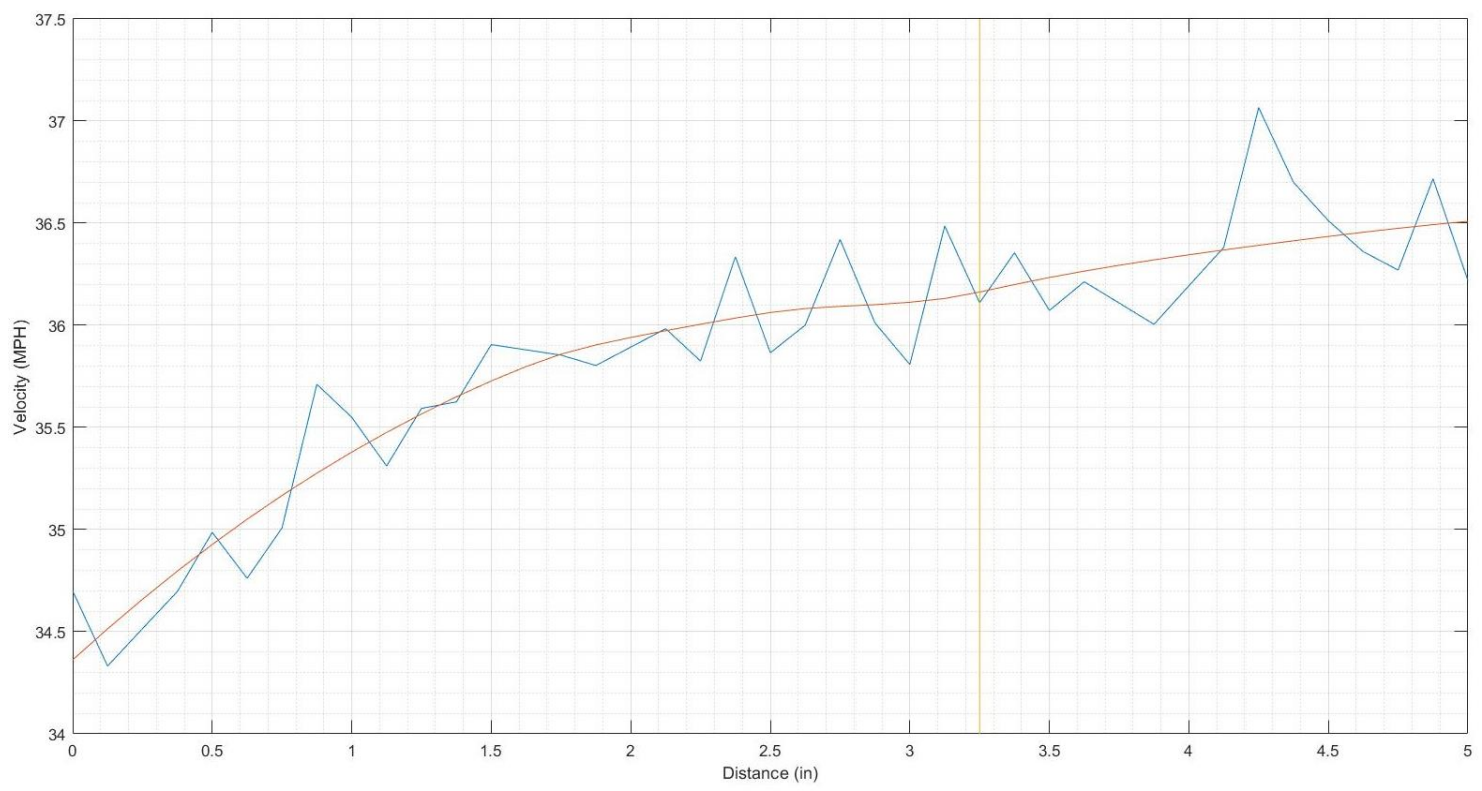

Figure 5.35: Boundary layer profile for $30 \mathrm{~Hz}$. 


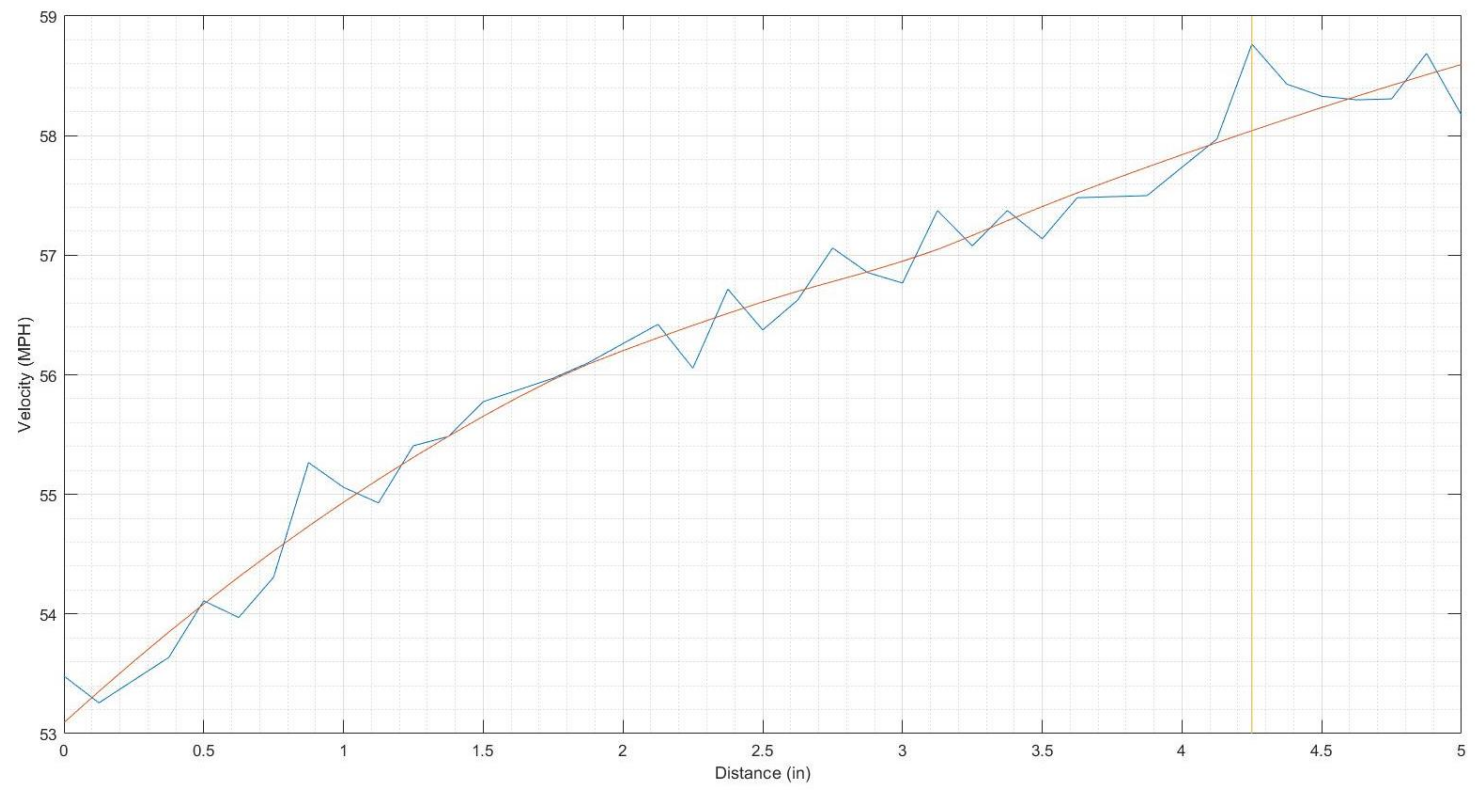

Figure 5.36: Boundary layer profile for $50 \mathrm{~Hz}$.

With the velocities and boundary layers realized, it is also valuable to evaluate the wind power in the test section compared to the power output at the fans. Previous research conducted with the EWT estimated theoretical performance values. These estimations were reviewed and compared to actual power data collected from the drives and wind speeds in the test section to gain an insight into how much power is actually seen at the test section versus total power output from the drives. The previous research evaluated each section of the whole wind tunnel for the pressure losses or pressure drops during operation [10]. Table 5.3 shows the total theoretical pressure loss coefficients for each section of the tunnel determined from previous research, where $K_{i}$ is the pressure loss coefficient, $q_{i}$ is the dynamic pressure, and $\Delta P_{i}$ is the pressure loss for each section [10]. A superficial velocity was used for the dynamic pressure calculations of the settling chamber and contraction, which is a hypothetical flow velocity calculated as if the given fluid were the only one flowing or present in a given cross sectional area [13]. This superficial velocity was set to be approximately $22 \mathrm{ft} / \mathrm{s}$, or $15 \mathrm{MPH}$. A velocity of approximately $102 \mathrm{ft} / \mathrm{s}$, or $70 \mathrm{MPH}$, was used for the dynamic pressure calculations for the fetch, test section, and diffuser. 
Table 5.3: Theoretical pressure loss for each section of the tunnel, determined from previous research [10].

\begin{tabular}{|c|c|c|c|}
\hline Tunnel Section & $\mathbf{K}_{\mathbf{i}}$ & $\mathbf{q}_{\mathbf{i}}\left(\mathbf{l b}_{\mathbf{f}} / \mathbf{f t}^{\mathbf{2}}\right)$ & $\mathbf{\Delta} \mathbf{p i}\left(\mathbf{l b}_{\mathbf{f}} / \mathbf{f t}^{\mathbf{2}}\right)$ \\
\hline Settling Chamber & 1 & 0.54 & 0.54 \\
\hline Contraction & 0.01 & 0.54 & 0.01 \\
\hline Fetch & 0.19 & 11.76 & 2.23 \\
\hline Test Section & 0.23 & 11.76 & 2.71 \\
\hline Diffuser & 0.551 & 11.76 & 6.48 \\
\hline \multicolumn{2}{|r}{} & Total & 11.97 \\
\hline
\end{tabular}

While finding $K_{i}$ for each section had different methods and equations, the equation for the dynamic pressure is shown in Equation 5.2, where $\rho$ is the averaged density and $V$ is air speed.

$$
q=\frac{1}{2} \rho V^{2}
$$

The equation for $\Delta P_{i}$ is shown in Equation 5.3, which is simply the pressure loss coefficient, $K_{i}$, multiplied by the dynamic pressure from Equation 5.1.

$$
\Delta P=K \frac{\rho V^{2}}{2}
$$

Using the total pressure loss calculated in Table 5.3 of approximately $12 \mathrm{lb}_{\mathrm{f}} / \mathrm{ft}^{2}$, this can be converted to power using Equation 5.4, where $A_{T S}$ is the area of the test section, $V_{T S}$ is the velocity in the test section, and $\Delta P_{T o t}$ is the total pressure loss. This gives a power value of approximately $18427 \mathrm{lb} f \mathrm{ft} / \mathrm{s}$. Dividing this value by 550 to convert to horsepower (hp) gives approximately $33.5 \mathrm{hp}$ of total pressure loss for the whole tunnel using a theoretical motor and fan efficiency of $65 \%$.

$$
\text { Power }=A_{T S} V_{T S} \Delta P_{T o t}
$$

To compare this theoretical power value to actual in the test section and actual power output from the drives, information on output current and voltage from each of the six drives was collected for each frequency from $18 \mathrm{~Hz}$ through $60 \mathrm{~Hz}$, see Appendix $\mathrm{O}$ for this code. Using an assumed motor efficiency of $85 \%$ and a fan efficiency of $80 \%$ for a combined estimated efficiency of $68 \%$ the motor power for each of the six drives was calculated using Equation 5.5 for a three-phase electrical motor [14]. Here, $V_{\|}$is the line to line voltage, $I$ is the current in amps, and cos $(\Phi)$ is the power factor, or also written as PF. Power factor is the phase shift between voltage and current 
from the drives. The voltage and current values collected from the drives were substituted into this equation and divided by the conversion of 745.7 to convert to horsepower.

$$
\text { Power }=3^{1 / 2} * V_{||} * I * \cos (\Phi)
$$

The total motor power was then found by summing this power calculation for all six drives to receive the total power output in horsepower from the motors. Figure 5.37 shows the power distribution from all six drives as a function of frequency. It can be seen that at the maximum frequency of $60 \mathrm{~Hz}$ each motor produces between $8 \mathrm{hp}$ and $9 \mathrm{hp}$.

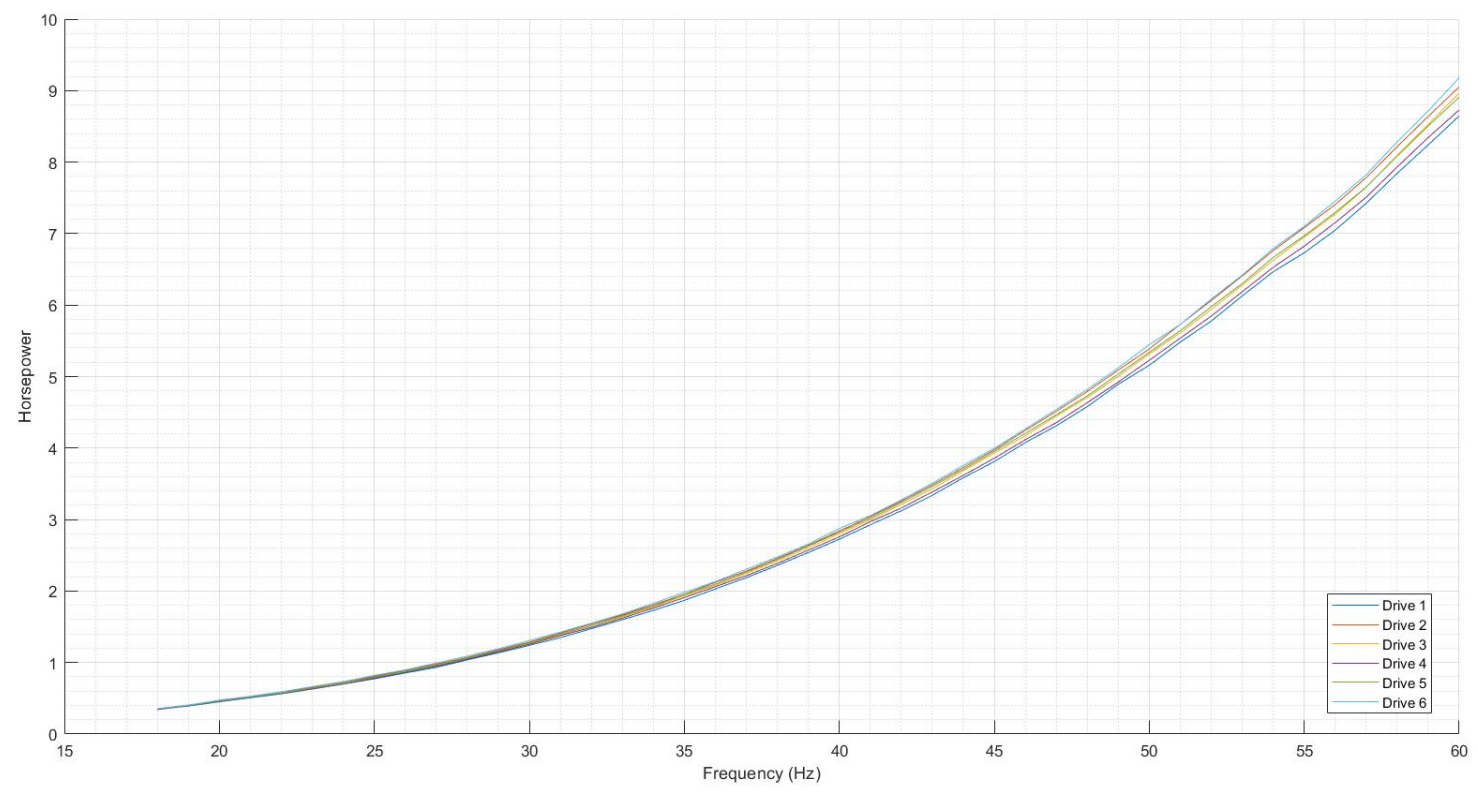

Figure 5.37: Horsepower as a function of frequency for each of the six drives.

Figure 5.38 shows the total horsepower combined of all six fans as a function of frequency. For a frequency of $60 \mathrm{~Hz}$ the total horsepower was found to be approximately $53.5 \mathrm{hp}$. See Appendix $\mathrm{P}$ for tables of these horsepower values for corresponding frequency. 


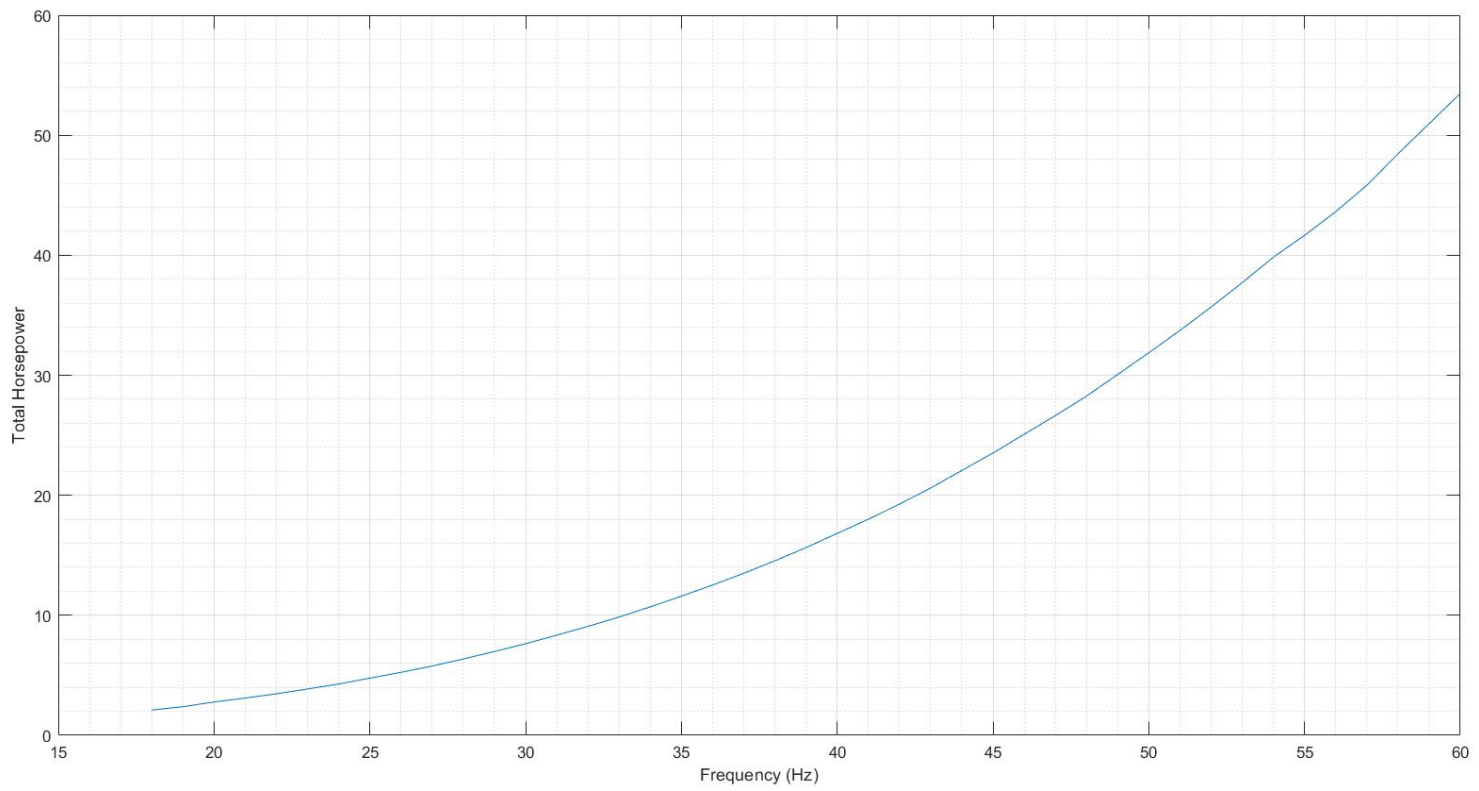

Figure 5.38: Total horsepower of all six drives combined.

Next, the wind power in the test section was determined by integrating across the test section area. The test section was divided into 36 blocks with a pitot tube from the grid near the center of each of these areas. Figure 5.39 shows a sketch of these divisions. Each plus sign represents a pitot tube on the grid. The solid boxed area represents the opening of the fetch, and each smaller boxed area represents the divisions developed with a pitot tube at the centers in order to integrate across the area of the test section. See Appendix $O$ for this code. 


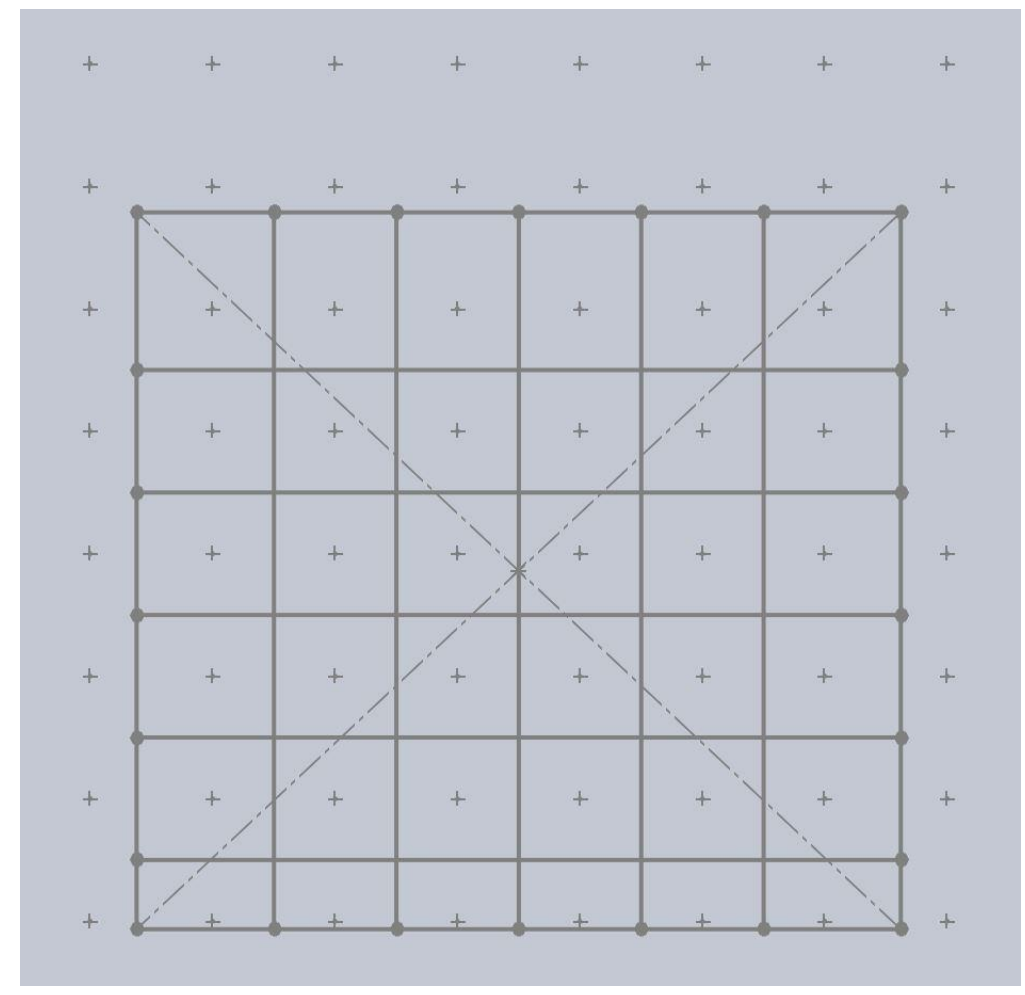

Figure 5.39: Test section area divisions for power calculations.

Using these areas, the power at the test section was calculated using Equation 5.5, where $\rho$ was the averaged density from the four days of testing, $A_{T S}$ was the area of the particular division of the test section found from the areas above, and $V$ was the averaged velocity in feet per second for the particular area for each frequency. These values were then divided by the conversion factor of 550 to convert the values to horsepower.

$$
\text { Wind Power }=\sum \frac{1}{2} \rho A_{T S} V^{3}
$$

Figure 5.40 shows the total combined wind horsepower in the test section. It can be seen that at the maximum of $60 \mathrm{~Hz}$ the total power seen in the test section is approximately $27 \mathrm{hp}$. This shows that only about $50 \%$ of the power output from the drives is seen in the test section. 


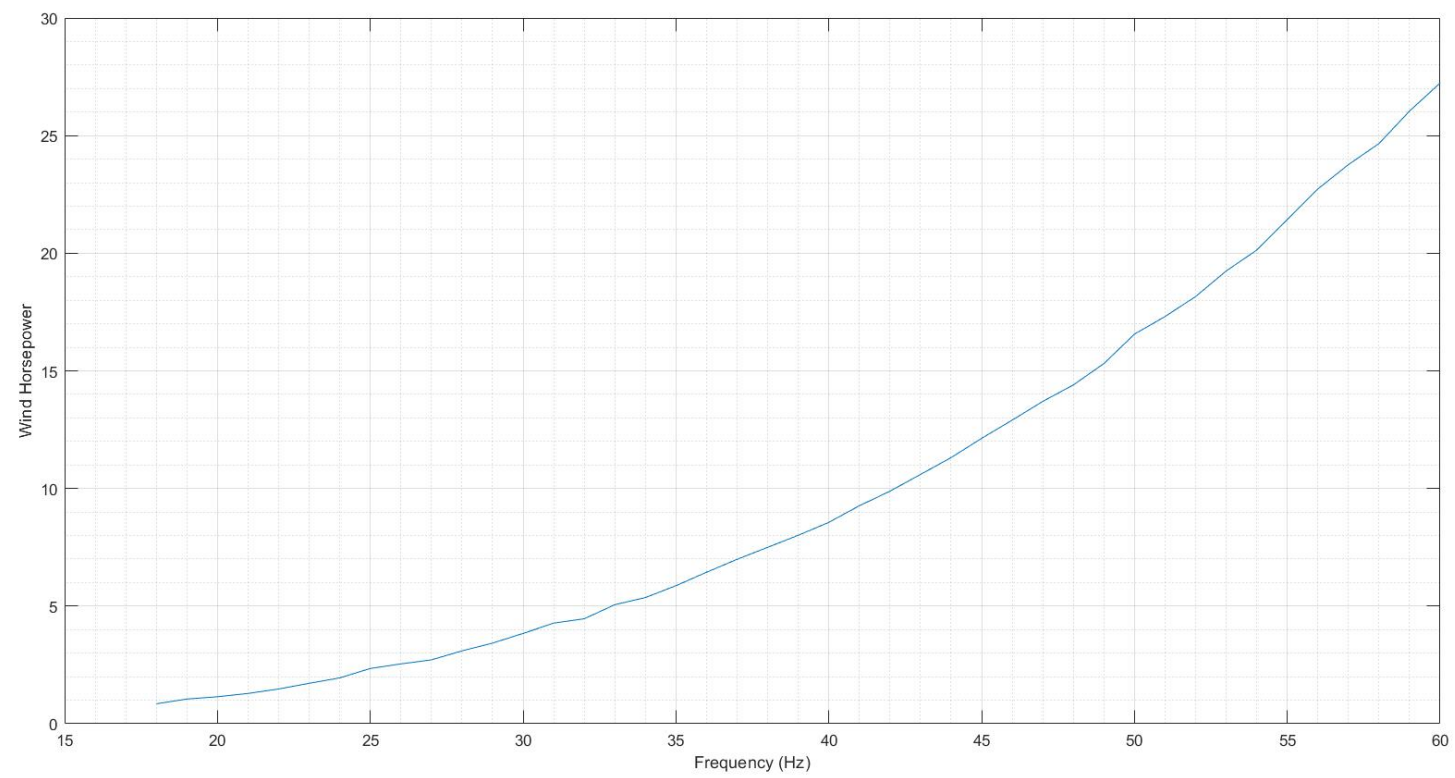

Figure 5.40: Wind horsepower in the test section as a function of frequency.

Figure 5.41 shows the efficiency percentage as a function of frequency. Here it can be seen that the efficiency is lower at lower frequencies, between $40 \%$ and $48 \%$ from $18 \mathrm{~Hz}$ to about $30 \mathrm{~Hz}$, and steadies to around $51 \%$ for higher frequencies.

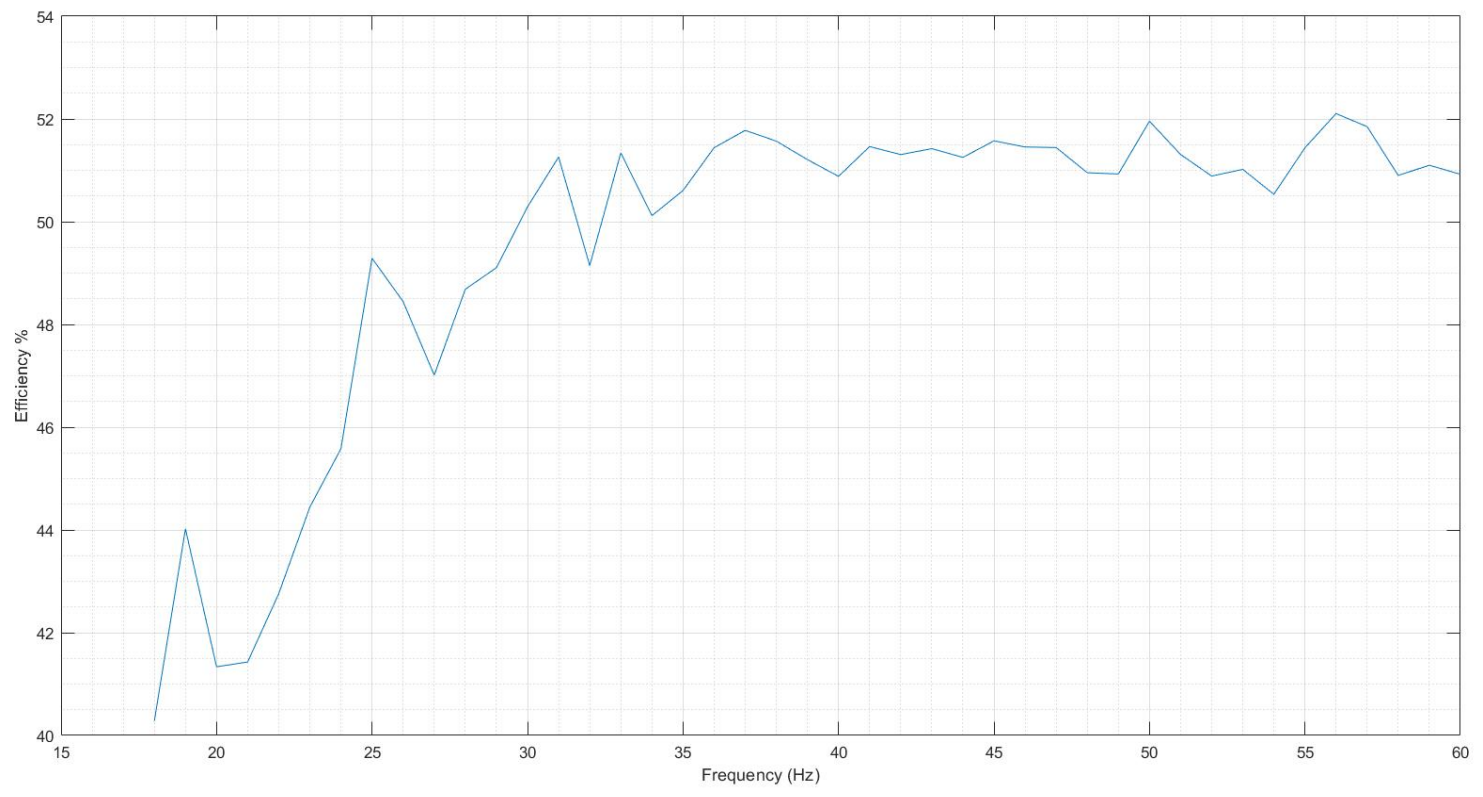

Figure 5 41: Efficiency as a function of frequency.

This efficiency graph assumes a constant efficiency of the motor and fan over the entire frequency range. It is likely that the efficiency of the fan decreases as the speed decreases resulting 
in the drop of efficiency below $30 \mathrm{~Hz}$. It is likely the aerodynamic efficiency of the tunnel is more uniform across the frequency range.

Finally, utilizing all the results from above, a function was created so that users may enter a desired average test section velocity and receive a frequency value to set all of the motors to in order to achieve that velocity. This function utilized the linear relationship developed between averaged test section velocity and motor speed to interpolate the motor speed for any given velocity within the range capable of the tunnel. The function accepts speeds with units MPH, knots, feet per second, meters per second, Mach, and kilometers per hour, and can be updated to include any other desired units in the future. See Appendix $Q$ for this function. For more statistical analysis on the data collected for this research, see Appendix R. 


\section{Chapter 6: Conclusion}

The environmental wind tunnel received in 2013 from Cornell University was updated for use at WVU. With these updates the flow field required qualification so that it could be used to its fullest potential by students and faculty at WVU. The tunnel is very important to students in the Aerospace Engineering program as well as those conducting research where computational methods may need supplemented with experimental results. Therefore, the velocity profiles and power availability in the test section were evaluated for the available range of motor speeds for the tunnel.

When the tunnel was updated for WVU, variable frequency drives were added so that the fans in the tunnel could be run at a larger range of speeds. This allowed the fans to be run from $18 \mathrm{~Hz}$ to $60 \mathrm{~Hz}$ in steps of one tenth of a Hz. This range corresponds to average test section speeds of approximately 22MPH to 70MPH. The ambient conditions for this experiment had a very tight range only a few degrees variation over the entire test, so these numbers are only accurate for this range and may need to be verified if the temperature is considerably different. A linear relationship between motor frequency and wind speed was discovered to be about $1 \mathrm{knot}$, or about 1.16 MPH per Hz. This would allow for a quick estimation of necessary motor speeds given a desired average test section velocity. A function was also developed for a more accurate estimation of necessary motor speeds given a desired average test section velocity. Given the system accuracy determined previously, the accuracy of this mapping is approximately $\pm 3 \mathrm{MPH}$ at $18 \mathrm{~Hz}, \pm 2 \mathrm{MPH}$ at $30 \mathrm{~Hz}$, $\pm 1.5 \mathrm{MPH}$ at $45 \mathrm{~Hz}$, and $\pm 1 \mathrm{MPH}$ at $60 \mathrm{~Hz}$, leading to an increase of accuracy as speed increases. Along with a mapping of the velocity in the test section, the wind power in the test section compared to the total power output from the motors was also mapped. The total power output from the motors at $60 \mathrm{~Hz}$ was determined to be approximately $53.5 \mathrm{hp}$, while the wind power in the test section was determined to be approximately $27 \mathrm{hp}$, leading to roughly $50 \%$ efficiency. At speeds lower than about $30 \mathrm{~Hz}$ the efficiency drops to around $40 \%$ efficiency. This flow field measurement and qualification will be useful to all who use the tunnel in the future and will allow a better understanding of the flow in the tunnel and could even allow the flow field to be manipulated to gain a greater variation of flows for various uses. 


\section{Chapter 7: Future Work}

There is still much research work that could be conducted with the WVU EWT. One recommendation would be to focus on the inlet guide vanes (IGV) outfitted on the six fans in the tunnel. While the IGVs were not focused on for this research, they could be analyzed in the future to determine how they interact with and impact the flow. It is possible that moving the IGVs to different positions could change the velocity profiles within the tunnel test section, thus allowing for more robust options with testing. Along with this, the table outfitted within the test section could allow for further analysis on the impact of the flow such as ground effects and boundary layer formation, compared to removing the table. The combination of these two items could allow for more test section qualification research to help determine a greater range of velocity profiles available. A similar grid or wake rake device with a greater concentration of pitot tubes in one area could allow for more detailed views of certain areas of the flow such as boundary layers.

Future work on flow field measurements and qualification could also include reconducting this research for a greater range of daily nuisance factors, especially temperature. Conducting the tests again for different temperature and pressure ranges would allow for evaluation of their impacts on the model. It could also lead to a more accurate and more widely available range of use for the model. This could also be done statistically with the data collected from this experiment using Matlab. It could also be determined which nuisance factors, if any, are significant to system response.

From the previous graduate research using the WVU EWT, other methods of flow variation were also introduced to produce more varied flow profiles. One such idea was the introduction of spires into the fetch, tall pyramidal shaped objects, and other roughness objects in order to mimic the idea of buildings in a city or other landscapes. The spires have wider bottoms at the base of the tunnel and taper off the taller they get. This can help mimic airflow through buildings of a city and allow for different types of research to be conducted as well, such as how city-scapes could impact wind turbines [9]. It would also be very beneficial in this case to document the turbulence within the tunnel. As suggested previously, a hot-wire anemometer could be used to investigate the turbulence intensity in the tunnel and thus create a deeper understanding of the available velocity profiles. 
In years prior, a manometer bank was used by the WVU Aerospace Engineering program in order to help visualize flow within wind tunnels but was unfortunately damaged beyond repair during a move of the tunnels to the WVU Hangar. It would be beneficial to recreate a digital manometer bank so that a visual reference can still be made for students in the Experimental Aerospace Engineering course when learning about flow fields in wind tunnels. The previous bank consisted of 50 upright manometers. Using the Scanivalve system to connect a model, it could be possible to have up to 64 digital visual manometers. This would be highly valuable for students learning about manometers and how flow interacts with them.

Before any future research is conducted using the Scanivalve used in this research, it would be strongly recommended to send the Scanivalve instrument back to Scanivalve Corp. for refurbishment and calibration. The current model used for this research is only being serviced by Scanivalve until 2026, after which models will be replaced with updated versions if they are returned for servicing. During the set up of the Scanivalve for this research, many issues were discovered that could be remedied by returning it to Scanivalve for servicing. For example, none of the ports read a zero voltage at zero pressure application, and a few would read higher than the maximum $1 \mathrm{~V}$ at zero pressure, leading them to be unusable once pressure was applied. There was also a whole bank of 8 ports, ports 33-40, that were unable to be calibrated due to their calibration port being broken and filled with a substance that appeared to be hot glue, which lead to this bank of ports being unusable. Sending the Scanivalve for servicing would allow it to read more accurately, as well as make use of all 64 pressure reading ports again. It is essential to upkeep precision instruments such as this so they can be useful for many years and in many different applications. 


\section{$\underline{\text { References }}$}

[1] Barlow, Jewel, et al. Low-Speed Wind Tunnel Testing. Third Edition, John Wiley \& Sons, INC., 1999.

[2] Ristic, Slavica, et al. "Review of methods for flow velocity measurement in wind tunnels." Scientific Technical Review, Vol. LIV, no. 3, 2004, pp. 60-71.

[3] Brown, Glenn. "Henry Darcy and the Pitot Tube." International Engineering History and Heritage, J. R. Rogers and A. J. Fredrich eds, ASCE, Reston, VA.

[4] Folsom, R.G. "Review of the Pitot Tube." Fluid Meters Research Committee of ASME meeting, 14-18 Nov 1955, Chicago, IL.

[5] "MAE to Enhance its Wind Tunnel Facilities." WVU Statler College MAE Annual 2012-2013, 4 Sep 2013, pp. 10.

[6] Bejan, Adrian. Convection Heat Transfer. Fourth Edition, John Wiley \& Sons, INC., 2013.

[7] Montgomery, Douglas. Design and Analysis of Experiments. Eighth Edition, John Wiley \& Sons, INC., 2013.

[8] Hughes, Christopher E. Flowfield Measurements in the NASA Lewis Research Center 9- by 15-Foot Low-Speed Wind Tunnel. NASA, 1 Mar 1989.

[9] ZOC 33/64Px and ZOC 33/64PxX2 Electronic Pressure Scanning Module Instruction and Service Module, Scanivalve Corporation, Liberty Lake, WA.

[10] Rotruck, Stephen N., "Design, Construction, and Qualification of the West Virginia University Environmental Wind Tunnel" (2016). Graduate Theses, Dissertations, and Problem Reports. 6534.

[11] “Kiel Probe.” Aeroprobe Revolutionary Technology, 2015.

[12] Laminar and Turbulent Flow in Pipes. Fluid Mechanics, Chapter 6. https://eng.utq.edu.iq/wp-content/uploads/sites/4/2019/09/fluid-mechanics-6.pdf

[13] Connor, Nick. "What is Superficial Velocity - Two-phase Flow - Definition." Thermal Engineering, 22 May 2019. 
[14] Engineering ToolBox, (2005). Three-Phase Power Equations. [online] Available at: https://www.engineeringtoolbox.com/three-phase-electrical-d_888.html 


\section{Appendix A: Mean Voltages and Standard Deviations for Pitot Tube Selection}

\begin{tabular}{|c|c|c|c|c|c|c|c|c|c|c|c|}
\hline \multicolumn{4}{|c|}{ Large } & \multicolumn{4}{|c|}{ Medium } & \multicolumn{4}{|c|}{ Small } \\
\hline $\begin{array}{c}\text { Standard } \\
\text { Deviation at } 0 \mathrm{~Hz} \\
\text { Initial }\end{array}$ & 0.000764 & $\begin{array}{c}\text { Mean at } 0 \mathrm{~Hz} \\
\text { Initial }\end{array}$ & 0.328 & $\begin{array}{c}\text { Standard } \\
\text { Deviation at } 0 \mathrm{~Hz} \\
\text { Initial }\end{array}$ & 0.000750 & $\begin{array}{c}\text { Mean at } 0 \mathrm{~Hz} \\
\text { Initial }\end{array}$ & 0.328 & $\begin{array}{c}\text { Standard } \\
\text { Deviation at } 0 \mathrm{~Hz} \\
\text { Initial }\end{array}$ & 0.000746 & $\begin{array}{c}\text { Mean at } 0 \mathrm{~Hz} \\
\text { Initial }\end{array}$ & 0.328 \\
\hline $\begin{array}{c}\text { Standard } \\
\text { Deviation at } 30 \\
\mathrm{~Hz}: 1\end{array}$ & 0.00146 & Mean at $30 \mathrm{~Hz}: 1$ & 0.348 & $\begin{array}{c}\text { Standard } \\
\text { Deviation at } 30 \\
\text { Hz:1 }\end{array}$ & 0.00156 & Mean at $30 \mathrm{~Hz}: 1$ & 0.348 & $\begin{array}{c}\text { Standard } \\
\text { Deviation at } 30 \\
\mathrm{~Hz}: 1\end{array}$ & 0.00113 & Mean at $30 \mathrm{~Hz}: 1$ & 0.349 \\
\hline $\begin{array}{c}\text { Standard } \\
\text { Deviation at } 30 \\
\mathrm{~Hz}: 2\end{array}$ & 0.00142 & Mean at $30 \mathrm{~Hz}: 2$ & 0.348 & $\begin{array}{c}\text { Standard } \\
\text { Deviation at } 30 \\
\text { Hz:2 }\end{array}$ & 0.00149 & Mean at $30 \mathrm{~Hz}: 2$ & 0.348 & $\begin{array}{c}\text { Standard } \\
\text { Deviation at } 30 \\
\text { Hz:2 }\end{array}$ & 0.00134 & Mean at $30 \mathrm{~Hz}: 2$ & 0.348 \\
\hline $\begin{array}{c}\text { Standard } \\
\text { Deviation at } 30 \\
\mathrm{~Hz}: 3\end{array}$ & 0.00158 & Mean at $30 \mathrm{~Hz}: 3$ & 0.348 & $\begin{array}{c}\text { Standard } \\
\text { Deviation at } 30 \\
\mathrm{~Hz}: 3\end{array}$ & 0.00161 & Mean at $30 \mathrm{~Hz}: 3$ & 0.348 & $\begin{array}{c}\text { Standard } \\
\text { Deviation at } 30 \\
\mathrm{~Hz}: 3\end{array}$ & 0.00127 & Mean at $30 \mathrm{~Hz}: 3$ & 0.349 \\
\hline $\begin{array}{c}\text { Standard } \\
\text { Deviation at } 30 \\
\mathrm{~Hz}: 4\end{array}$ & 0.00154 & Mean at $30 \mathrm{~Hz}: 4$ & 0.348 & $\begin{array}{c}\text { Standard } \\
\text { Deviation at } 30 \\
\mathrm{~Hz}: 4\end{array}$ & 0.00151 & Mean at $30 \mathrm{~Hz}: 4$ & 0.348 & $\begin{array}{c}\text { Standard } \\
\text { Deviation at } 30 \\
\mathrm{~Hz}: 4\end{array}$ & 0.00138 & Mean at $30 \mathrm{~Hz}: 4$ & 0.348 \\
\hline $\begin{array}{c}\text { Standard } \\
\text { Deviation at } 60 \\
\mathrm{~Hz}: 1\end{array}$ & 0.00534 & Mean at $60 \mathrm{~Hz}: 1$ & 0.403 & $\begin{array}{c}\text { Standard } \\
\text { Deviation at } 60 \\
\mathrm{~Hz}: 1\end{array}$ & 0.00539 & Mean at $60 \mathrm{~Hz}: 1$ & 0.400 & $\begin{array}{c}\text { Standard } \\
\text { Deviation at } 60 \\
\mathrm{~Hz}: 1\end{array}$ & 0.00466 & Mean at $60 \mathrm{~Hz}: 1$ & 0.404 \\
\hline $\begin{array}{c}\text { Standard } \\
\text { Deviation at } 60 \\
\text { Hz:2 }\end{array}$ & 0.00561 & Mean at $60 \mathrm{~Hz}: 2$ & 0.402 & $\begin{array}{c}\text { Standard } \\
\text { Deviation at } 60 \\
\mathrm{~Hz}: 2\end{array}$ & 0.00562 & Mean at $60 \mathrm{~Hz}: 2$ & 0.400 & $\begin{array}{c}\text { Standard } \\
\text { Deviation at } 60 \\
\text { Hz:2 }\end{array}$ & 0.00532 & Mean at $60 \mathrm{~Hz}: 2$ & 0.402 \\
\hline $\begin{array}{c}\text { Standard } \\
\text { Deviation at } 60 \\
\mathrm{~Hz}: 3\end{array}$ & 0.00524 & Mean at $60 \mathrm{~Hz}: 3$ & 0.404 & $\begin{array}{c}\text { Standard } \\
\text { Deviation at } 60 \\
\mathrm{~Hz}: 3\end{array}$ & 0.00558 & Mean at $60 \mathrm{~Hz}: 3$ & 0.403 & $\begin{array}{c}\text { Standard } \\
\text { Deviation at } 60 \\
\mathrm{~Hz}: 3\end{array}$ & 0.00481 & Mean at $60 \mathrm{~Hz}: 3$ & 0.402 \\
\hline $\begin{array}{c}\text { Standard } \\
\text { Deviation at } 60 \\
\mathrm{~Hz}: 4\end{array}$ & 0.005383 & Mean at $60 \mathrm{~Hz}: 4$ & 0.403 & $\begin{array}{c}\text { Standard } \\
\text { Deviation at } 60 \\
\text { Hz:4 }\end{array}$ & 0.00566 & Mean at $60 \mathrm{~Hz}: 4$ & 0.401 & $\begin{array}{c}\text { Standard } \\
\text { Deviation at } 60 \\
\mathrm{~Hz}: 4\end{array}$ & 0.00498 & Mean at $60 \mathrm{~Hz}: 4$ & 0.403 \\
\hline $\begin{array}{c}\text { Standard } \\
\text { Deviation at } 0 \mathrm{~Hz} \\
\text { Final }\end{array}$ & 0.000760 & $\begin{array}{c}\text { Mean at } 0 \mathrm{~Hz} \\
\text { Final }\end{array}$ & 0.328 & $\begin{array}{c}\text { Standard } \\
\text { Deviation at } \mathrm{O} \mathrm{Hz} \\
\text { Final }\end{array}$ & 0.000747 & $\begin{array}{c}\text { Mean at } 0 \mathrm{~Hz} \\
\text { Final }\end{array}$ & 0.328 & $\begin{array}{c}\text { Standard } \\
\text { Deviation at } 0 \mathrm{~Hz} \\
\text { Final }\end{array}$ & 0.000752 & $\begin{array}{c}\text { Mean at } 0 \mathrm{~Hz} \\
\text { Final }\end{array}$ & 0.328 \\
\hline
\end{tabular}
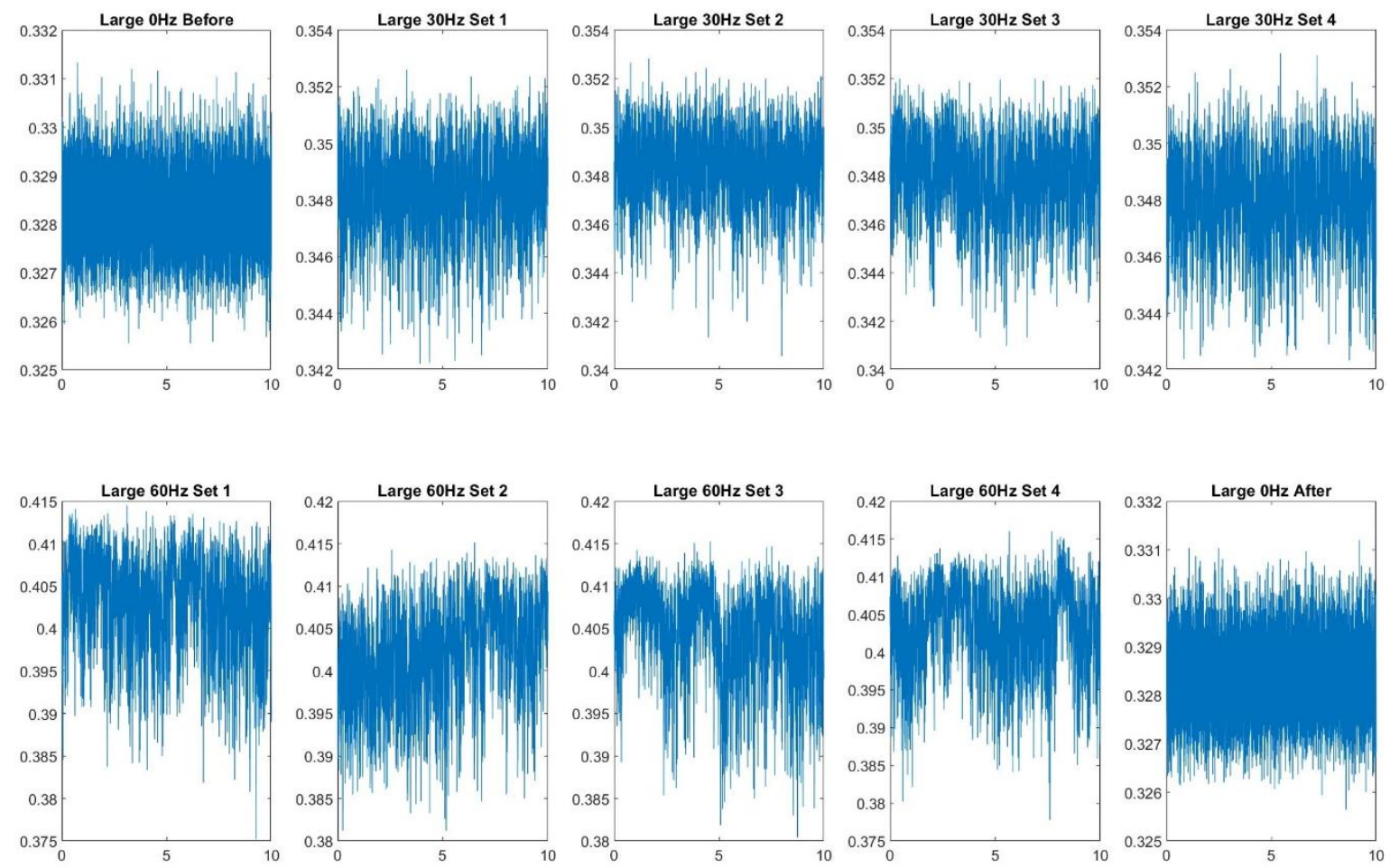

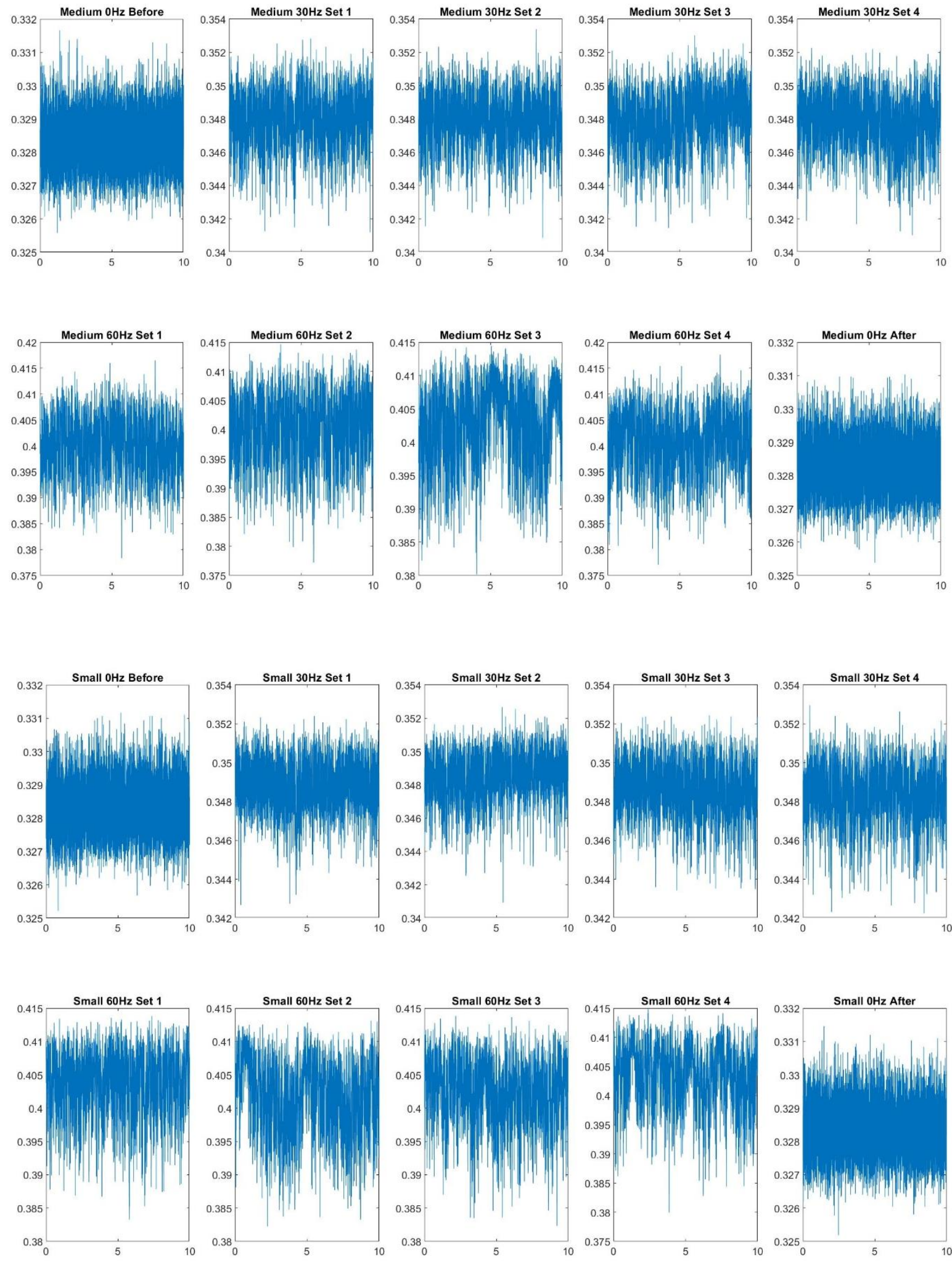
Appendix B: Grid Design

D
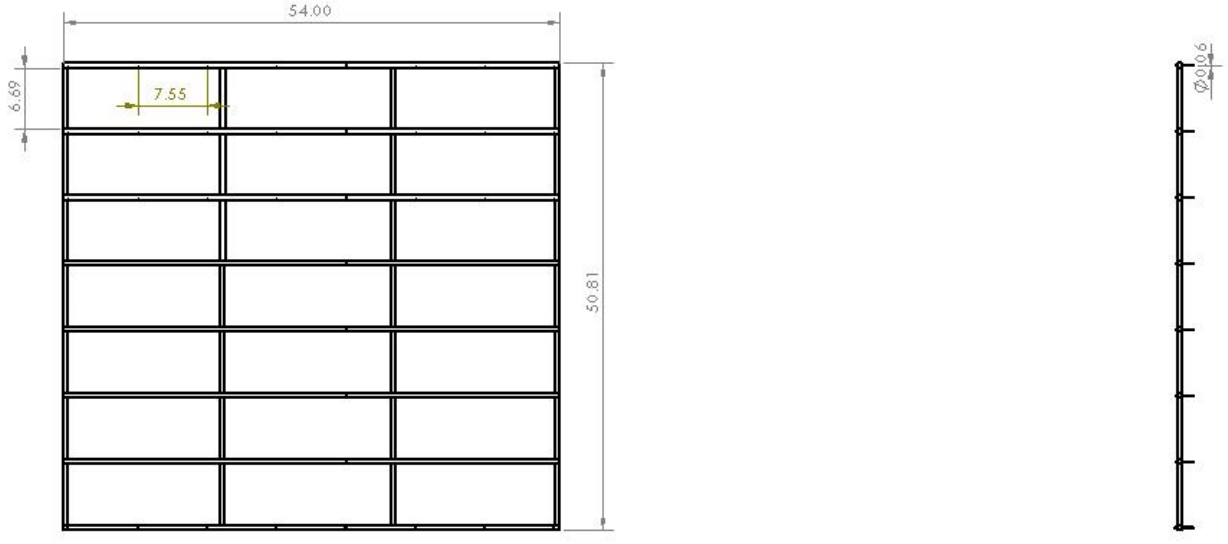

C

B
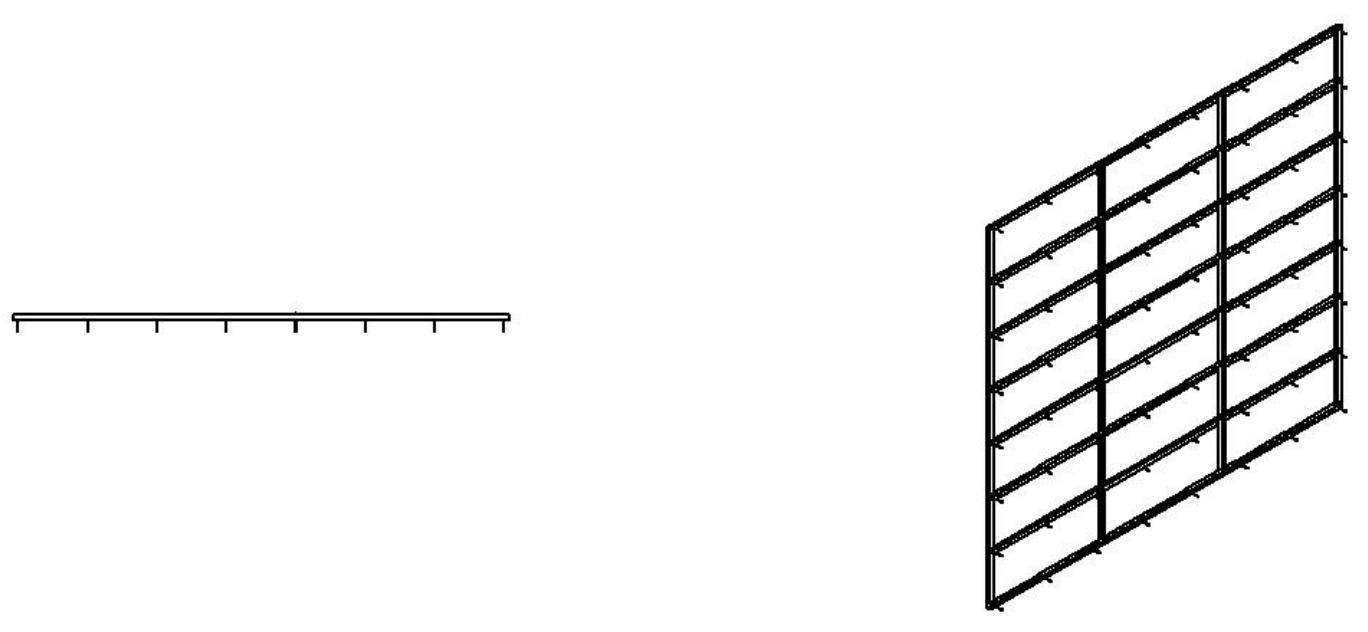
2

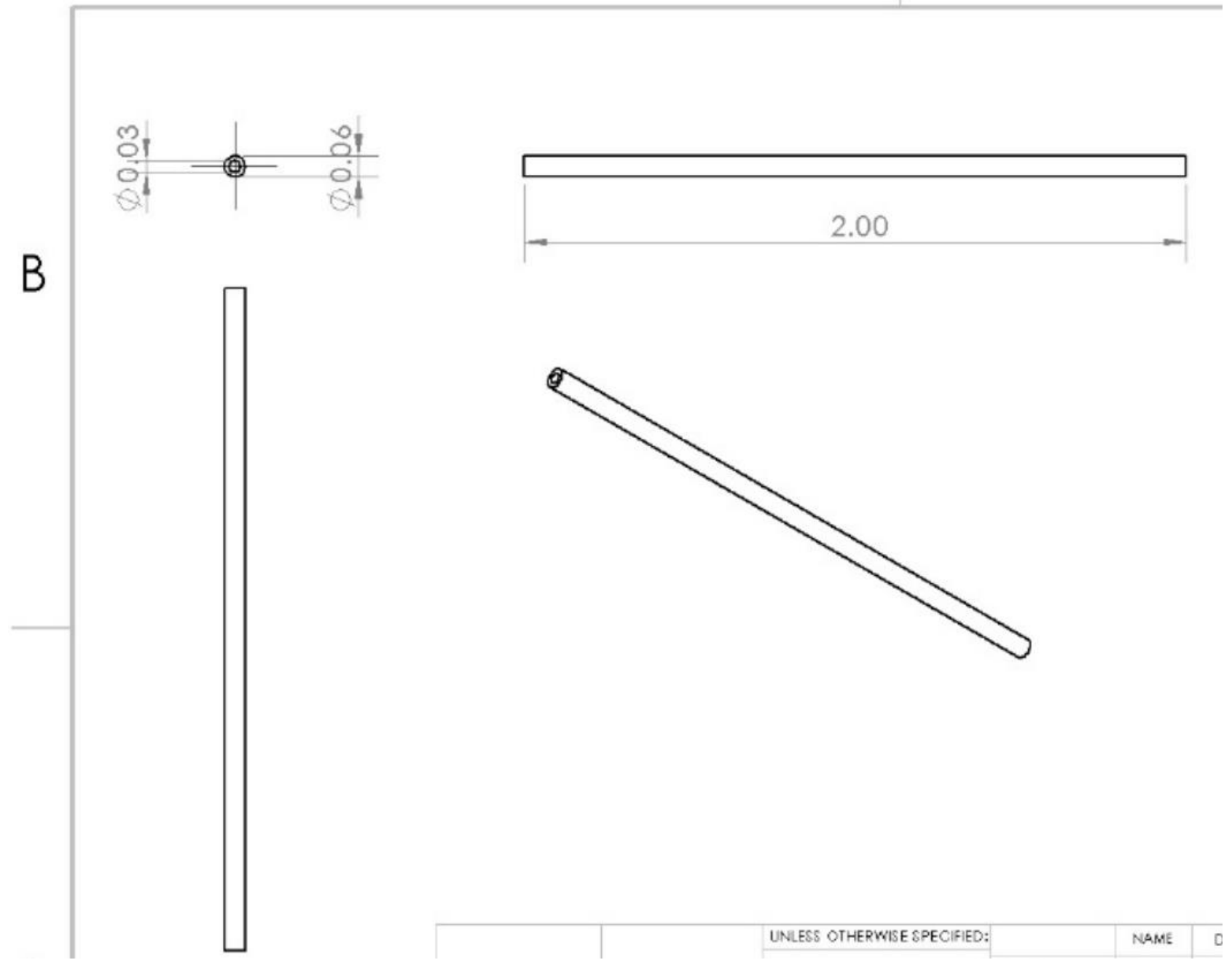




\section{Appendix C: Calibration Code and Curves}

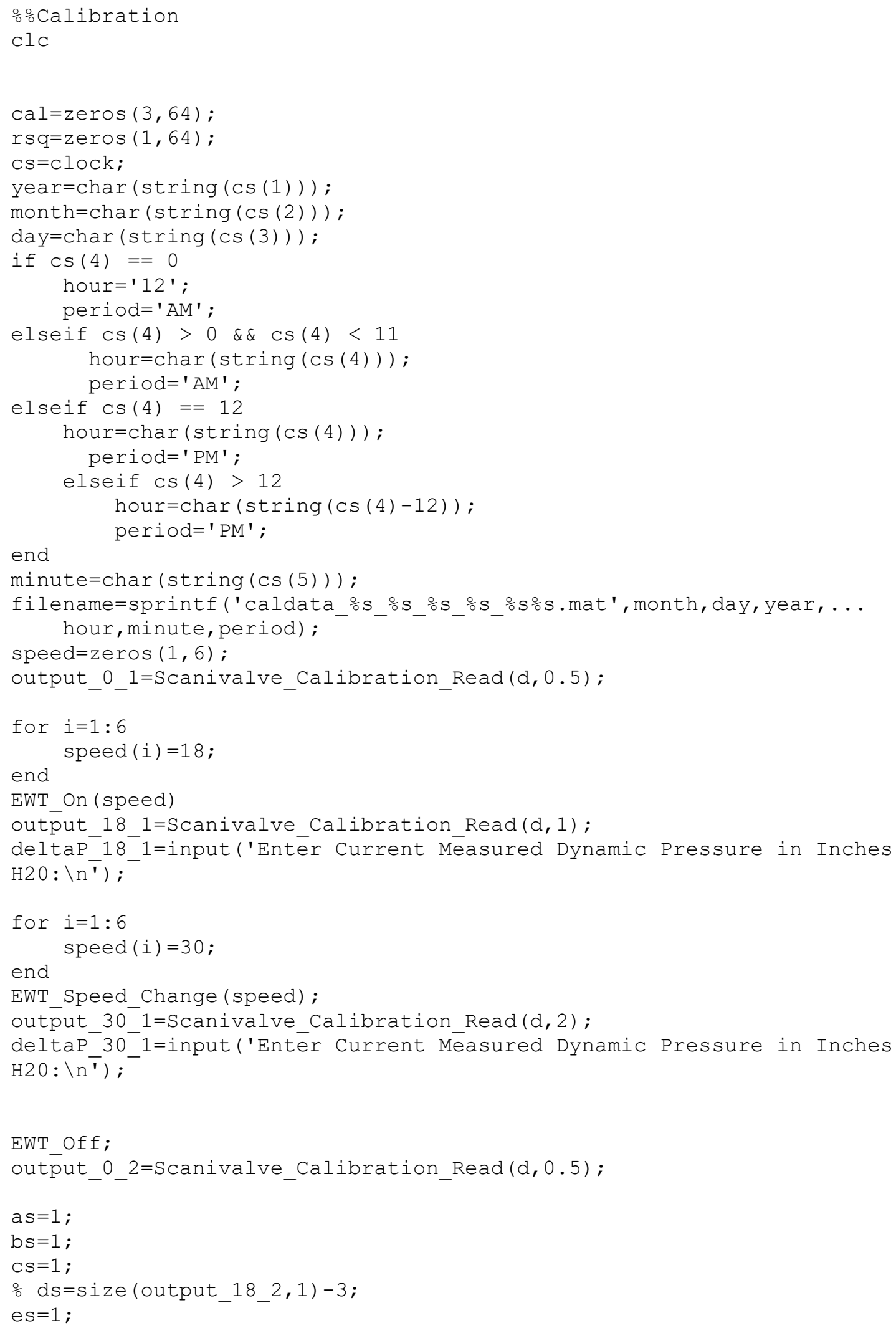




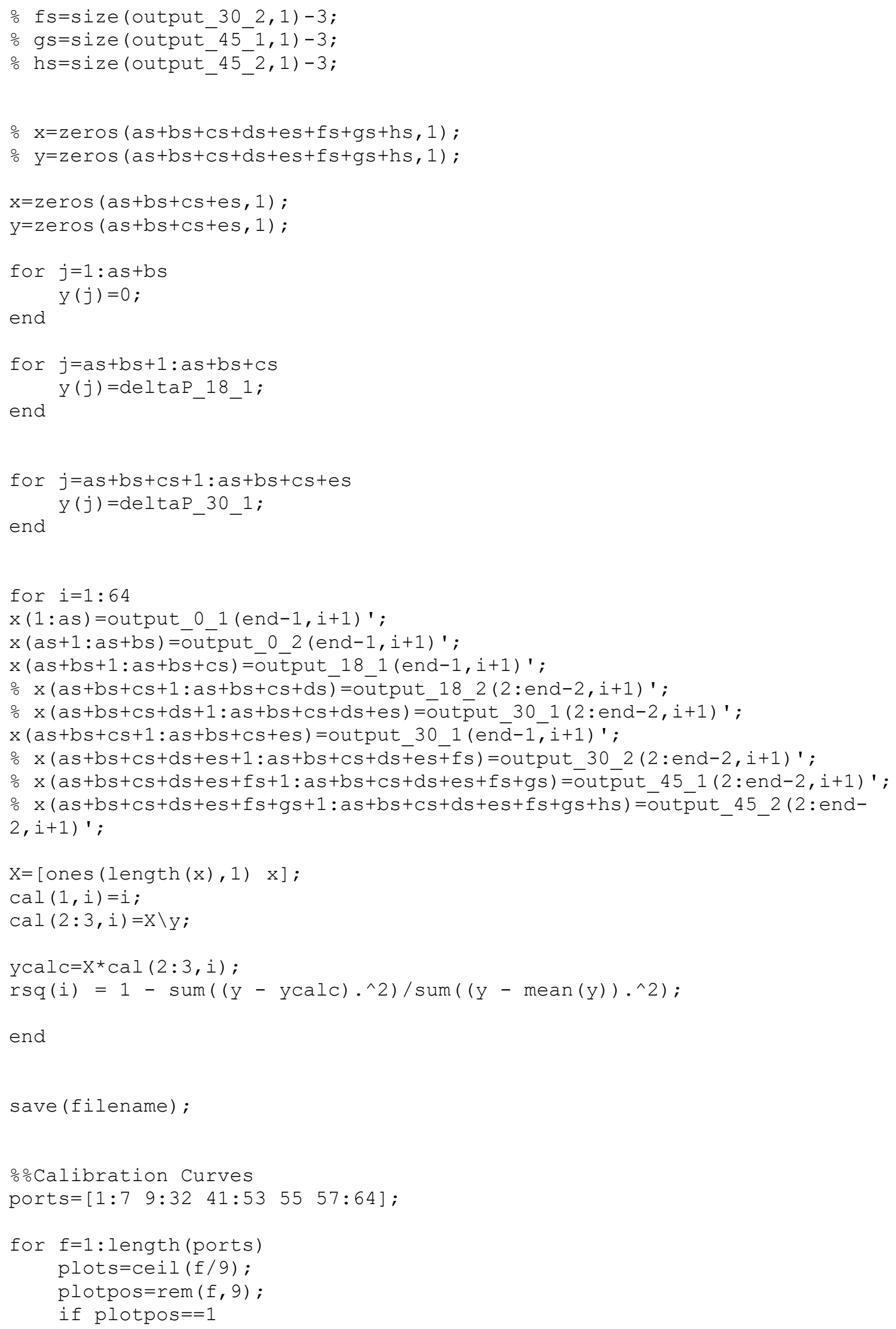




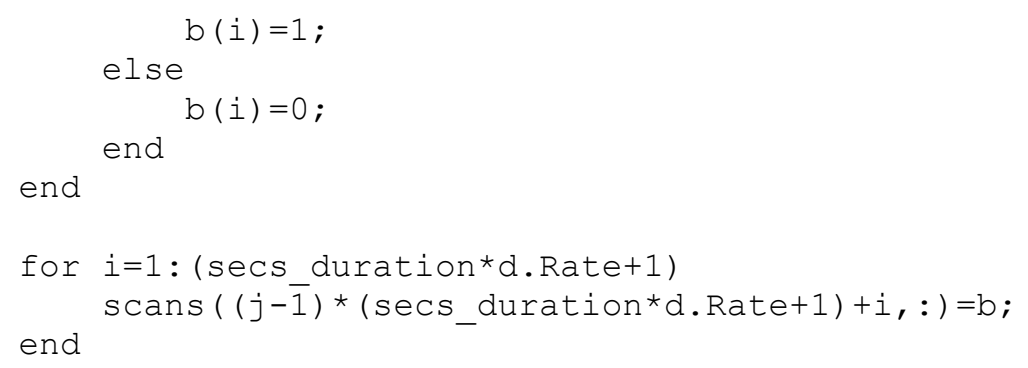

end 


\section{Day 1 Calibration Curves}
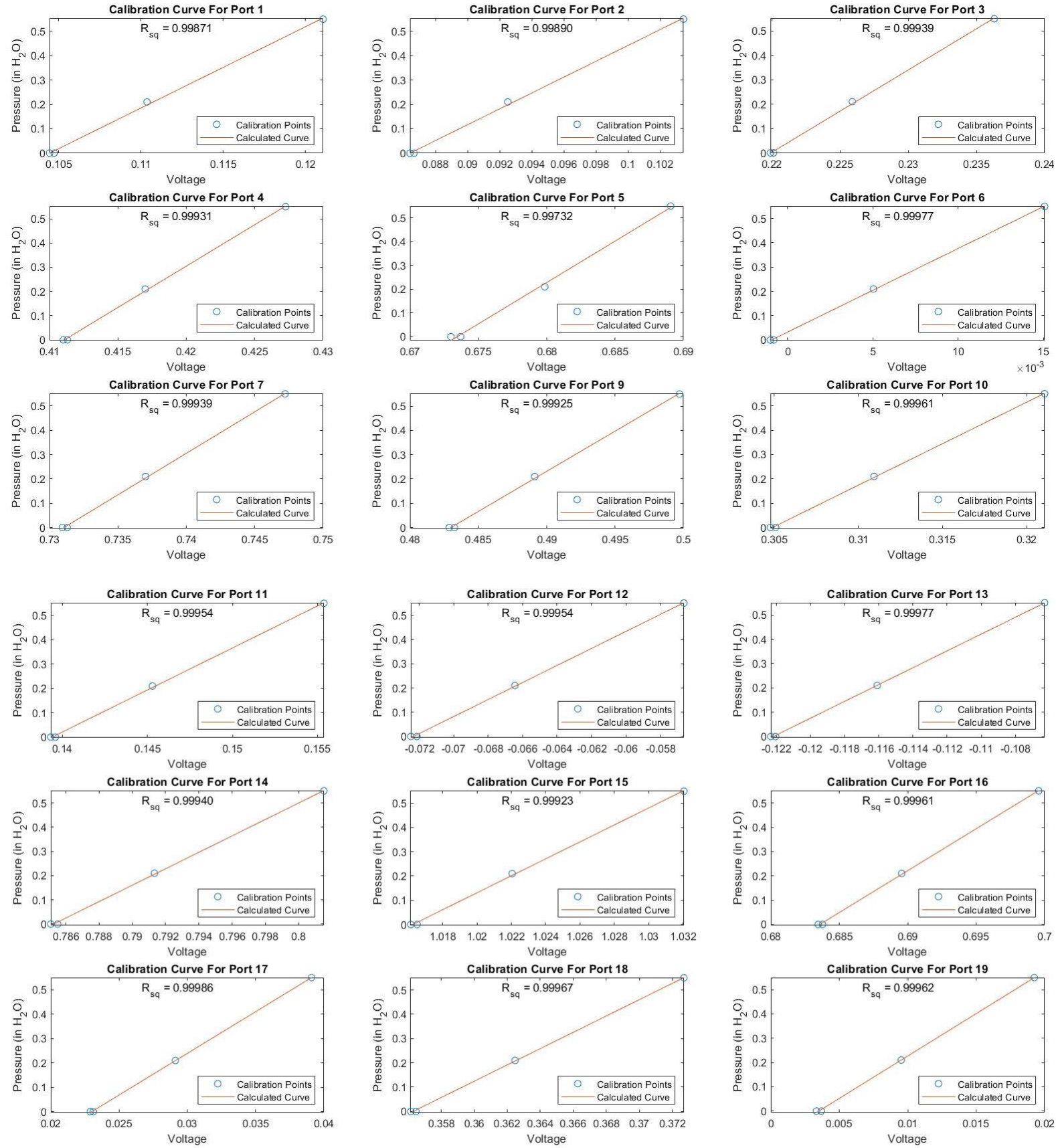

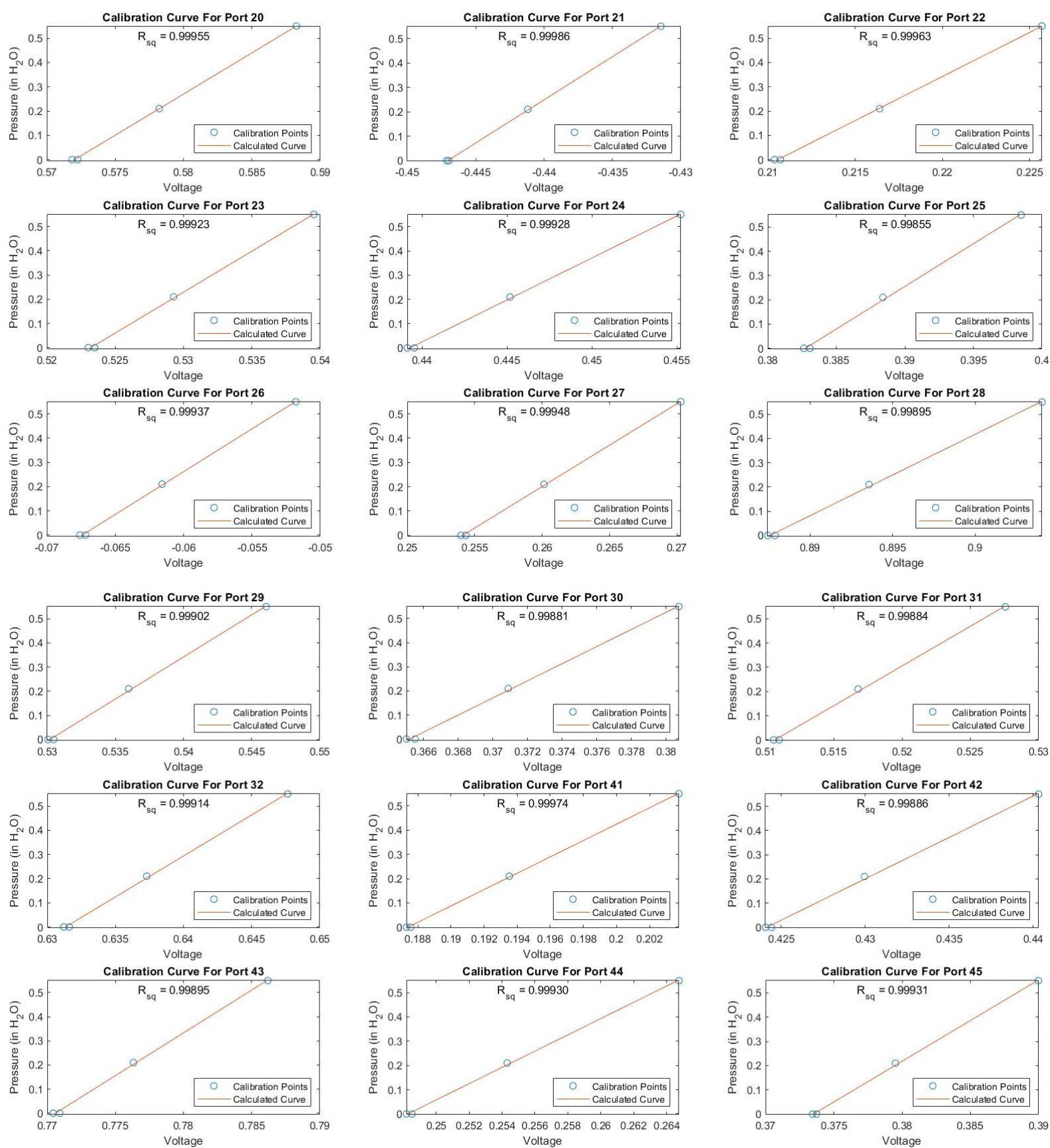

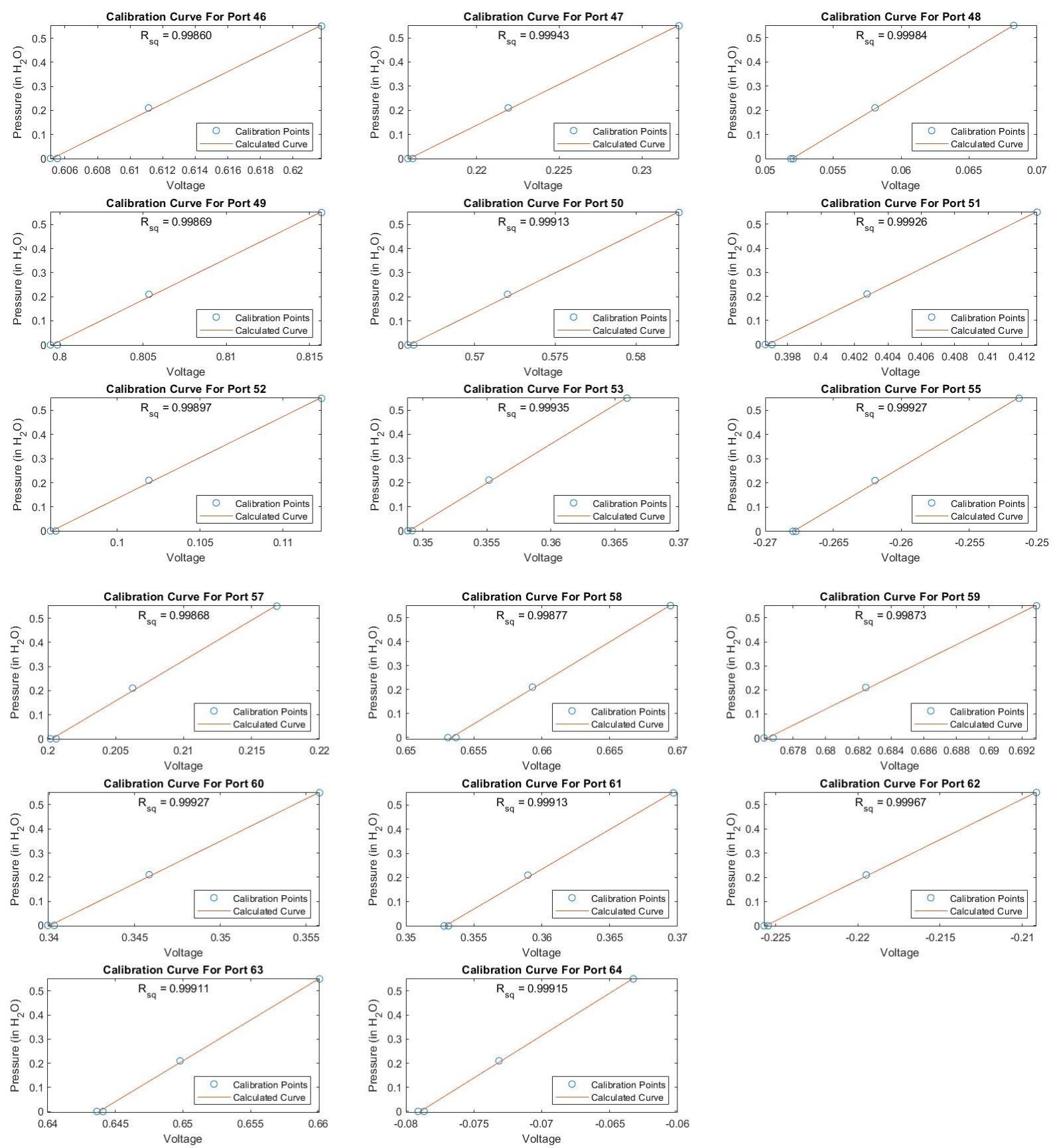


\section{Day 2 Calibration Curves}
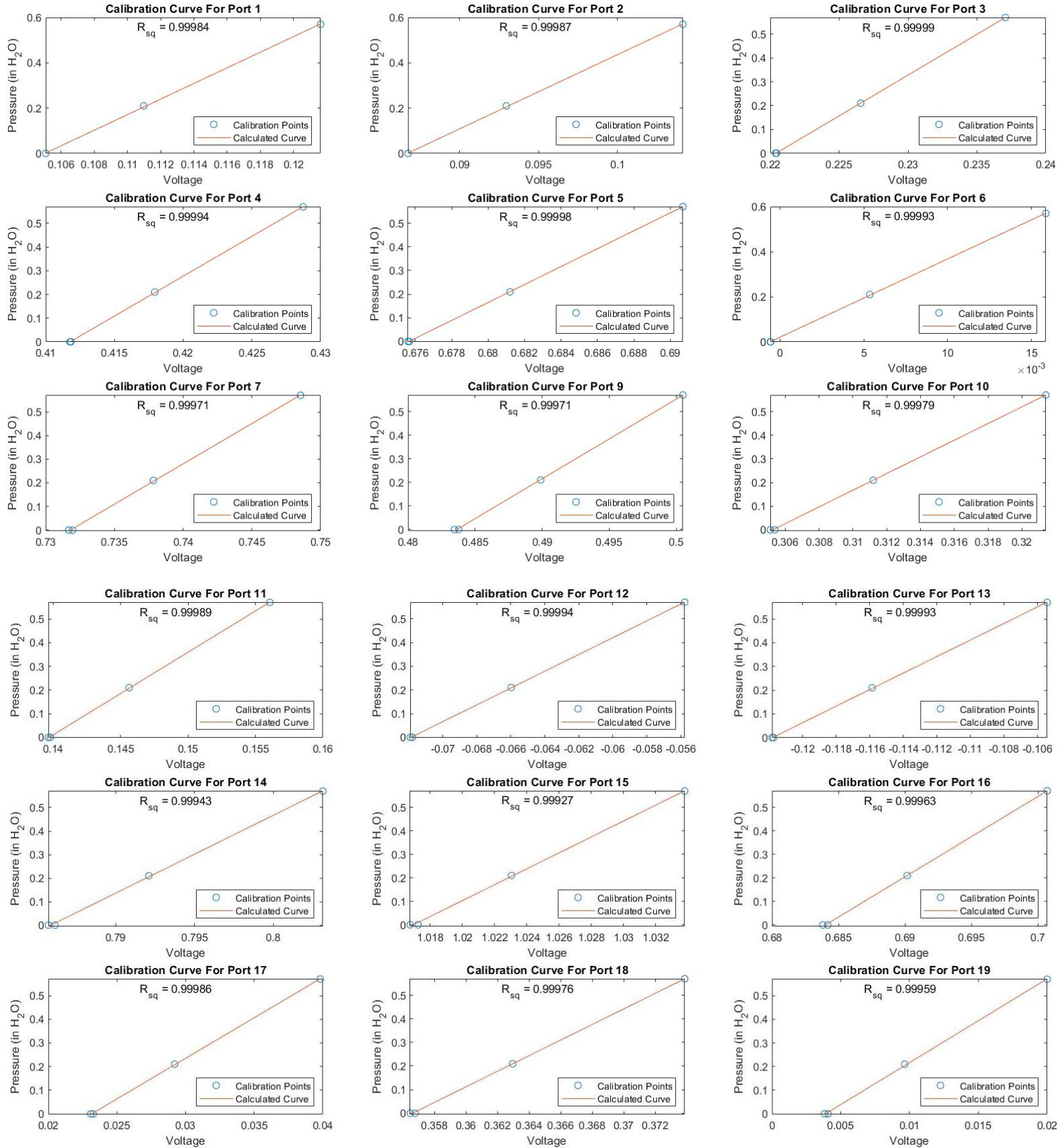

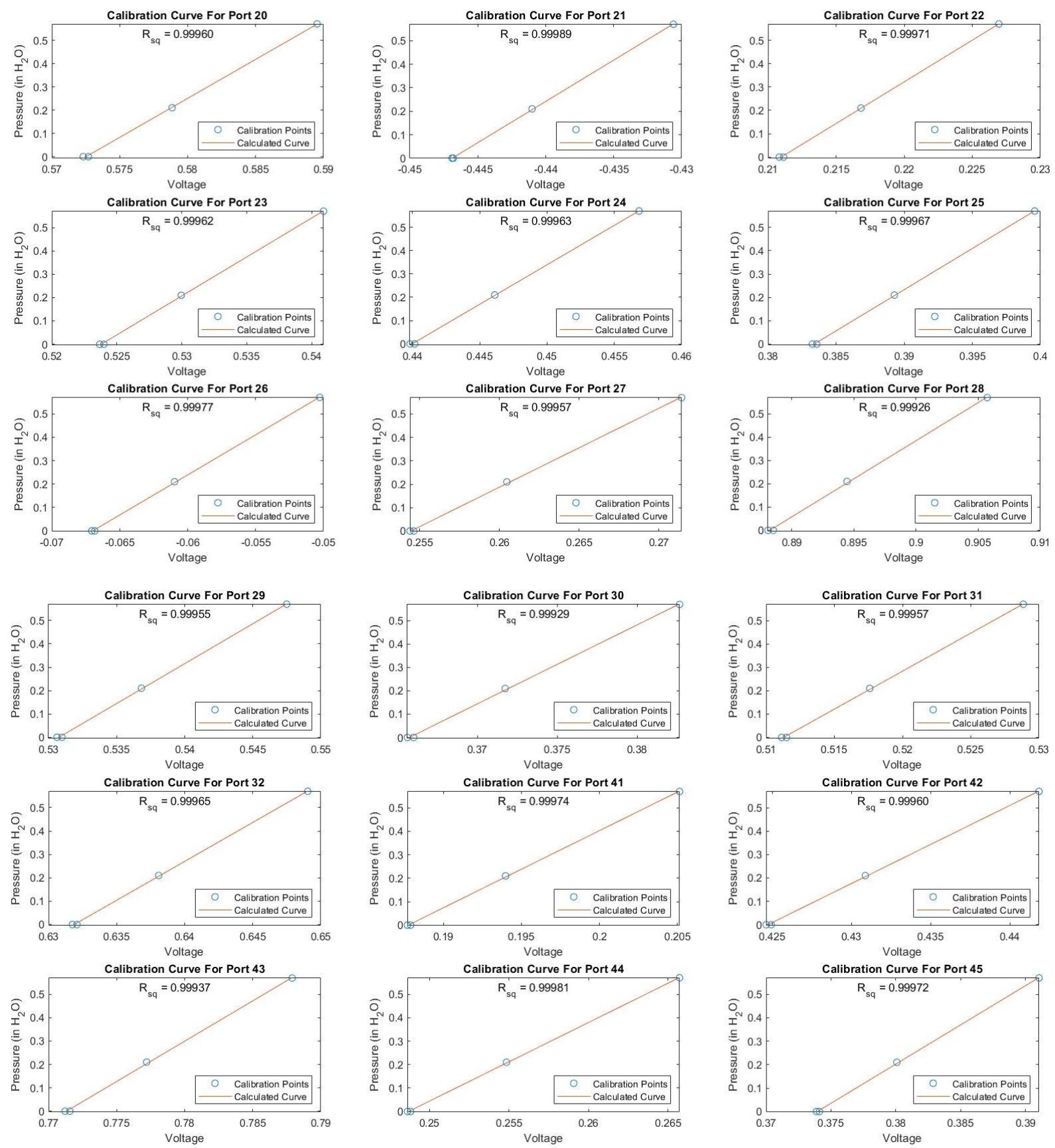

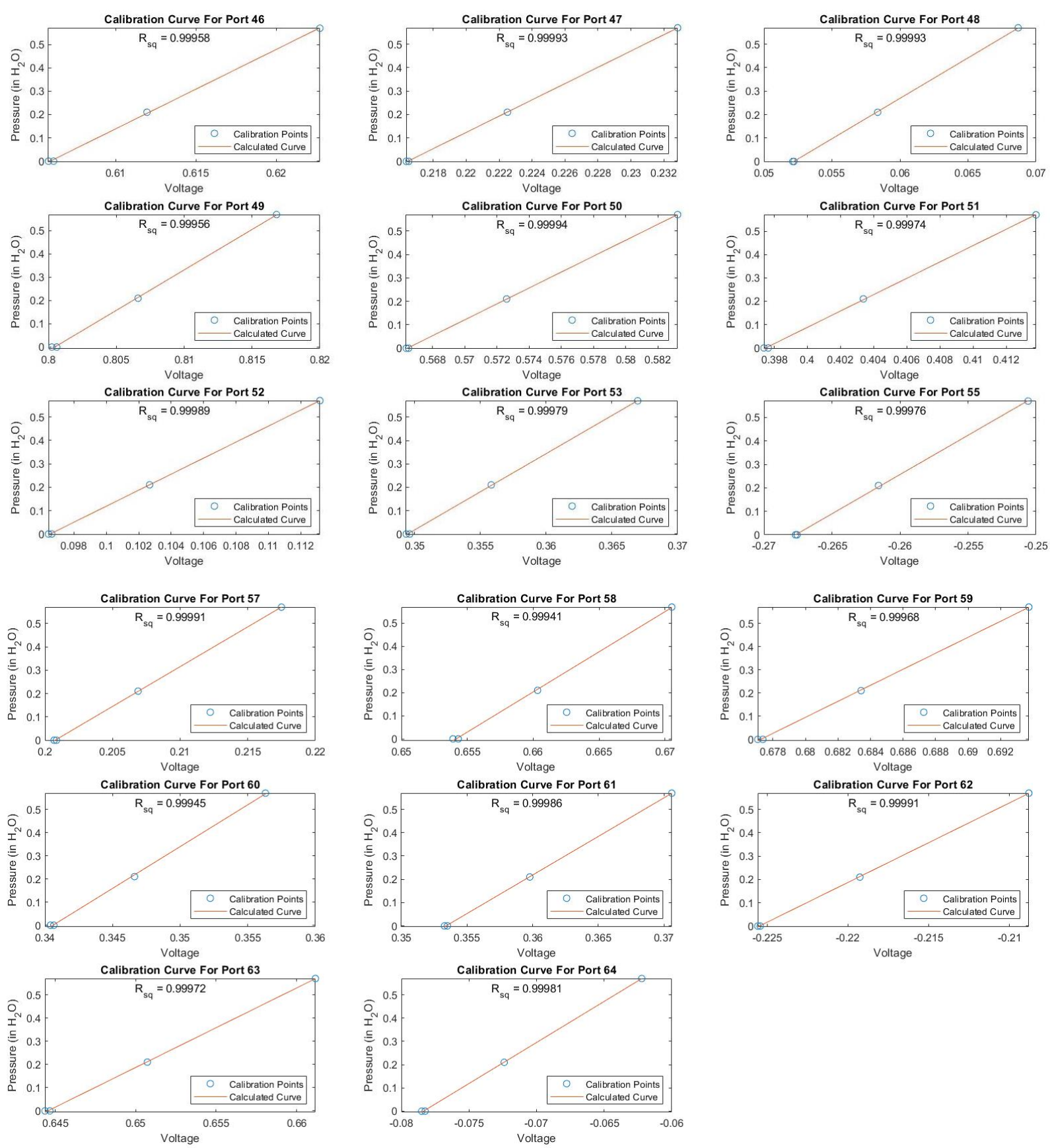


\section{Day 3 Calibration Curves}
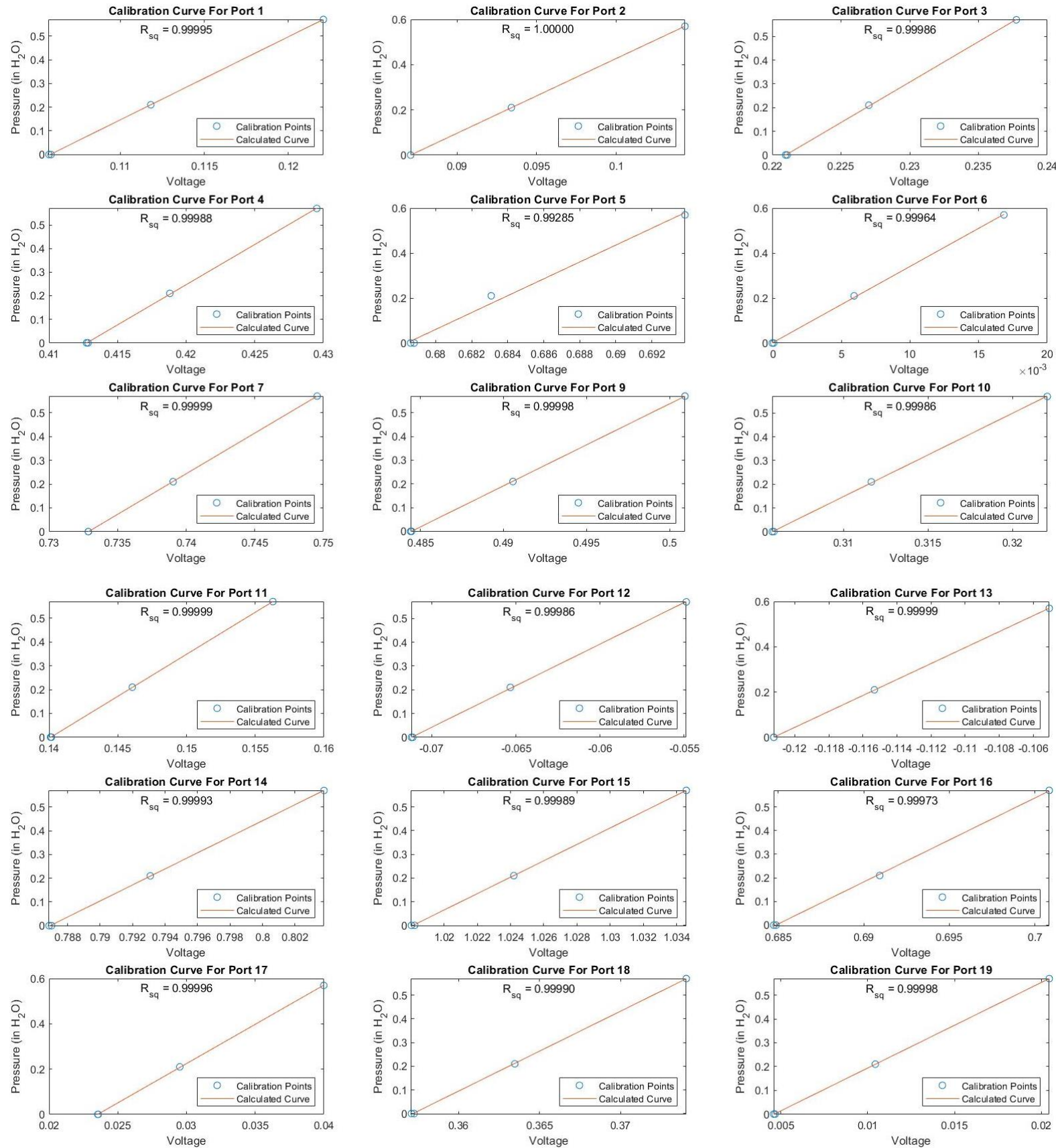

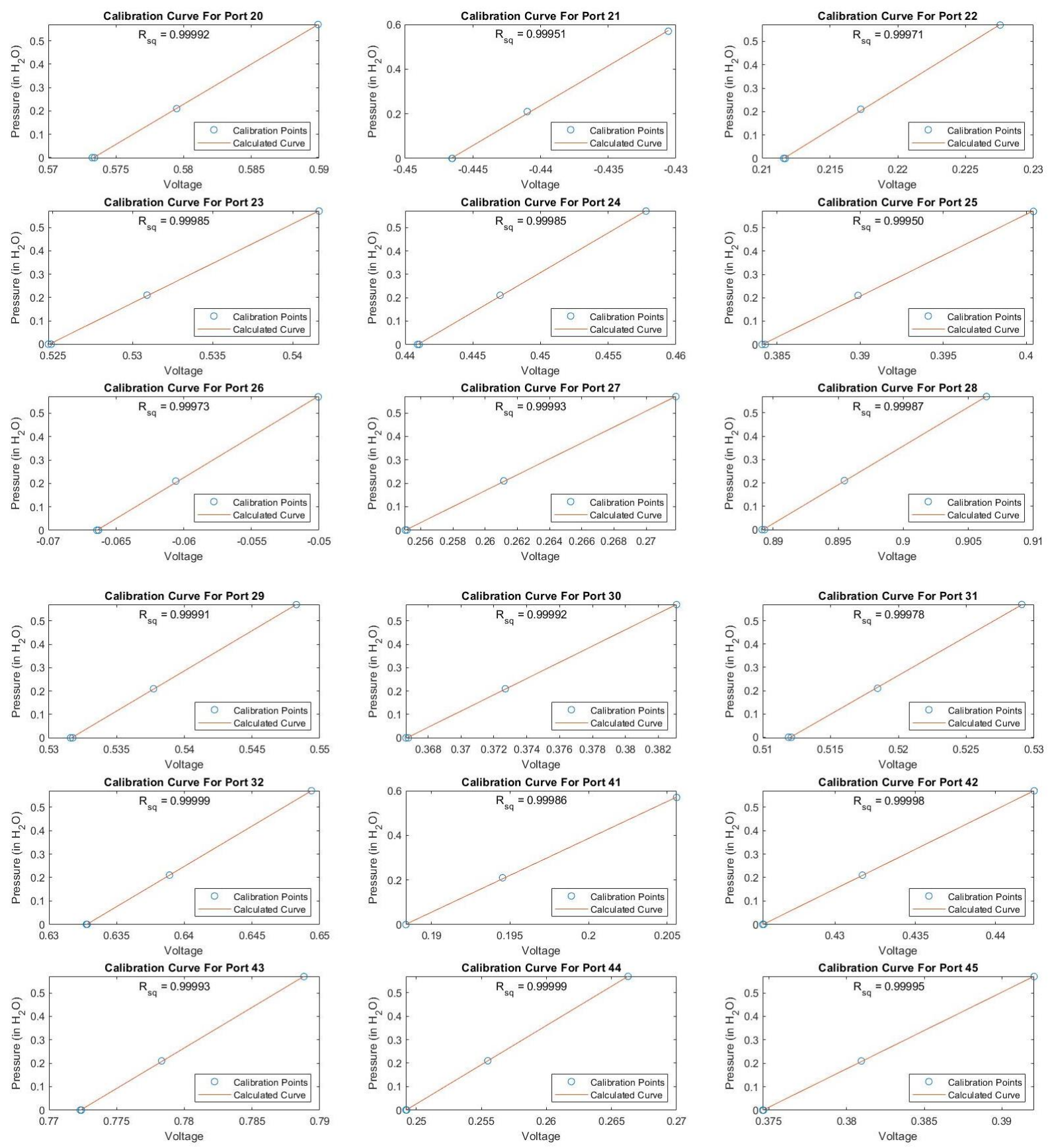

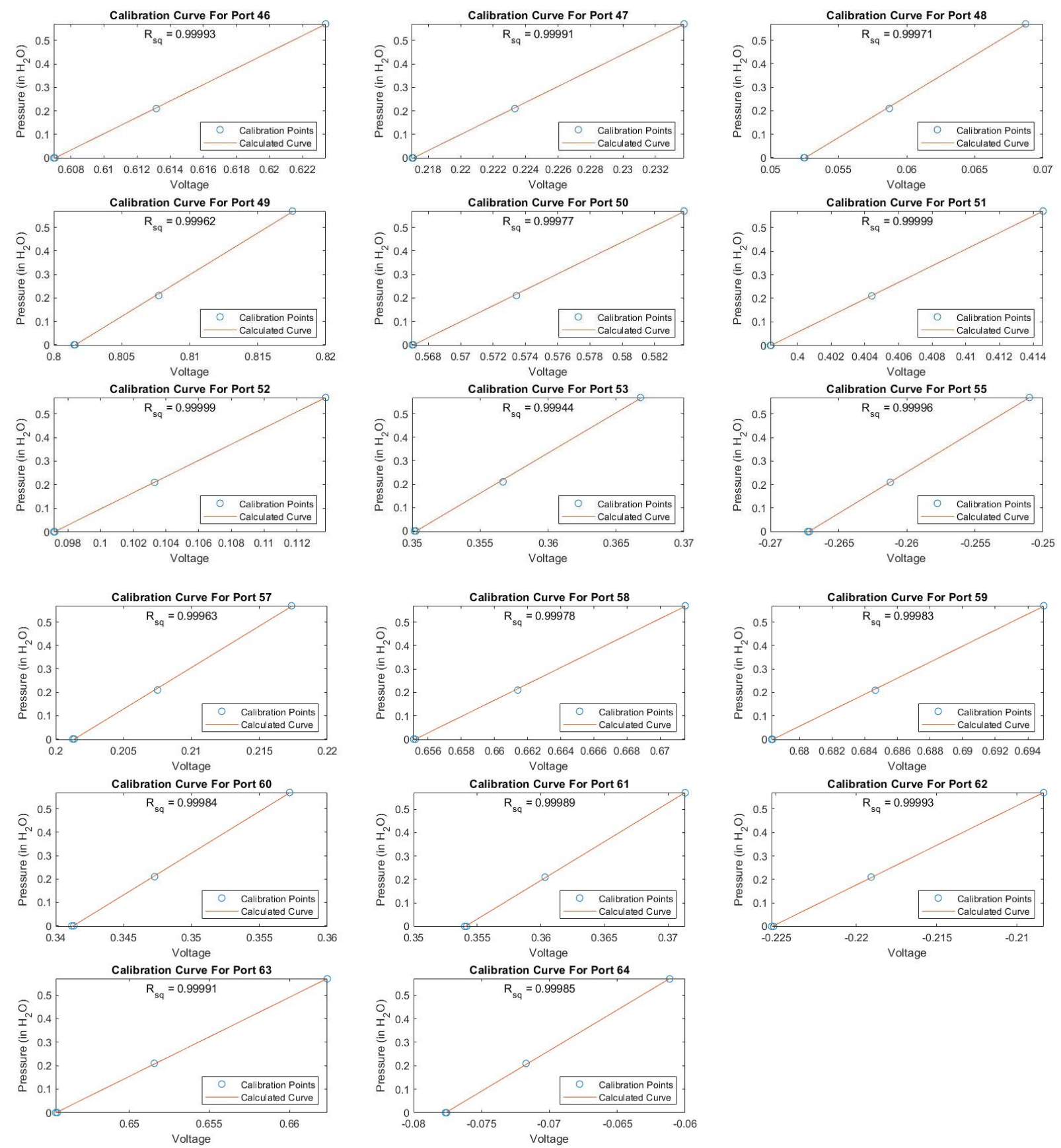


\section{Day 4 Calibration Curve}
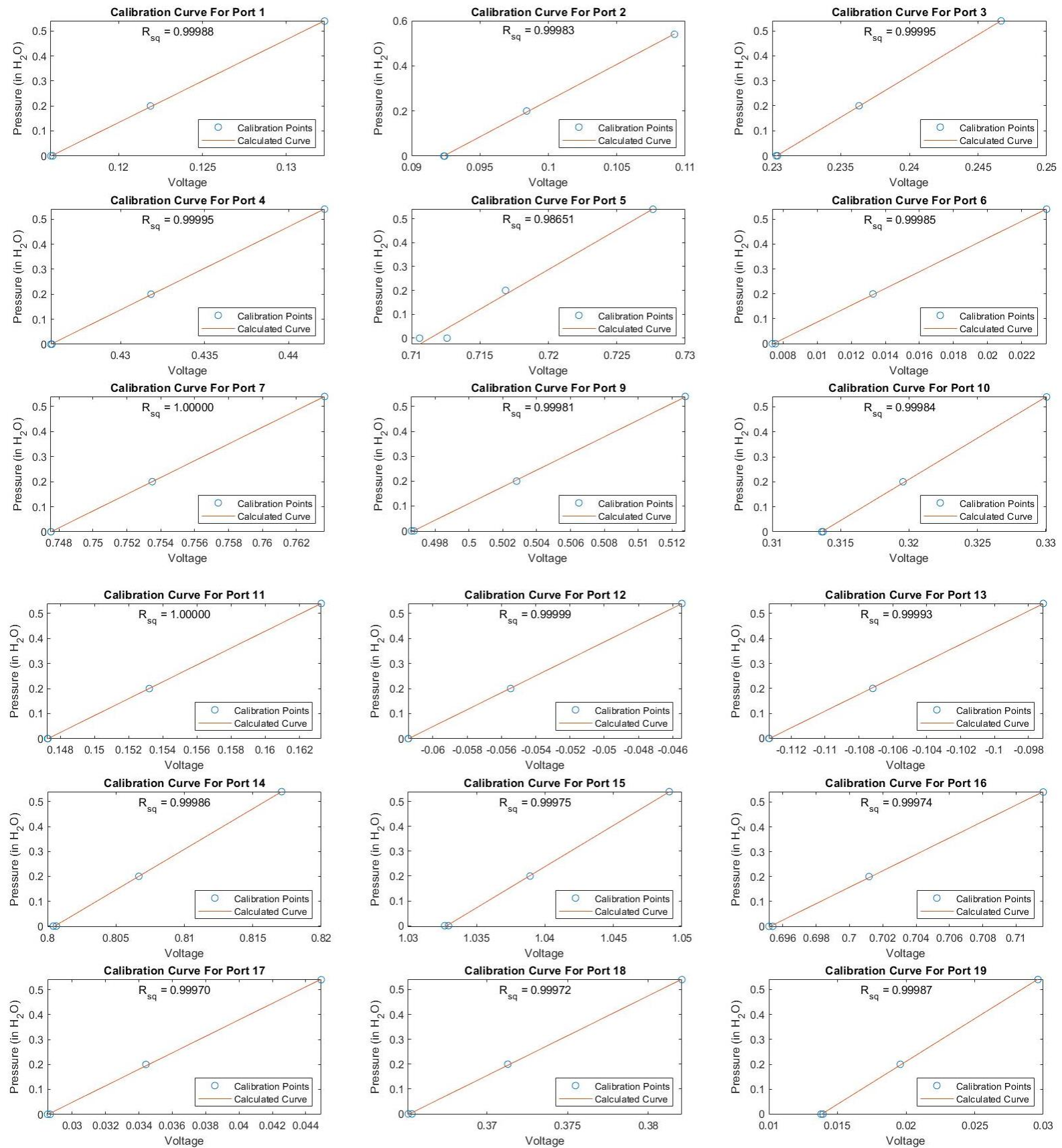

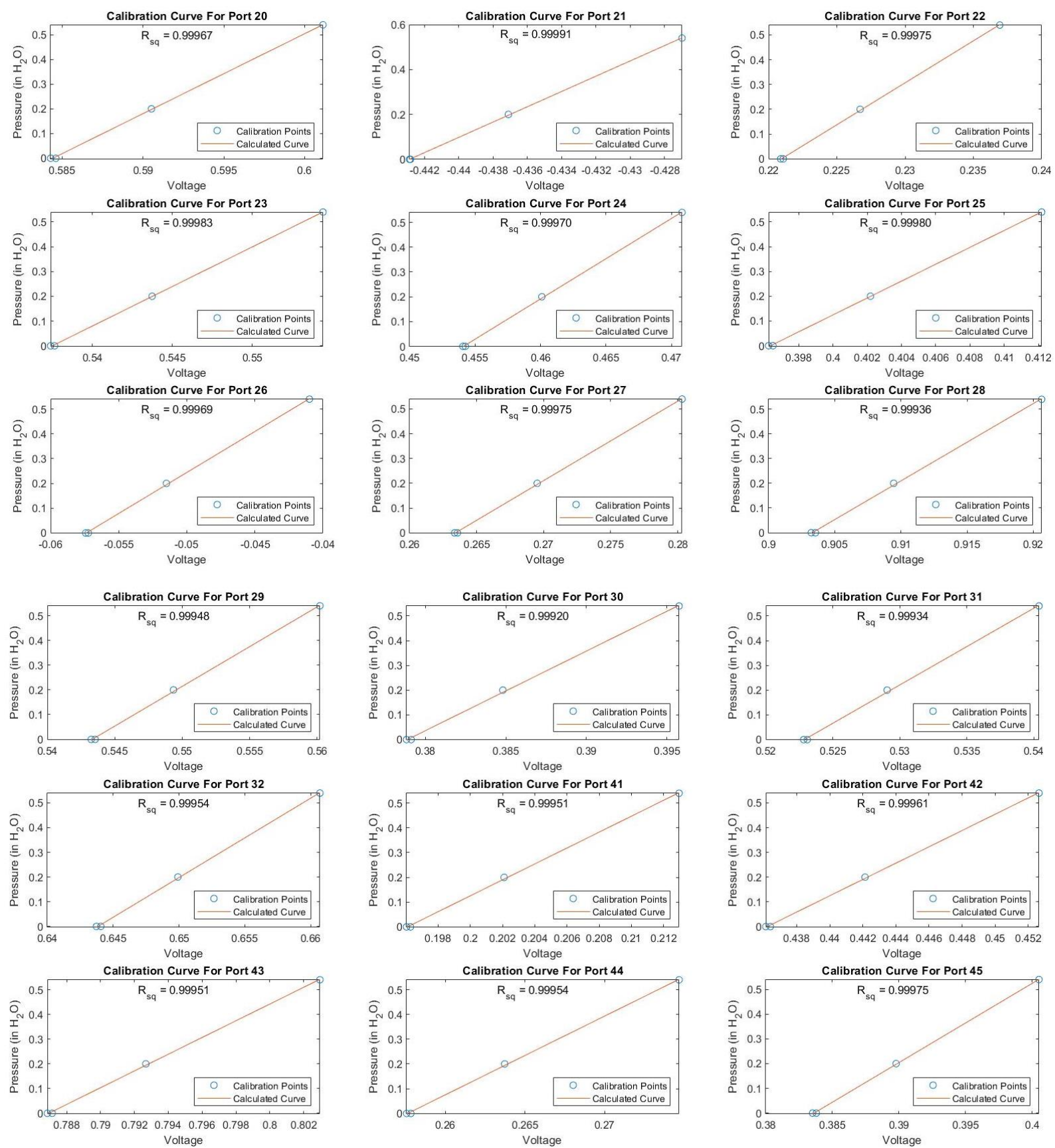

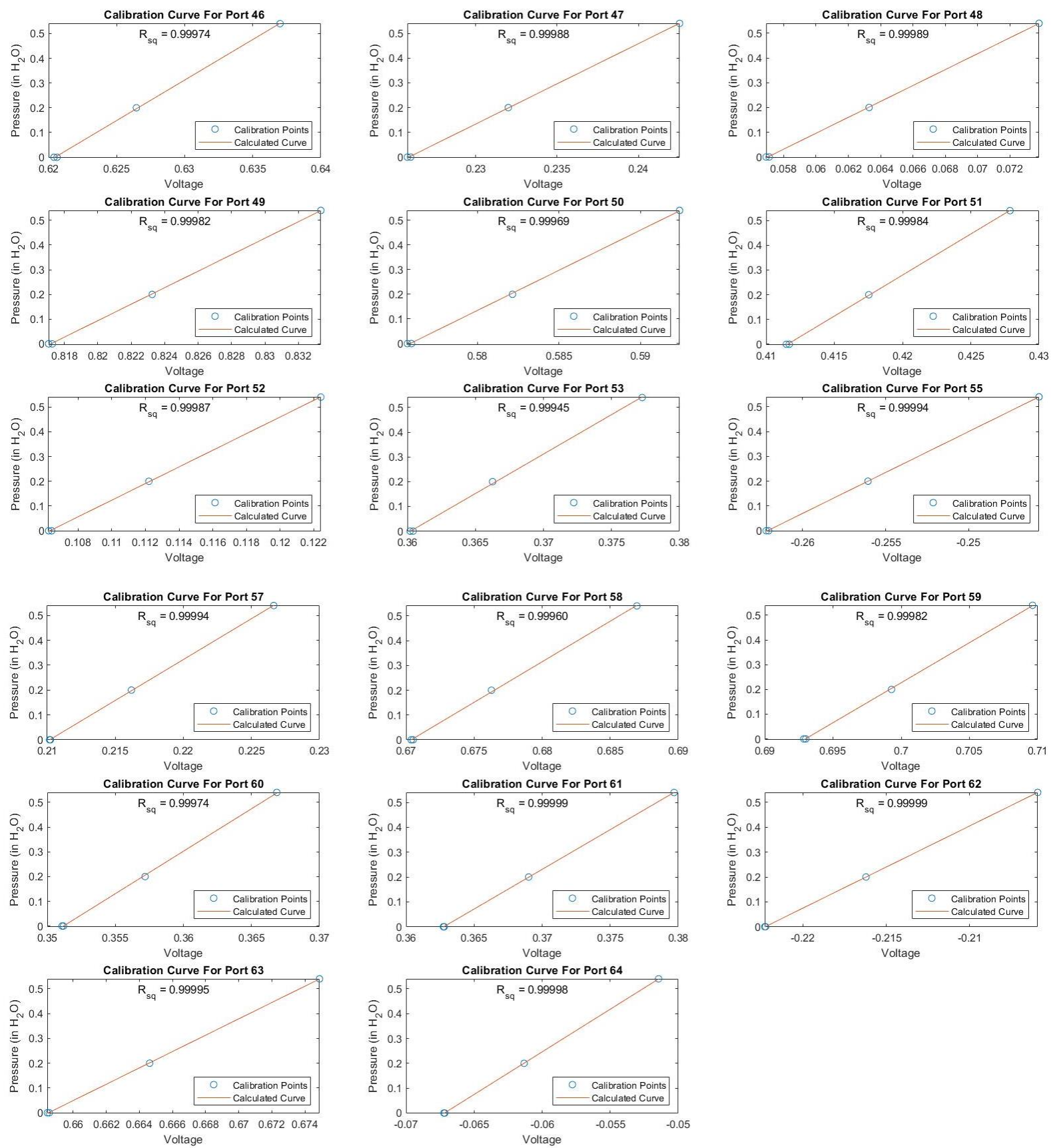


\section{Appendix D: DAQ Initialization and Configuration Code}

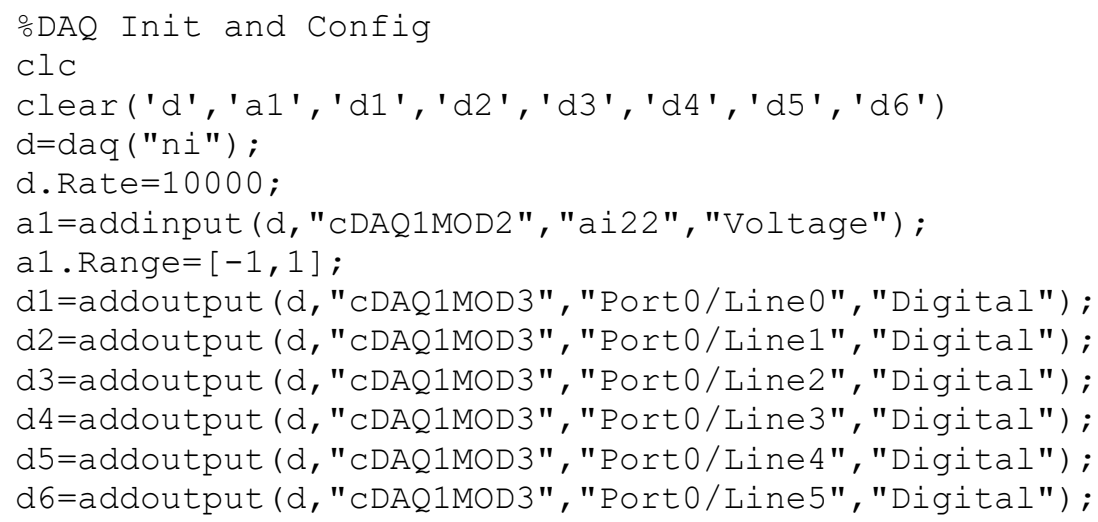




\section{Appendix E: Parts for Control Board and Scanivalve Control}

\begin{tabular}{|c|c|c|}
\hline Manufacturer & Part Number & Description \\
\hline Weidmüller & 1842320000 & $\begin{array}{l}2 \text { Position Terminal Block Header, } \\
\text { Male Pins, Shrouded (4 Side) 0.138" } \\
\text { (3.50mm) Vertical - Through Hole }\end{array}$ \\
\hline Weidmüller & 1842360000 & Position Terminal Block \\
\hline Weidmüller & 1615670000 & TERM BLOCK PLUG 2POS STR 3.5MM \\
\hline Weidmüller & 1610180000 & $\begin{array}{c}6 \text { Position Terminal Block Plug, } \\
\text { Female Sockets 0.138" (3.50mm) - } \\
180^{\circ} \text { Free Hanging (In-Line) }\end{array}$ \\
\hline Stackpole Electronics Inc & RNF18FTD13K3 & $\begin{array}{l}\text { RES 13.3K OHM 1/8W 1\% AXIAL } \\
\pm 1 \% 0.125 \mathrm{~W}, 1 / 8 \mathrm{~W} \text { Through Hole } \\
\text { Resistor Axial Flame Retardant } \\
\text { Coating, Safety Metal Film }\end{array}$ \\
\hline Stackpole Electronics Inc & RNF18FTD3K32 & $\begin{array}{l}\text { RES 3.32K OHM 1/8W 1\% AXIAL } \\
\pm 1 \% 0.125 \mathrm{~W}, 1 / 8 \mathrm{~W} \text { Through Hole } \\
\text { Resistor Axial Flame Retardant } \\
\text { Coating, Safety Metal Film }\end{array}$ \\
\hline Everlight Electronics Co Ltd & HLMP-K150 & $\begin{array}{c}\text { Red - LED Indication - Discrete 1.6V } \\
\text { Radial }\end{array}$ \\
\hline AVX Corporation & SR215C104JAR & $\begin{array}{l}\text { CAP CER 0.1UF 50V X7R RADIAL } \pm 5 \% \\
\text { 50V Ceramic Capacitor X7R Radial }\end{array}$ \\
\hline TDK Corporation & FG18X7R1H334KRT06 & $\begin{array}{c}\text { CAP CER 0.33UF 50V X7R RADIAL } \\
\pm 10 \% \text { 50V Ceramic Capacitor X7R } \\
\text { Radial }\end{array}$ \\
\hline Texas Instruments & UA78L05ACLPM & $\begin{array}{l}\text { IC REG LINEAR 5V 100MA T092-3 } \\
\text { Linear Voltage Regulator IC Positive } \\
\text { Fixed Output 100mA TO-92-3 }\end{array}$ \\
\hline Texas Instruments & SN7407N & $\begin{array}{l}\text { IC BUF NON-INVERT 5.25V 14DIP } \\
\text { Buffer, Non-Inverting } 6 \text { Element } 1 \text { Bit } \\
\text { per Element Open Collector Output } \\
\text { 14-PDIP }\end{array}$ \\
\hline XP Power & DRC30US15 & $\begin{array}{c}\text { Enclosed AC DC Converters Output } \\
15 \mathrm{~V}-- \text { - 2A } 85 \sim 264 \text { VAC Input }\end{array}$ \\
\hline
\end{tabular}




\section{Appendix F: Stabilization Code}

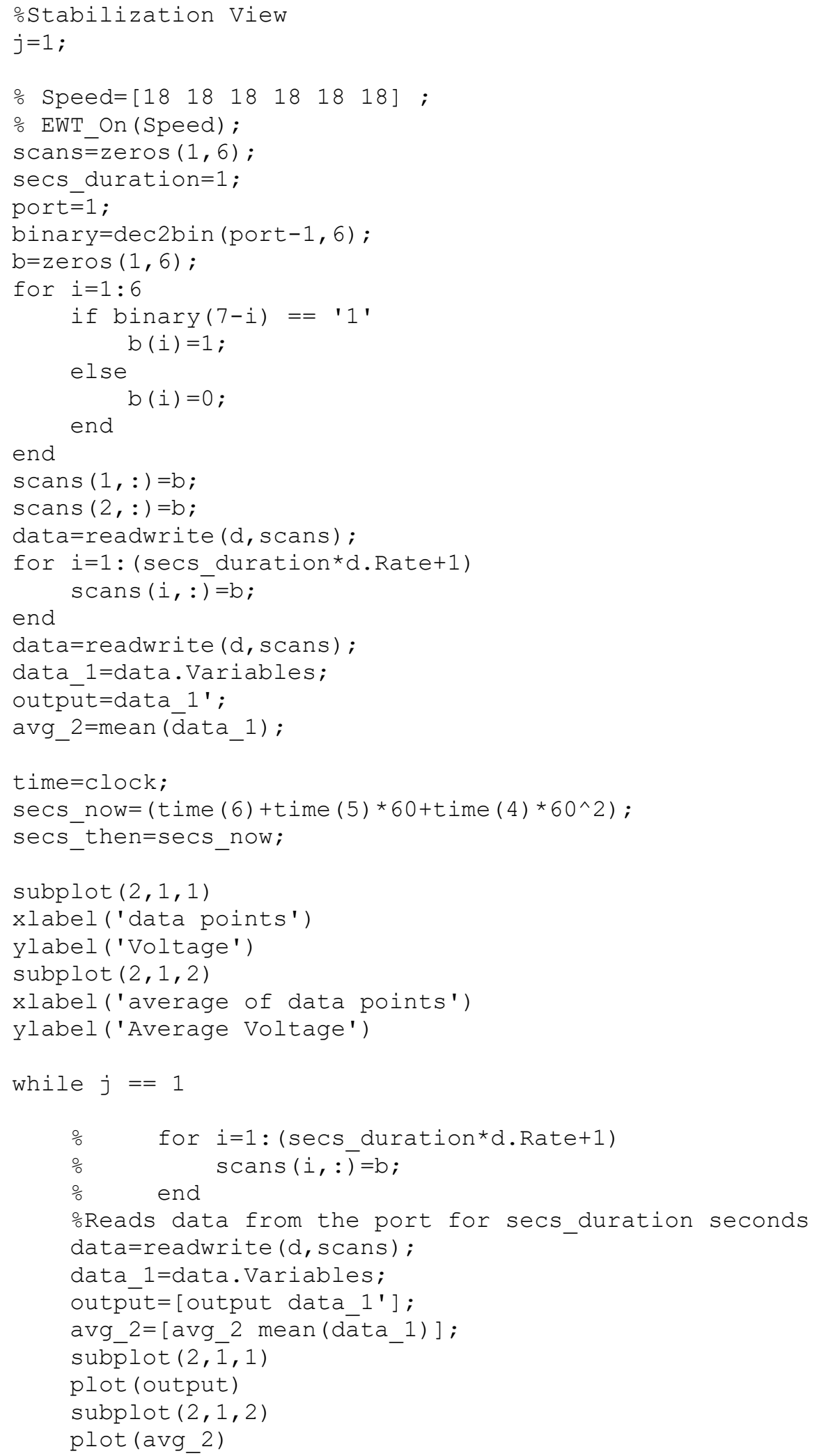




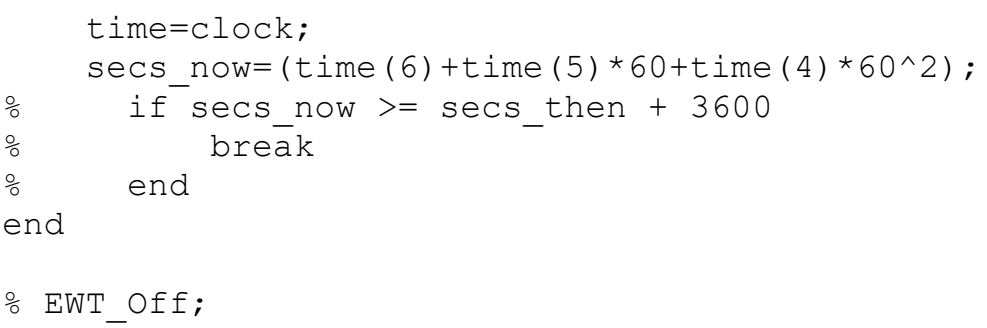




\section{Appendix G: Minimum Sample Time and Rate}

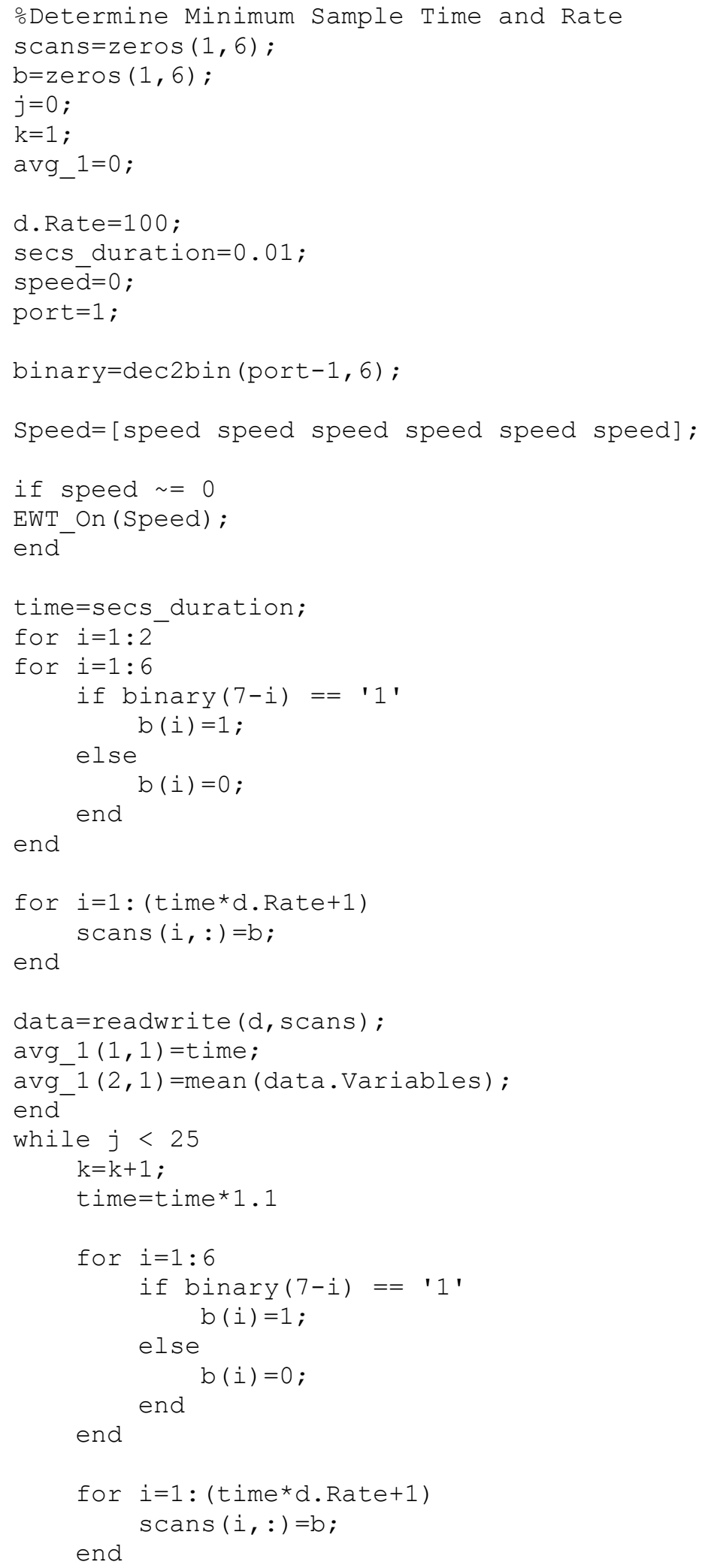




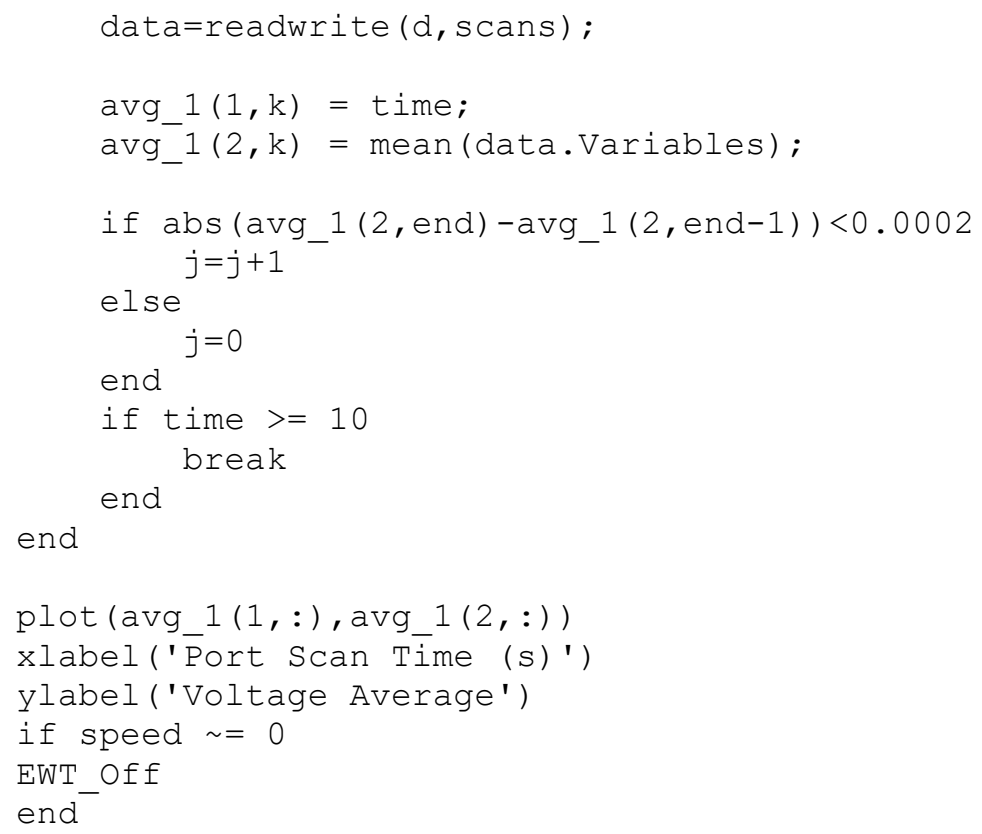




\section{Appendix H: Data Collect Function}

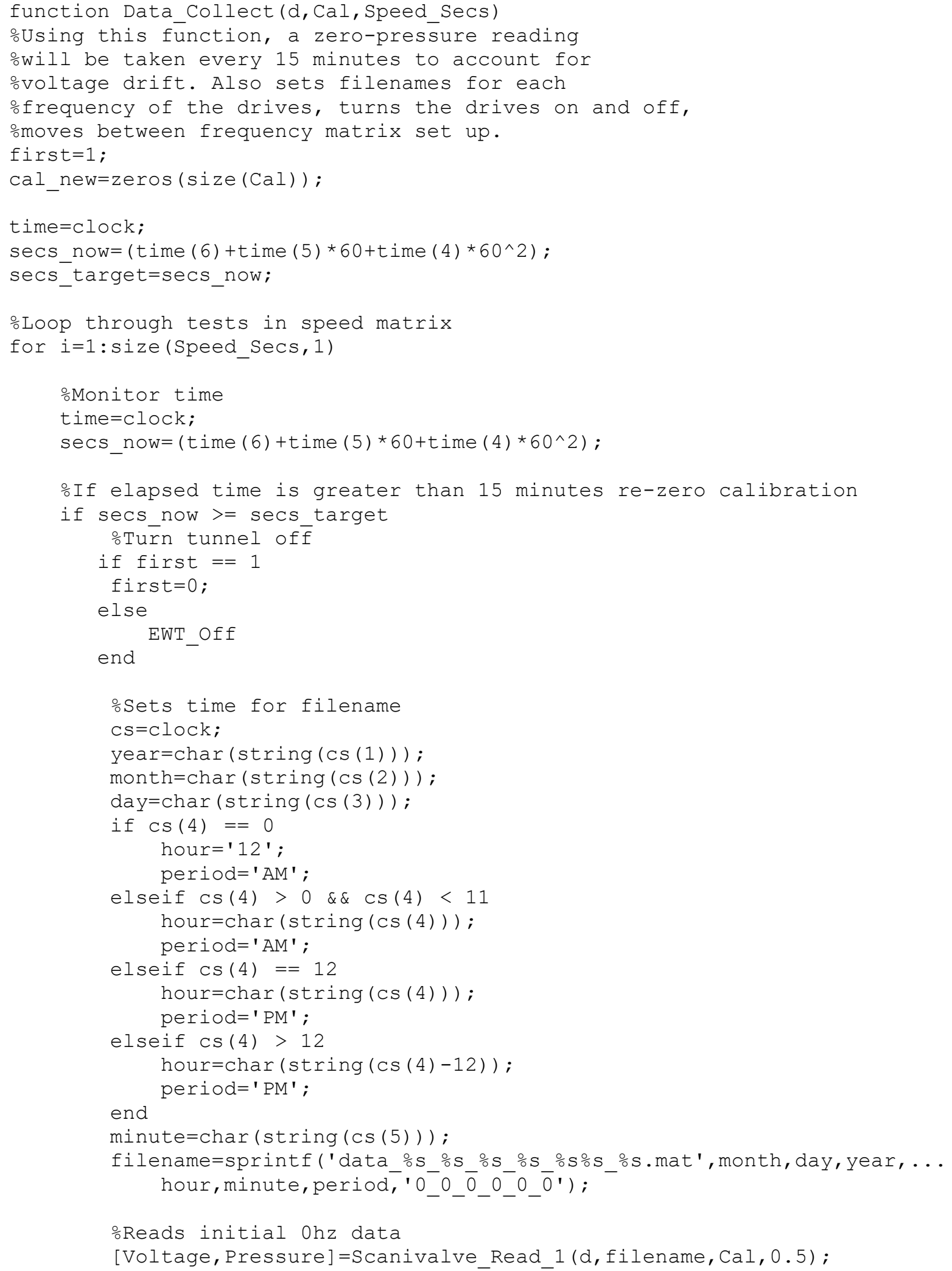




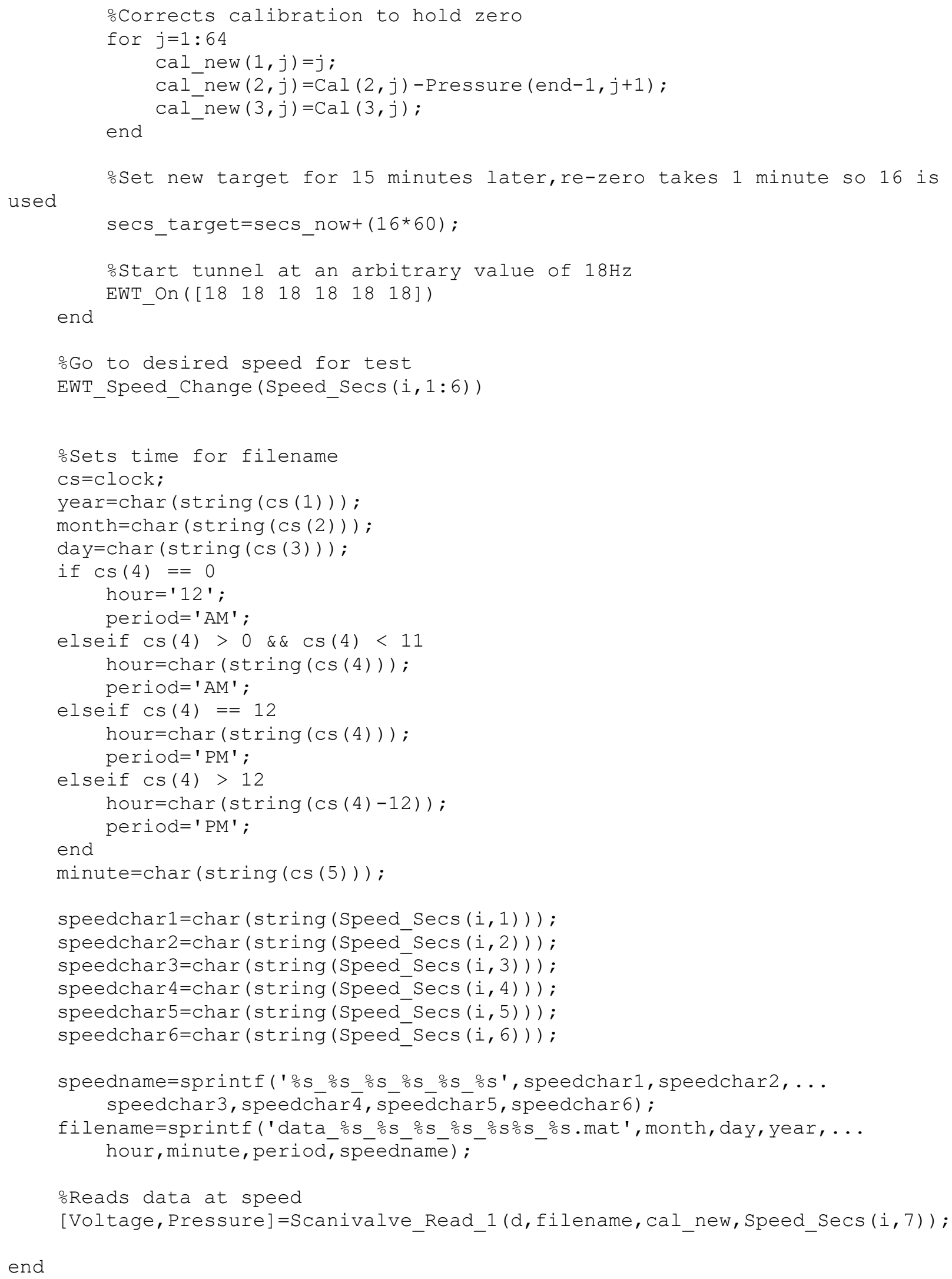


oTurn tunnel off to conclude test

EWT Off

end

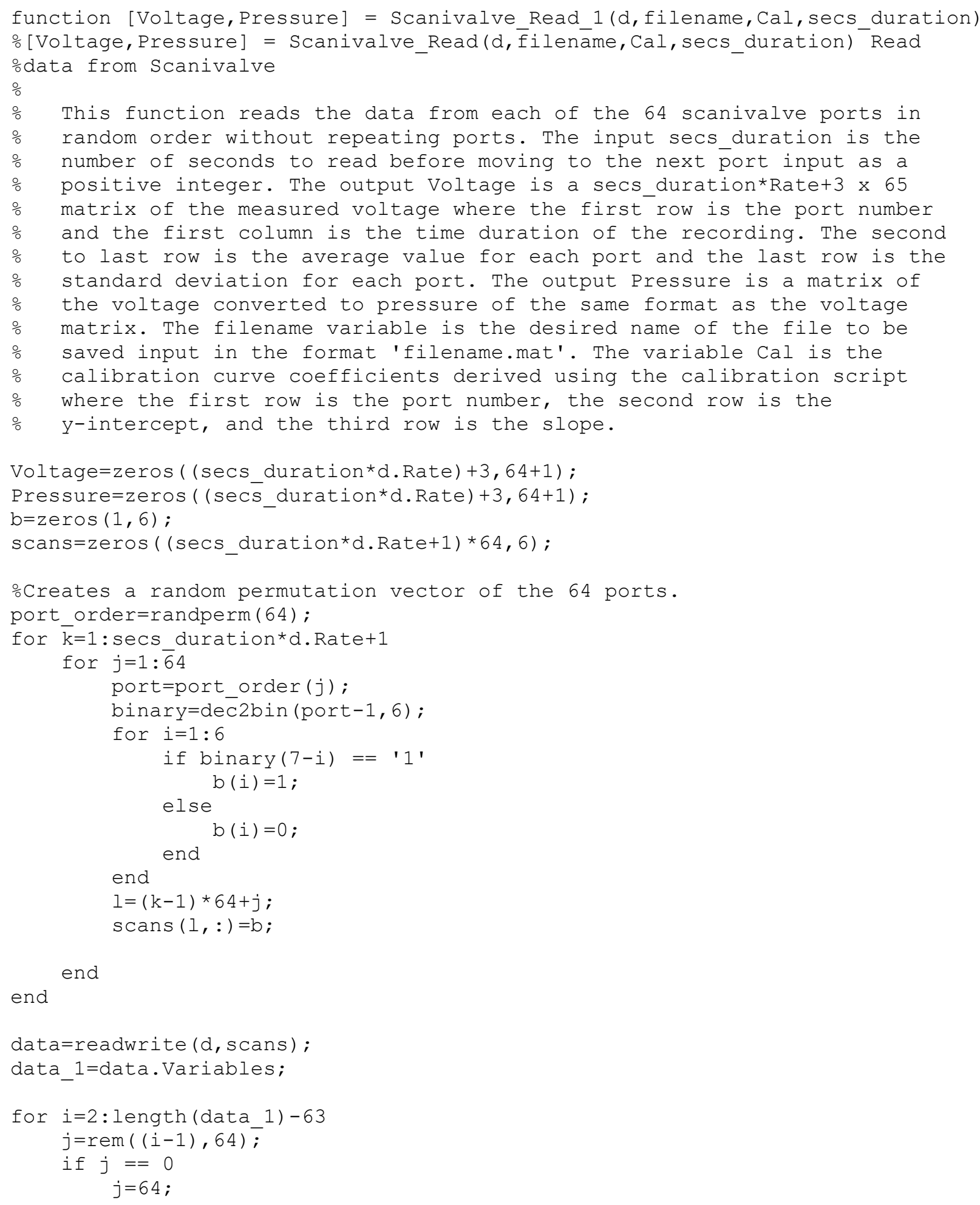




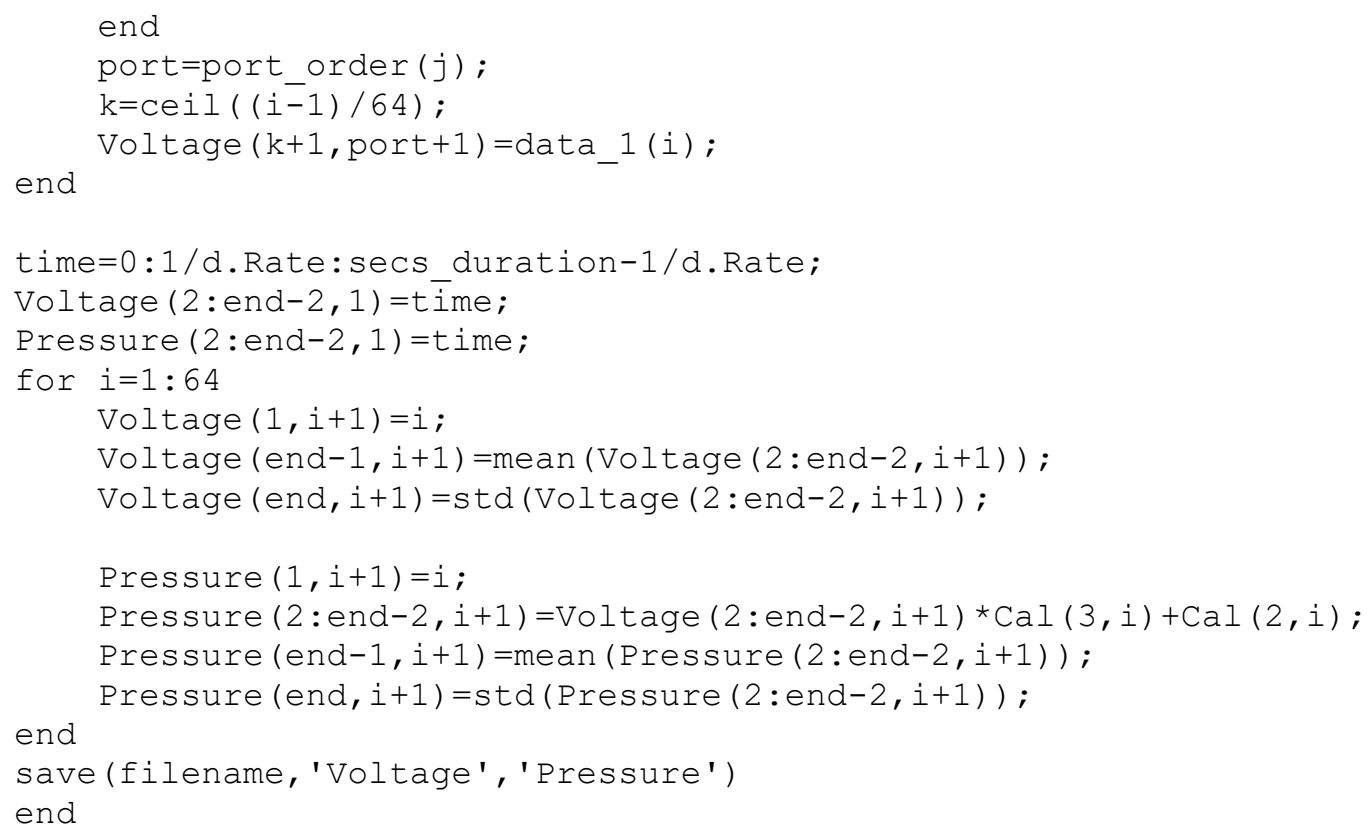




\section{Appendix I: Functions for EWT Control}

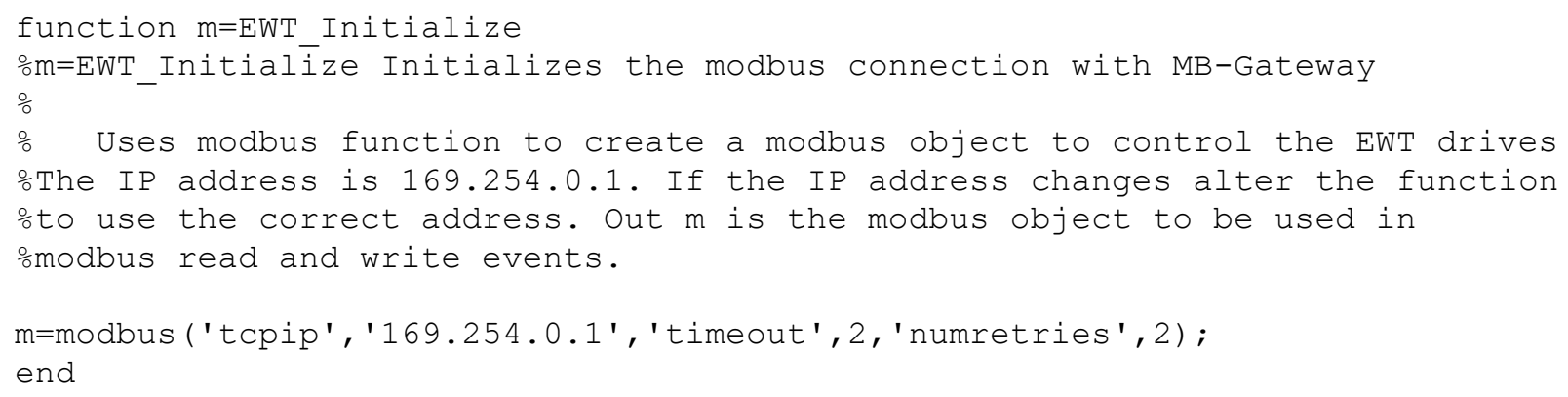




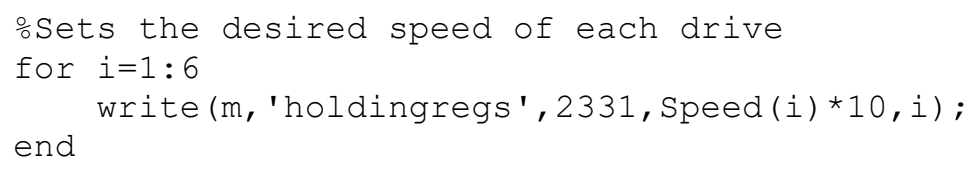




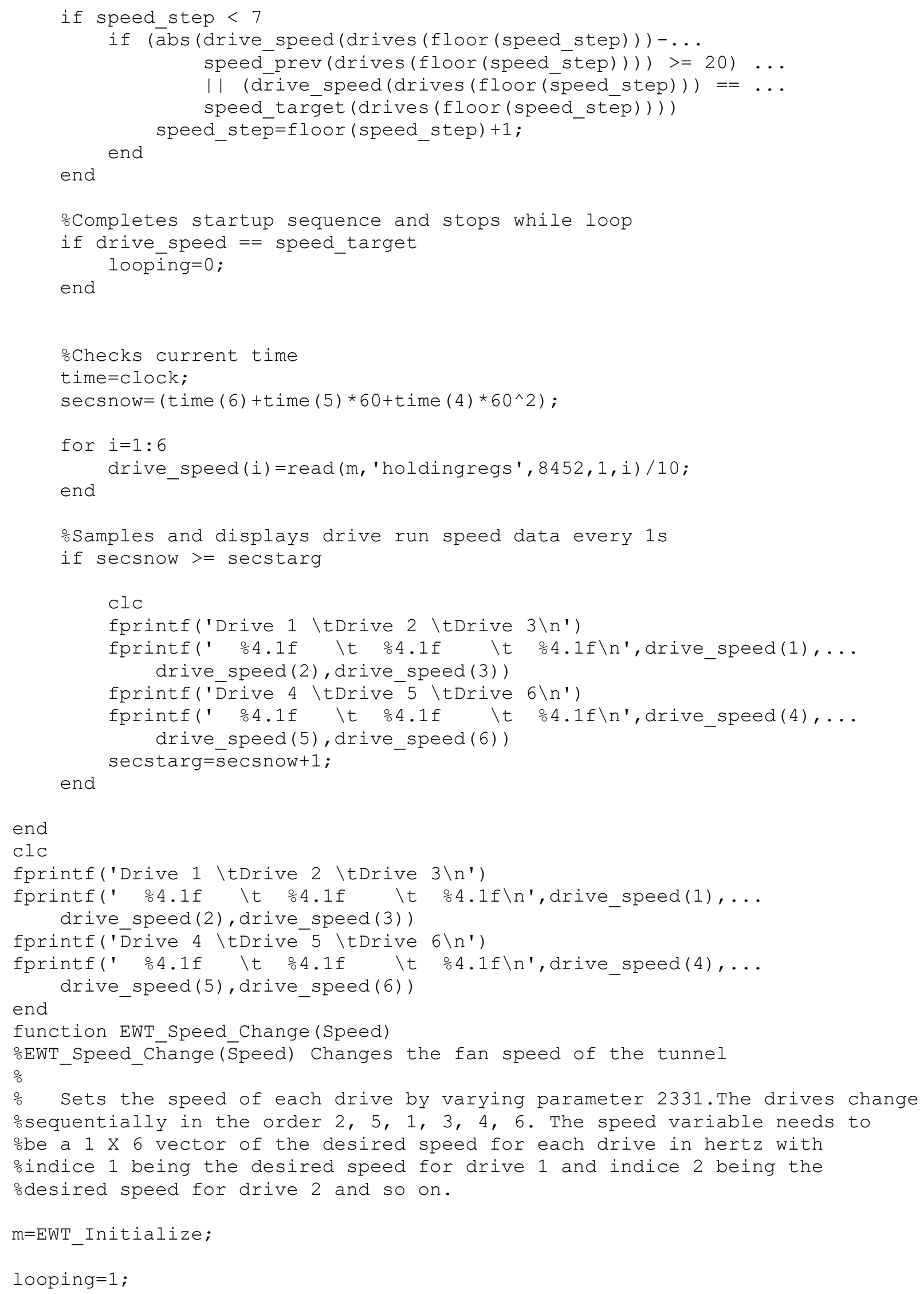




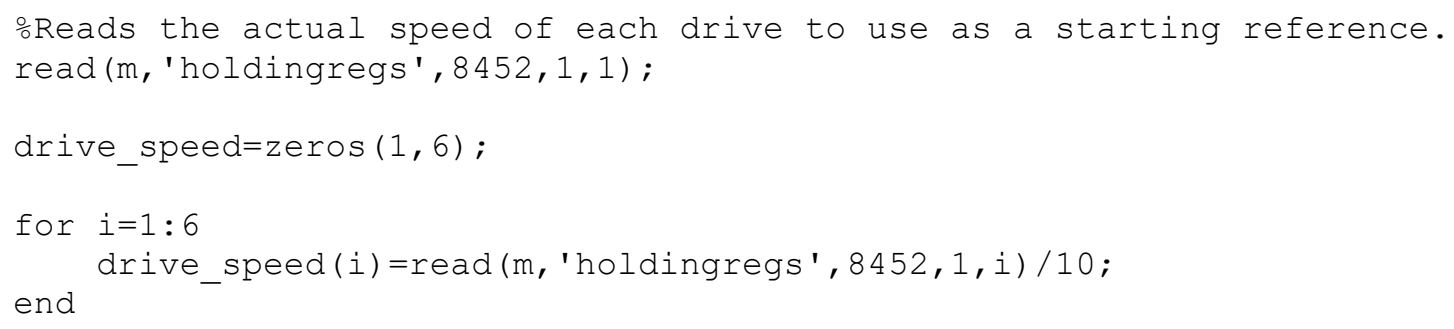




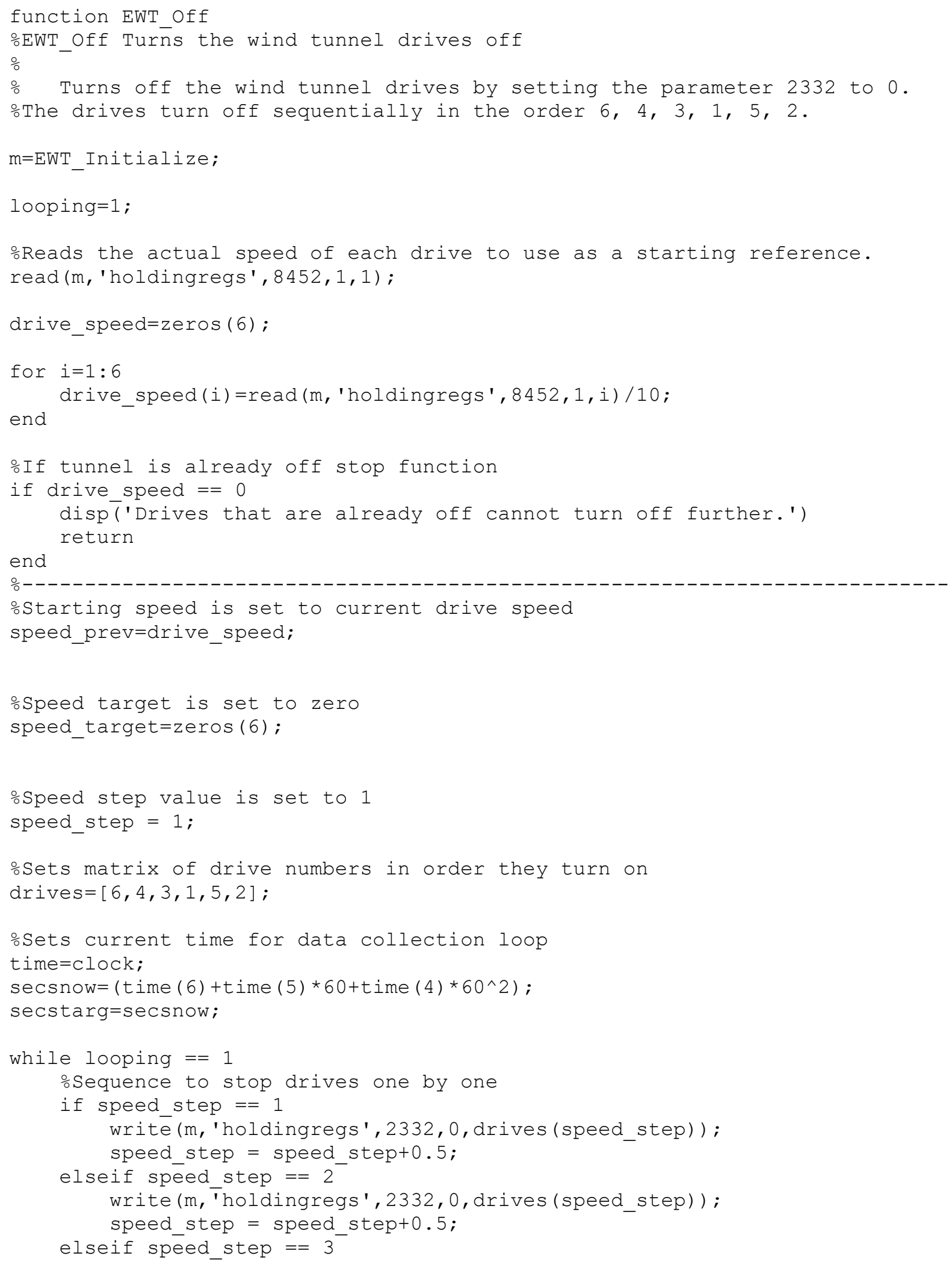




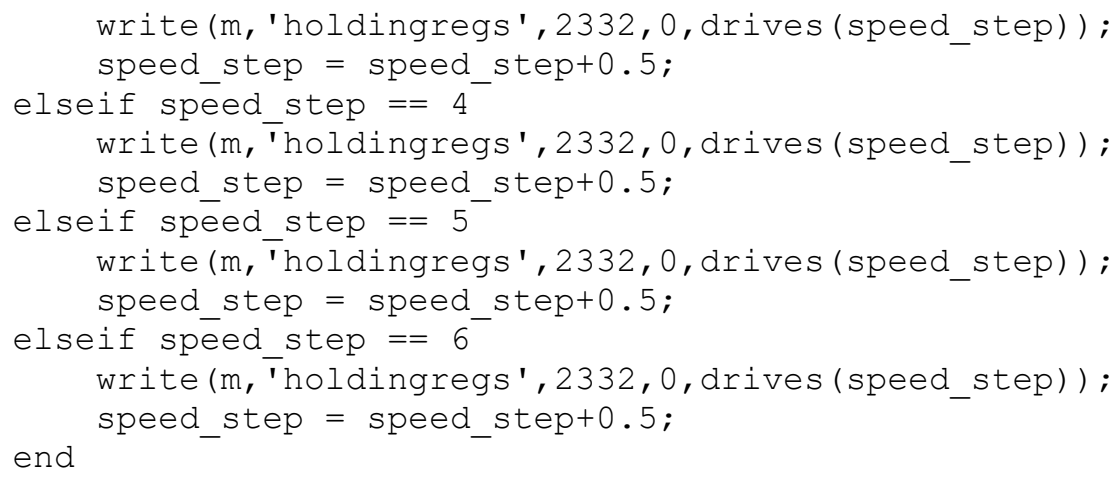




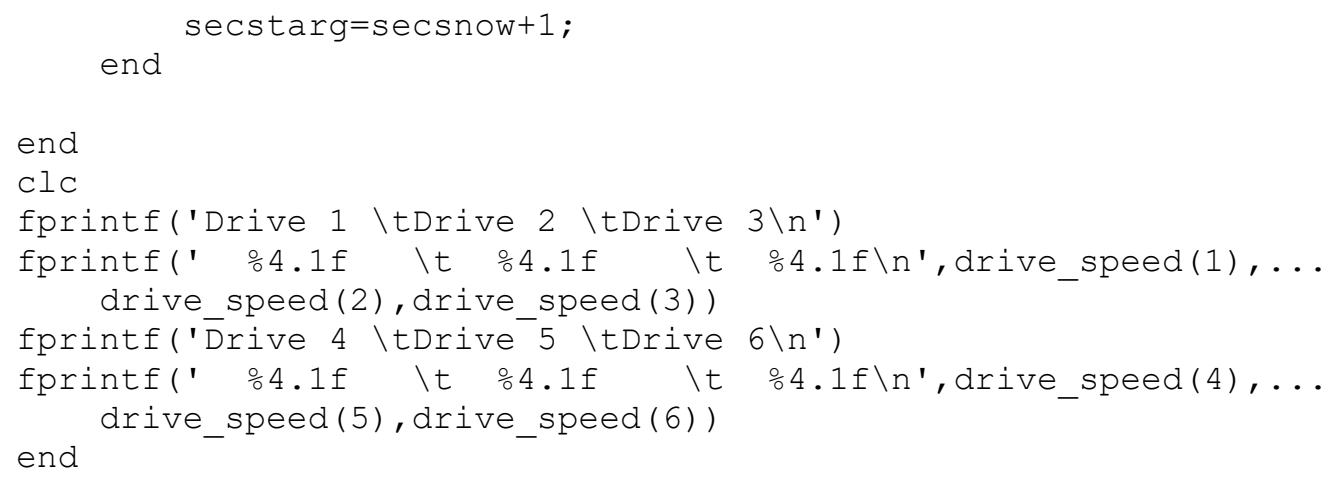




\section{Appendix J: Randomized Speed Matrix Code}

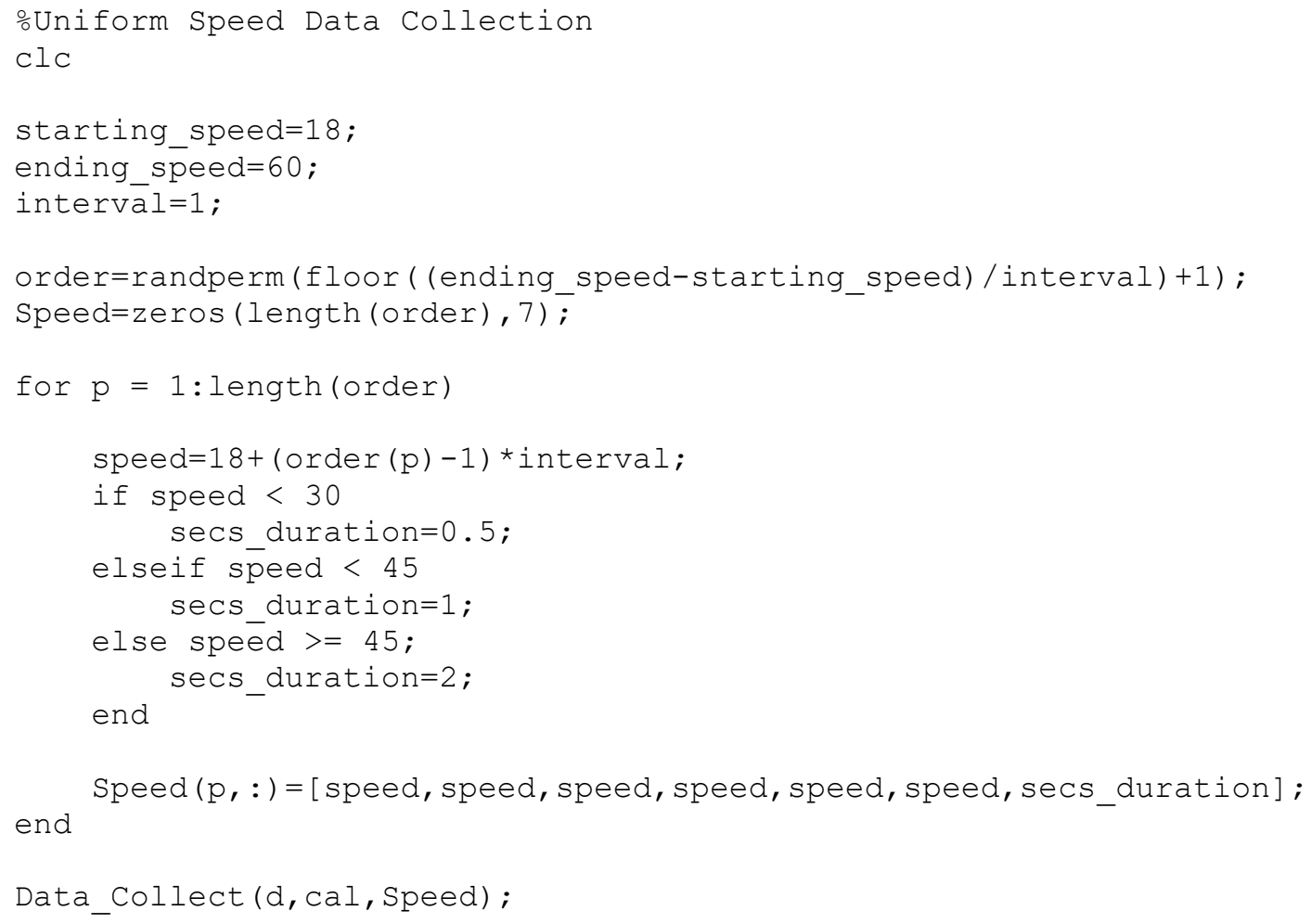




\section{Appendix K: Speed versus Frequency Plots Code}

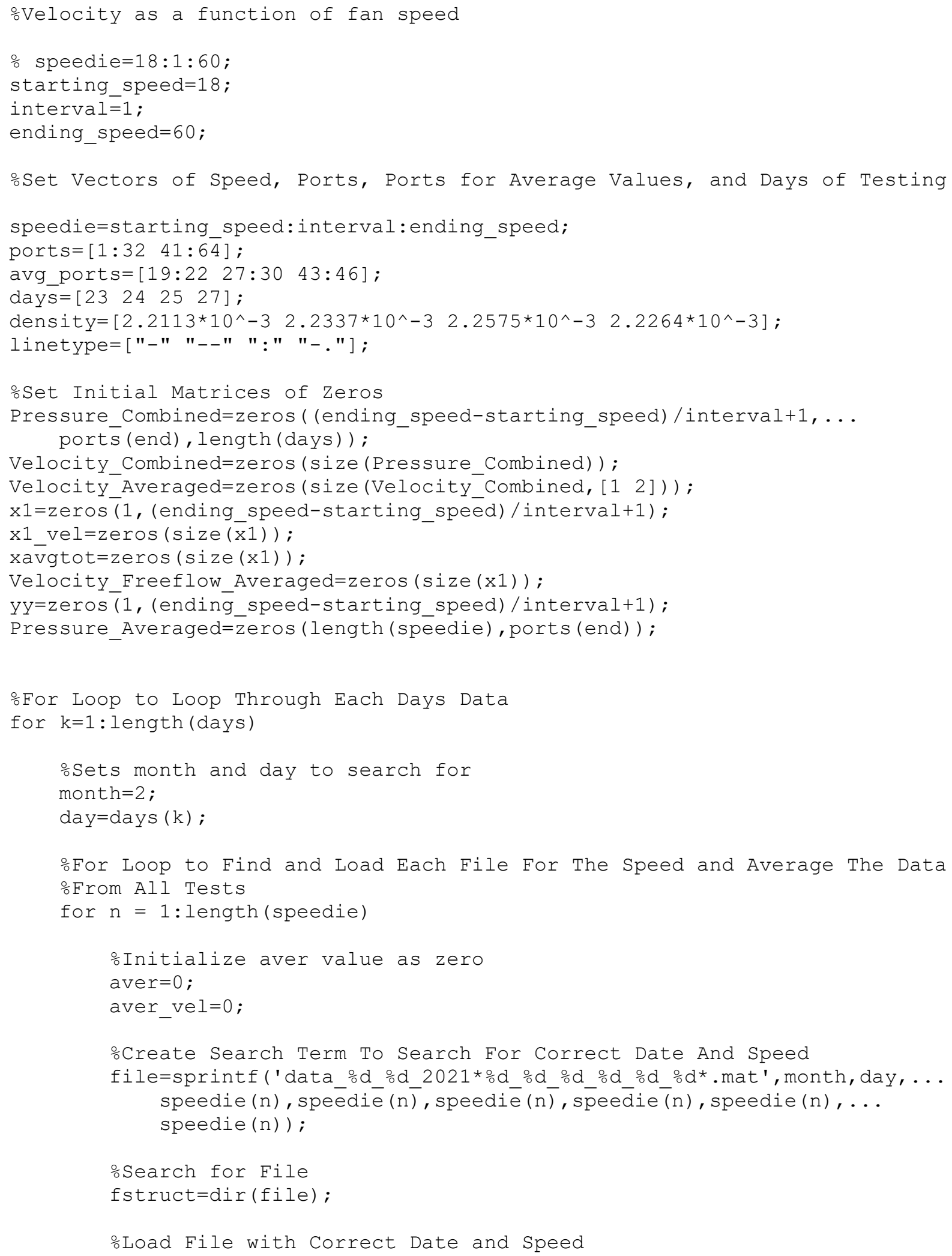


load (fstruct.name) ;

oFor loop to assemble all days data into one matrix then average oeach ports data for each speed over all tests.

for $m=1$ :length (ports) Pressure_Combined $(n, p o r t s(m), k)=\operatorname{Pressure}($ end-1, ports $(m)+1)$; if Pressure Combined (n,ports $(m), k)<0$

end

oAxis Labels for Pressure vs Fan speed Plot

xlabel ('Pressure (in H_2O)')

ylabel ('Fan Frequency ( $\mathrm{Hz})$ ')

legend('Day 1', 'Day 2', 'Day 3', 'Day 4')

Averaged Pressure For Each Port For Each Speed, Ports run Across and Speed oruns down

Pressure_Averaged=Pressure_Averaged/length (days); 


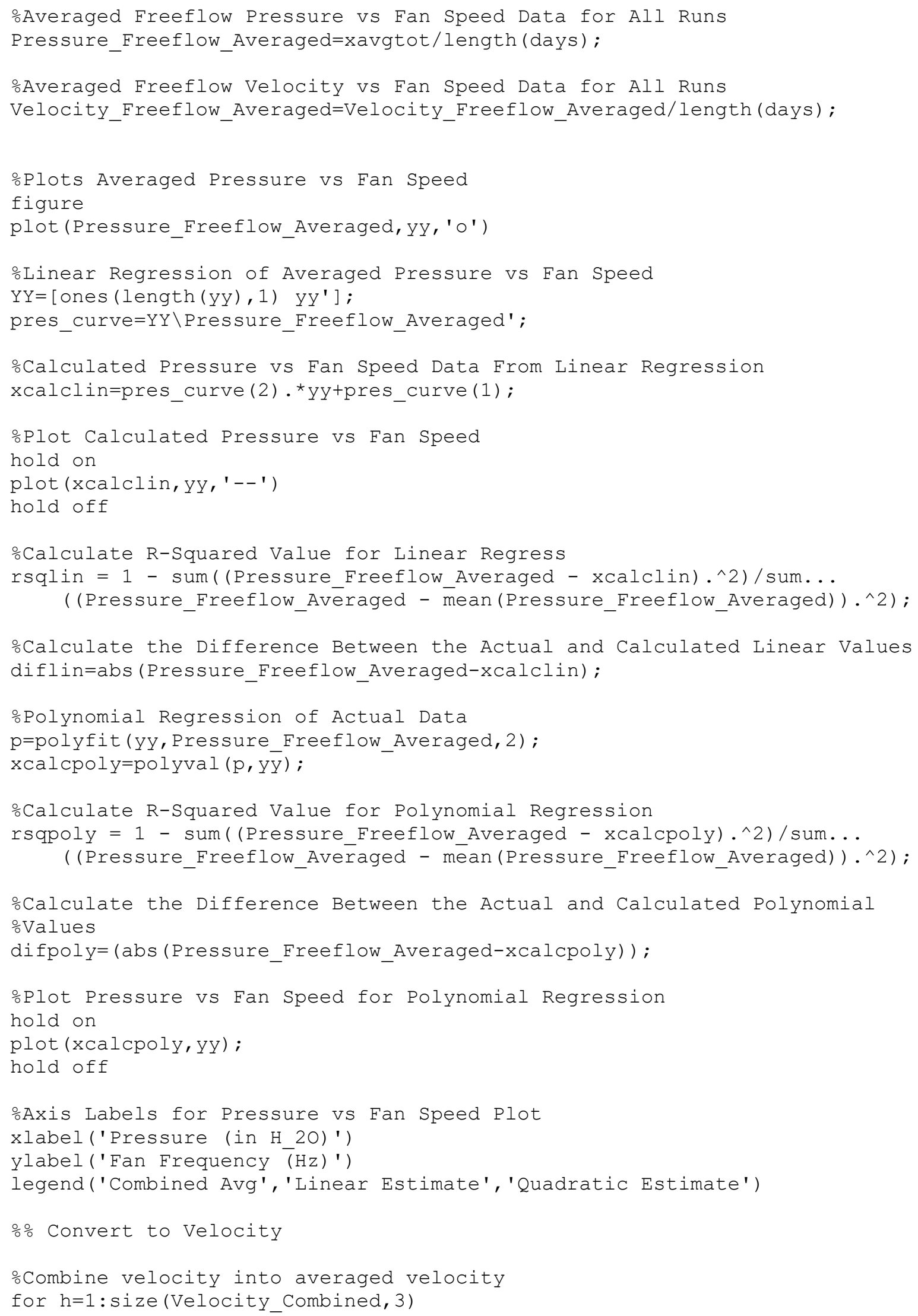




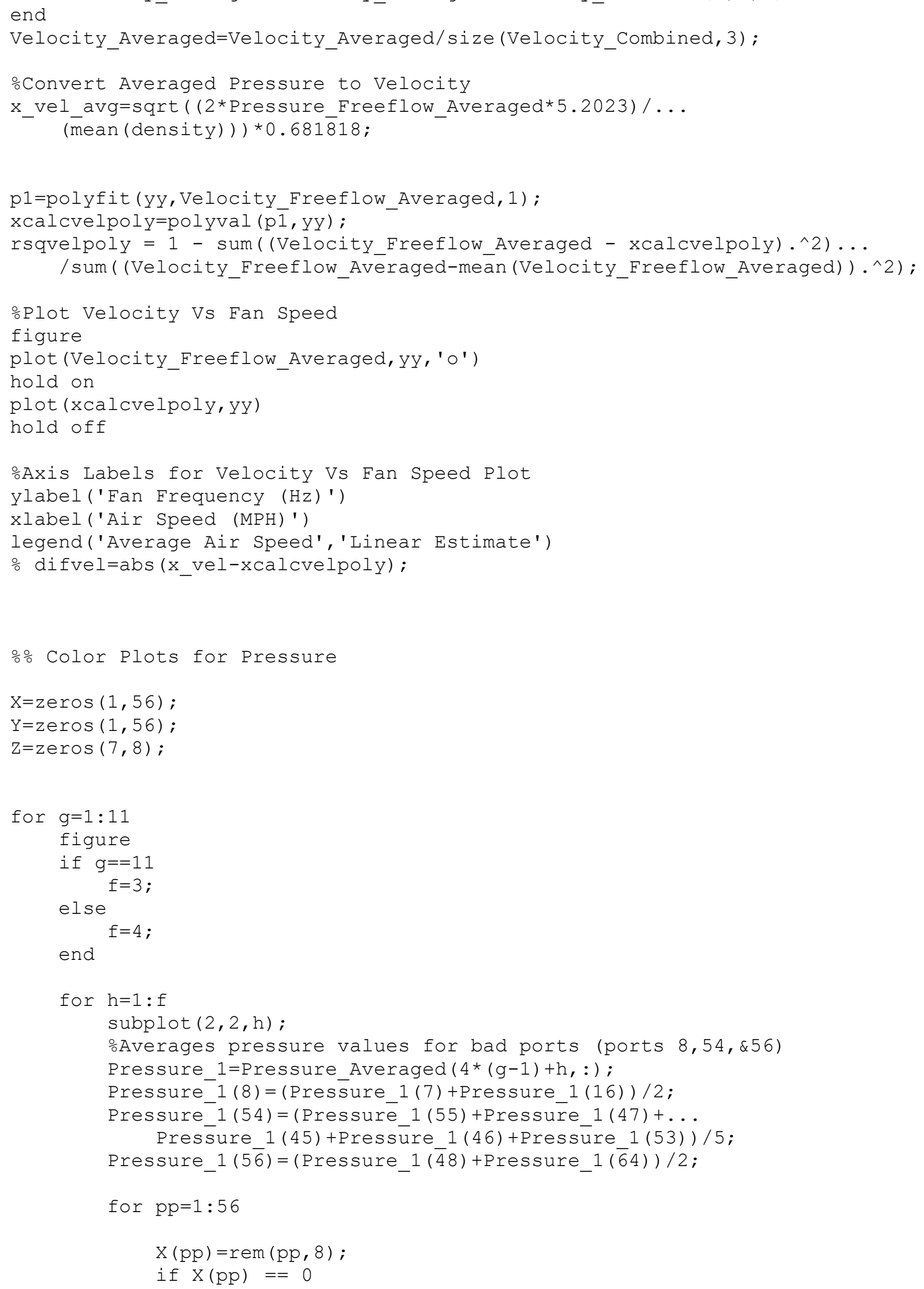




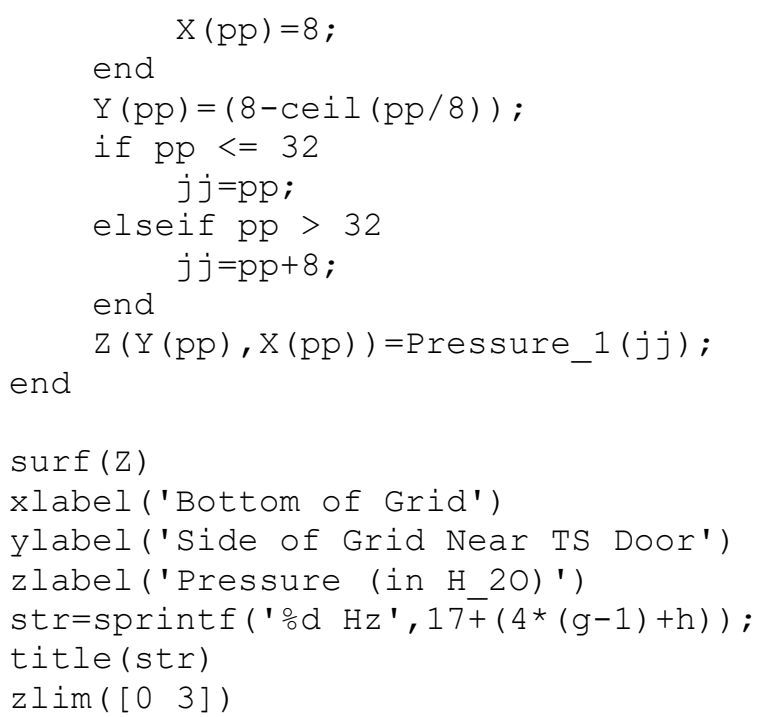




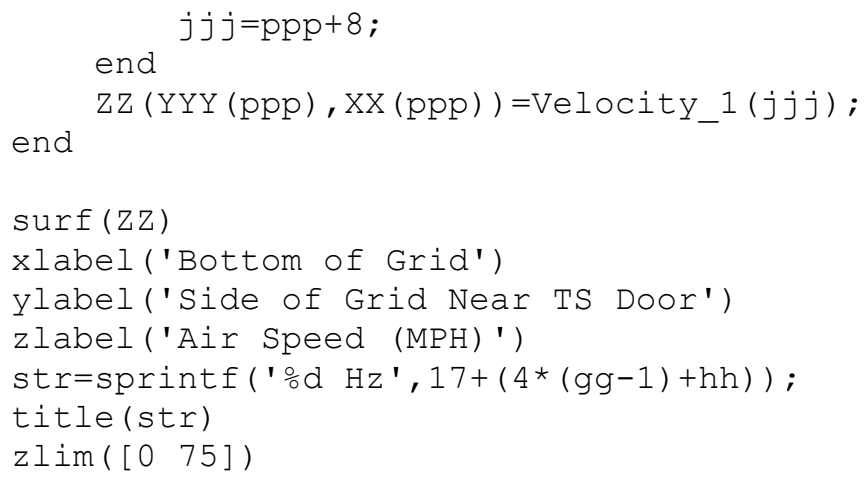




\section{Appendix L: Averaged and Maximum Averaged Pressure Values}

Averaged Pressure Values, Each Row is a Frequency, Each Column is a pitot tube port.

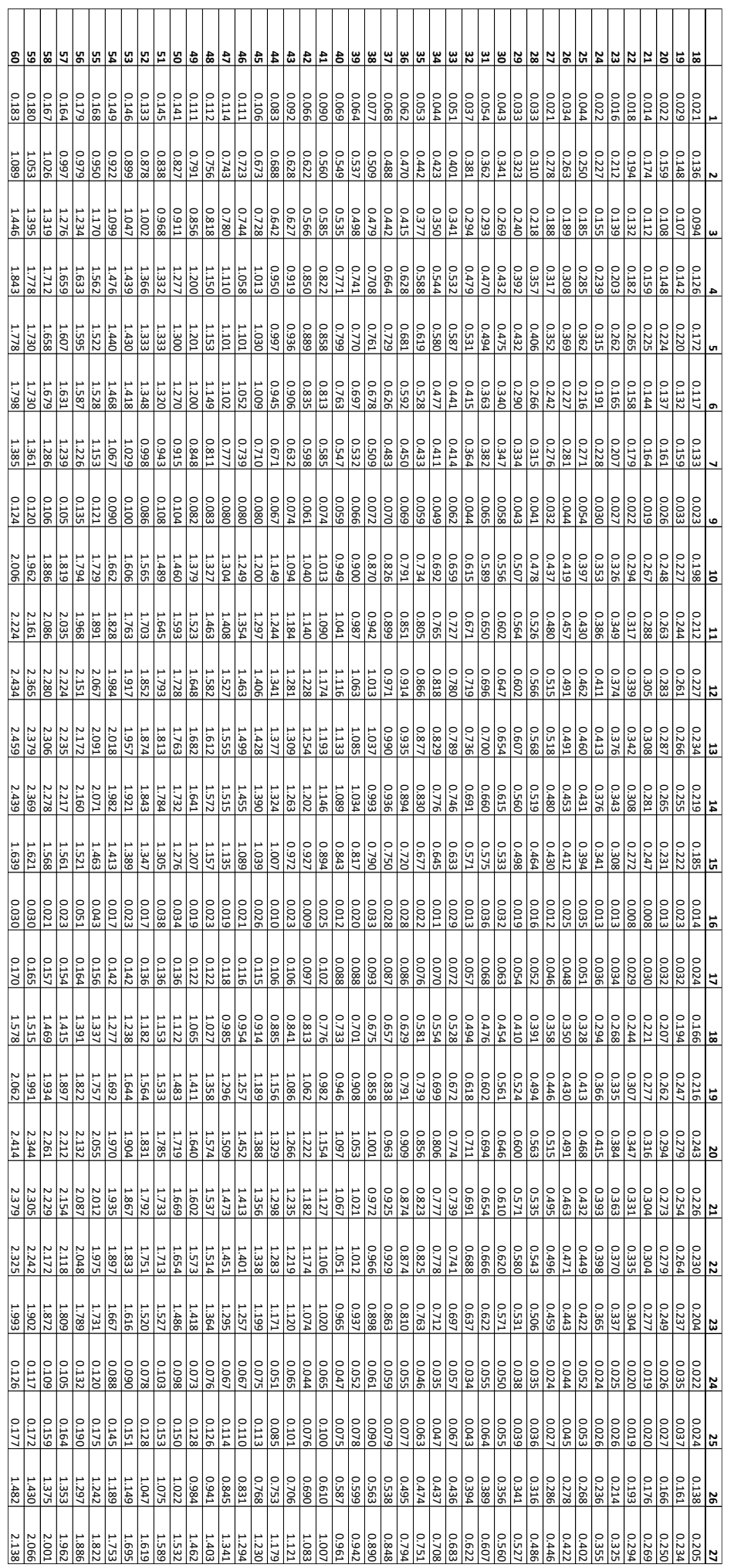




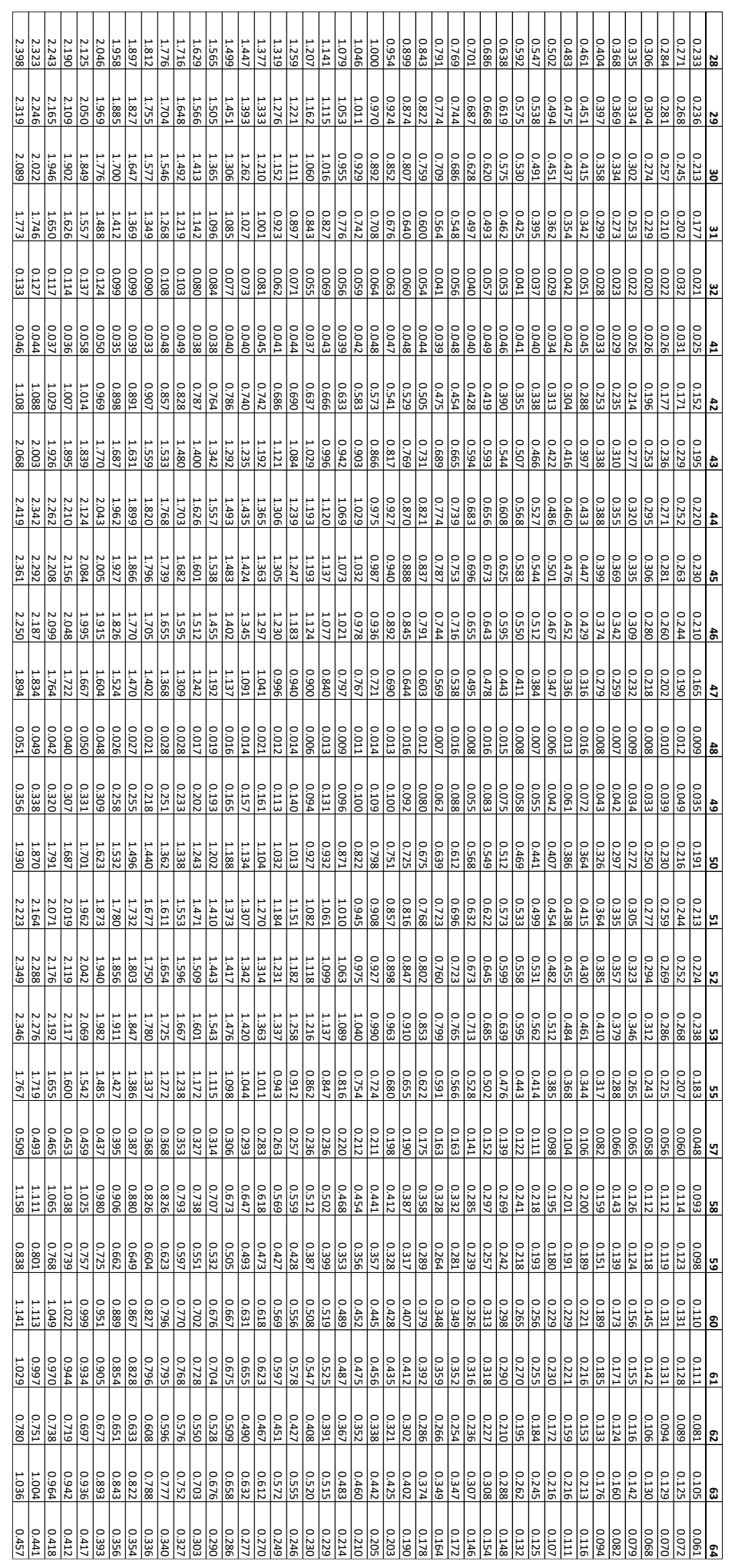


Maximum Averaged Pressure Values for Each Frequency (Bold)

\begin{tabular}{|r|r|r|r|r|r|r|r|}
\hline $\mathbf{1 8}$ & $\mathbf{1 9}$ & $\mathbf{2 0}$ & $\mathbf{2 1}$ & $\mathbf{2 2}$ & $\mathbf{2 3}$ & $\mathbf{2 4}$ & $\mathbf{2 5}$ \\
\hline 0.243 & 0.279 & 0.294 & 0.316 & 0.347 & 0.384 & 0.415 & 0.468 \\
\hline $\mathbf{2 6}$ & $\mathbf{2 7}$ & $\mathbf{2 8}$ & $\mathbf{2 9}$ & $\mathbf{3 0}$ & $\mathbf{3 1}$ & $\mathbf{3 2}$ & $\mathbf{3 3}$ \\
\hline 0.491 & 0.518 & 0.568 & 0.607 & 0.654 & 0.700 & 0.736 & 0.789 \\
\hline $\mathbf{3 4}$ & $\mathbf{3 5}$ & $\mathbf{3 6}$ & $\mathbf{3 7}$ & $\mathbf{3 8}$ & $\mathbf{3 9}$ & $\mathbf{4 0}$ & $\mathbf{4 1}$ \\
\hline 0.829 & 0.877 & 0.935 & 0.990 & 1.037 & 1.085 & 1.133 & 1.193 \\
\hline $\mathbf{4 2}$ & $\mathbf{4 3}$ & $\mathbf{4 4}$ & $\mathbf{4 5}$ & $\mathbf{4 6}$ & $\mathbf{4 7}$ & $\mathbf{4 8}$ & $\mathbf{4 9}$ \\
\hline 1.254 & 1.309 & 1.377 & 1.428 & 1.499 & 1.555 & 1.612 & 1.682 \\
\hline $\mathbf{5 0}$ & $\mathbf{5 1}$ & $\mathbf{5 2}$ & $\mathbf{5 3}$ & $\mathbf{5 4}$ & $\mathbf{5 5}$ & $\mathbf{5 6}$ & $\mathbf{5 7}$ \\
\hline 1.763 & 1.813 & 1.874 & 1.957 & 2.018 & 2.091 & 2.172 & 2.235 \\
\hline $\mathbf{5 8}$ & $\mathbf{5 9}$ & $\mathbf{6 0}$ & & & & & \\
\hline 2.306 & 2.379 & 2.459 & & & & & \\
\hline
\end{tabular}




\section{Appendix M: Averaged and Maximum Averaged Velocity Values}

Averaged Velocity Values, Each Row is a Frequency, Each Column is a pitot tube port.

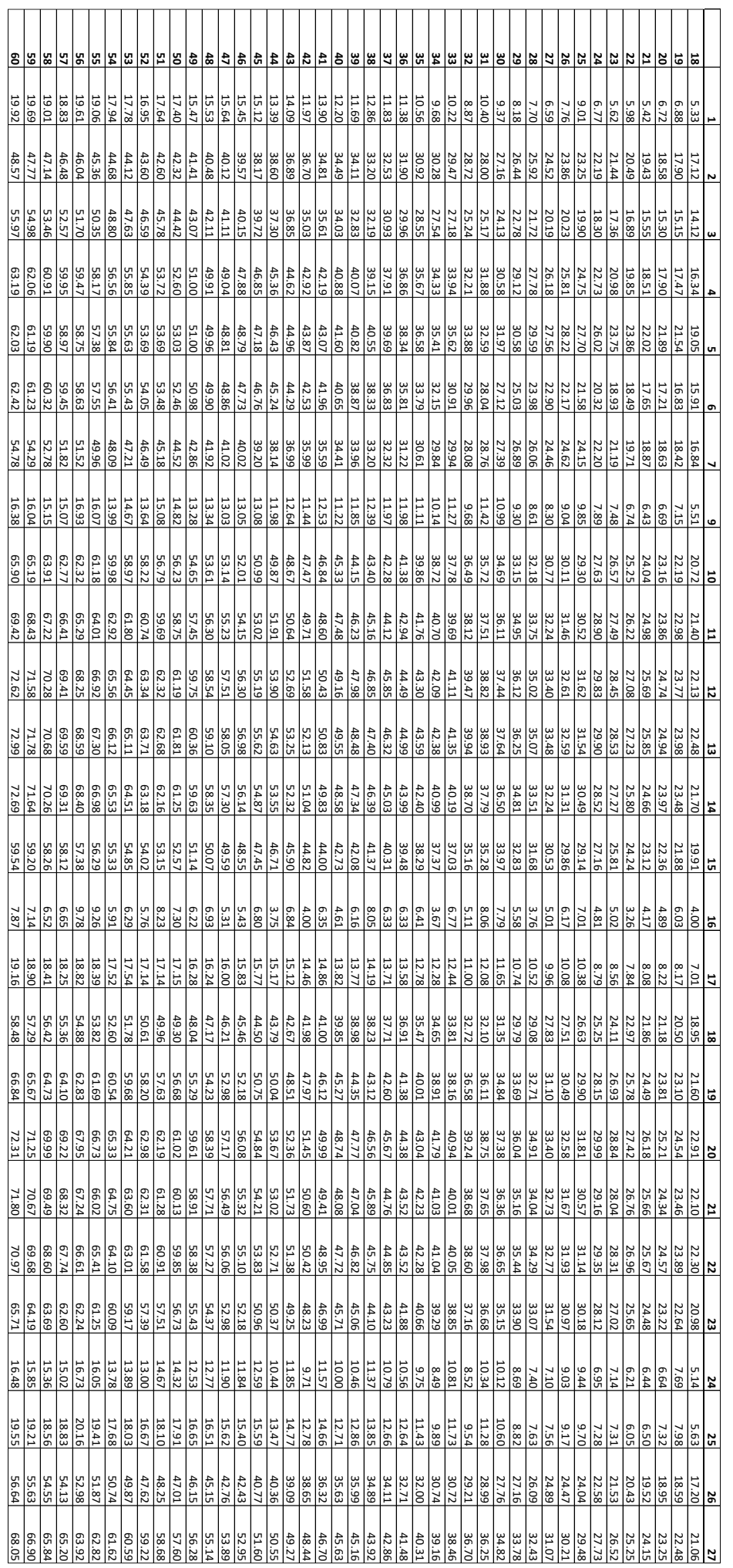




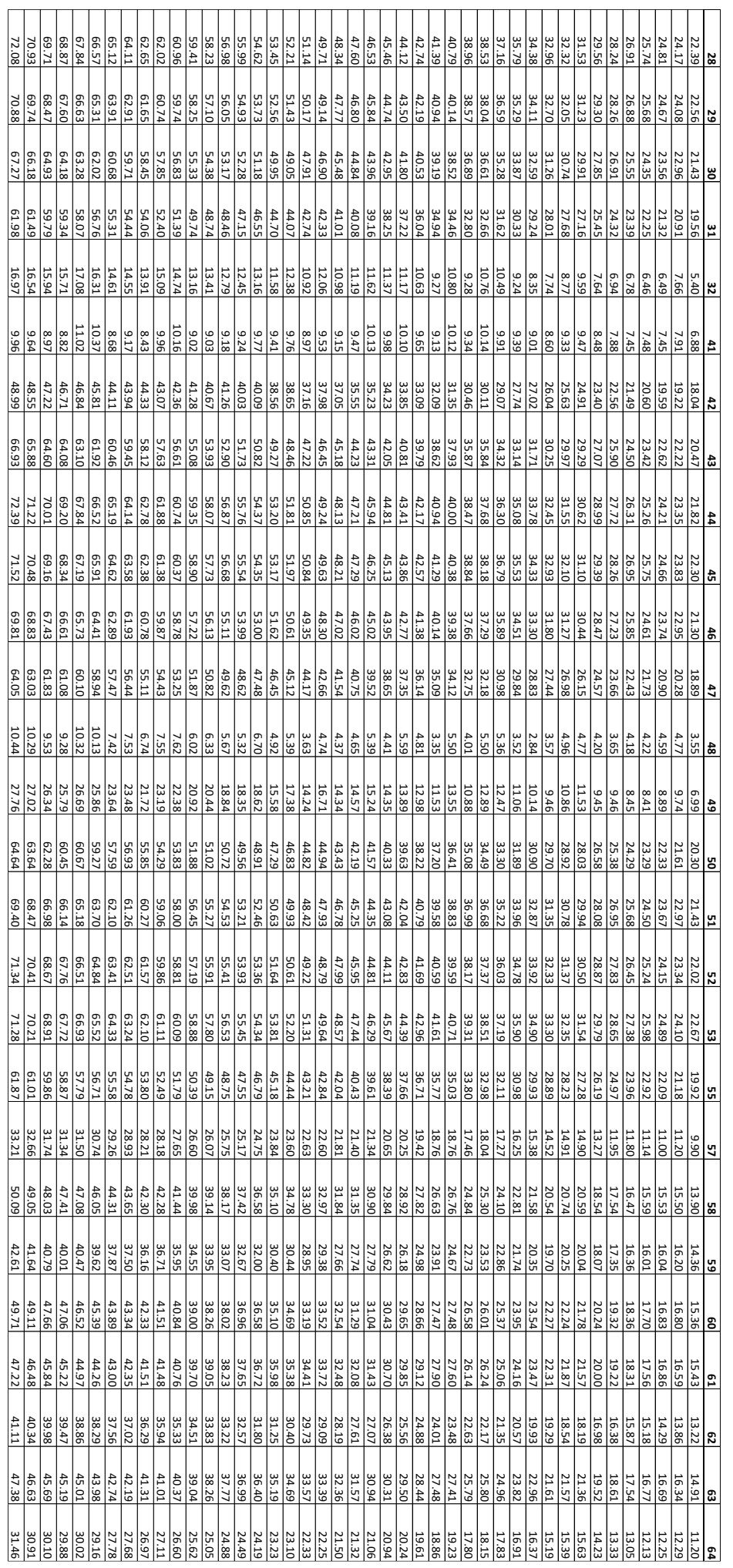


Maximum Averaged Velocity Values for Each Frequency (Bold)

\begin{tabular}{|r|r|r|r|r|r|r|r|}
\hline $\mathbf{1 8}$ & $\mathbf{1 9}$ & $\mathbf{2 0}$ & $\mathbf{2 1}$ & $\mathbf{2 2}$ & $\mathbf{2 3}$ & $\mathbf{2 4}$ & $\mathbf{2 5}$ \\
\hline 22.91 & 24.54 & 25.21 & 26.18 & 27.42 & 28.84 & 29.99 & 31.81 \\
\hline $\mathbf{2 6}$ & $\mathbf{2 7}$ & $\mathbf{2 8}$ & $\mathbf{2 9}$ & $\mathbf{3 0}$ & $\mathbf{3 1}$ & $\mathbf{3 2}$ & $\mathbf{3 3}$ \\
\hline 32.61 & 33.48 & 35.07 & 36.25 & 37.64 & 38.93 & 39.94 & 41.35 \\
\hline $\mathbf{3 4}$ & $\mathbf{3 5}$ & $\mathbf{3 6}$ & $\mathbf{3 7}$ & $\mathbf{3 8}$ & $\mathbf{3 9}$ & $\mathbf{4 0}$ & $\mathbf{4 1}$ \\
\hline 42.38 & 43.59 & 44.99 & 46.32 & 47.40 & 48.48 & 49.55 & 50.83 \\
\hline $\mathbf{4 2}$ & $\mathbf{4 3}$ & $\mathbf{4 4}$ & $\mathbf{4 5}$ & $\mathbf{4 6}$ & $\mathbf{4 7}$ & $\mathbf{4 8}$ & $\mathbf{4 9}$ \\
\hline 52.13 & 53.25 & 54.63 & 55.62 & 56.98 & 58.05 & 59.10 & 60.36 \\
\hline $\mathbf{5 0}$ & $\mathbf{5 1}$ & $\mathbf{5 2}$ & $\mathbf{5 3}$ & $\mathbf{5 4}$ & $\mathbf{5 5}$ & $\mathbf{5 6}$ & $\mathbf{5 7}$ \\
\hline 61.81 & 62.68 & 63.71 & 65.11 & 66.12 & 67.30 & 68.59 & 69.59 \\
\hline $\mathbf{5 8}$ & $\mathbf{5 9}$ & $\mathbf{6 0}$ & & & & & \\
\hline 70.68 & 71.78 & 72.99 & & & & & \\
\hline
\end{tabular}




\section{Appendix N: Boundary Layer Code}

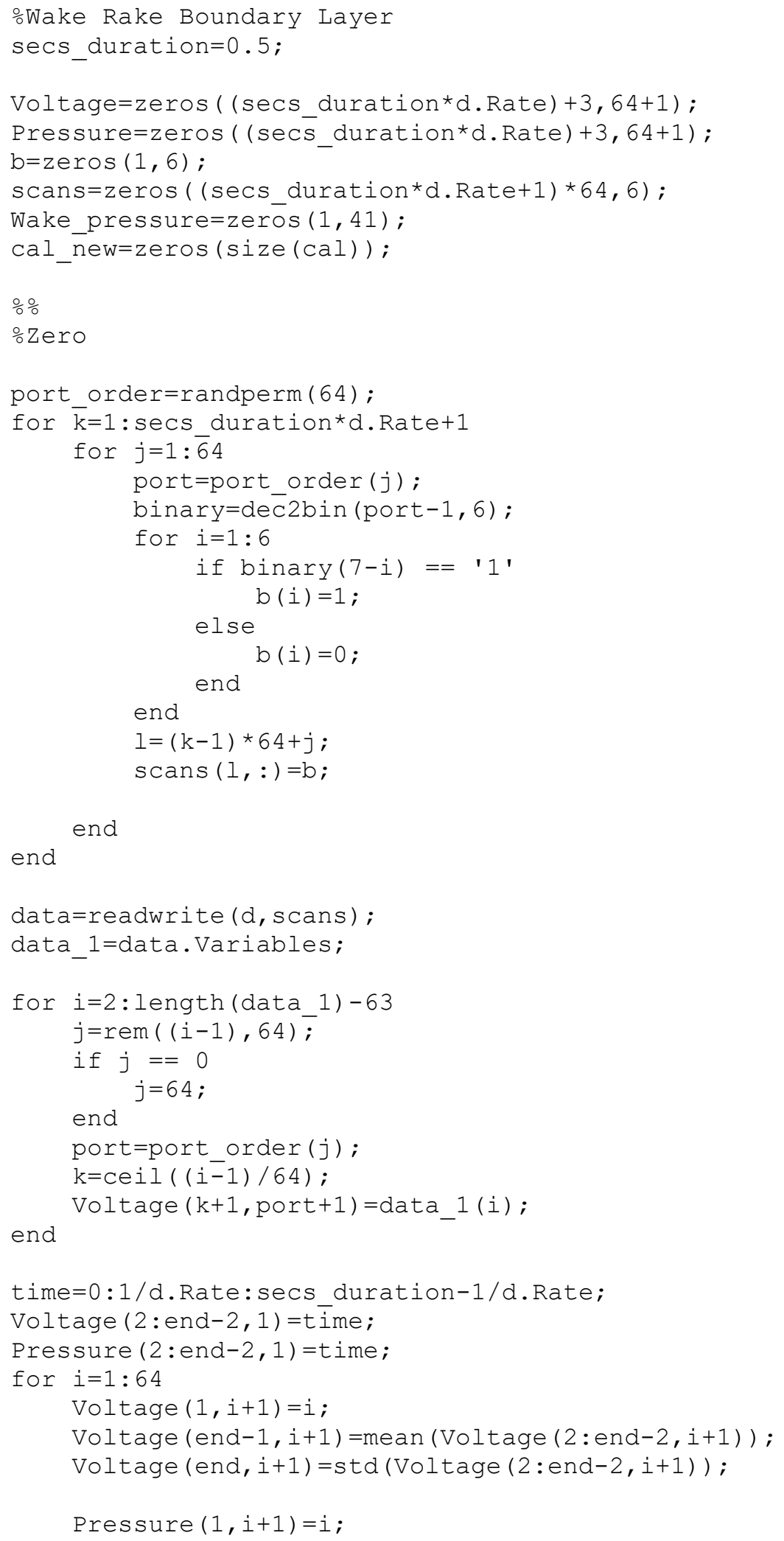




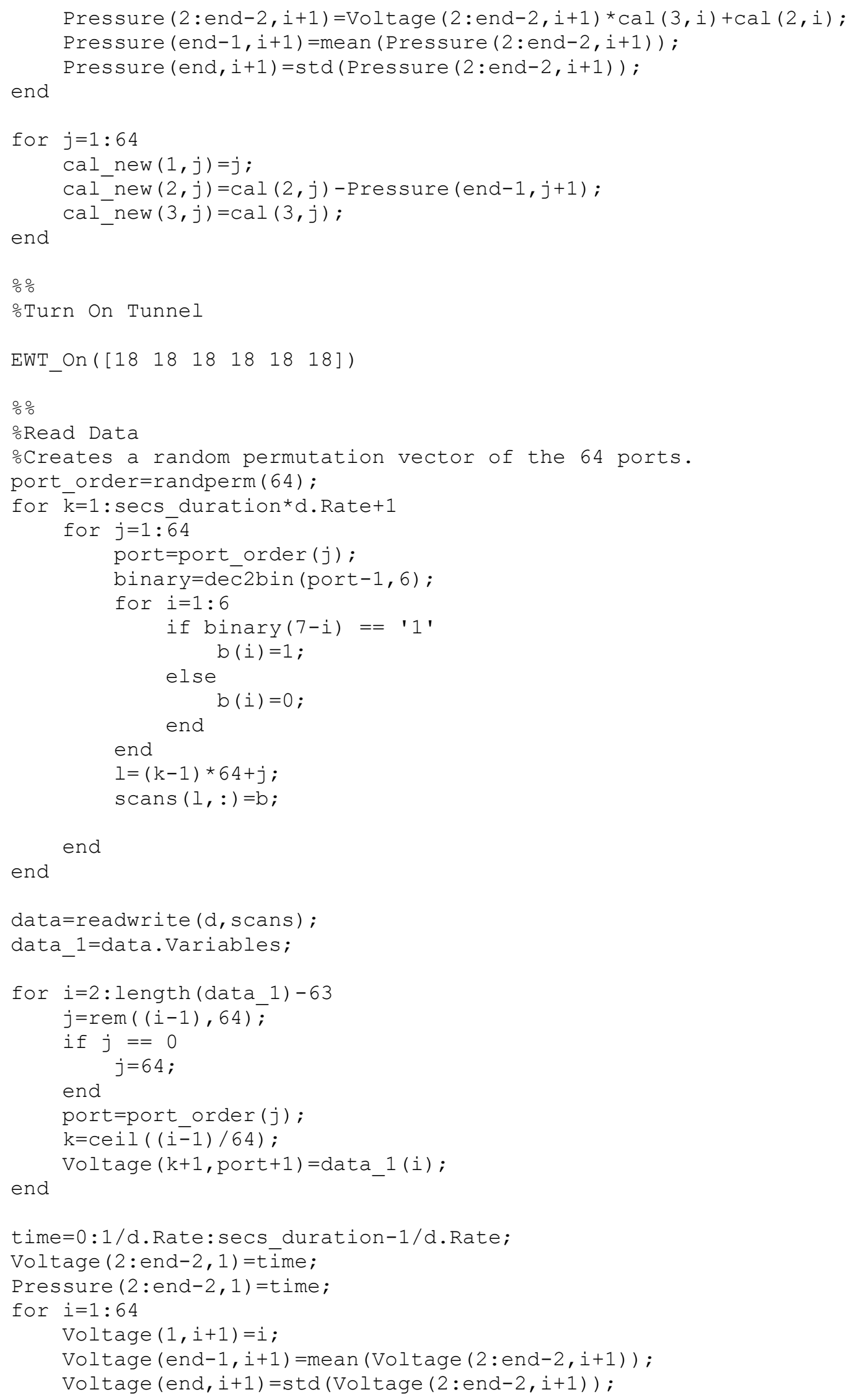




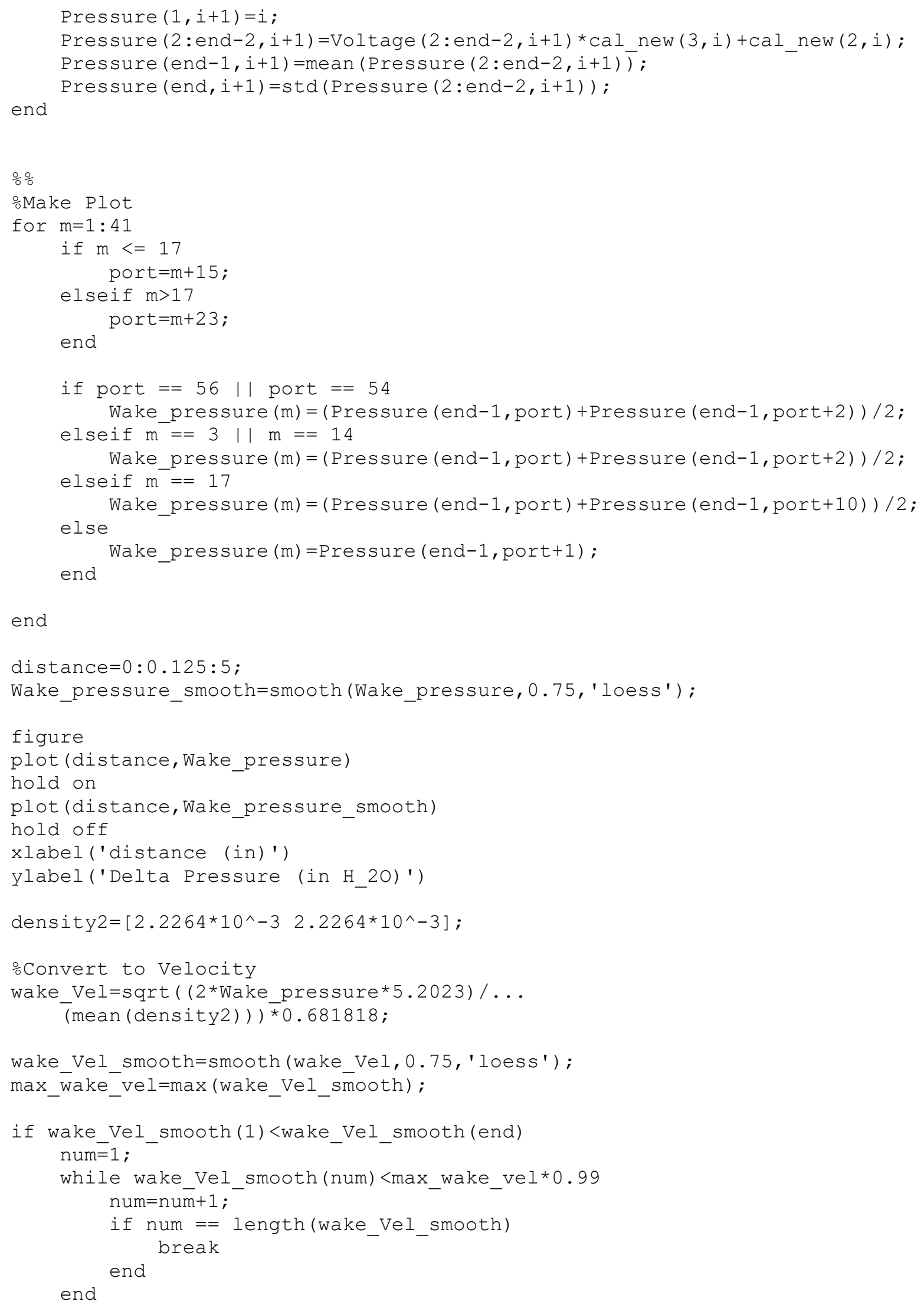




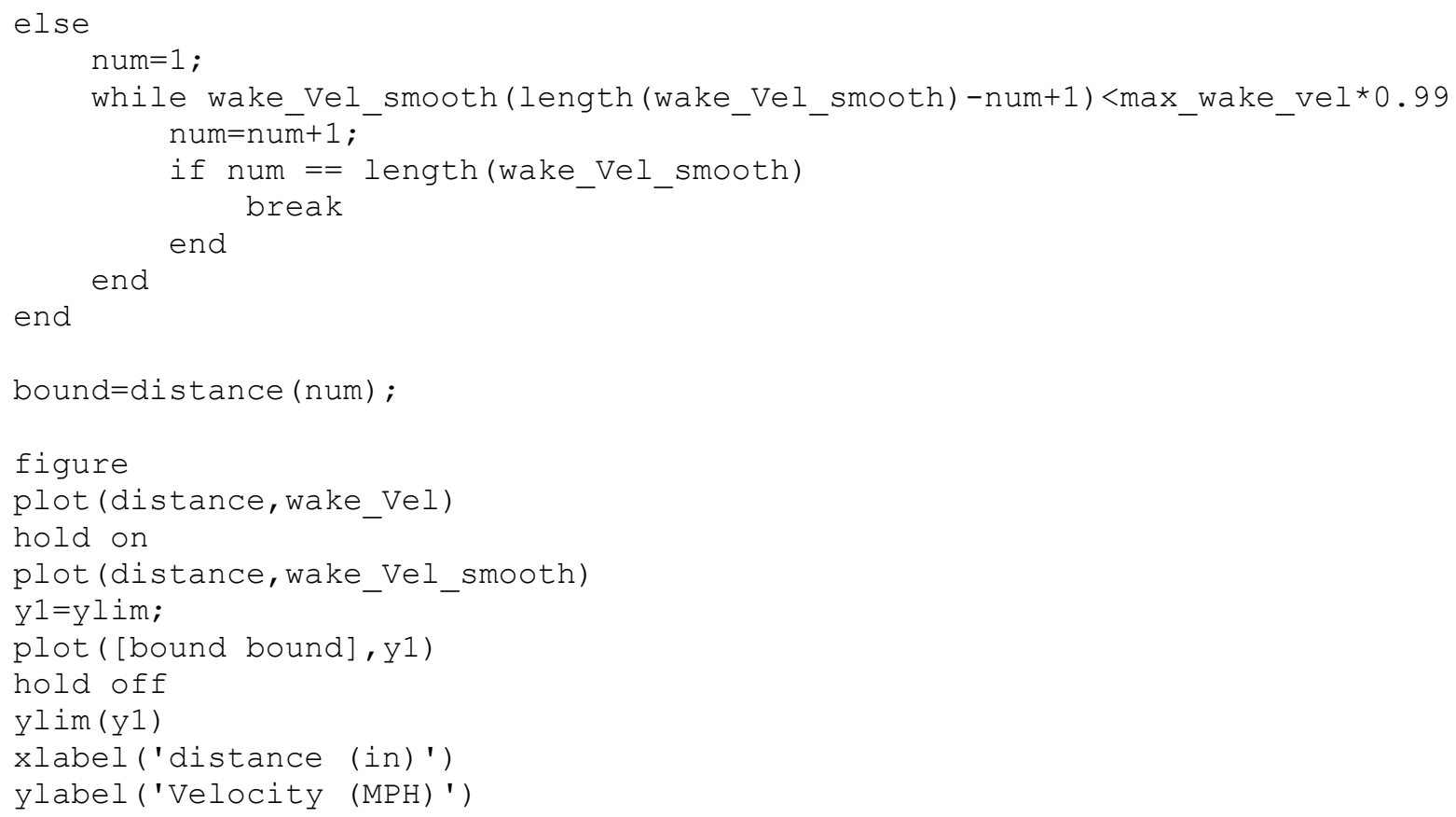




\section{Appendix O: Power in Tunnel}

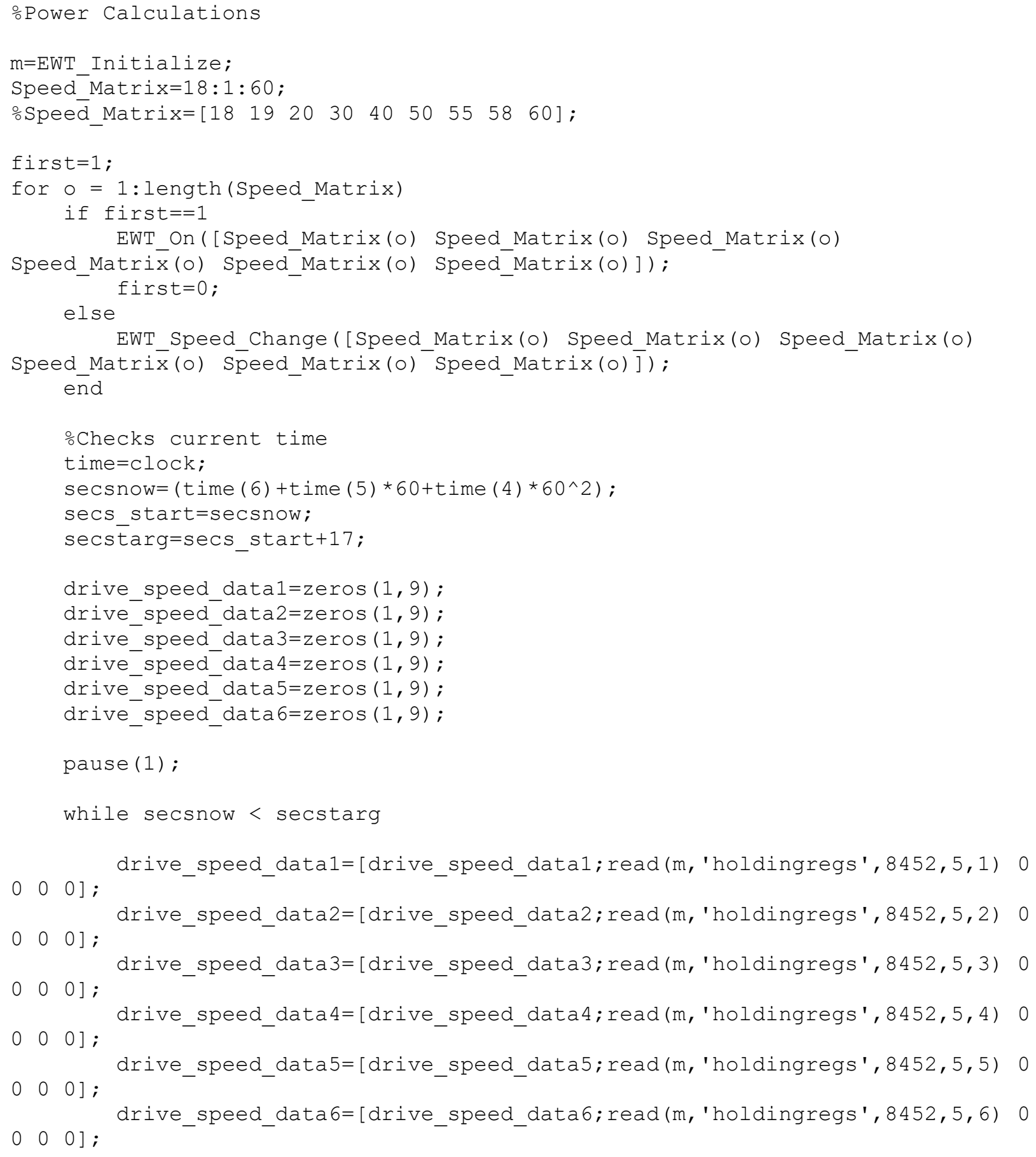




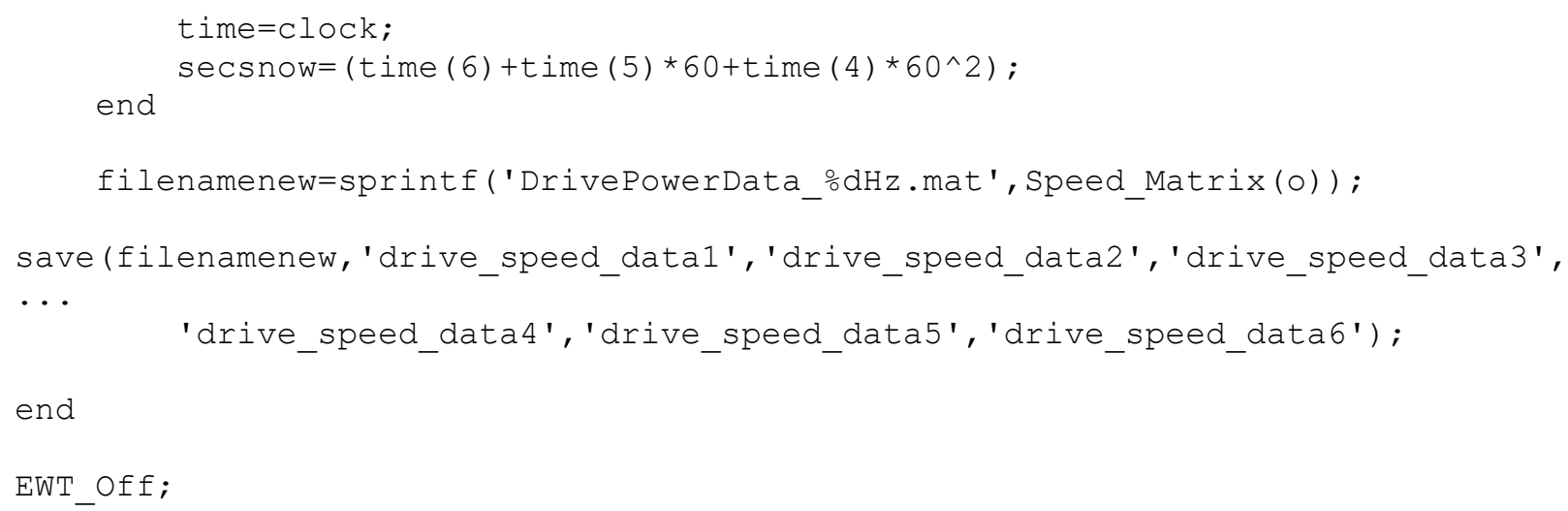




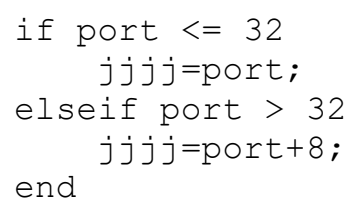


Appendix P: Horsepower Values per Motor Frequency

Total Horsepower Values from the Motors for Each Frequency (Bold)

\begin{tabular}{|r|r|r|r|r|r|r|r|}
\hline $\mathbf{1 8}$ & $\mathbf{1 9}$ & $\mathbf{2 0}$ & $\mathbf{2 1}$ & $\mathbf{2 2}$ & $\mathbf{2 3}$ & $\mathbf{2 4}$ & $\mathbf{2 5}$ \\
\hline 2.11 & 2.38 & 2.77 & 3.11 & 3.46 & 3.86 & 4.28 & 4.76 \\
\hline $\mathbf{2 6}$ & $\mathbf{2 7}$ & $\mathbf{2 8}$ & $\mathbf{2 9}$ & $\mathbf{3 0}$ & $\mathbf{3 1}$ & $\mathbf{3 2}$ & $\mathbf{3 3}$ \\
\hline 5.25 & 5.77 & 6.36 & 6.98 & 7.63 & 8.35 & 9.08 & 9.86 \\
\hline $\mathbf{3 4}$ & $\mathbf{3 5}$ & $\mathbf{3 6}$ & $\mathbf{3 7}$ & $\mathbf{3 8}$ & $\mathbf{3 9}$ & $\mathbf{4 0}$ & $\mathbf{4 1}$ \\
\hline 10.70 & 11.60 & 12.52 & 13.50 & 14.54 & 15.64 & 16.82 & 18.00 \\
\hline $\mathbf{4 2}$ & $\mathbf{4 3}$ & $\mathbf{4 4}$ & $\mathbf{4 5}$ & $\mathbf{4 6}$ & $\mathbf{4 7}$ & $\mathbf{4 8}$ & $\mathbf{4 9}$ \\
\hline 19.26 & 20.61 & 22.07 & 23.52 & 25.08 & 26.63 & 28.26 & 30.06 \\
\hline $\mathbf{5 0}$ & $\mathbf{5 1}$ & $\mathbf{5 2}$ & $\mathbf{5 3}$ & $\mathbf{5 4}$ & $\mathbf{5 5}$ & $\mathbf{5 6}$ & $\mathbf{5 7}$ \\
\hline 31.87 & 33.73 & 35.68 & 37.72 & 39.84 & 41.66 & 43.63 & 45.84 \\
\hline $\mathbf{5 8}$ & $\mathbf{5 9}$ & $\mathbf{6 0}$ & & & & & \\
\hline 48.45 & 50.97 & 53.48 & & & & & \\
\hline
\end{tabular}

Total Horsepower Values of Wind Power in Test Section for Each Frequency (Bold)

\begin{tabular}{|r|r|r|r|r|r|r|r|}
\hline $\mathbf{1 8}$ & $\mathbf{1 9}$ & $\mathbf{2 0}$ & $\mathbf{2 1}$ & $\mathbf{2 2}$ & $\mathbf{2 3}$ & $\mathbf{2 4}$ & $\mathbf{2 5}$ \\
\hline 0.849 & 1.05 & 1.15 & 1.29 & 1.48 & 1.72 & 1.95 & 2.35 \\
\hline $\mathbf{2 6}$ & $\mathbf{2 7}$ & $\mathbf{2 8}$ & $\mathbf{2 9}$ & $\mathbf{3 0}$ & $\mathbf{3 1}$ & $\mathbf{3 2}$ & $\mathbf{3 3}$ \\
\hline 2.54 & 2.71 & 3.10 & 3.43 & 3.84 & 4.28 & 4.46 & 5.06 \\
\hline $\mathbf{3 4}$ & $\mathbf{3 5}$ & $\mathbf{3 6}$ & $\mathbf{3 7}$ & $\mathbf{3 8}$ & $\mathbf{3 9}$ & $\mathbf{4 0}$ & $\mathbf{4 1}$ \\
\hline 5.36 & 5.87 & 6.44 & 6.99 & 7.50 & 8.01 & 8.56 & 9.27 \\
\hline $\mathbf{4 2}$ & $\mathbf{4 3}$ & $\mathbf{4 4}$ & $\mathbf{4 5}$ & $\mathbf{4 6}$ & $\mathbf{4 7}$ & $\mathbf{4 8}$ & $\mathbf{4 9}$ \\
\hline 9.88 & 10.60 & 11.31 & 12.13 & 12.91 & 13.70 & 14.40 & 15.31 \\
\hline $\mathbf{5 0}$ & $\mathbf{5 1}$ & $\mathbf{5 2}$ & $\mathbf{5 3}$ & $\mathbf{5 4}$ & $\mathbf{5 5}$ & $\mathbf{5 6}$ & $\mathbf{5 7}$ \\
\hline 16.56 & 17.31 & 18.16 & 19.24 & 20.13 & 21.43 & 22.73 & 23.77 \\
\hline $\mathbf{5 8}$ & $\mathbf{5 9}$ & $\mathbf{6 0}$ & & & & & \\
\hline 24.66 & 26.04 & 27.23 & & & & & \\
\hline
\end{tabular}




\section{Appendix Q: EWT Speed Estimation Function}

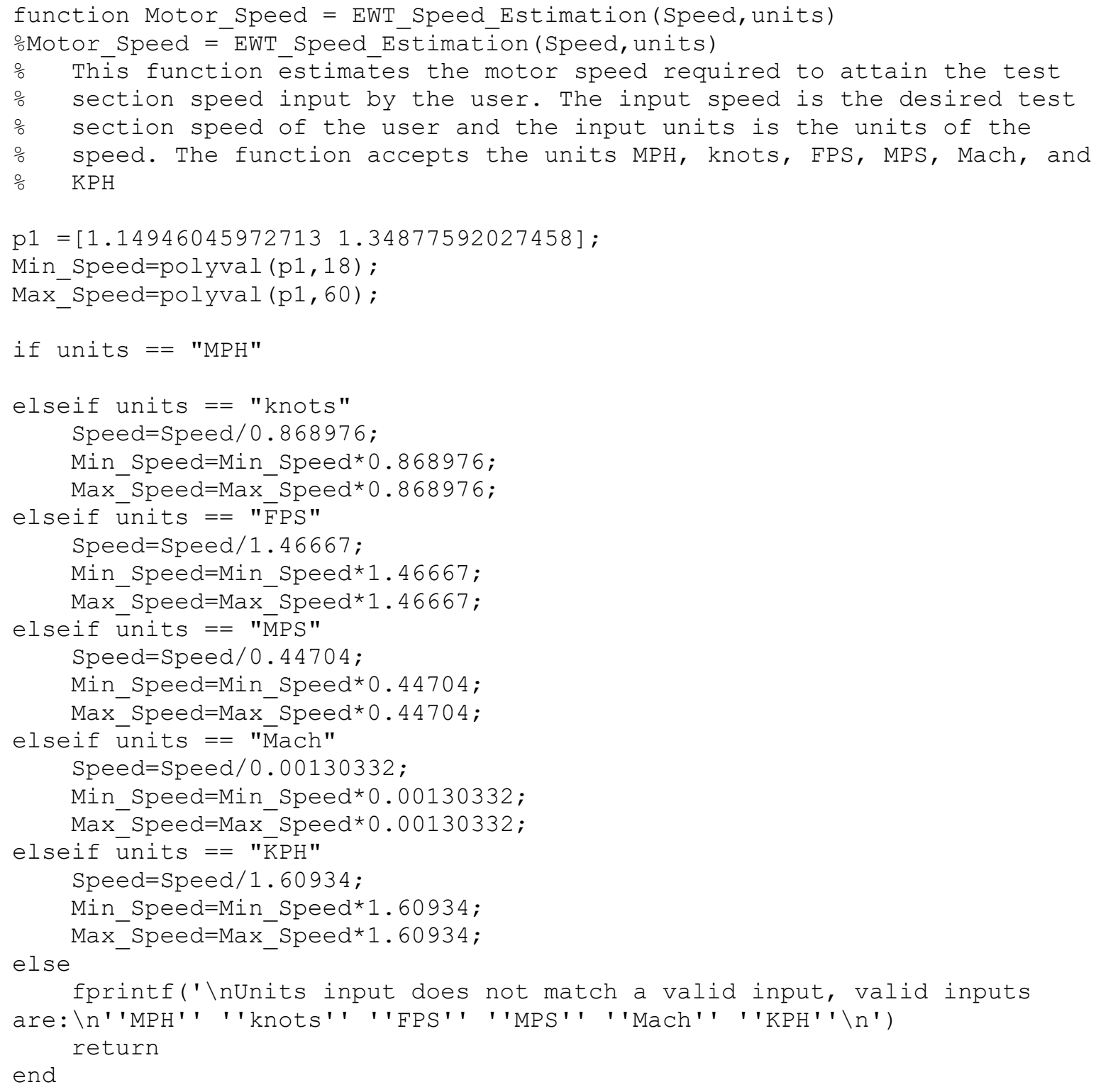


else

fprintf(' \nCalculated Motor Speed For Input speed is: $\% 0.1 f$ $\mathrm{Hz} \backslash \mathrm{n} \backslash \mathrm{n}^{\prime}$, Motor_Speed)

end

end 


\section{Appendix R: Statistical Analysis}

This appendix includes the standard deviations determined for each pitot tube on the grid across the four days of measurements. The plot shows the standard deviations are greater towards the outer edges of the grid, which shows that these areas were outside of the range of flow and any variation in pressure had a much larger impact on the measurements and standard deviations. The table displays the total averaged standard deviation for each pitot tube (number in bold 1-64) as well as the percent of max standard deviation. For example, for pitot tube 1, the standard deviation was 1.88 with a percent of max value of $54 \%$.

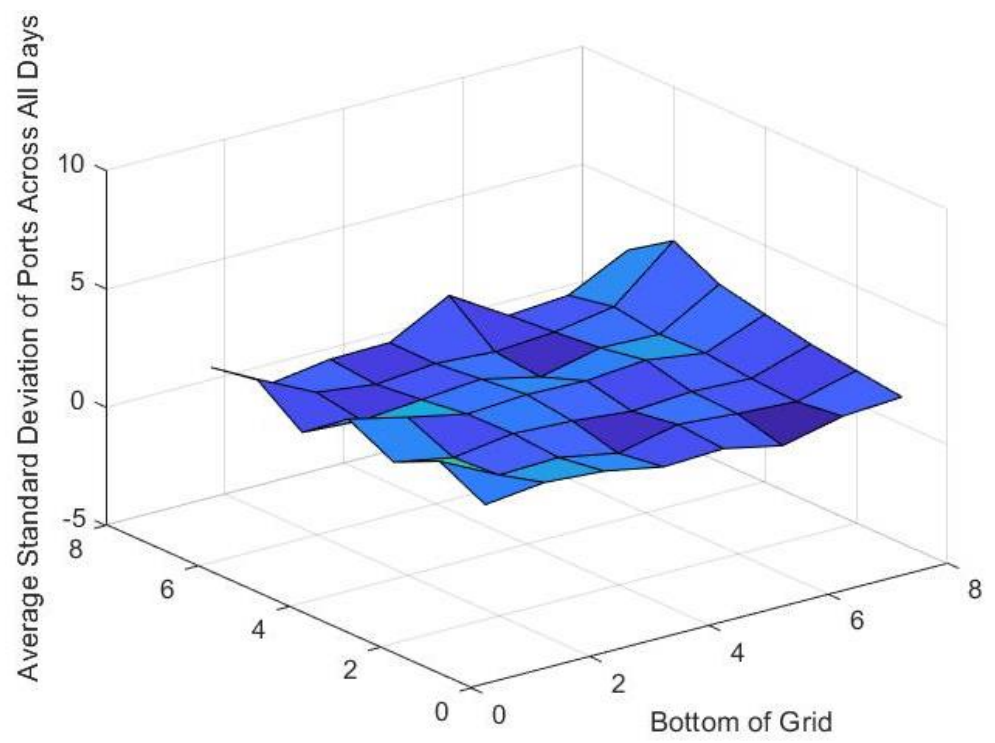

Side of Grid Near TS Door 


\begin{tabular}{|r|r|r|r|r|r|r|r|}
\hline $\mathbf{1}$ & $\mathbf{2}$ & $\mathbf{3}$ & $\mathbf{4}$ & $\mathbf{5}$ & $\mathbf{6}$ & $\mathbf{7}$ & $\mathbf{9}$ \\
\hline 1.88 & 0.53 & 0.90 & 0.95 & 2.28 & 0.78 & 0.97 & 2.24 \\
\hline $54 \%$ & $15 \%$ & $26 \%$ & $27 \%$ & $66 \%$ & $22 \%$ & $28 \%$ & $65 \%$ \\
\hline $\mathbf{1 0}$ & $\mathbf{1 1}$ & $\mathbf{1 2}$ & $\mathbf{1 3}$ & $\mathbf{1 4}$ & $\mathbf{1 5}$ & $\mathbf{1 6}$ & $\mathbf{1 7}$ \\
\hline 1.02 & 0.70 & 0.92 & 0.76 & 0.94 & 1.34 & 3.47 & 0.85 \\
\hline $29 \%$ & $20 \%$ & $27 \%$ & $22 \%$ & $27 \%$ & $39 \%$ & $100 \%$ & $24 \%$ \\
\hline $\mathbf{1 8}$ & $\mathbf{1 9}$ & $\mathbf{2 0}$ & $\mathbf{2 1}$ & $\mathbf{2 2}$ & $\mathbf{2 3}$ & $\mathbf{2 4}$ & $\mathbf{2 5}$ \\
\hline 0.70 & 0.91 & 1.12 & 0.56 & 1.13 & 1.04 & 2.49 & 2.27 \\
\hline $20 \%$ & $26 \%$ & $32 \%$ & $16 \%$ & $32 \%$ & $30 \%$ & $72 \%$ & $65 \%$ \\
\hline $\mathbf{2 6}$ & $\mathbf{2 7}$ & $\mathbf{2 8}$ & $\mathbf{2 9}$ & $\mathbf{3 0}$ & $\mathbf{3 1}$ & $\mathbf{3 2}$ & $\mathbf{4 1}$ \\
\hline 1.69 & 1.17 & 1.33 & 1.25 & 1.47 & 1.11 & 2.08 & 1.31 \\
\hline $49 \%$ & $34 \%$ & $38 \%$ & $36 \%$ & $42 \%$ & $32 \%$ & $60 \%$ & $38 \%$ \\
\hline $\mathbf{4 2}$ & $\mathbf{4 3}$ & $\mathbf{4 4}$ & $\mathbf{4 5}$ & $\mathbf{4 6}$ & $\mathbf{4 7}$ & $\mathbf{4 8}$ & $\mathbf{4 9}$ \\
\hline 0.85 & 1.20 & 1.07 & 0.82 & 1.00 & 0.89 & 1.68 & 2.21 \\
\hline $24 \%$ & $34 \%$ & $31 \%$ & $24 \%$ & $\mathbf{2 9 \%}$ & $26 \%$ & $48 \%$ & $64 \%$ \\
\hline $\mathbf{5 0}$ & $\mathbf{5 1}$ & $\mathbf{5 2}$ & $\mathbf{5 3}$ & $\mathbf{5 5}$ & $\mathbf{5 7}$ & $\mathbf{5 8}$ & $\mathbf{5 9}$ \\
\hline 0.97 & 1.05 & 0.57 & 1.13 & 0.77 & 1.23 & 1.51 & 1.33 \\
\hline $28 \%$ & $30 \%$ & $16 \%$ & $32 \%$ & $22 \%$ & $36 \%$ & $44 \%$ & $38 \%$ \\
\hline $\mathbf{6 0}$ & $\mathbf{6 1}$ & $\mathbf{6 2}$ & $\mathbf{6 3}$ & $\mathbf{6 4}$ & & & \\
\hline 0.85 & 0.96 & 0.43 & 1.01 & 1.17 & & & \\
\hline $25 \%$ & $28 \%$ & $12 \%$ & $29 \%$ & $34 \%$ & & & \\
\hline & & & & & & & \\
\hline
\end{tabular}

